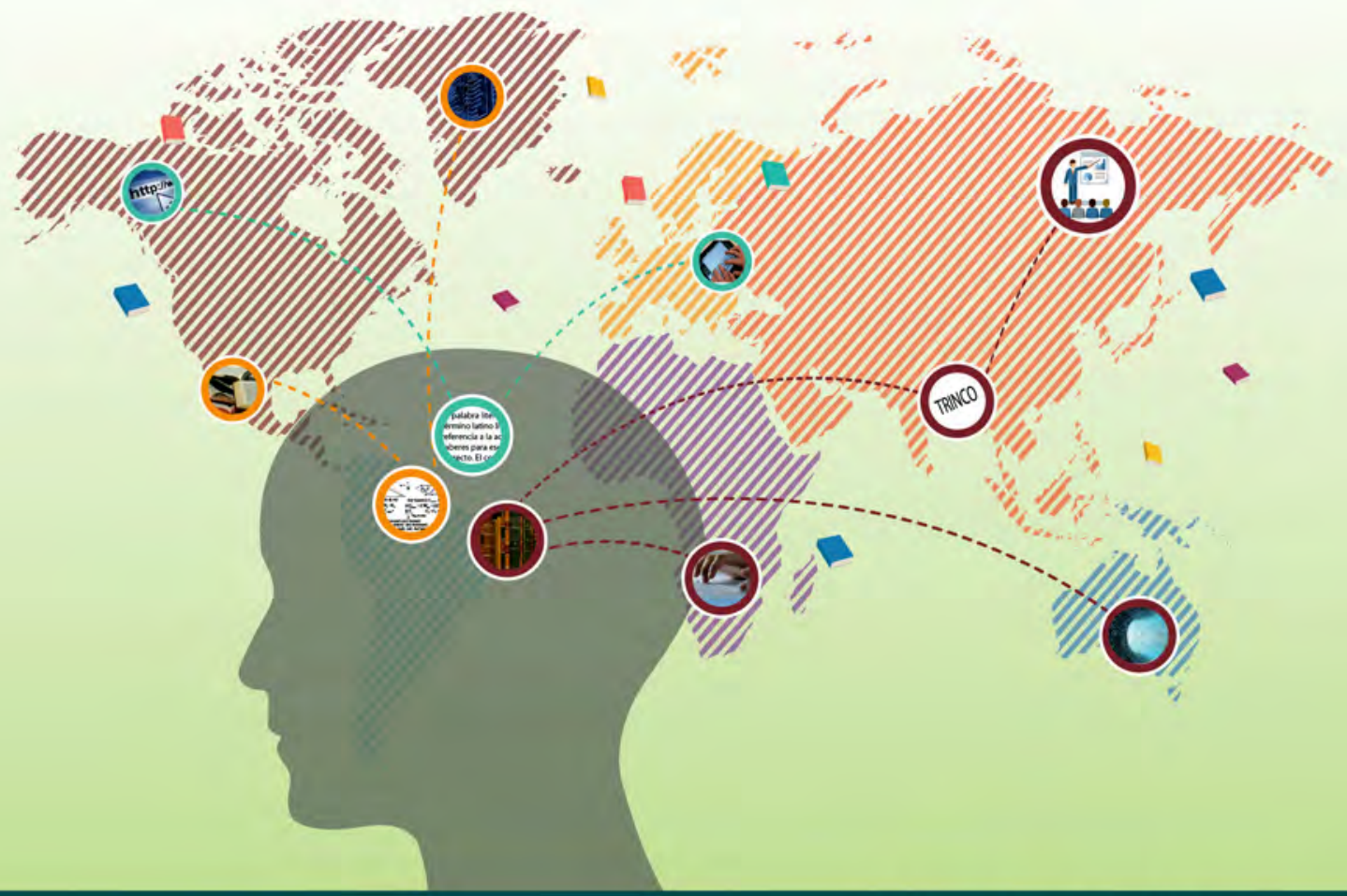

Edilma Naranjo Vélez

\title{
Didáctica de los Sistemas de Información Documental: transformación de la información en conocimiento
}




\section{La presente obra está bajo una licencia de:}

\section{http://creativecommons.org/licenses/by-nc-sa/3.0/deed.es MX}

\section{Atribución-No Comercial-Licenciamiento Reciproco 3.0 Unported}

Eres libre de:

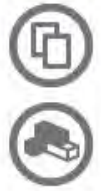

copiar, distribuir y comunicar públicamente la obra

hacer obras derivadas

Bajo las condiciones siguientes:

Atribución - Debes reconocer la autoría de la obra en los términos

especificados por el propio autor o licenciante.

No comercial - No puedes utilizar esta obra para fines comerciales.

Licenciamiento Recíproco - Si alteras, transformas o creas una obra a

partir de esta obra, solo podrás distribuir la obra resultante bajo una licencia

igual a ésta.

\section{Esto es un resumen fácilmente legible del: texto legal (de la licencia completa)}

En los casos que sea usada la presente obra, deben respetarse los términos especificados en esta licencia.
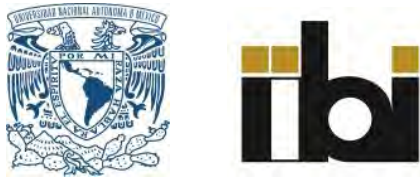
Didáctica de los Sistemas de Información Documental: transformación de la información en conocimiento 


\title{
Didáctica de los Sistemas de Información Documental: transformación de la información en conocimiento
}

\author{
Edilma Naranjo Vélez
}

Universidad Nacional Autónoma de México

2014 
Z668

N37

Naranjo Vélez, Edilma

Didáctica de los Sistemas de Información

Documental : transformación de la información

en conocimiento / Edilma Naranjo Vélez. - México :

UNAM, Instituto de Investigaciones Bibliotecológicas

y de la Información, 2014.

$\mathrm{xi}, 283 \mathrm{p}$.

ISBN: 978-607-02-5739-1

1. Didáctica -- Sistemas de Información Documental

2. Análisis de Sistemas de Información

Diseño de la portada: Editorial Albatros

Primera edición 2014

DR () Universidad Nacional Autónoma de MéXico

Ciudad Universitaria, 04510, México D.F.

Impreso y hecho en México

ISBN: 978-607-02-5739-1 


\section{Contenido}

Introducción $\ldots \ldots \ldots \ldots \ldots \ldots \ldots \ldots \ldots \ldots \ldots \ldots \ldots \ldots \ldots \ldots \ldots \ldots \ldots$, vii

\section{PRIMERA PARTE \\ Entre el pasado y las tendencias de la investigación}

Los datos y la información, o la necesidad de superar la heteroestructuración y la autoestructuración para transformarlos en conocimiento.................. 3

La dialéctica del problema o la pregunta, en tanto lo teórico ..... 4

De la tesis o cómo asume los datos el profesor tradicional ....... 7

De la antítesis o el docente que fomenta el autoaprendizaje (autoestructuración) .............................. 10

La síntesis o el profesor que conversa con el estudiante para transformar la información en conocimiento ............ 15

Hipótesis abductiva o la pregunta en cuanto lo práctico ......... 21

Una relación pertinente: la pregunta (en tanto lo teórico)

y la hipótesis (en cuanto lo práctico)................... 22

Los conceptos en el devenir de los Sistemas de Información

Documental (SID) o el horizonte del pasado................. 27

El dato por el dato o lo dado ........................ 29

La información o el insumo del conocimiento ............. 38

¿De la información al conocimiento?.................... 60

El presente de los SID en la educación superior

desde el estado de la cuestión $\ldots \ldots \ldots \ldots \ldots \ldots \ldots \ldots \ldots \ldots \ldots$

Proceso y precisiones metodológicas ................... 77

Análisis y comprensión de categorías .................... 86

Proceso hermenéutico de la interpretación y consideraciones

parciales ..................................... 97 


\section{SEGUNDA PARTE \\ El trabajo de campo o cómo ven los actores su realidad}

El mundo real con los SID desde el acopio de la información ... . 103

Elementos metodológicos ............................... 103

Encuesta de prejuicios . . . . . . . . . . . . . . . . . . . . 106

La conversación ................................. 126

TERCERA PARTE

Una senda hacia la cosa creada

Estrategia didáctica TRINCO: transformación de la información

en conocimiento .............................. 137

La didáctica, las estrategias y el sistema didáctico

tienen un lugar en la universidad...................... 137

Estrategia didáctica TRINCO: Transformación de la Información

en Conocimiento................................ 163

Una organización para la estrategia didáctica: fases

y segmentos ............................... 164

Fundamentación metodológica ..................... 166

Desarrollando las fases de la estrategia didáctica TRINCO . . . . . 169

Sistemas de Información Documental (SID): medios didácticos para

transformar la información en conocimiento ............... 206

Los componentes didácticos y sus interrelaciones con la estrategia

didáctica TRINCO o la subversión del sistema didáctico

con la presencia de los SID ........................ 216

Vivencia con la estrategia didáctica TRINCO: Transformación

de la Información en Conocimiento..................... 227

Consideraciones finales o el cierre temporal

de la experiencia hermenéutica...................... 245

Bibliografía $\ldots \ldots \ldots \ldots \ldots \ldots \ldots \ldots \ldots \ldots \ldots \ldots \ldots \ldots \ldots \ldots \ldots$

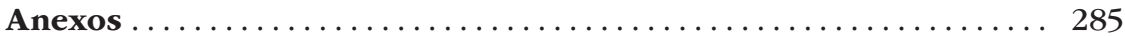




\section{Introducción}

T a presencia de las Tecnologías de la Información y Comunicación (TIC) han revolucionado la visibilidad de la acción y efecto de informar, contribuyen al cambio de la vida personal, laboral y profesional de los miembros de la sociedad. La universidad y demás instituciones de educación superior no pueden aislarse de esas transformaciones del entorno que afectan, además de lo educativo, lo cultural, lo científico, lo tecnológico, lo laboral, lo socioeconómico, y lo ético. Por eso la educación superior, como un sistema de esa sociedad, debe prepararse y preparar a su comunidad educativa para apropiarse compresivamente del saber y del conocimiento generado por otros, que es visible en las fuentes de información organizadas en los Sistemas de Información Documental (SID), en tanto medios didácticos que dinamizan la forma (tiempo y espacio) de la enseñanza y posibilitan la transformación de los datos y la información en conocimiento, en cuanto contenido.

Relación que se construyó a partir de una proyección a futuro, o lo que Gadamer denomina, una proyección de sentido 
que parte de una pregunta de investigación: ¿cómo los SID, en tanto medios, posibilitarían la transformación de los datos y la información en conocimiento dentro de la educación superior?, y de una hipótesis formulada como otra pregunta: ¿será que una estrategia didáctica fundamentada teórica y metodológicamente en los SID, posibilita la transformación de los datos y la información en conocimiento?

Las respuestas a estas inquietudes señalan a los Sistemas de Información Documental como medios didácticos esenciales entre los componentes del sistema didáctico educativo, pues son los sistemas que albergan, tanto la información impresa como la electrónica, en un espacio real o virtual, organizado para facilitar la búsqueda, localización y recuperación de la información; proceso que precisa de un paso previo en el que los sujetos, usuarios de la información, deben saber reconocer lo que requieren y para qué lo necesitan. Luego, es necesario que esa información se pueda comprender e interpretar para lograr su transformación en conocimiento útil para la vida personal y profesional de los sujetos que la sociedad requiere.

De esta manera, y en busca de ese conocimiento útil, la investigación se abordó desde un paradigma cualitativo y un enfoque hermenéutico, con el interés de comprender e interpretar los conceptos: dato, información, conocimiento, estrategia didáctica; e indagar el nivel de apropiación que presentaban los profesores y los estudiantes universitarios sobre el uso de Sistemas de Información Documental, además de caracterizar éstos en la relación medios-contenido-espacio-método dentro del sistema didáctico; lo que finalmente permitió diseñar y evaluar una estrategia didáctica para posibilitar la transformación de los datos y la información en conocimiento.

Esto permitió estructurar el documento en tres partes bien diferenciadas. En la primera, denominada Entre el pasado y las tendencias de la investigación, se ubican los tres primeros 
capítulos, el primero de los cuales se plantea el problema dialéctico de la investigación, sustentado en teóricos que asumen diferentes posturas y en donde se presenta la pregunta de la investigación y la hipótesis como proyección de sentido. El segundo capítulo da cuenta de una aproximación histórica a los conceptos dato, información y conocimiento, como componentes centrales del proceso perteneciente a la transformación y síntesis de un saber, y abre un horizonte de comprensión a medida que se avanza en la elucidación de la palabra, luego del término y hasta llegar al concepto, cumpliendo una función epistemológica en diferentes disciplinas. El tercer capítulo aborda el estado de la cuestión del uso de la información mediada por los SID, con el cual se pretendió encontrar las tendencias que en materia de investigación presentaban estos sistemas en diferentes países e idiomas, en un periodo contemplado entre los años 2000 y 2008.

El trabajo de campo o cómo ven los actores su realidad, es la segunda parte del texto y la conforma el cuarto capítulo, nominado "El mundo real con los SID desde el acopio de la información". Se presenta aquí un compendio de lo que fue el acopio, análisis e interpretación de la información a partir de la encuesta de prejuicios que se aplicó a profesores y estudiantes de las universidades: Nacional de Colombia sede Medellín, el CES y la Universidad de Antioquia, así también la conversación que se sostuvo con bibliotecólogos expertos en el tema de la formación de usuarios, y con otros profesores de estas mismas instituciones, considerados usuarios reconocidos; es decir, profesores que en los tres sistemas de bibliotecas de las universidades son respetados como conocedores del tema con base en el uso de los SID para el desarrollo de las actividades académicas. El análisis y la interpretación de la información partieron de la propuesta metodológica en relación con la experiencia hermenéutica, concretamente desde el procedimiento, 
momento en el que se pretende conversar con las autoridades para llegar a un acuerdo frente a la unidad de sentido, la estrategia didáctica.

Por último, se encuentra la tercera parte Una senda hacia la cosa creada, compuesta por el capítulo quinto, nombrado "Estrategia didáctica TRINCO: Transformación de la Información en Conocimiento”. Después de disponer de los horizontes que se avizoraron en las dos primeras partes, se empieza a ver el todo que se visualizó como posibilidad de respuesta a las preguntas de la investigación e hipótesis. En este capítulo se analiza, comprende e interpreta la didáctica universitaria que junto con los componentes del sistema didáctico porta, como parte del método, las estrategias didácticas que facilitan las acciones comunicativas de los procesos de enseñanza y de aprendizaje del acto educativo. Asimismo, se presentan los fundamentos teóricos y conceptuales que soportan la estrategia didáctica para la Transformación de la Información en Conocimiento (TRINCO) -siendo este el objetivo general de la investigación- y da cuenta de los resultados que surgen después de haber aplicado la prueba piloto de la estrategia, lo que permitió mostrar la importancia, solidez y validez de ésta.

Para terminar, se presentan las consideraciones finales como un cierre temporal de este trabajo que partió de la experiencia hermenéutica, y generó nuevas preguntas e inquietudes para futuras investigaciones.

Con esta publicación, producto de la tesis doctoral "Los sistemas de información documental como medios didácticos: de la información al conocimiento", para optar al título de Doctora en Educación, se quiere compartir -con los docentes que por formación y profesionales por vocación se desempeñan como profesores comprometidos con los procesos de enseñanza y de aprendizaje- esta experiencia y el conocimiento creados, para que se acerquen y conozcan esta estrategia didáctica 
con la que, intencionalmente, se pretende ayudarles a que comprendan el papel de la información en su papel de facilitadores de la educación superior, al igual que en su trasegar personal, lo cual, generará como último y real beneficiario a los estudiantes, usuarios permanentes y constantes de la información. 


\section{Primera Parte}

ENTRE EL PASADO Y LAS TENDENCIAS

DE LA INVESTIGACIÓN 


\section{Los datos y la información, o la necesidad de superar la heteroestructuración y la autoestructuración para transformarlos en conocimiento}

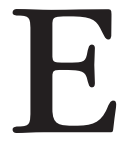

n la educación superior es posible encontrar profesores que recurren a diferentes estilos de enseñanza, amparados en diversos modelos educativos que dan cuenta de la forma en que se interpretan los contenidos y los métodos que constituyen parte de los procesos de enseñanza y de aprendizaje. Se tienen profesores que enseñan en forma tradicional, donde ellos son el centro del proceso y los estudiantes parecen objetos en los que se deposita un saber; y otros que, por el contrario, se consideran guías en el proceso de aprendizaje del estudiante, donde este último es quien establece lo que debe aprender. Son dos posiciones divergentes que se pueden ver como extremas y llevan a pensar que existe un problema que es necesario resolver.

Esta investigación procuró comprender e interpretar esta disyuntiva, y para ello tomó la dialéctica (Hegel, 1973) como el método que facilita la superación de la oposición de la tesis y la antítesis, en uno nuevo, la síntesis; y permitió presentar inicialmente la realidad del contexto de esa enseñanza tradicional 
que se puede llamar heteroestructuración del conocimiento (Not, 1994) que se denominó como tesis; y también está la negación, o posición contraria de la afirmación anterior, la cual se conoce como autoestructuración del conocimiento, y que conformó la antítesis. Ante ambas realidades (dinámicas, no estáticas) como contrarias, fue necesario buscar una conciliación o encuentro, es decir la síntesis, concebida a partir de la interestructuración del conocimiento, con lo cual se pretendía superar el conflicto y permitir que tanto profesores como estudiantes utilizaran los datos y la información dentro del proceso educativo, con el fin de transformarlos en conocimiento. Así, la síntesis conserva todo aquello que deba permanecer de la tesis y la antítesis, con un enfoque hermenéutico que incluye procesos de análisis, comprensión e interpretación, sin desconocer los prejuicios del intérprete (Gadamer, 2005) sobre las situaciones planteadas.

\section{LA DIALÉCTICA DEL PROBLEMA O LA PREGUNTA, EN TANTO LO TEÓRICO}

La formulación de la tesis y la antítesis basada en el enfoque hermenéutico se realizó, inicialmente a partir del desarrollo histórico del problema y analizando los prejuicios del investigador para abordar las lecturas y realizar la reflexión, el análisis, la comprensión, la interpretación y la síntesis. Posteriormente se trabajó el tema desde la contemporaneidad elaborando un estado de la cuestión. Y a medida que se avanzaba en el proceso hermenéutico surgieron interrogantes que se consignaron en la escritura y se analizaron hasta formular una serie de preguntas, que pueden leerse en los párrafos correspondientes a cada momento dialéctico, y que permitieron orientar el trabajo metodológico de la investigación. 
Las preguntas de la tesis sirvieron de asomo a la antítesis, en la medida en que se hizo necesario negar las afirmaciones de los autores en cuanto a la educación tradicional y el uso de las fuentes de información; y fueron también un sentido de orientación que facilitó la visualización del horizonte para acercarse a la síntesis, la cual, encierra el problema y la pregunta orientadora de la investigación.

Antes de proseguir es necesario aclarar algunos términos que utiliza el enfoque hermenéutico para la formulación dialéctica del problema. González, E. (2006: 49) expresa que "[...] analizar es ir de lo superficial a lo profundo, de la expresión al contenido, de lo que se dice a aquello a lo cual se refiere; es decir, la significación emerge de su propia estructura”. Por otra parte, se comprende la interpretación como una proyección de la comprensión, puesto que "[...] la interpretación es en cierto sentido una recreación, pero ésta no se guía por un acto creador precedente, sino por la figura de la obra ya creada, que cada cual debe representar del modo como él encuentra en ella algún sentido" (Gadamer, 2005: 165). La síntesis se refiere también al hecho de "encadenar un texto nuevo al texto en interpretación", en la que se pueden observar los prejuicios, el análisis, la comprensión, la interpretación y la escritura del intérprete. "En la síntesis el lector se convierte en un autor para la comunidad específica que maneja un tipo de lenguaje dentro de un sistema de creencias" (González: 2006, 57-58).

En el gráfico siguiente se representa la relación entre la tesis, la antítesis y la síntesis para llegar finalmente a la pregunta de investigación que orientará el desarrollo de la investigación. 
GRÁFICO 1

FORMULACIÓN DE UN PROBLEMA DIALÉCTICO

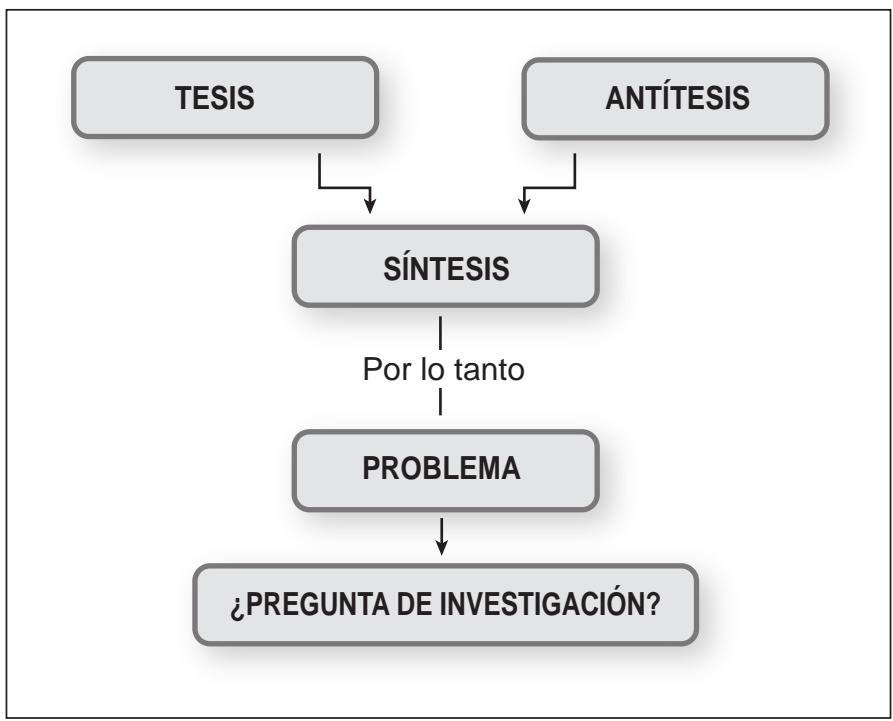

En conclusión, la tesis se formuló partiendo de la mirada que presentan algunos autores desde la educación tradicional, quienes consideran que los profesores transmiten datos e información como parte del proceso de enseñanza. Sucede que cuando se problematiza la tesis se presenta un anticipo o introducción a la antítesis, y que, de igual manera, la labor de problematizarla conlleva a la formulación de la síntesis y estipula un sentido de orientación. De este modo, el método para la formulación del problema permite visualizar su horizonte en la síntesis, puesto que cuestionar el conocimiento en sí mismo le da posibilidades a su devenir, de allí que se formule la pregunta de investigación. "Se trata de ponerlo [el sentido del preguntar] en suspenso, de manera que se equilibren el pro y el contra" (Gadamer, 2005: 440). 


\section{DE LA TESIS O CÓMO ASUME LOS DATOS EL PROFESOR TRADICIONAL}

En los procesos de enseñanza y aprendizaje en la educación universitaria, es común que se enseñe a partir de un discurso teórico, que se organiza para su presentación como limitado a un conjunto de datos, ${ }^{1}$ tomados como expresiones mínimas que se convierten en el punto de partida para llegar al conocimiento de información (López, 2004). Es decir, el dato es la representación de algo que está ahí y es percibido por un sujeto que tiene pretensiones de conocer (Mockus, Hernández, Charum, Castro, y Granés, 1995). Así, algunos profesores presentan datos seleccionados - de acuerdo con sus criterios y conocimientos- a un estudiante que es poco visible; lo importante aquí es transmitir, regularmente a partir de la exposición oral, un saber terminado que permita ver el objeto de estudio y la voz y función del profesor, por encima del alumno. Por tanto, el estudiante es un sujeto pasivo que repite lo que aquél le transmite. Esto indica que el saber disciplinar u objeto de estudio se encuentra y organiza desde el exterior -lo que se denomina heteroestructuración del conocimiento (Not, 1994)- para que el alumno lo reciba como si fuera -en palabras de Freire (1972)- una cuenta bancaria, en la que se acumula el conocimiento que se cree poseer. Cabe entonces preguntarse:

¿Será que el discurso oral de los profesores les posibilita a los estudiantes

la transformación de los datos y la información, en conocimiento?

1 Para ampliación ver el capítulo dos: Los conceptos en el devenir de los SID o el horizonte del pasado. 
En este enfoque la educación busca relacionar a los estudiantes con lo que la sociedad establece que ellos deben ser, de ahí la necesidad de que el profesor les diga cuáles son los libros y obras que debe consultar (Not, 1994). Así se llega a la transmisión de datos e información de carácter enciclopédico; es decir, datos e información generales de poca profundidad que se deben memorizar para repetir sin permitir el error, y para lograr esto la acción se repite cuantas veces sea necesario, como lo dice Skinner: "[...] no es suficiente multiplicar las preguntas para acrecentar los reforzamientos; es preciso también hacer lo posible para que la probabilidad de obtener respuesta acertada sea elevada [...] Algo aprendemos de nuestros errores (aunque sea no volver a cometerlos)" (1968: 14). Esto indica que no importa la comprensión e interpretación del contenido, sino es su memorización como muestra de aprendizaje, lo que desconoce de esta forma es que el conocimiento no se almacena en la memoria como si fuera una copia, sino que se debe asumir como una acción efectiva, la cual, se estructura constantemente y les permite a las personas continuar en el mundo de la vida para contribuir al desarrollo de ésta, aunque no se desconoce que la memoria "[...] permite el asentamiento de una base de información que luego conformará nuestros criterios para valorar, y que nos permitirá la estructuración de los conocimientos" (Alás et al., 2002: 24).

Los datos y la información se reproducen también en el aula de clase mediante la lectura de autores, representantes de las escuelas de pensamiento, con los cuales el profesor tiende a identificarse. Estos autores son llevados a la clase a través de medios tales como manuales, compilaciones, libros y fotocopias de capítulos de libros, entre otras cosas facilitadas por los profesores, hasta el punto, como lo señalan Henao y Castañeda (2002), de entregarles a los estudiantes la fotocopia del capítulo, a veces sin indicar siquiera los datos bibliográficos de la fuente original. 


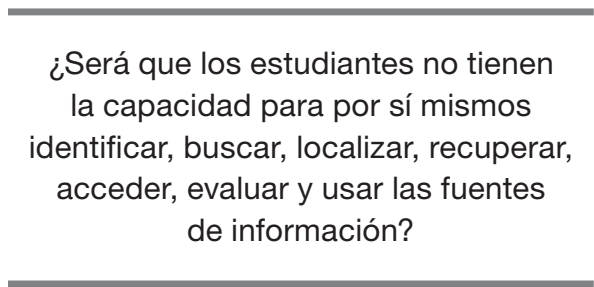

En esta misma línea, Jaime Vélez, en su artículo El retorno de los brujos (2002: 62) comenta "[...] en virtud de la máquina fotocopiadora, por ejemplo, un ignorante cualquiera puede hoy salir graduado de una universidad, como por arte de magia, sin necesidad de haber leído un solo libro completo en toda su carrera [...] La época actual ha asistido, en consecuencia, al nacimiento de un nuevo tipo de intelectual: 'el doctor en fotocopias'". Estas percepciones las corrobora Litwin (1997: 27) cuando expresa "[...] la fotocopia democratizó el acceso a las fuentes de estudio al tiempo que recortó y fragmentó los relatos". Surge otra interrogante:

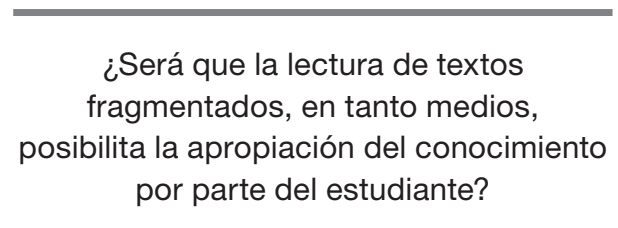

Este panorama: bibliografía seleccionada y limitada por el profesor, fragmentos de textos y entrega personalizada de lecturas al estudiante, es comentado y ampliado por Mockus, quien introduce dos nuevas situaciones; el profesor:

puede enseñar las reglas básicas de la cultura escolar y, al mismo tiempo, limitar el aprendizaje de soluciones meramente nomi- 
nales $^{2}$ [y además] las fuentes indirectas de conocimiento, características de la academia, pueden introducirse de manera parcial y distorsionada: hay que saber lo que dice el texto o el cuaderno y decirlo en el momento oportuno, hay que copiar en el cuaderno lo escrito sobre el tablero, hay que escribir en la hoja, en el cuaderno o en el tablero, lo que se ordena escribir; una amplia gama de actividades se puede realizar sin que se haga presente, al menos de manera explícita, una pretensión de conocimiento (Mockus et al., 1995: 34)

con lo cual se presenta una reducción del contenido y se distorsiona este pensamiento del filósofo Medawar (1982: 13): “[...] un buen maestro enseñaba toda la materia, y no sólo esa parte de ella en que estuviese especialmente interesado o tuviese especial capacitación; desde luego, "enseñar» no significaba "dar información fáctica»".

\section{DE LA ANTÍTESIS O EL DOCENTE QUE FOMENTA EL AUTOAPRENDIZAJE (AUTOESTRUCTURACIÓN)}

En contraste con lo anterior, dice Mockus:

El conocimiento estático y el aprestamiento específico no son suficientes para sobrevivir en un mundo en permanente cambio tecnológico y en el cual la capacidad de utilizar la información se vuelve fundamental. Por esto, una educación que busque ser pertinente debe desarrollar la capacidad de aprendizaje permanente de los individuos. En consecuencia, se estimularán todas las metodologías pedagógicas que promuevan el autoaprendizaje y la interacción de los estudiantes, para superar aquellas que reproducen el modelo tradicional del alumno como receptor de conocimientos (Mockus, 2001).

2 "Feynman hace una crítica convincente de esa enseñanza de nombres con la que usualmente se bloquea todo genuino preguntar, convenciéndonos desde muy temprano de que un término puede constituir una adecuada respuesta a una pregunta" (citado en Mockus et al., 1995: 34). 
En este enfoque el eje central de la educación es el estudiante, protagonista de su aprendizaje, donde él es un aprendiz activo y el profesor un orientador. De ese modo el objeto de estudio se toma como un elemento que se experimenta, que se inventa, según el alumno, para hacer efectivo el conocimiento; es decir, se presenta la autoestructuración del conocimiento (Not, 1994). En ésta, la apropiación de los contenidos de un programa académico se considera una experiencia individual y autónoma; y por tanto el estudiante es "el autor de su propio desarrollo" (Not, 1994: 122). Igualmente se busca realizar y lograr operaciones de análisis para formar un pensamiento sistemático y global en personas más creativas (Not, 1994). Esto lleva a que el proceso de aprendizaje sea más importante que el de enseñanza puesto que la educación se planea partiendo del desarrollo del mundo interior del estudiante: "[...] el maestro se constituye mediador, en tanto, reconoce en el otro, el alumno, su voz, su inquietud, su espíritu especulativo para experimentar desde sus propias inquietudes, para asirlas de lo posibilitado por el maestro" (González y Castrillón, 2001: 47).

Aun así, esta concepción presenta tres inconvenientes:

En primer lugar, el individuo debe encontrar en sí mismo una fuerza suficiente para sostener su progreso hacia el saber. En seguida, debe descubrir por sí mismo las vías en las que conviene adentrarse para lograr un saber que por definición ignora del todo [...] Por último, debe disponer de procedimientos que puede poner en práctica un individuo que actúe solo, cuando quiere adquirir un saber que le permita comprender el mundo en el que vive y adaptarse a él, transformándolo o transformándose él mismo (Not, 1994: 122).

Estos inconvenientes muestran a un individuo aislado, encerrado en su mundo, que, al parecer, sólo cree en sí mismo. No obstante, la presencia del profesor, que funge como guía, puede detener este aislamiento y propiciar la autonomía e independencia del estudiante. 
Desde esta perspectiva los medios disponibles deben apoyarse en las Tecnologías de la Información y la Comunicación, TIC, sostenidas por los avances de la ciencia y los desarrollos tecnológicos; y en consonancia, es posible que la información sea ampliamente usada por profesores y estudiantes, puesto que los adelantos tecnológicos y sus múltiples aplicaciones así lo permiten, más aún cuando el soporte de la información avanza hasta los sistemas multimediales y sus posibilidades informáticas interactivas que combinan la escritura con la imagen y el audio, y facilitan así el esparcimiento de los datos y la información en el espacio cibernético donde "[...] los usuarios de un ordenador tienen acceso a los ordenadores de todos los demás y a sus contenidos" (Stepp, 1993). Este espacio, conocido como ciberespacio, es también un medio, pues permite tanto la convivencia, como la construcción de relaciones de diversos tipos y grados basados en la virtualidad, como una situación subjetiva de las interacciones humanas.

Los avances tecnológicos afectan el diario acontecer de muchas personas, entre ellas, aquellas que se mueven en el ámbito universitario como profesores y estudiantes, lugar que le ha dado gran reconocimiento a los nuevos escenarios soportados en las TIC, las cuales se están convirtiendo en algo natural en la vida de las personas, especialmente en los jóvenes (Vargas, 2006a). Las TIC son consideradas muchas veces como los únicos medios que le permitirán al estudiante apropiarse del conocimiento de acuerdo con los intereses y necesidades que presente, y como sujeto responsable y determinador de los saberes que requiere para su formación profesional y personal (según la visión formativa de la autoestructuración) o, como lo expresa Vargas "[...] es volver la mirada sobre el horizonte de realización que compete asumir a quienes se forman y se encuentran en proceso de comunicación tanto de idealidades como de estructuras simbólicas" (2006a: 123). 
Los recursos tecnológicos están subvirtiendo el espacio tradicional del aula de clase, si se consideran al tiempo y el espacio como elementos del sistema didáctico con los cuales se organizan los partícipes del proceso educativo, con base en "[...] la distribución de los estudiantes en relación con el profesor y la asignación de intervalos de tiempo en correspondencia con el contenido por asimilar y el objetivo por alcanzar" (Álvarez y González, 2002: 59). Cabe aclarar que el sistema didáctico es un elemento de la didáctica -cuyo objeto de estudio son los procesos de enseñanza y de aprendizaje- que permite combinar, interrelacionar e interactuar varios componentes de la formación de un sujeto; a saber: el objeto o realidad a estudiar, el objetivo o aquello que se pretende alcanzar, los contenidos o saberes de la humanidad, el método como procedimiento para construir el conocimiento, los medios que sirven como herramientas que favorecen la transformación del objeto, la forma u organización espacial y temporal del ambiente educativo, y la evaluación que verifica el desarrollo del proceso (González y Díaz, 2008).

Sin embargo, en relación con los recursos tecnológicos y su uso en los procesos de enseñanza y aprendizaje hay que ser cuidadosos, pues no todo lo que se encuentra en el ciberespacio es útil, ya que "[...] al navegar en la red, se localiza gran cantidad de datos e información desperdigados sin orden y rigor académicos, que el estudiante acumula en su computador y puede llegar a asumirlos como un saber completo" (Vélez, J., 2002: 62).

En este mismo sentido, para navegar por el ciberespacio y aprovechar las aplicaciones de las TIC, se deben poseer habilidades y conocimientos que ayuden a distinguir aquella información que es útil y valiosa de la que no lo es, como lo corrobora Tim Berners-Lee -inventor del World Wide Web- cuando expresa su preocupación "[...] por la forma en que se está abusando de la Red para difundir informaciones que no son vera- 
ces" (EFE, 15 Sep. 2008). Y en esa dirección, Fernando Sáez ${ }^{3}$ sostiene que "[...] el fenómeno Internet, tan positivo y estimulante en tantos aspectos y tan dudoso en el origen de mucha de su información -fechas, sucesos, biografías y obras- está viviendo el feliz desparpajo del descontrol que [le] da igual empuje al conocimiento que a la chapucería”. Es posible incluso indicar que, a veces, el proceso de localizar, recuperar y usar la información mediada por las TIC es más complejo y requiere de conocimientos, habilidades, destrezas y actitudes lo suficientemente estructuradas como para encontrar lo que realmente se necesita; más aun cuando se dispone de diversas aplicaciones tecnológicas como las redes electrónicas, entre ellas Internet, o los sitios web, bases de datos, redes sociales, weblogs, bibliotecas y repositorios digitales, que albergan infinidad de documentos electrónicos y digitales.

Las TIC también han hecho su incursión en las unidades de información universitarias que, preocupadas por prestar mejores servicios y respaldar las funciones misionales de la institución académica, utilizan éstas en sus actividades de organización, preparación y divulgación de la información, al igual que en el acceso y uso de ésta por parte de los usuarios. Concretamente, esperan contribuir en los procesos de enseñanza y aprendizaje, tanto de profesores como de estudiantes, en la medida en que los servicios, colecciones y otros sistemas de información que ofrecen se encuentran respaldados por las propias TIC, de manera que puedan resolver necesidades de información propios del proceso formativo. Sin embargo, se espera que el estudiante en su proceso de autoestructuración -con la orientación del profesor- haga uso de ellas, lo cual significa que este último debe

3 El director ejecutivo de la Fundación Pablo Neruda dice esto en una nota periodística de la agencia EFE, titulada Muere lentamente: un falso Neruda que no para de crecer en Internet (EFE, 11 Ene. 2009). 
estar preparado para orientar a aquél; pero en muchas ocasiones no lo está.

Consecuentemente surgen dos preguntas:

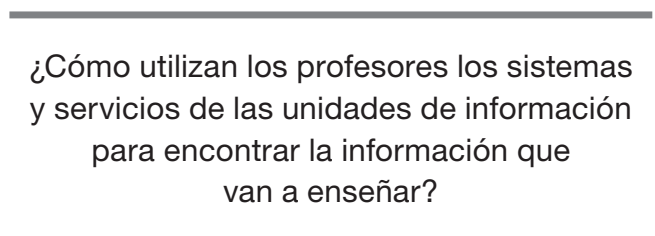

¿Se puede asegurar que con el uso de documentos electrónicos y digitales los estudiantes transformarán los datos y la información en conocimiento?

\section{LA SÍNTESIS O EL PROFESOR QUE CONVERSA CON EL ESTUDIANTE PARA TRANSFORMAR LA INFORMACIÓN EN CONOCIMIENTO}

En el siglo XX la información se constituyó en elemento vital para el desarrollo científico y tecnológico, al convertirse en insumo y producto para la generación y organización del conocimiento, del que puede decirse que "[...] es todo lo que un ser humano ha aprendido, asimilado y organizado de acuerdo con aquellos conceptos, imágenes o relaciones que ha podido dominar; el conocimiento es una abstracción mental que supone cierto razonamiento y enjuiciamiento, el cual organiza la información mediante su comparación y clasificación” (Morales, 1998: 2). Este interés por el conocimiento se debió, en parte, al incremento de la actividad científica, al adelanto tecnológico y a los deseos de crecimiento y progreso (Debons, Horne y Gro- 
nenweth, 1988), lo que llevó a considerar la información como un insumo básico y necesario de toda práctica social.

La información se asume -de manera general- como el conjunto de datos o elementos doctrinarios organizados sobre un tema (López, 2004), lo cual no debe confundirse con los datos sino que debe tomarse como el producto de lo que se hace con éstos; por ello los datos deben tener "valor" de carácter informativo y esto lo brinda el contexto. Así, la información no existe en forma aislada y terminada sino que requiere del mundo material, de otros y de lo externo, y es una cualidad del signo lingüístico que debe ser registrada. La información se toma como un elemento de interés para el hombre o, como expresa Moreiro (2006), "es la materia prima del conocimiento". De esta forma, la información se da en un sistema que debe tener presente la relación entre dos: un receptor y un destinatario, quienes, en lo posible, deben estar interesados en informarse para generar un cambio en el estado de su conocimiento. Así pues, la información, que nace de un conjunto de datos organizados intencionalmente, busca variar la estructura cognitiva de un sujeto a partir de la transformación que éste haga de aquella mediante un proceso de reflexión, análisis, comprensión e interpretación.

En la relación que se establece entre conocimiento e información, puede decirse junto a Davenport y Prusak (1998) que el conocimiento es la información más valiosa; ¿por qué dice esto? porque cuando alguien le brinda una información en un contexto, con un significado especial, a partir de una interpretación, a otra persona, es porque aquél ha procesado otra información que se transformó en acción y efecto de conocer; procesamiento en el que, además, intervienen los conocimientos anteriores agregándole valor a esa información que se comunica. Esto es, el conocimiento está relacionado directamente con la persona y con sus percepciones, así ésta codifica, decodifica, 
usa o distorsiona la información de acuerdo con sus modelos mentales y características personales.

En la interestructuración se asume que la formación de un individuo implica su transformación, en la que la adquisición del conocimiento se logra con la interrelación sujeto-objeto, superando las miradas aisladas de o sobre cada uno de ellos. En esta interrelación el individuo se toma como sujeto pedagógico, puesto que se convierte en el centro de las iniciativas de la acción formativa de las cuales él es consciente, al igual que lo es de la forma en que se dan los cambios que lo afectan. En este proceso "[...] el sujeto es fuente de acciones y el objeto es el lugar de una acción que se ejerce en él" (Not, 1994: 10); es decir, el sujeto está llamado a conocer a partir del objeto de estudio que pretende discernir, pues, en palabras de Piaget: "[...] conocer un objeto (material o puramente ideal) es actuar y transformarlo para aprehender los mecanismos de esta transformación en relación con las acciones transformadoras mismas" (1969: 48). En esta transformación el sujeto pedagógico es acompañado por el docente quien contribuye a la formación del primero con su saber disciplinar y didáctico, y acudiendo a la conversación, al diálogo, que se convierten en elementos centrales para lograr la participación horizontal de los sujetos vinculados en el proceso pedagógico.

No obstante, en el aula de clase la discusión requiere algo más que el diálogo o los contenidos, pues precisa de otros medios, los cuales, favorezcan el proceso metódico para comunicar los contenidos. Uno de esos medios son los Sistemas de Información Documental (en adelante SID), denominación que abarca el conjunto de personas, máquinas y procedimientos que transforman la información documental y bibliográfica en una información que se puede identificar, buscar, localizar, recuperar, acceder, evaluar y usar para la toma de decisiones (Moscoso, 2002). 
La formación universitaria, desde el punto de vista de la interestructuración del conocimiento, se beneficia con la implementación y uso de los SID, que permiten el acceso al mundo del conocimiento al convertirse en los medios por excelencia dentro de la comunicación pedagógica. Esta última es la directriz del proceso formativo que busca la apropiación del contenido, el surgimiento de habilidades y el desarrollo y consolidación de actitudes y valores en los estudiantes (Álvarez y González, 2002), donde el habla y la expresión corporal y gestual de profesores y estudiantes, son el canal o medio directo de interacción y discusión, así como los SID facilitan y median el proceso educativo de los sujetos que en él participan con la información que organizan para ponerla al alcance de éstos y así transformarla en conocimiento.

Los SID como conjunto de elementos que se interrelacionan a partir de los documentos cognitivos y las necesidades de información que presentan los usuarios, se estructuran en bibliotecas, centros de documentación, archivos, bases de datos, y en el ciberespacio (en el cual gravita Internet), y posibilitan la búsqueda, localización, recuperación, selección y uso de la información con el fin de resolver problemas y tomar decisiones de carácter académico e investigativo.

De esta forma se justifica la necesidad de caminos que les permitan a profesores y estudiantes acceder a la información como insumo de aquello que debe transformarse en conocimiento; en estos caminos deberán estar presentes los SID. Parafraseando a Gotbeter (2006), más allá de lo motivante que resulta que un conocimiento sea útil, el acceso al mismo, la discriminación de la información relevante de la irrelevante y la pertinencia resultante de la misma, hacen que en todo proyecto se progrese en la adquisición de conocimientos.

Es posible decir entonces que la educación tradicional (heteroestructuración del conocimiento) basada en medios como 
la bibliografía seleccionada y limitada por los profesores, los fragmentos de textos así como la entrega personalizada de las lecturas al estudiante, la enseñanza nominal y la reducción de los contenidos, al pasar hacia una enseñanza más activa (autoestructuración del conocimiento) a través de medios digitales, donde los datos y la información están desperdigados en el ciberespacio, y donde algunos profesores no se capacitan en el uso de los SID y los estudiantes se aíslan en la construcción del conocimiento, no se logre que los estudiantes universitarios utilicen los SID como medios eficaces que posibilitan la transformación de los datos y la información en conocimiento. De este conflicto emerge una síntesis en la que se observa una alternativa donde los profesores y estudiantes universitarios, sin dejar de utilizar las fuentes de información tradicional, se apropian de las fuentes de información mediadas por las TIC, y realzan el papel que juegan los SID como medios didácticos indispensables en los procesos de enseñanza y aprendizaje.

Es así como el uso de los SID se convierte en tema de interés dentro de la didáctica universitaria, toda vez que ésta, en tanto estudia los procesos de enseñanza y aprendizaje, se preocupa por los elementos que conforman su sistema, entre los cuales los medios se asumen como esenciales para el desarrollo de los procesos mencionados, especialmente cuando existe la inquietud de cómo deben proceder profesores y estudiantes universitarios para transformar los datos y la información en conocimiento.

A modo de reflexión orientadora para el trasegar de esta investigación, se pregunta:

¿Cómo los SID, en tanto medios, posibilitarían la transformación de los datos y la información en conocimiento con fines formativos en la educación superior? 
El siguiente gráfico ilustra la relación dialéctica del problema de investigación, la tesis (heteroestructuración del conocimiento), la antítesis (autoestructuración del conocimiento) y la síntesis (interestructuración del conocimiento) que revierten en la transformación de los datos y la información en conocimiento a partir de una estrategia didáctica.

GRÁFICO 2

RELACIÓN ENTRE TESIS Y ANTITTESIS: LA SÍNTESIS

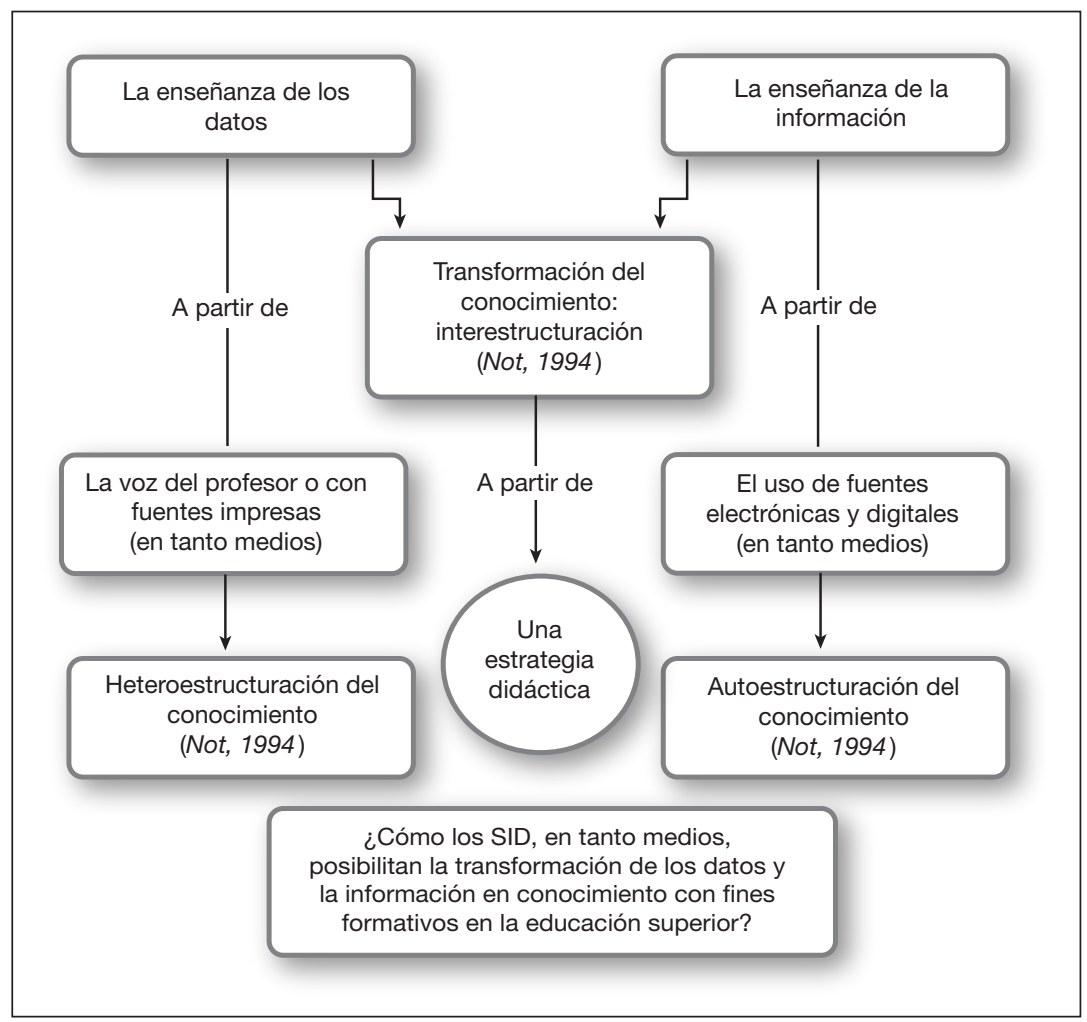




\section{HIPÓTESIS ABDUCTIVA O LA PREGUNTA \\ EN CUANTO LO PRÁCTICO}

Una vez planteado el problema fue menester establecer posibles salidas a éste y para ello se partió del trabajo de Pierce (1970) alrededor de la abducción, ${ }^{4}$ un proceso de razonamiento del cual surgen ideas, hipótesis y teorías que, en concreto "[...] constituye, pues, la preferencia de una hipótesis sobre otras, previa a todo conocimiento de su verdad y a cualquier examen a que pueda ser sometida." (Pierce, 1970: 21). Para llegar a la abducción se pasa por un proceso de generación de hipótesis, que surge de los fenómenos observados como un hecho sorprendente, porque se sale de lo normal o tradicional tratando de ver "[...] qué resultados sobrevendrán de las predicciones de la hipótesis" (Santaella, 1998).

La hipótesis abductiva se enuncia como una interrogación, surgida de una duda o una sospecha que conlleva a la búsqueda de explicaciones que satisfagan la curiosidad. Cuando la hipótesis pasa la etapa de la interrogación, se dice que entra a "[...] la fase crítica de su comprobación" (Pierce, 1970: 22); para lo cual se apoya en los indicios y los íconos. En esta fase hacen presencia conjunta la inducción, que podría asumirse como el proceso de verificación de los elementos de la hipótesis, y la deducción o "[...] el proceso de inferir las consecuencias probables y necesarias de una hipótesis" (Santaella, 1998).

Se puede comprender esto diciendo que la inducción es un proceso de comprobación, mientras que la abducción lleva a la adopción de hipótesis como son éstas, y no como resultado de una serie de opiniones. Se dice entonces que la abducción es revisión de los hechos, los cuales, pueden llegar a sugerir alguna teoría.

4 Antes de hablar de este término Pierce utilizó las palabras hipótesis, conjetura o suposición (Génova, 1996). 
Como lo indica Moreno, se:

llega a la hipótesis abductiva cuando realiza el tránsito entre el pensamiento inductivo y el deductivo. La inducción se caracteriza porque parte de un "antecedente" que proviene del hecho sorprendente y se convierte en una premisa. Seguidamente aparece un 'consecuente' que se desprende del hecho. Finalmente, el sujeto cognoscente se encuentra en el terreno de la 'probabilidad' cuando reúne el consecuente y las consecuencias del hecho (Moreno, 2008).

La hipótesis abductiva, que se caracteriza porque lo que enuncia es una probabilidad, no es algo que deba ser necesario, pues lo que ella hace es explicar un fenómeno observado que sorprendió. En consecuencia se pregunta, como una anticipación de sentido:

¿Será que una estrategia didáctica fundamentada teórica y metodológicamente en los SID, en tanto medios, dinamiza la forma (tiempo y espacio) de la enseñanza y posibilita la transformación de los datos y la información en conocimiento, en cuanto contenido con fines formativos en la educación superior?

UNA RELACIÓN PERTINENTE: LA PREGUNTA (EN TANTO LO TEÓRICO) Y LA HIPÓTESIS (EN CUANTO LO PRÁCTICO)

A modo de cierre de este capítulo se presenta la pertinencia de la pregunta en relación con la hipótesis para comprender la formulación del problema y vislumbrar un posible horizonte y la anticipación del sentido. 
GRÁFICO 3

PERTINENCIA DE LA PREGUNTA EN RELACIÓN CON LA HIPÓTESIS

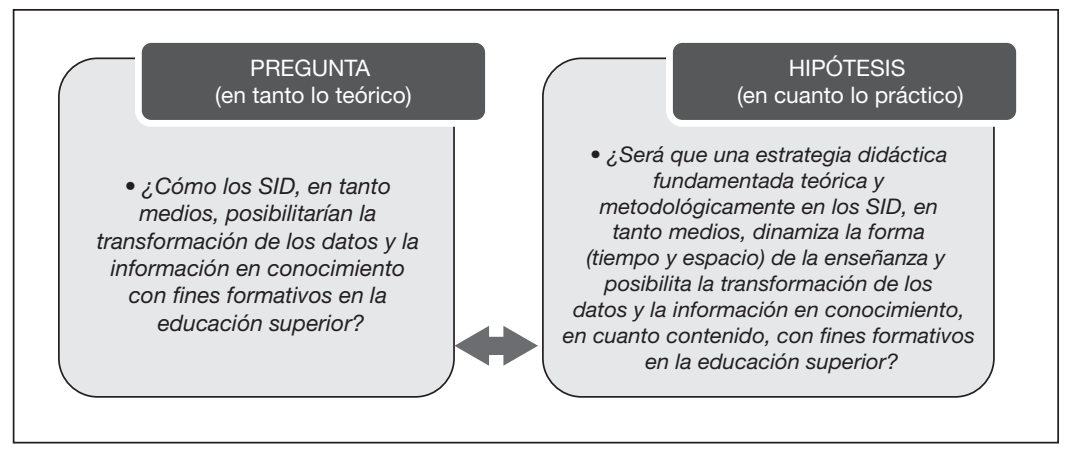

La respuesta a estas preguntas que a su vez son síntesis del problema dialéctico planteado y de la hipótesis abductiva, implicó un proceso de investigación en el cual los SID se asumieron como medios didácticos, en tanto son fundamentales en el acceso a la información, pues facilitan el uso de mejores fuentes previamente seleccionadas y subvierten el espacio de la clase presencial hacia el ciberespacio; a la vez que desordenan el tiempo lineal de las clases tradicionales, y por tanto se incluyen en el sistema didáctico y junto con los contenidos, el método en tanto proceso comunicativo, y la forma (el espacio, y el tiempo), conformando triadas didácticas que permiten su reconceptualización. No se limitan por ello a ser facilitadores del acceso a la información, sino que también adquieren su protagonismo al contribuir al desarrollo del contenido, en tanto conocimiento, en un espacio y en un tiempo que no necesariamente debe ser sincrónico, y que más bien facilita la asincronía. Además, es básico que como acción el proceso didáctico requiera de medios que faciliten la comunicación. Todos ellos se verán, a su vez, afectados y modificados. 
En la relación de estos cuatro componentes y con miras a realizar una propuesta práctica que se sustentara en la hipótesis abductiva, fue viable, entonces, enunciar que una estrategia didáctica ${ }^{5}$ fundamentada teórica y metodológicamente en los SID, en tanto medios, dinamiza la forma (tiempo y espacio) de la enseñanza y posibilita la transformación de los datos y la información en conocimiento, en cuanto contenido, con fines formativos en la educación superior.

Este fue el inicio de una discusión dialéctica alrededor del papel que juegan los SID como elementos centrales dentro de los procesos de enseñanza y aprendizaje que, orientados desde la didáctica a partir de una estrategia en la que se involucran los diferentes componentes de aquella, le permiten al profesor orientar el proceso educativo en el cual enseñan datos e información a manera de contenido, con la intención de que tanto él como los estudiantes los transformen en conocimiento científico, artístico, tecnológico, técnico o cotidiano.

De esta manera el problema se planteó desde la didáctica universitaria, haciendo una relación directa con los principios y teorías de la ciencia de la información. Se utilizó el enfoque hermenéutico para interpretar los textos y el enfoque dialéctico para entender el problema de investigación, sintetizado en una pregunta, en tanto lo teórico, y se diseñó la hipótesis de carácter abductivo, en tanto lo práctico, como posibilidad de acercamiento a la solución del problema.

El análisis de la forma como los profesores universitarios hacen uso de los SID, en tanto medios didácticos que facilitan

5 Olga Lucía Zuluaga manifiesta que "[...] la estrategia debe entenderse como las determinaciones de poder y de saber que actúan en un campo complejo y heterogéneo de fuerzas diseminadas en las prácticas sociales (incluyendo entre éstas las prácticas discursivas); tales determinaciones requieren para su despliegue de una red de instituciones, sujetos y discursos (saberes), atravesados por sus fines o delimitados para sus fines, y para introducir mecanismos estables de dominación en el conjunto de fuerzas” (Zuluaga, 1999: 141). 
la transformación de los datos y la información en conocimiento, fue el tema que se abordó en esta investigación. A partir de la revisión de los teóricos del tema se encontraron dos posiciones contrarias que se contrastaron mediante un enfoque hermenéutico para buscar y proponer un acuerdo entre ambas, a fin de alcanzar los objetivos propuestos.

De esta forma, el enlace entre la pregunta de investigación y la hipótesis abductiva permitieron el primer acercamiento a la comprensión de los conceptos que ampliaron el horizonte de sentidos de los textos y que, junto con los objetivos de la investigación, mostraron la manera de allanar el camino que facilitó develar la tesis a lo largo de este proceso investigativo. 


\section{Los conceptos en el devenir de los Sistemas de Información Documental (SID) o el horizonte del pasado}

na palabra opera como concepto, ${ }^{1}$ pues tiene efectos discursivos, institucionales y prácticos; un concepto se afianza porque surge una palabra, de ésta pasa al término y de éste a la teoría del conocimiento, lo que indica que emerge cuando tiene una función epistemológica y supera el uso lingüístico general. El concepto resiste el paso del tiempo, pervive y en el presente tiene plenitud de sentidos; aun así, los conceptos son campos móviles que evolucionan y por lo tanto un campo conceptual no debe dogmatizarse.

Desde esta perspectiva es menester preguntarse por los alcances y las implicaciones que aparecen al interrelacionar los puntos de vista de quienes dieron inicio a la palabra y luego al término, de quienes procuraron esclarecer éste, y de quienes lo ubicaron

1 "Si la unidad elemental del pensamiento es el concepto, la unidad organizada del pensamiento es proposición, la cual se puede expresar en sentencias diferentes, según las modalidades de lenguajes que emplee. Cada componente de una sentencia es un término. El término puede designar un concepto y los conceptos pueden referirse a realidades" (García y García, 1996: 77). 
en un ámbito disciplinar determinado; además de buscar un acercamiento a la solución de los problemas del significado perteneciente a las expresiones. Esta mirada a veces aislada, y otras a partir de un trabajo interdisciplinario o transdisciplinario, lleva a encontrar apreciaciones contradictorias, redundantes y hasta recíprocas.

El interés de este capítulo es presentar la mirada histórica del papel que cumplen los conceptos dato, información y conocimiento en la educación superior, concretamente en la transformación de la información en conocimiento, al ampararse en los SID como entidades que respaldan y acompañan la función del profesorado en esta transformación. Así, se dispuso de un sinnúmero de trabajos de investigación, reflexión y ensayos anclados en diferentes ópticas disciplinarias: la psicología, la bibliotecología, la documentación, la ciencia de la información, la filosofía, la biología, la física, la sociología, entre otras; sin olvidar las definiciones que se encuentran en las obras de referencia especializadas, y buscando la etimología de las palabras en cuestión, aunque con la conciencia de que los problemas reales que se generan a través de un concepto no se deben sustituir por problemas verbales. ${ }^{2}$

2 Con este capítulo no se pretende demostrar un desarrollo conceptual definitivo de los términos que se presentan, la idea es comprender cómo es cada concepto, qué se ha hecho de él o cómo ha llegado a ser de esa manera (Gadamer, 2005) y para ello se sigue el proceso hermenéutico en el que conversan los textos, proceso en el que intervienen el análisis, la comprensión, la interpretación y la síntesis del hermeneuta. Se trata de ver la identidad y la diferencia semánticas entre el pasado y el presente de un término, sus usos y relaciones, sin simplificaciones, o sea sin perder de vista posibles puntos de enlace que permitan no sólo conocer conjeturalmente el pasado desde la perspectiva presente sino también tomar distancia del presente observándolos desde el pasado, para así abrirse a futuros cambios de sentido. 


\section{EL DATO POR EL DATO O LO DADO}

El origen etimológico de la palabra dato se encuentra en el latín datum: lo que ha sido dado. El dato se toma en primera instancia como un antecedente que se requiere para llegar al conocimiento de algo, siendo la base de un razonamiento o una investigación, además de permitir deducir las consecuencias de un hecho. Con el pasar del tiempo se le atribuye el valor de documento o de testimonio y fundamento de algo, y también se le considera información que está disponible para quien la requiera. El dato se puede presentar como el resultado de una observación o de una experiencia. Desde las matemáticas se mira como las cantidades que hacen parte de un enunciado o problema, mientras que en la estadística es la información que se utiliza para realizar el análisis de un tema o evento. Con el dato como detalle en un asunto, se posibilita la elaboración de una idea en una noticia (Moliner, 1997; Real Academia Española, 2002).

Se dice que los datos conforman el conocimiento y que éste opera mediante la selección de datos significativos y el rechazo de datos no significativos: cuando separa, está distinguiendo o desarticulando y cuando une, asocia o identifica; también establece jerarquías diferenciando lo principal de lo secundario; y, asimismo, centraliza y entonces nuclea nociones claves. En esta actividad está presente la lógica, en la que participan los principios de organización del pensamiento de acuerdo con la visión de los sujetos, un proceso complejo que a veces es inconsciente (Morin, 1994).

Esta selección y rechazo tuvo lugar con la visión geocéntrica de Ptolomeo y con la visión heliocéntrica de Copérnico; la primera rechazaba los datos que resultaban inexplicables a la razón y los consideraban no significativos, teniendo en cuenta que para Ptolomeo su sistema se regía explícitamente por 
un método de cálculo de los datos que en él participaban; él se regía por un método de comprobación; en tanto en la segunda, Copérnico escogía precisamente esos datos, pues los consideraba significativos para concebir el sistema heliocéntrico (Morin, 1994). Estas discusiones, han sido esenciales para el desarrollo científico, y también para darle espacio al papel de los datos como elementos fundamentales en la develación del conocimiento.

Es posible decir que los datos hacen parte de una ciencia, una disciplina, o del proceso de investigación, puesto que se surten de hechos y de principios que permiten iniciar un razonamiento de base perteneciente a dicho proceso. Desde esta posición, el dato puede asumirse como elemento de información que hace parte del contenido de un documento; pero también como la expresión mínima de un hecho o acontecimiento. Es decir, el dato es representación de algo que está ahí y que es percibido por un sujeto con pretensiones de conocer, de allí que también se diga que es punto de partida del conocimiento; o llevándolo a la hermenéutica gadameriana, el dato es la parte, mientras que el conocimiento es el todo.

Sin embargo, el dato por sí solo puede carecer de sentido. Para que un dato tenga sentido y sea significativo, debe estar acompañado de otros datos, contextualizarse y hacer parte del público que lo recibe; por ejemplo, el número 8 (ocho) es una representación gráfica más, pero para algunos matemáticos puede adquirir un sentido numérico en una suma o en cualquier otra operación, mientras que para otro grupo de personas puede ser el número de la calle en la cual se encuentran; de allí la importancia de tener claro el contexto en que se ubican. Puede decirse que un conjunto de datos forman una información; esto es, se tiene el mensaje comprensible que, tal vez, genere conocimiento, o con el cual se llegue a conclusiones o ideas; por lo tanto, el dato se toma como antecedente que permite 
llegar al conocimiento cuando se organiza con el fin de comunicar una información completa.

Cuando se acopian y analizan los datos se busca la producción de información, sin olvidar que "[...] si bien los datos son el elemento principal de la información, para quien los recibe, no todos los informes son igualmente importantes y oportunos" (Burch y Strater, 1981: 44). Consecuentemente, la asociación o reunión de los datos significativos, con sentido, es lo que permite hablar de la información que brinda conceptos, significados, conocimiento, conclusiones o ideas. En la informática, una de las disciplinas que trabaja con los datos, éstos se consideran "[...] expresiones generales que describen características de las entidades sobre las que operan los algoritmos. Estas expresiones deben presentarse de una cierta manera para que puedan ser procesadas por una computadora" (Laudon, 1996: 154). Esto indica que es necesario el procesamiento adecuado de los datos para que surja la información. Razón para considerarlos elementos iniciales del contenido perteneciente a la información y conocimiento, ya que al ser resultados de la realidad es difícil controvertirlos, a pesar de que su interpretación dependa de la forma como se registran, de los usos discursivos, de las perspectivas de la realidad y del contexto en el que surgen (Huaylupo, 2008).

Se tienen datos de imágenes gráficas y en movimiento, alfanuméricos, o los de audio, que una vez que se interrelacionan generan determinada información y se convierten en la materia prima de la información a fin de disipar la incertidumbre sobre un hecho, lo que crea una necesidad de información o de conocimiento, pues "[...] sólo los hechos relacionados con las necesidades de información ${ }^{3}$ son pertinentes. Así, la organi-

3 Las necesidades de información han existido en la vida del hombre desde siempre, éstas aumentan en la medida en que avanza el desarrollo de la sociedad desde la ciencia y la tecnología. Se dice entonces que una "necesidad 
zación selecciona hechos entre sucesos y entidades particulares para satisfacer sus necesidades de información" (D’Ambrosio). Esto denota que los datos se convierten en información de acuerdo con la importancia que ésta tenga frente a los intereses y necesidades de los usuarios, sean éstos personas, organizaciones o entidades, puesto que lo que para unos es información para otros son datos carentes de sentido.

Los datos son válidos para tomar decisiones y son significativos cuando representan símbolos que distingue la comunidad en la que se encuentran inmersos; además deben ser diáfanos para evitar la ambigüedad, a fin de posibilitar su reconocimiento e interpretación. Asimismo, los datos deben conllevar una integridad; esto es, que a partir de los datos con los que se cuenta se pueda responder en cierto momento a una pregunta determinada; otra razón para que se tomen como parte fundamental y constitutiva del conocimiento.

Cabe preguntarse: en la actualidad ¿qué clase de problemas generan los datos?

No puede desconocerse que desde que se estableció en la sociedad contemporánea la información como el cuarto poder (McLuhan, 1972), ésta viene siendo utilizada con mayor interés, aplicación y conciencia desde diferentes ámbitos; la academia, la industria, el Estado, los medios masivos de comunicación, y la cultura, entre otros, son algunos de los entes que la usan.

En periodos recientes los datos se han convertido en una nueva mercancía y se producen, venden y compran sin importar su consistencia, a pesar de que para ser válidos deben hacer parte de la realidad contextual para lograr su interpretación y asegurar el proceso comunicativo entre los actores sociales que participan de su elaboración y uso, y no arriesgar la explicación

de información se asume como el reconocimiento de una carencia o la aceptación de un vacío del conocimiento por parte del usuario, aun cuando muchas veces este no sepa expresar esa carencia” (Naranjo y Álvarez, 2003: 17). 
científica que conllevan (Huaylupo, 2008). Con esta forma de ver el papel de los datos en ocasiones se tergiversa su razón de ser, al desconocer la importancia de la contextualización para su comprensión e interpretación.

Mientras esto ocurre en la economía y el mercadeo, para las ciencias sociales y humanas los datos son expresiones mínimas del contenido de un tema, por eso no se les da un valor fundamental, aun así no se descarta su valor en el avance científico y social, pues son dinámicos en la medida en que hacen parte del contexto y su presencia depende del desarrollo socioeconómico alcanzado (Montero, 2001).

A la par con esta situación, también se tiene que los datos en muchas ocasiones se asumen como manifestaciones tan precisas de la realidad que no se permite su cuestionamiento; desconociendo así que los absolutos no existen ni para el dato, ni para la realidad, mucho menos para la interpretación que se les dé a aquéllos, puesto que los datos, además de hacer parte de la visión y percepción de las personas, también permiten la interacción entre éstas dentro de sus contextos sociales e históricos, los cuales, conllevan prejuicios, creencias, ideas y, posiblemente, interpretaciones.

Continuando con la posición crítica de Huaylupo, puede decirse que "no son los datos [los] que otorgan significación a los fenómenos de la realidad, son las apreciaciones cognoscitivas e interpretativas, las que están dando una dimensión significativa al dato o al conjunto de ellos" (2008: 129). Por consiguiente, la realidad es el sustento de los datos, porque éstos la representan, pero no puede desconocerse el papel que cumplen la elaboración de teorías y las interpretaciones valorativas de los mismos para reflexionar, analizar, comprender e interpretar dicha realidad. Además, debe agregarse que la interpretación que hacen las personas de los datos puede variar entre una y otra. Si el contexto espacial genera determinado 
significado para los datos, el contexto del discurso también, lo que significa que se debe tener en cuenta que algunos datos poseen asiento en las expresiones culturales, míticas e ideológicas; asimismo, en ocasiones es factible que estén revestidos de prejuicios o subjetividad que llevan a apreciarlos como evidencias en las reflexiones científicas. Cabe preguntarse ¿el dato puede comunicar?

El dato está presente en el mundo cotidiano y en la realidad social a través de la comunicación; sin olvidar su presencia en la vida académica, científica e investigativa como elemento de reflexión, análisis, comprensión e interpretación de los diferentes objetos de estudio. No obstante,

[...] los datos en una interpretación, no constituyen la realidad, sólo [son] su representación construida según determinadas racionalidades, metodologías o formas de concebir esa realidad. Así, según se profundizan las exploraciones de la realidad, se han reconstruido acontecimientos trascendentes en la historia de los pueblos, pero con datos distintos. Cada explicación requiere de datos, pero otras interpretaciones de una misma realidad usarán otros datos y aquellos datos comunes no tendrán iguales significaciones. (Huaylupo, 2008: 132)

De este modo la realidad se puede expresar en forma objetiva a partir de los datos; y de esta manera se convierten en la evidencia de las "verdades" de la ciencia. Es decir, se cuenta con los datos dentro de una investigación como elementos que dan información; y se dice entonces que se objetiva lo subjetivo, lo cual indica que aquello que hace parte de los imaginarios, creencias, prejuicios, intuiciones, opiniones y vivencias de los investigadores y científicos se objetiva y se da un acercamiento a la verdad. Así, el conjunto de datos se asume como hecho real, que tiene fundamentos para su existencia o quehacer a pesar de que no todos los miembros de la comunidad lo acepten, no obstante, encontrarse en un entorno académico y tener el respaldo de una teoría o de un paradigma. 
Sin embargo, los datos no son los únicos elementos que permiten la objetivación de lo subjetivo en una investigación. No se puede caer en el error de considerarlos absolutos e indispensables en la solución de los problemas académicos, sociales, económicos o políticos, entre otros, porque por sí solos su información es limitada y requieren de una interpretación sostenida en la realidad contextual y teórica.

Como lo expresa Russell: "[...] el dato real y efectivo es irrecusable, pero a la extensión que instintivamente le atribuimos no le pasa lo mismo [...] No existen palabras que describan el hecho efectivo en toda su particularidad" (1963: 255). Por consiguiente, es posible exponer que los datos son relativos, en la medida en que en su existencia y visibilización inciden el contexto y el uso que se les dé, y las teorías y paradigmas que los respaldan en su interpretación de la realidad.

Se reitera, los datos por sí mismos no explican la realidad, ellos hacen parte de la totalidad de ésta y es cuando adquieren valor, sentido y significado. Se habla entonces de la relación que existe entre el todo y las partes, donde los datos se convierten en las partes que permiten elaborar un todo, como es la información, y de ésta el conocimiento, relación que no es pasiva, sino dinámica, dialéctica y en constante devenir, en donde influye la época, así como el pasado y el presente.

Sobre el papel que cumplen los datos en la enseñanza de las ciencias, las artes y la tecnología, es menester hablar de los datos cualitativos y cuantitativos, sin entrar en la discusión permanente de si son más importantes unos u otros; se alude a ellos para decir que éstos tienen valor -como se ha explicado en párrafos anteriores- de acuerdo con el contexto en que se utilicen y la intención que se tenga de ellos. Éstos deben asumirse también como resultados o expresiones de una realidad específica, generados por situaciones previas que revisten las características y las particularidades que le dan forma. 
Como dice Montero al respecto: “[...] el dato es más bien una relación entre lo real y su reflejo subjetivo que epistemológicamente proporciona una aproximación a su conocimiento; es una piedra angular en la construcción axiológica" (Montero, 2001: 57).

De igual manera, desde una visión positivista es factible decir que los datos permiten "[...] medir e identificar algún aspecto de nuestro mundo-realidad la cual nos enfrenta a un universo de fuentes y elementos factuales en espera de que desarrollemos las técnicas para medirlos e identificarlos, es decir convertirlos en datos" (Beazley, Boenisch y Harden, 2004: 184). Esto revela que el dato se transforma en información cuando las personas, entidades o instituciones se interesan en un conjunto de ellos; y así, adquieren un significado. En las ciencias sociales y humanas se dice que la expresión mínima de un contenido se encuentra en los datos, lo cual, da paso a la información.

Entonces, ¿qué es lo dado?

Desde las ciencias del espíritu, en concreto desde la hermenéutica gadameriana, se habla de lo dado, que va en concordancia con la etimología de la palabra. Desde este enfoque

[...] los datos revisten un carácter bastante especial [...] lo que Dilthey [...] intenta justificar epistemológicamente [es] el conocimiento del mundo histórico a partir de este modo particular de estar dados sus datos. Los datos primarios a los que se reconduce la interpretación de los objetos históricos no son datos de experimentación y medición, sino unidades de significado (Gadamer, 2005: 101-102).

Ahí donde lo dado es aquello que se ha vivido, lo que conforma la vivencia de las personas, es donde se encuentra la "unidad vivencial" (Gadamer, 2005: 102). Pero al decir que conforma la vivencia, se refiere a las formaciones de sentido que en un principio pueden parecer extrañas e incomprensibles, las cuales, pueden llevarse por horizontes que permitan 
su claridad en la conciencia, hasta que no tengan nada extraño o, citando al mismo autor, "[...] unidades que ya no contengan nada extraño, objetivo ni necesitado de interpretación. Se trata de las unidades vivenciales, que son en sí mismas unidades de sentido" (2005: 102).

De esta manera, cuando se dice que los datos carecen de sentido si no se ubican en un contexto determinado, o si no llegan al público correspondiente, no es tan simple, porque se requiere, además de estas características, de la conciencia para comprenderlos, analizarlos e interpretarlos hasta que se supere su incomprensión y extrañeza; es decir, hasta que tengan sentido, significado.

Entre la visión positivista y las ciencias del espíritu se encuentran diferencias relacionadas con el concepto de datos, que Gadamer resalta en la siguiente reflexión:

[...] lo que caracteriza a los datos de las ciencias del espíritu frente a los de las ciencias de la naturaleza es que hay que apartar del concepto de lo dado en este terreno todo lo fijo, todo lo extraño que es propio de las imágenes del mundo físico. Todo lo dado es aquí producido. La vieja ventaja atribuida ya por Vico a los objetos históricos es lo que fundamenta según Dilthey la universalidad con que la comprensión se apropia el mundo histórico (Gadamer, 2005: 287).

No todo es visible, ni palpable, en la conciencia se encuentran datos intangibles, psíquicos, tal vez inmedibles que, una vez interpretados se establecen como unidades de sentido.

Consecuentemente, los datos permiten conocer el pasado, a la vez que actualizarlo, en la medida en que se asumen como unidades de sentido y no sólo aspectos de medición o de experimentación. Es decir, los datos se convierten en una parte de la información y también del conocimiento. 


\section{LA INFORMACIÓN O EL INSUMO DEL CONOCIMIENTO}

Este concepto se aborda teniendo en cuenta que la información es un término que se utiliza en diferentes contextos, ciencias y disciplinas dando lugar a múltiples definiciones, que parten de la filosofía y la historia, pasan por las ciencias sociales, incluyendo la ciencia de la información, y llegan a la ingeniería y las ciencias de la computación y de la comunicación, sin olvidar el papel de la educación. Esa característica polisémica lleva a considerar la información como energía, comunicación, hechos, datos y conocimiento (Ros, 2002).

En párrafos previos se expuso lo que se considera como un prejuicio; frente al concepto que nos atañe, decimos que nuestro prejuicio, pre-dice que la información es y ha sido un elemento clave en el proceso de enseñanza, que desde la bibliotecología y la ciencia de la información pasa por una serie de actividades antes de llegar al usuario y que éste pueda aprovecharla de acuerdo con sus necesidades e intereses. Al finalizar este apartado se observará si el prejuicio se modificó -y de qué manera- o si permanece con algunos cambios.

Por lo pronto caben las preguntas ¿cuál es el origen de la palabra información? Y ¿qué significado presenta este concepto?

Etimológicamente el término información proviene del latín informatio que significa explicación o elucidación, "acción de formar", "dar forma»; es decir, procede de forma, que sirve para designar la forma exterior de un objeto; esto es, poner límites, estructurar y organizar un ente, cosa o materia (Rendón, 2005). Informar, en latín, también es educar, formar. La palabra tiene varios sentidos, pero todos se dirigen a la idea de construcción, de elaboración. El Diccionario de la Real Academia (2002, en línea) define información, entre otras como "[...] comunicación o adquisición de conocimientos que permiten ampliar o 
precisar los que se poseen sobre una materia determinada", cumpliendo con lo expresado anteriormente. Luego, existen dos usos básicos para el término: el acto de moldear la mente y el acto de comunicar el conocimiento, acciones que se encuentran profundamente relacionadas.

El prefijo in tiene, en este caso, el sentido de acentuar la acción pudiendo significar también negación como en el caso de informis, es decir 'sin forma'. El término es utilizado por autores clásicos como Virgilio (70-19 AC) cuando se refiere, por ejemplo, en la Eneida a Vulcano y los cíclopes que modelan con sus manos un rayo para Zeus (informatum manibus). Tertuliano (160-220 DC) llama a Moisés populi informator o sea un 'modelador del pueblo', un uso pedagógico (y político) que se mantiene en algunas lenguas occidentales derivadas del latín muchos siglos más tarde (Capurro, ${ }_{4}^{4} 2008$, en línea).

Continuando con la revisión de Capurro, se halla que el término informatio tiene un uso técnico y una relación evidente con las nociones griegas idea/eidos y morphé, y con términos como tipos (impresión) o prolepsis (representación). Cicerón (106-45 AC) traduce en De natura deorum el concepto prólepsis, (representación de las imágenes de los dioses y las cosas en el alma humana) como informatio rei. Del mismo modo se propone describir el ideal del orador (informato) cuya actividad más relevante consiste en que pueda observar en su alma "lo que Platón llama ideas". En otra obra Cicerón defiende a su maestro, el poeta griego Archias, acusado de haber adquirido ilegalmente la ciudadanía romana, indicando

Rafael Capurro es uno de los principales estudiosos del concepto, su formación lo convierte en un referente indispensable: posdoctorado en Filosofía Práctica de la Universidad de Stuttgart, donde elaboró la tesis: "Hermenéutica de la información científica"; es profesor emérito de ciencia de la información y de ética de la información en la Universidad de los Medios de Stuttgart. En este trabajo el uso de documentos elaborados por este autor cuentan con su aprobación. 
que él, Cicerón, fue instruido por Archias en técnicas como la escritura que tienen como finalidad la de educar o in-formar a los jóvenes en su devenir humano (quibus aetas pueriles ad bumanitatem informari solet).

Agustín (354-430 DC) y Tomás de Aquino (1225-1274 DC) recibieron la influencia de la epistemología y de la ontología griegas frente al término en discusión. El proceso de la percepción, de acuerdo con Agustín (De trinitate), se denomina informatio sensus y se refiere a las "metáforas epistemológicas platónicas y aristotélicas de la impresión (imprimitur)" y en la obra De civitate dei este filósofo "describe al proceso de conocimiento o iluminación de la sociedad celeste como informatio civitatis sanctae" (Capurro, 2008, en línea).

En Tomás de Aquino el término informatio tiene un lugar central tanto en la epistemología como en la ontología. El hilomorfismo aristotélico es traducido informatio materiae pero interpretado dentro de la metafísica creacionista cristiana, que lleva a Tomás a diferenciar netamente entre el proceso físico y biológico de reproducción de formas "per modum informationis" -en especial la "información" del cuerpo por el alma- de la actividad divina "per modum creationis". En otras palabras, informatio y creatio expresan una diferencia ontológica fundamental ajena al pensamiento griego. El demiurgo platónico es un dios artesano que actúa, visto desde el pensamiento de Tomás, inmanentemente sólo "per informationem" mientras que el dios cristiano es una causa trascendente que crea "ex nibilo". Tomás hace así compatibles de forma elegante lo que hoy llamamos creacionismo y evolucionismo. En el plano epistemológico Tomás distingue entre "informatio sensus» e "informatio intellectus" siguiendo la doctrina aristotélica del "retorno a los fenómenos" ("conversio ad phantasmata) (Summa theol. I, 14.2.co/4) y subrayando también el rol activo del "intellectus agens» en el proceso de re-conocimiento de las formas abstraídas de los fenómenos. Finalmente utiliza también el término informatio en un contexto pedagógico y ético ("informatio virtutum", «informatio morum») (Summa theol. III, 110.4.co/15). (Capurro, 2008, en línea). 
Este uso técnico del término informatio fue algo común entre los autores de la época medieval; sin embargo, sólo a partir del siglo XVIII aparece codificado en las enciclopedias generales y en los diccionarios filosóficos, en ocasiones aparece acompañado de una nota en la que se aclara que en el lenguaje común no se conserva el significado ontológico y que sólo se conserva el término técnico en filosofía. De acuerdo con Capurro, esta nota

[...] expresa en realidad nada menos que el cambio paradigmático de la concepción medieval del mundo enraizada en la filosofía greco-romana y en especial en el aristotelismo a la concepción subjetiva moderna de información con las teorías científicas y las formas de vida que se derivan de ella. El pasaje de la concepción de información como un proceso objetivo a la de un proceso subjetivo es vigente en lenguas europeas derivadas directamente del latín como el castellano, francés o italiano, o influenciadas por éste, como el inglés, desde el siglo XIV.

Por ejemplo, en el Diccionario de autoridades (Real Academia Española, 1734), el término información se recuerda como un término técnico de la filosofía escolástica y se aclara que no pertenece al lenguaje ordinario.

Debe aclararse que el derrumbe de las instituciones medievales durante los siglos XVII y XVIII no generó, inicialmente, una pérdida sustancial en la noción de información, ésta se asumió como la actividad o proceso de darle forma a la materia (significado ontológico), al igual que para comunicarle algo a una persona, ${ }^{5}$ esta concepción varió posteriormente, permeada, quizás, por el cambio que se tuvo en la idea de que el universo

5 Esta concepción se puede observar en la filosofía de Descartes, quien expresa que las ideas son formas del pensamiento, pues informan a la mente que se dirige a esta parte del cerebro, puesto que una idea es una imagen o una representación, algo presente en la mente, se observa una relación problemática con las cosas reales en el mundo (Descartes, 1989). 
había sido ordenado por las formas; de esta manera, la noción de información pasó de la materia a la mente.

La acción de informar, relacionada con el modelado de la mente o el carácter o con la formación o la enseñanza, datan del siglo XIV -según lo expuesto antes desde los griegos- y, de acuerdo con el Oxford English Dictionary (1989), esa relación conllevaba un uso restringido, tanto en inglés como en otras lenguas europeas. Por consiguiente ¿qué significa la idea de que la acción de informar modela la mente? Lenguas como el inglés heredaron el término informatio, que se transformó en information (no ha perdido su significado epistemológico: comunicarle conocimiento a una persona), lo mismo ocurre con el alemán, lengua en la que la palabra información se ha usado para referirse a educación y comunicación desde el siglo XV. De esta forma, "Informatio fue traducido literalmente -primero en un contexto místico como in-Bildunge o in-Formunge y posteriormente en un sentido pedagógico general-, como el usado por Christoph Martin Wieland (1733-1813) con Bildung" (Capurro, 1978, en línea).

En el fondo, encontramos una realidad del cambio en la mirada del sujeto de la época, puesto que en la escolástica se hablaba de un sujeto sustancial, en la edad moderna se hizo alusión al sujeto comunicacional, situación que se reforzó con el auge de la ciencia empírica moderna desde el siglo XVII. En esta transición del medioevo a la modernidad se dio la pérdida del sentido objetivo de información (darle forma "sustancial» a algo) al sentido subjetivo, que podría denominarse moderno y que significaba "comunicarle algo a alguien".

Dentro de la filosofía empirista, la palabra información también formaba parte de su reflexión: para los filósofos de esta escuela la información fue de su interés, especialmente para determinar "[...] cómo la mente es informada por las sensaciones del mundo" (Capurro y Hjorland, 2007, en línea). En un 
primer momento estar informado se entendía como «en forma de»; en un segundo momento significó «informes recibidos de», pero cuando la conciencia comenzó a asumirse como punto central en la acción del sujeto, el significado del término se modificó y pasó de forma a sensación. Esto lleva a considerar que "[...] la información se movió gradualmente de la estructura a la esencia, de la forma a la sustancia, del orden intelectual a los impulsos sensoriales" (Capurro, 2008, en línea).

Entonces ¿qué ocurre cuando la información pasa de la estructura a la esencia? Vale decir que en este paso la información tiene que ver con la actividad humana de percepción y conocimiento del mundo, no con los procesos formativos mismos o con el perfeccionamiento moral individual o social, lo que permite expresar que actualmente el concepto de información se relaciona directamente con el acto de comunicar, y se le comunica el conocimiento a alguien. Una vez comprendido el origen del concepto, es factible preguntarse ¿cómo se dio la interdisciplinariedad de la información?

Puede decirse que a partir de la edad contemporánea (S. XIXactualidad), la noción técnica de información ha sufrido una serie de modificaciones, pero sin perder sus raíces fundantes. Desde fines del siglo XIX y comienzos del XX, los aportes de físicos e ingenieros como Ludwig Boltzmann (1844-1906), John von Neumann (1903-1957), Leo Szilard (1898-1964), Harry Nyquist (1889-1976) y Ralph V. L. Hartley (1888-1970) contribuyeron a estas modificaciones. Este último publica en 1928 un artículo con el título Transmission of Information, en el cual, escribe que dado que los sistemas de transmisión eléctrica no tienen nada que ver con seres humanos sino con máquinas, es mejor eliminar todos los «factores psicológicos» involucrados en dicha noción (Capurro, 2008).

Con autores más recientes como Shannon y Weaver, Wiener, Saracevic, Goffman, Auckland, Capurro, Machlup y Mansfield, 
Weizsäcker, Battesson y Dretske, entre otros, el concepto de información se adapta según la disciplina que lo interprete y de allí que presenten la información, bien como una entropía negativa o una fuerza básica o de utilidad pública, o como algo que es transmitido en un proceso de comunicación, es decir, una "cosa».

Por consiguiente, hay que reflexionar si la información es universal, si es un elemento básico, por ejemplo, materia o energía; y de igual manera, si hace alusión al campo mental o a otros campos, como es el caso del código genético en la biología, o el de la ciencia de la información, que desde su contexto básico se presenta en un soporte físico que requiere de un proceso de comunicación (emisor, receptor y canal). Para ampliar las distintas valoraciones se debe establecer una visión general sobre las apreciaciones del concepto de información; igualmente, es necesario pararse en una situación concreta, pues según Mahler (1995) la información es un concepto contextual.

De allí que el concepto de información haga parte de la jerga de casi todas las disciplinas científicas, pues se utiliza tanto en su propio contexto como en relación con fenómenos específicos. No obstante, no se puede decir que se cuente con un concepto unificado, como lo expresara Bogdan (1994: 53):

Mi escepticismo con respecto a un análisis definitivo de la información se debe a la infame versatilidad de ésta. La noción de información ha sido usada para caracterizar una medida de organización física (o su disminución, en la entropía), un modelo de comunicación entre fuente y receptor, una forma de control y retroalimentación, la probabilidad de que un mensaje sea transmitido por un canal de comunicación, el contenido de un estado cognitivo, el significado de una forma lingüística o la reducción de la incertidumbre. Estos conceptos de información son definidos en diversas teorías como la física, la termodinámica, la teoría de la comunicación, la cibernética, la teoría estadística de la información, la psicología, la lógica inductiva y así sucesivamente. Parece que no hay una idea única de 
información para la cual estos diferentes conceptos converjan y, por lo tanto, ninguna teoría es propiedad (propia) de la información.

La discusión sobre el concepto sigue presente, lo cual corrobora el escepticismo de Bogdan, y se enmarca en la relación que éste podría tener con el proceso de conocimiento; además, se encuentran divergencias en apreciaciones sobre el concepto en distintas ciencias y disciplinas; como en las ciencias de la computación, bibliotecología, ciencia de la información, lingüística, psicología y física, al igual que en las ciencias sociales. Como se indica en The Study of Information (1983), la controversia se inició con Shannon y Weaver cuando presentaron la primera teoría de la información de las que se tiene referencia en la época actual; y expusieron que ésta se encontraba en el contexto de la transmisión de señales y que respondía al conteo de las emisiones; desconociendo que la información se dirige a la mente humana y ésta también la recibe; es decir, la información es un fenómeno humano en el que las personas transmiten y reciben mensajes en el contexto en que se desenvuelven. A continuación se abordarán algunas de esas ciencias y disciplinas.

Con la cibernética se inicia en el siglo XX la discusión sobre el concepto de información, época en la que los conceptos de comunicación y de información se expresaron en un nivel elevado de abstracción y no se limitaron a la comunicación del conocimiento humano, como lo dijo Norbert Wiener (1948: 132) con la frase: "La información es información, no materia o energía”.

Entonces ¿cómo se concibe la información hoy en día? Desde el punto de vista de Weizsäcker (1980: 154), es posible expresar que ésta se ve como algo "diferente a la materia y la conciencia", apreciación antigua, pues como expusiera el mismo Weizsäcker (p. 184): "[la información] es el eidos platónico, la forma aristo- 
télica, revestidas de tal manera que también un hombre del siglo XX pueda aprender a entrever su sentido".

Los matemáticos Shannon y Weaver definen la información a partir de la relación entre señal y ruido, la consideraron como una medida estadística de la incertidumbre del sistema (dentro de un sistema entrópico); su pretensión fue entregar un concepto que se pudiera expresar en medidas. Para ellos el total de información esencial en una situación determinada permitía eliminar la incertidumbre (Shannon \& Weaver, 1972). ${ }^{6}$ Esta apreciación es un poco limitada, pues solamente se refiere a la medición de términos para determinar si se logra la comunicación esperada, no se tiene en cuenta ni el contexto ni los sujetos que participan en ella, que la generan y la reciben.

A partir de una mirada cuantitativa, estos científicos dicen que la información se da entre un emisor y un receptor, en ésta se seleccionan y analizan los símbolos físicos que participan en este intercambio, lo que indica que más que transmisión de información, parece una transmisión de la señal o del mensaje, lo cual, permite pensar en una teoría diferente, más estadística o matemática; pues se centra básicamente en la reproducción de una serie de símbolos seleccionados y no en la comunicación de un mensaje comprensible, con sentido.

El trabajo de Shanon y Weaber dio paso a la relación de la información con las matemáticas desde la teoría matemática de la comunicación, en la que se estableció una especie de marco de referencia al uso de la información, con dos dimensiones precisas: la semántica y la pragmática, puesto que se considera que el emisor le comunica al receptor mensajes y no información, ya que estos autores entienden este último concepto en el sentido semántico y pragmático como el significado de

6 Si bien el texto del que se dispone se publicó en 1972, la primera edición data de 1948. 
un mensaje; además, clasifican la transmisión de los mensajes a partir de los sistemas de comunicación.

Esta mirada estadística de la información, o preferible, de la cantidad de mensajes que pueden emitirse, es criticada por Capurro, quien al respecto expone: “[...] así vista, esta teoría no es ni una teoría de la comunicación en el sentido de transmisión de un significado, ni tampoco una teoría de la información en cuanto se entienda por este término el significado de un mensaje, sino que es una teoría de la codificación y transmisión de mensajes" (Capurro, 2008, en línea).

La palabra información no se limita a ser un término exclusivamente matemático; también se toma como concepto de la administración, que además tiene relación con las ciencias naturales, la ingeniería, la informática y la sociología. La información "[...] no es sólo una medida de organización, es también la organización en sí, unida al principio del orden” Zema (¿2006?). Bertalanffy (2001) expuso desde la teoría de sistemas, que la teoría de la información, en el sentido de Shannon y Weaver, se basa en el concepto de información definido como una cantidad mensurable, mediante expresión isomórfica con la entropía ${ }^{7}$ de la física, de ahí la esperanza de que la información sirva de medida de la organización. Aspecto que lleva a enlazar esta reflexión con otra disciplina, como la física cuántica, en la que el escenario es dinámico, puesto que allí se trabaja por sistemas y las decisiones que se toman por parte de los miembros del sistema dependen del flujo de las informaciones, por lo tanto, se da una combinación entre la dinámica del sistema y la dinámi-

7 Dicen Arnold y Osorio (1998, en línea) que "el segundo principio de la termodinámica establece el crecimiento de la entropía, es decir, la máxima probabilidad de los sistemas es su progresiva desorganización y, finalmente, su homogeneización con el ambiente. Los sistemas cerrados están irremediablemente condenados a la desorganización. No obstante, hay sistemas que, al menos temporalmente, revierten esta tendencia al aumentar sus estados de organización”. 
ca de la información. Como dijera Mahler: "[...] la información sólo puede ser definida dentro del escenario y no fuera de él" (1995: 117).

En el ámbito de la termodinámica, la información significa lo contrario de la entropía, pues ella presenta dimensiones sintácticas, semánticas y pragmáticas, lo que permite superar el desorden progresivo que se pudiera presentar en la conciencia de quienes toman decisiones (The study of information, 1983).

Weizsäcker establece que la información se caracteriza porque presenta dos vertientes de una categoría: en la primera, la información es sólo "[...] aquello que puede ser comprendido" (Weizsäcker, 1980: 184); en la segunda, la información es "aquello que genera información" (p. 186), por lo cual, manifiesta que el concepto de información se relaciona con la forma o estructura; y agrega, además, que para el ser humano la información se refiere más al concepto que al proceso de pensamiento en sí. Pero para que un concepto sea información, debe cumplir con dos condiciones: "ser una entidad lingüística" (p. 184) y sólo presentar una definición, es decir, debe ser unívoco.

Disciplinas de las ciencias sociales y humanas tienen también relación directa con el concepto información. Por ejemplo, en la psicología a partir de 1956 y con el tema de la cognición, la información obtuvo un papel relevante al identificarla como "[...] un paradigma del procesamiento de la información" (Capurro y Hjorland, 2007, en línea). Sin embargo, y a pesar de esa característica, no se encuentra documentación que dé cuenta de una profunda discusión sobre el concepto en este campo, con excepción -de acuerdo con los citados Capurro y Hjorland- de trabajos realizados por algunos como: Hamlyn (1977), Harrah (1958), Miller (1988), Rapoport (1953) y Rogers (1998). Lo que puede encontrarse al respecto es una tendencia en la psicología en los procesos cognitivos y el papel del procesamiento de la información; una analogía con el procesamiento de la informa- 
ción que se realiza con el uso de las computadoras. Esta tendencia podría considerarse reduccionista, puesto que "[...] los seres humanos son vistos como extrayendo información de las propiedades físicas y químicas de los estímulos sensoriales" (Karpatschof, 2007). Este reduccionismo es contrario a lo que se busca desde la hermenéutica, en la que la percepción se observa como una síntesis en la que participan factores culturales y la información pasa por un proceso de comprensión para poder interpretarla, y no sólo por los mecanismos de operación del cerebro.

Entre tanto, Dretske (1999) expone la teoría semántica de la información y en ella realiza una diferenciación entre información y significado. Frente al término de interés, el autor indica que la información es una condición necesaria para adquirir el conocimiento, aquélla no requiere de un proceso de interpretación. Además, la información no se debe asumir como un concepto absoluto, ya que una sola fuente puede brindar diversos niveles de información. De acuerdo con Dretske (pp. 80-81), la información es relativa al "conocimiento preexistente de los receptores", es "algo que es necesario para el conocimiento", la asume como una "ficción inofensiva" y agrega: "no hay información falsa, lo que no hay es un significado real". La apreciación da a entender que la información permite la producción del conocimiento, el cual necesita de la verdad, ${ }^{8}$ por lo tanto, la información también necesita de ella.

8 Gadamer expone al respecto: "Es pretensión de la ciencia cuestionar los prejuicios y conocer así la realidad mejor que hasta ahora. Pero a medida que los métodos de la ciencia se extienden a todo lo existente resulta más dudoso que los presupuestos de la ciencia permitan plantear la cuestión de la verdad en todo su alcance" (Gadamer, 2006b: 52). El filósofo amplía la idea cuando se formula la pregunta: "¿Qué clase de experiencia es la que hace consistir la verdad en el discurso mostrante?". Ante lo cual responde: "Verdad es desocultación. Dejar estar lo desocultado, hacerlo patente, en el sentido del discurso. Uno presenta algo que así está presente y se comunica a otro tal como está presente para uno" (Gadamer, 2006b: 54). 
Asimismo, esta teoría ubica la información en una estructura que además de cognitivista es realista. Por lo tanto, ¿de qué depende el contenido de la información?

El contenido de la información no depende del conocimiento del receptor; esto es, ante una información determinada dos receptores pueden seleccionar, reflexionar, analizar, comprender e interpretar en forma diferente a raíz de las limitaciones, situaciones y contextos diversos en que se desenvuelven. Sin embargo, el incremento del contenido de información "[...] puede definirse sólo en relación con las clasificaciones o grupos de situaciones conectados por canales por los cuales se transmite la información sin ninguna referencia a la interpretación del receptor" (Capurro, 2008). Puede decirse que "[...] la estructura del lenguaje natural requiere la formación de cadenas de entidades lingüísticas" (Capurro y Hjorland, 2007). Por lo tanto, el análisis del concepto semántico de la información indica que, incluso si la información es vista como algo que existe independientemente del conocimiento del receptor, esto no implica necesariamente que la información sea absoluta.

No obstante, la objetividad del conocimiento científico no se alcanza excluyendo al conocedor, sino sobre la base del proceso intersubjetivo de información, lo que lleva a afirmar que "[...] la información es un concepto relacionado con el sistema" (Oeser, 1976, II: 86, citado en Capurro y Hjorland, 2007, en línea); reflexión que conduce a retomar la teoría de sistemas y su relación con el concepto de información. En esta teoría el concepto presenta un carácter pragmático, puesto que "[...] la información se acoge como una entidad poderosa que es capaz de cambiar la estructura y comportamiento de los sistemas" (Kornwachs, 1996: 174).

Para disciplinas como la sociología, la economía o la ciencia política, la información es un concepto clave, especialmente cuando se habla de la sociedad de la información. Denominar 
esta sociedad implica establecer cinco criterios que, de acuerdo con Webster (2002) serían: tecnológico (aplicaciones tecnológicas de la informática), económico (participación de las redes de información y la presencia de redes de mercado), ${ }^{9}$ cultural (influencia de los medios de comunicación en la sociedad); asimismo están los criterios laboral y espacial. Bell, Giddens, Schiller, Habermas, Baudrillard, Vattimo, Póster, Lyotard y Castells ${ }^{10}$ son reconocidos como los teóricos representativos de la sociedad de la información.

Para referirse a la sociedad de la información Rifkin (2000) habla de la era del acceso, en la que se dan tres procesos claves para la economía: la producción, la distribución y el acceso a la información. Asimismo se observan cambios terminológicos, como es el paso de la sociedad de la información a la sociedad del conocimiento, lo que permite comprender que el mayor reto al que se enfrentan tanto la economía como la sociedad en general, es el contenido y no las tecnologías de la información y la comunicación. Esta apreciación también permite superar la idea de que las TIC por sí solas le dan forma a la organización social, pues no es la información compartida la que mantiene unidas a las personas, es la interpretación que se haga de esa información.

Queda entonces preguntar: ¿qué es la información? Las reflexiones anteriores llevan a considerar que la información es, más que un objeto, un medio que, a través de una serie de acciones o procedimientos desarrollados en forma procesual -como son la búsqueda, selección, reflexión, análisis, comprensión e interpretación del contenido que alberga-, permite la comunicación entre las personas y el cambio de la sociedad.

9 Para ampliar ver Castells, 1989.

10 Este último autor, asume el concepto de información que presenta Porat: "la información son los datos que se han organizado y comunicado" (Porat, 1977: 2, citado en Castells, 1998: 43). 
Luego, ¿cómo se puede interpretar el concepto información en la ciencia de la información?

Para la ciencia de la información (en adelante CI), este concepto se ha convertido en uno de sus principales objetos de estudio que gira entre los procesos, la gestión, las actividades y la adquisición para ofrecerla a varios tipos de públicos que, en general, se denominan usuarios de la información. ${ }^{11}$

La palabra información hace parte de una larga historia enriquecida desde los campos de investigación de disciplinas como la bibliotecología, la documentación y la ciencia de la información; casi todas surgidas en el Siglo XX. Pero como se ha visto, el término recibe la influencia de otros campos del conocimiento que permean -y a veces entorpecen- su comprensión. Esa influencia ha provocado que dentro de la CI se retomen varias propuestas teóricas o, como se expone en The study of information: "[...] en sentido amplio la CI es un conjunto de trozos escogidos de una variedad de disciplinas que hablan de información en uno de sus muchos significados" (1983: 22). A pesar de esta dificultad, es fundamental interpretar el concepto dentro de este campo específico.

El término información en el ámbito bibliotecario lo utilizó en 1915 la estadunidense Ethel Johnson, quien estableció que una biblioteca especializada es un departamento de informa-

11 "Los usuarios de la información pueden acudir a las unidades de información en búsqueda de los documentos; pero, más que ser asistentes esporádicos, son sujetos activos, participativos y determinantes en el desempeño del sistema de información y de la calidad de los servicios que el sistema preste. En efecto, los usuarios consumen información, brindan información y producen información. Es por ello que se dice que interactúan con los componentes del sistema de información y con el ambiente en el cual funciona éste [por ejemplo, la universidad]. Los usuarios se enfrentan a una realidad que les plantea problemas, y que (en el mejor de los casos) están en condiciones de resolver. Estos problemas pueden ser de tipo cognoscitivo, social, político, económico, cultural, sociológico, psicológico, recreativo, entre otros" (Naranjo y Álvarez, 2003: 20). 
ción, cuya función es facilitar la disposición de esa información (Williams, 1998).

En época más reciente, los especialistas en información científico-técnica Mikhailov, Chernyi y Giliarevskii (1984) consideran la información como una simple colección de datos organizados con antelación, para emitir un juicio o asumir una línea de pensamiento. De igual modo, se puede considerar aquélla como la representación de los contenidos recibidos del mundo externo, compuesta por datos que recibe un sujeto para formarse una idea o modificar su opinión sobre algo. También puede tomarse como el conjunto de datos revestidos de sentido, que portan un significado y conllevan un propósito y una intención, pues la información es el resultado de los datos contextualizados que permiten visualizar una solución frente a una toma de decisiones (Angeloni, 2003).

En sentido estricto, según Alonso (2004: 63) la información "[...] es el resultado de nuestra estructuración individual y significativa de los datos, aquello que resulta al darles una utilidad específica”. Interpretando a este autor, podría decirse que la información no debe confundirse con los datos sino asumirse como el producto de lo que se hace con estos últimos; por ello, los datos deben tener "valor» de carácter informativo y esto lo brinda el contexto, pues si los datos no se ubican en el contexto adecuado, es posible que no se dé el resultado esperado: la información, con valor y sentido.

Ahora bien ¿qué relación tienen los datos con la información? Tanto los datos como los objetos sensibles ${ }^{12}$ le dan origen

12 Se hace alusión a aquél que es captado sólo y únicamente por un sentido, por ejemplo, la vista ve el color, el oído capta el sonido, el gusto percibe el sabor, el olfato detecta el olor, el tacto siente lo que palpa. O como le dice Sócrates a Teetetes: "La clase de cosas sensibles es producida al mismo tiempo por las sensaciones correspondientes; los colores de todas clases corresponden a visiones de todas clases; sonidos diversos son relativos a diversas afecciones del oído, y las demás cosas sensibles a las demás sensaciones" (Platón, 1992: 32). 
a la información, puesto que "la información está más allá de los datos, ella no actúa directamente sobre nuestros órganos de los sentidos, sino que son los datos los que actúan sobre estos últimos" (Rendón, 1997: 62), lo que permite comprender que la información se elabora, se constituye desde el mundo material, ya que no se asume como algo acabado o independiente de aquél, además es una "[...] cualidad secundaria de un objeto particular: del signo lingüístico registrado” (Rendón, 2005: 53).

Por lo tanto, la información precisa del mundo material, del contexto y de los sujetos; es lo que lleva a considerar que debe ser registrada, pues cualifica al signo lingüístico. Es factible decir que para darse la información deberán establecerse una serie de relaciones de carácter múltiple, pues siendo estrictos, en éstas participan el contexto, el sujeto con sus necesidades e intereses, y la disponibilidad de la información requerida. Esas relaciones conllevan una intervención que permite la reformulación o estructuración de los datos y la información en otros discursos, los cuales, para ser validados y confiables requieren de una comunidad en la actualidad denominada red de conocimiento.

Como se expresó antes, el uso de cualquier término y su definición científica, en este caso la información, depende del soporte y la función que ella le dé a las teorías y a las acciones prácticas del contexto en que se ubiquen y de la disciplina que respalden. De allí que Spang-Hanssen (2001, en línea) frente al término información, exponga:

De hecho, no estamos obligados a aceptar la palabra información como un término profesional en sí. Puede que esta palabra sea más útil cuando se presenta sin una definición formal como, por ejemplo, la palabra discusión o la palabra dificultad o la palabra literatura. Puede ser que la palabra información sea más útil particularmente cuando intentamos aumentar nuestro status profesional en relación con otras profesiones; suena inteligente e imponente y da un aire de tecnicidad. No presento objeciones morales a este tipo de uso de las palabras; el lenguaje no es ciertamente solamente para usos informativos 
(informativo aquí se refiere al así llamado sentido intelectual o factual de un texto o locución). Con todo, debemos comprender que el efecto de aumento de status de una palabra depende precisamente de su uso también en otros campos, preferiblemente en campos con status elevado, como ingeniería y, actualmente, sociología.

Esto muestra que, muchas veces, las definiciones se establecen con la pretensión de darle estatus a una profesión o su campo de investigación; sin embargo, también se puede caer en el error de generar confusión al interior de la disciplina, y llevar a una falta de respeto sobre la misma.

Cuando usamos los términos información en CI, deberíamos tener siempre en mente que información no es lo que es informativo para una determinada persona. Lo que es informativo depende de las necesidades interpretativas y habilidades del individuo (a pesar de que éstas sean similares frecuentemente para los integrantes de una misma comunidad) (Capurro y Hjorland, 2007, en línea).

Diferencia que depende de la pregunta que deba responderse.

La información se encuentra representada en diferentes objetos que sirven a diversas personas, por ejemplo, una piedra tiene una información y un sentido específico para un geólogo, información y sentido que puede ser diferente para un arqueólogo. Se reafirma entonces que la información es una respuesta a una pregunta, la cual, es formulada por una persona (usuario de la información) que presenta características y necesidades específicas. Se dice entonces que la información se define de acuerdo con las necesidades de los usuarios (grupales o individuales) y que los especialistas en información pretenden atender. Por consiguiente,

[...] la generación, recolección, organización, interpretación, almacenamiento, recuperación, difusión y tratamiento de la información debe, por lo tanto, basarse en visiones y teorías sobre los problemas, preguntas y objetivos que la información debe satisfacer (Capurro y Hjorland, 2007). 
El concepto actual de información tiene un papel central en la denominada sociedad de la información, ${ }^{13}$ que emerge después de la Segunda Guerra Mundial. Hoy en día, la sociedad acepta la información como un insumo esencial en el desarrollo y funcionamiento de ella misma, tal como considera el trabajo, las materias primas y el dinero. En esa medida, la información se toma como un elemento de interés para el hombre, o como expresa Moreiro (2006: 45) "[...] es la materia prima del conocimiento", expresión que dentro de la CI se asume como el proceso de selección, almacenamiento, análisis, organización y difusión, de manera que el sujeto la pueda usar cuando lo estime necesario.

Este concepto de información entendido como el resultado de nuestro propio proceso de estructurar datos y acceder a un significado resulta de suma importancia para la educación, dado que es común suponer que la información es el contenido objetivo del mensaje -los datos puros- que se transmite de una persona a otra, cuando [...] la información que yo obtengo a partir de los datos de mi medio ambiente, es mi interpretación de la realidad; si deseo evocar en común este significado con mis semejantes tendré que difundirlo, comunicarlo, transmitirlo en los términos de los otros para poder entendernos (Alonso, 2004: 63).

Es decir, la información es un elemento que se caracteriza por su propiedad de estar compuesta de datos organizados; porque se encuentra en diferentes soportes y formatos, se apoya en diversos procedimientos para su estructuración y movimiento y tiene en cuenta al otro y su contexto.

Se considera la información como el conjunto de datos comunicados en cualquier soporte, lo que permite decir que el conocimiento

13 El surgimiento de las TIC y sus impactos globales, son elementos que caracterizan a la denominada sociedad de la información (Capurro y Hjorland, 2007). 
se encuentra registrado o representado, puesto que posee a su vez, una naturaleza física y objetiva, al igual que una imagen tangible de lo que puede generar [...] Con la información, además de pasar datos de un lugar a otro, también se logra el intercambio de conocimiento (Naranjo y Álvarez, 2003: 16).

De esta manera, la información que nace de un conjunto de datos organizados intencionalmente, busca variar la estructura cognitiva de un sujeto a partir de la estructuración que hagan de ella mediante un proceso de análisis, comprensión e interpretación.

En opinión de Capurro y Hjorland (2007):

[...] la distinción más importante en los conceptos de información es la distinción entre la información como un objeto o una cosa (por ejemplo, número de bits) y la información como un concepto subjetivo, la información como un signo; es decir, en función de la interpretación de un agente cognitivo. La visión interpretativa desplaza la atención de los atributos de las cosas a los mecanismos de "liberación" para los que esos atributos son de importancia. Esto puede generar frustración, porque es difícil y porque implica principios teleológicos que son ajenos a los principios de la ciencia positivista. Es relativamente fácil contar el número de palabras en un documento o describirlo de otras maneras. Es mucho más difícil intentar descubrir, ese documento, para quién es importante y cuáles son las preguntas importantes que el documento puede responder. Las preguntas de interpretación también son difíciles debido a que a menudo confundimos interpretación y enfoque individualista. El significado es, por lo tanto, determinado en los contextos sociales y culturales.

No obstante, se debe considerar que para obtener información se requiere de una síntesis (en el sentido dialéctico). En esa síntesis la persona une los elementos objetivos citados antes, que podemos denominar datos, sin olvidar los objetos sensibles, e incluir los elementos subjetivos (estructuras interpretativas); con estos últimos se procesará, organizará, estruc- 
turará y se les dará forma a los datos, haciendo uso racional de los símbolos, para "[...] interpretarlos, enlazándolos con su referente y [sus] sentidos ideales” (Rendón, 2005: 53). Así, se le da sentido a la etimología de la palabra información que se presentó en un principio: dar forma, es decir, "[...] establecer límites a la materia, dotarla de estructura y organización" (Rendón, 2005: 53).

Así, es posible decir que en el ámbito social la información es vista cada vez más como algo elemental para el funcionamiento de la sociedad junto al capital, el trabajo y las materias primas; por lo tanto, la información no es producto puro de la observación, es más un constructo teórico que se presenta a partir de una interpretación de los datos.

El concepto de información en el lenguaje cotidiano y de gran auge en la sociedad contemporánea, se asume como el conocimiento comunicado, y que gana relevancia a partir de la Segunda Guerra Mundial; pues la información tiene que ver con la actividad humana de la percepción y el conocimiento del mundo.

Teniendo en cuenta las explicaciones anteriores para efectos de esta tesis, se asumirán los datos y la información como la materia prima o insumo del conocimiento que se comunica; éstos a su vez se tomarán como recurso esencial para desarrollar los procesos de enseñanza y aprendizaje buscando la discusión del contenido, impulsado hacia la transformación de ellos en el conocimiento que se pretende alcancen los sujetos que intervienen.

Para ello se requiere que los sistemas de información documental (SID) permitan su recuperación y acceso. Estos sistemas trabajan con la información, realizando un proceso de representación, organización, análisis y administración para que aquella pueda llegar al usuario que la necesita, de acuerdo con sus necesidades, propósitos e intereses. 
Se debe ser consciente que disponer de información no implica poseer el conocimiento, y precisamente, el poder de la sociedad actual radica en el conocimiento que permite la toma de decisiones en el ámbito personal y económico. Igualmente, existen diferencias entre información y conocimiento; la información se compone de datos y acontecimientos, mientras que el conocimiento se relaciona con la comprensión y el significado que se le da a la información. En consecuencia "[...] el reto de la Era de la Información se puede definir como [la] creación del conocimiento a partir de la información" (Barnett, 2001: 22).

Con el cambio de épocas el término información ha pasado por diferentes transiciones; sin embargo, se conserva su significado epistemológico, y su significado ontológico ha sufrido transformaciones, pero sin abandonar su idea inicial de moldear la materia.

En síntesis, de la información se puede decir que es un término polisémico que se utiliza en diferentes disciplinas y contextos, lo cual, lleva a que la información se considere como insumo, datos, conocimiento, energía, comunicación, etc. Por eso la información no existe en forma aislada y terminada, sino requiere del mundo material, de otros y de lo externo. Es factible decir que para que se dé la información deberán establecerse una serie de relaciones de carácter múltiple, pues siendo estrictos, en éstas participan el contexto, el sujeto con sus necesidades e intereses y la disponibilidad de la información que se requiere.

Se dice entonces, que la información es el insumo esencial del conocimiento que se comunica, la cual, está compuesta de datos y acontecimientos, mientras que el conocimiento se relaciona con la comprensión y el significado que se le da a la información. Es decir, la información es conocimiento comunicado; que se encuentra registrado o representado, puesto que posee a su vez, una naturaleza física y objetiva, al igual que una imagen tangible de lo que puede generar. 
Lo importante es ver cómo hoy en día este concepto tiene una relación directa con el concepto de conocimiento.

\section{¿DE LA INFORMACIÓN AL CONOCIMIENTO?}

Las fuentes del conocimiento establecidas desde la reflexión filosófica, sociológica, psicológica, pedagógica, entre otras, en el contexto universitario y a partir de los sistemas de información documental, permiten mostrar que la información también es una fuente del conocimiento puesto que es resultado de ella y surge a partir de ella, y si la información existe en el mundo material como un ente ideal, el conocimiento la retoma para elaborarse; de allí, que se acoja la idea de Shera, cuando expone: "[...] distinguimos entre información y conocimiento [...] la información es el insumo del conocimiento, y siempre es recibida a través de los sentidos [por lo tanto] no puede haber conocimiento sin un conocedor" (Shera, 1990: 18); un conocedor que comprende e interpreta, que modifica en última instancia, que transforma.

Cuando se pretende clarificar la definición que brindan las obras de referencia especializadas como diccionarios, enciclopedias, léxicos y vocabularios para el término conocimiento, lo primero que éstos hacen es remitir a la palabra conocer. De ellas se infiere que el conocimiento implica acción y conlleva el hecho de conocer; o sea, es un acto que supone actividad. Por lo tanto, antes de abordar históricamente el concepto, se debe aclarar el significado de conocer, pues le da el origen al término de interés. Luego, ¿qué es conocer?

Son varios los autores que describen el término, como Corominas (1980), Ferrater (1994), Moliner (1997) Lalande (1953) y la Real Academia Española (2002), aunque algunos aclaran que en español existen los términos conocer y saber, y que en 
ocasiones se usan indistintamente, como lo expone Ferrater. Se dice entonces que el término viene del viejo latín (g)no-sco, esto es nosco (conocer), novi (conocer), notus (cosa conocida, conocido) y del griego $\gamma \omega \tilde{\sigma \varepsilon \omega}$ (gnóseo) «(re)conozco» y este de

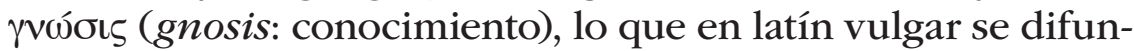
de como conôscěre (en arcaico gnoscere) y en latín cognôscěre, el que a su vez se deriva de noscěre, que conlleva a notio noción. Por lo tanto, dependiendo del contexto puede presentar diferentes significados.

En el Diccionario de Autoridades se encuentra al respecto: "[...] CONOCER... Percibir el objeto como distinto de todo lo demás que no es él [...] Viene del latino Cognoscere, que significa esto mismo" (Real Academia Española, 1729: 519, 1).

Casares define el término como un verbo transitivo que significa "averiguar por el ejercicio de las facultades intelectuales la naturaleza, cualidades y relaciones de las cosas. Entender, advertir, saber, echar de ver. Percibir el objeto como distinto de todo lo que no es él" (1997: 221). Si se amplía esta definición, puede decirse que conocer implica tener presente en la mente un objeto de pensamiento real o verdadero, con la condición de que el objeto de pensamiento, en tanto conocido, se distinga del pensamiento que lo conoce, pero ese objeto de pensamiento no se debe asumir solamente como algo dado, sino también como algo "[...] captado en su naturaleza y sus propiedades" (Lalande, 1953: 230), lo que le da un sentido más relacionado con el sustantivo conocimiento ( $\gamma v \omega ́ \sigma \iota \varsigma)$, término de interés en esta investigación.

Una vez hechas estas aclaraciones, surge la pregunta ¿qué es el conocimiento?

Del Diccionario de Autoridades se retoma la definición que ofrece para la palabra conocimiento: 
CONOCIMIENTO. s. m. Inteligéncia y noticia práctica y cierta de las cosas. Es del latino Cognitio, que significa esto mismo. FR. L. DE GRAN. Symb. part. 1. cap. 1. Por todo lo que este gran Philósopho nos ha enseñado en todas estas palabras, vemos como por el conocimiento de las criaturas, nuestro entendimiento se levanta al conocimiento del Criadór: assí como por el conocimiento de los efectos, venimos en conocimiento de las cáusas de dóprocéden. MARQ. GOB. lib. 1. cap. 5. Hallo que notar que en este hecho de Moisén, que el primérpasso del gobierno Christiano ha de ser el desengaño del Gobernadór y el conocimiento de sí mismo. SAAV. Empr. 46. Para el conocimiento cierto de las cosas, dos disposiciones son necessarias, de quien conóce, y del sujeto que ha de ser conocido [...] (Real Academia Española, 1729: 521, 1).

Los diccionarios de autoridades -en sus diferentes épocasse refieren a la actividad de conocer, al proceder para conocer, o la presencia en la mente de ideas acerca de una cosa; es decir, la cosa conocida, reiterando de esta manera lo que se decía en los diccionarios que los antecedieron, lo que corrobora la idea planteada en el Vocabulario técnico de Lalande. De allí que Moliner (1997) se refiera al conocimiento como cosas que se saben de cierta ciencia, arte, etc., y agrega que esta actividad "[...] es la facultad de saber lo que es o no es conveniente y de obrar de acuerdo con ese conocimiento" (Moliner, 1997: 729). Además, también se aplica a la presentación de un objeto o al hecho de comprenderlo (para distinguirlo, en el sentido de saber lo que es y el comprenderlo, en el sentido de explicarse por qué es así), esto indica que la palabra conocer conlleva a la relación entre sujeto y objeto, dejando a veces la sensación de que el primero se subordina al segundo (Lalande, 1953). Por consiguiente "[...] conocer y conocimiento designan, pues, un género cuyas especies son comprobar, comprender, percibir, concebir, etc. Se oponen a creer y creencia, no por la fuerza de la adhesión, sino por el hecho de que estos dos últimos términos no implican necesariamente la idea de verdad." (1953: 230). 
Pasando la interpretación etimológica del término, se prosigue con la época griega con la frase gnothiseauton (conócete a ti mismo), que se hizo célebre porque para acudir al oráculo era fundamental que la persona tuviera claridad sobre lo que necesitaba preguntar (Fernández, 2009). Con Sócrates la frase adquirió otra connotación, y fue la de servir de base para la estructuración de la personalidad; de allí que él haya defendido el método inductivo para observar la realidad concreta y superar la filosofía de los presocráticos, quienes partían -según Sócrates- de afirmaciones sobre la totalidad del mundo (Platón, 1975).

La forma de ver la ciencia en Sócrates lleva a considerar que para él el conocimiento auténtico, el verdadero saber, era el saber práctico, no el saber teórico, puesto que veía en la práctica una utilidad para el hombre. Por eso el diálogo se convierte en su método, ya que lleva la conversación a la dialéctica, al razonamiento inductivo y para ello se apoya en la mayéutica; con ésta el filósofo busca que los discípulos se den cuenta, a partir del análisis de definiciones, de su propia ignorancia y del desconocimiento de lo que se define; una vez se asume ese desconocimiento se procede a buscar la verdad y para ello, durante el diálogo, se observa el progreso de las definiciones, las cuales en principio son incompletas e inadecuadas, hasta llegar a formular otras más precisas y firmes, ${ }^{14}$ que permiten en muchos casos la definición universal, o lo que se podría decir hoy en día, el reconocimiento de la comunidad científica y académica.

Continuando con este desarrollo, se muestra el legado que heredó Platón de Sócrates cuando el primero va en procura del conocimiento, puesto que consideraba que éste es certero e infalible; además de que el conocimiento debe ir en busca

14 Como lo hace en el diálogo "Teeteto o sobre la ciencia» en el que con Teeteto trata de esclarecer lo qué es la ciencia (Platón, 1992). 
de la verdad para superar lo que es sólo apariencia; es decir, buscar lo real. Esta idea lo lleva a dudar del empirismo y del conocimiento que surge de la experiencia -como lo planteó Sócrates-, puesto que para él, lo que surge de la experiencia no puede asumirse como un conocimiento verdadero, sino como aquello que tiene un nivel de probabilidad.

Así, Platón en el mito de la caverna establece que el saber tiene dos niveles: opinión y conocimiento. En el primero se refiere a lo que se dice sobre lo visible, de lo que se tiene en el mundo físico, aun, lo que se propone y observa en la ciencia, opiniones que a veces se encuentran bien argumentadas, en otras carecen de fundamento convincente. Entretanto el conocimiento es la escala más alta del saber, el cual, surge porque se presenta un proceso de raciocinio, la razón lleva a que las ideas, debidamente analizadas, se vuelvan ciertas y aceptadas en el mundo real, lo que sustenta su reflexión sobre la experiencia (Platón, 1990).

Entonces ¿qué es el conocimiento ${ }^{15}$ Pregunta que se ha formulado desde los griegos, lo mismo que en la época medieval, en la que tanto San Agustín como los filósofos escépticos procuraron resolver el problema de la posibilidad o no del conocimiento. Sin embargo, sólo en la época moderna el problema se vuelve uno de los temas centrales del pensamiento filosófico, inquietud que surge con la preocupación de los autores por "[...] el método y la estructura del conocimiento, [con filósofos como...] Descartes, Malebranche, Leibnitz, Locke, Berkeley, Hume" (Ferrater, 1994: 657, T. I). Con Kant el problema se convierte en objeto de estudio de la teoría del conocimiento. Este trasegar ha hecho de esta palabra un concepto de la filosofía.

15 Se aclara que este análisis no es parte de un rastreo filosófico exhaustivo, ni es una discusión filosófica; no obstante se apoya en algunos filósofos. 
Otros, como Muñoz, abordan el término conocimiento como parte del saber, diciendo que éste ha sido tratado por la historia de la filosofía desde varias perspectivas, una de las cuales se preocupa por la trascendencia del conocimiento; al respecto, indica "[...] en orden a ella el objeto es definido como "trascendente» al sujeto y el sujeto sólo puede alcanzarlo cuando va "hacia» él (sujeto-objeto)" (Muñoz, 2000: 140). Esto indica que el conocimiento del sujeto va más allá del objeto exterior, razonamiento que además ha sido discutido desde el realismo, el idealismo, el materialismo gnoseológico y el escepticismo, entre otros.

En la Edad Moderna surgen varios enfoques o escuelas que se plantean el tema del conocimiento; en forma sucinta se presentan algunos de éstos. El racionalismo, se caracteriza por su discusión alrededor de los aspectos lógico-racionales del conocimiento; se dice que la razón es la fuente principal que origina el conocimiento; en tanto, el empirismo establece la experiencia como su germen al partir de hechos concretos, y centra su discurso en validar el papel que cumple la experiencia en la construcción y el desarrollo del conocimiento científico-filosófico. Asimismo, se cuenta con una mirada que muestra una relación entre los dos anteriores enfoques: el kantismo. Desde éste se expresa que la relación entre razón y experiencia producen el conocimiento, Kant es su principal representante.

En la escuela racionalista se destaca René Descartes como su principal exponente, filósofo que le da entrada a la necesidad de dudar, pero no una duda sin sentido, sino aquella que lleva un proceso, que aplica un método para poder ser razonada, labor que incluye la duda sobre lo que se duda, lo cual implica pensar constantemente, razonar incansablemente, indicando que la persona que duda y piensa es un ser que existe, que vive un mundo real, y esto le permite la construcción del conocimiento - "pienso porque soy (Cogito, ergo sum)" (Des- 
cartes, 1989). Se comprende que para Descartes las ideas se convierten en los pilares esenciales del conocimiento, pues hacen parte de la realidad.

Por otro lado, los principales representante del empirismo son David Hume y John Locke. Este último, alrededor del conocimiento, indica que la experiencia es la base de éste y no valida la presencia de las ideas innatas como elemento básico para su construcción, dándole gran peso a la sensación y a la reflexión (Locke, 2002). Locke considera que las ideas son el cimiento del conocimiento:

[...] nuestro conocimiento se refiere a nuestras ideas, puesto que la mente, en todos sus pensamientos y razonamientos, no tiene ningún otro objeto inmediato que no sean sus propias ideas, las cuales sólo ella contempla o puede contemplar, es evidente que nuestro conocimiento se ocupa únicamente de esas ideas (Locke, 2002: 523).

Esto permite comprender que sólo se considera como verdadero aquello que es posible comprobar mediante los sentidos, pues, de acuerdo con Locke, la experiencia es la base de las ideas, las cuales forman parte de la realidad interna (el yo) o externa. Se encuentran así ideas de tipo reflexivo como el raciocinio, el pensamiento, la voluntad o el conocimiento, como actividades propias de la mente. También se tienen las ideas de sensación, aquellas externas o que se encuentran en la naturaleza, por ejemplo, los colores, los sabores, la temperatura o los olores, es decir, lo que la mente percibe.

Puede asumirse como la síntesis de las dos posturas anteriores la de Inmanuelle Kant, para quien el conocimiento es el proceso en el que intervienen tanto la empírica como la razón. Kant explica que si bien el conocimiento se inicia con los sentidos, también requiere de la formulación de categorías y de conceptos, en donde se presenta el proceso dialéctico en el que intervienen la experiencia sensible y la razón, esta última 
generando la conceptuación. "No hay duda alguna de que todo nuestro conocimiento comienza con la experiencia" (Kant, 1787). Con esta afirmación, el filósofo expone su idea de la generación del conocimiento con el uso de los sentidos, los cuales, permiten las diversas representaciones de la realidad y le facilitan al sujeto realizar comparaciones, relaciones o separaciones que llevan al conocimiento. No obstante, si bien el conocimiento comienza en la experiencia no todo conocimiento se origina en ella, puesto que el ser posee facultades para conocer, independientemente de la experiencia (a priori). Al conocimiento que se adquiere por la experiencia, propio de los empíricos, se le distingue como a posteriori.

Entenderemos por conocimientos a priori no los que tienen lugar independientemente de ésta o aquélla experiencia, sino absolutamente de toda experiencia. A estos opónense los conocimientos empíricos o sea los que no son posibles más que a posteriori, es decir por experiencia. De entre los conocimientos a priori llámanse puros aquellos en los cuales no se mezcla nada empírico. Así por ejemplo, la proposición: todo cambio tiene su causa, es una proposición a priori, mas no es pura, porque el cambio es un concepto que no puede ser sacado más que de la experiencia (Kant, 1787).

Estas apreciaciones involucran la relación e integración compleja entre el sujeto y el objeto, en las que el sujeto cumple un papel activo en la construcción y elaboración del conocimiento. Con estas reflexiones Kant contribuyó a la teoría del conocimiento al considerar que la razón humana (el sujeto) es esencial para organizar las interacciones entre el hombre y el mundo físico.

Asimismo, puede expresarse que el conocimiento, de acuerdo con Kant (1787), se inicia por los sentidos, hasta llegar al entendimiento y alcanzar la razón, proceso en el que esta última, a partir de la abstracción del contenido y el uso real del mismo, permite la comprensión y la interpretación. 
De época contemporánea, Martín Heidegger (2005) procura replantear el sentido clásico de la trascendencia del conocimiento, y para ello se basa en la interioridad de éste, propia del sujeto que conoce. Heidegger define el conocimiento no como algo que está simplemente en el sujeto, sino como un modo de ser, como un constitutivo ontológico suyo.

De igual manera, la perspectiva de la fenomenología del conocimiento trata de describir el fenómeno o proceso del conocimiento y para ello Muñoz expresa que

el conocer ha sido asumido como lo que tiene lugar cuando un sujeto aprehende un objeto que le trasciende. En la medida en que tal aprehensión sea el caso, el objeto pasa a estar de alguna manera -no física ni metafísica, sino 'representativamente'- en el sujeto. Si la representación del objeto por el sujeto es fiel a como éste es, se habla de conocimiento verdadero, de lo contrario, de conocimiento falso (Muñoz, 2000: 140).

Por consiguiente, el conocimiento es la apropiación o aprehensión que hacen las personas de lo real, en la que intervienen la inteligencia, el entendimiento y la razón, lo que facilita establecer la relación entre los objetos y de estos con los sujetos, reiterando el pensamiento de Heidegger.

En este proceso de apropiación, aprehensión o adquisición intervienen elementos individuales, propios del hombre, considerados como capacidades para observar, memorizar y emitir juicios, entre otros, dando apertura para plantear que el sujeto aplica sobre el objeto de conocimiento un proceso para poder (potencia) adquirir dicho conocimiento, siendo de esta forma modificado en su estructura, lo que no ocurre con el objeto.

Desde este punto de vista, puede decirse que el hombre incurre en tres tipos de conocimiento que tienen relación directa con el mundo real (Muñoz, 2000): 
- La realidad de sí mismo, autoconocimiento o conciencia

- La realidad natural o conocimiento del mundo

- El mundo espiritual

A todo esto, es factible indicar que el conocimiento presenta ciertas divisiones, de acuerdo con la gnoseología o teoría del conocimiento, que comprenden el estudio del origen, la naturaleza y los límites del conocimiento humano; esto es, tres tipos de conocimiento: el proposicional (qué se conoce o se sabe de...), el práctico o preformativo (cómo se adquiere o se enseña determinado conocimiento), y el producido por familiaridad (Truncellito, 2009).

Pero ¿se podría hablar de un conocimiento científico? El trabajo sistemático es una de las principales características de este conocimiento, pues trata de organizar las ideas establecidas en los conocimientos generados en una determinada esfera; se dice así que "[...] el tipo o carácter de científico depende del uso de una determinada estrategia que cumple dos condiciones: sistematicidad y rigor" (Vargas, 2006b: 11). El carácter sistemático lo adquiere porque este conocimiento comunica parte específica de la realidad dentro de un contexto que se mueve en un espacio y un tiempo determinado, relacionado con una serie de nexos con esa realidad. Esto puede entenderse como la interpretación de un conjunto de proposiciones que se aprehenden por la definición; la descripción permite su comprensión y la explicación facilita su entendimiento. O como lo expone Camilloni (2008: 50): "[...] el conocimiento es científico cuando es un pensamiento fundado, cuando es integral y no acepta incoherencias. Su carácter científico exige comprobación de las teorías y la posesión de una base empírica”.

Este conocimiento se adquiere apoyándose en la reflexión, el razonamiento lógico y los métodos de investigación, que buscan un acercamiento a la verdad. Para lograrlo se ayuda en con- 
jeturas, conceptos, enunciados, fórmulas, etc., los cuales, analiza para poder explicar el objeto en estudio. Razón por la cual la descripción de los hechos responde -en lo posible- tal como se observan, procurando que el investigador supere sus emociones y pensamiento personal al respecto, así el objeto de estudio se presenta de acuerdo con su realidad y no con su ideal.

Este interés de objetividad implica un proceso de búsqueda intencionado, planeado de acuerdo con estrategias metodológicas revestidas de validez, donde se da cabida a la conjetura, a la sospecha sobre un hecho que conlleva a su análisis, a su comprensión e interpretación; surgen y se descarta así una serie de conclusiones a modo de síntesis.

Este conocimiento requiere de su comunicación para que la comunidad lo reconozca y lo valore desde su cientificidad, pues al comunicarlo está dando cuenta del proceso sistemático de estudio e investigación que lo precedió.

Desde otras miradas, el conocimiento se asume como

un saber que se coloca como capaz de demostrar su validez, afirmando su potencia para aprehender su objeto, en el dominio de su legitimidad. En ese sentido, en su figura dominante, todo conocimiento es auto-referente: implica, desde su inicio, el conocimiento que organiza un dominio de dispersión regulada de lo conocido (González, M. N., 2003: 19).

Este enfoque presenta al conocimiento como objeto, el cual se ajusta e interrelaciona con elementos como: el agente que lo produce o sujeto cognoscente; el objeto, los modos, los instrumentos, los fines y los productos, lo que conlleva una acción social que se modifica de acuerdo con los contextos y situaciones, para lo que se requiere de un sujeto conocedor (como lo dice Shera, 1990), el cual, no necesariamente debe coincidir con el sujeto del conocimiento, por lo tanto, esto no puede verse de una manera tan limitada. 
Se asume entonces que el conocimiento es una elaboración mental acerca de lo real, puesto que el sujeto lo alcanza sólo cuando va hacia él. Por lo tanto, para que se dé el conocimiento son imprescindibles el sujeto y el objeto, pero el objeto no necesariamente debe ser modificado para que surja el conocimiento, contrariamente a lo que ocurre con el sujeto, quien modifica sus estructuras a partir de la adquisición y el enriquecimiento que logra al dirigirse conscientemente hacia dicho objeto, por eso se dice que el conocimiento es, además, una abstracción interior, personal, de alguna cosa que fue experimentada por alguien; es decir, el conocimiento del sujeto va más allá del objeto exterior, puesto que él debe ir hacia éste para aprehenderlo y lograr así el anhelado conocimiento.

Esto permite decir con Núñez que "[...] el conocimiento es un componente del proceso de comunicación humana, que ha garantizado y garantiza la sostenibilidad de la especie más allá de la limitada herencia genética, debido a que es un proceso esencialmente educativo" (2007). Por ende, el conocimiento debe ser comunicable y comunicado para que pueda ser adquirido por los individuos, puesto que es parte del crecimiento del sujeto, al permitirle organizar y recordar su experiencia, facultándolo para inferir y proyectarse. Es decir, el conocimiento que una persona ha aprehendido o asimilado se refleja en valores, hechos o información, además de que lo organiza de acuerdo con los conceptos, las imágenes o las relaciones que él puede establecer y dominar, esto es lo que se puede expresar como lo que es conocido.

Si se aplicara la teoría de Shannon y Weaver, podría decirse que "[...] dado un estado del conocimiento, que se ve afectado por algún incremento de información, se tiene como resultado un nuevo estado del conocimiento" (Brookes, 1975). Pero el conocimiento no puede concebirse ni interpretarse como la acumulación de información, sino como una estructura comple- 
ja, en la que participan diversos elementos que se relacionan entre sí por sus semejanzas o, inclusive, por sus diferencias. Dicha estructura se enriquece y transforma constantemente por la información que genera y la que llega. Sin embargo, otras estructuras son indiferentes y no se ven afectadas; lo ideal es que éstas sufran una modificación.

La modificación de las estructuras de estudiantes, profesores, programas académicos e investigativos, desde el conocimiento, debe verse reflejada en el quehacer de cada uno, en su preparación y desempeño, además de permitirle asumir una postura crítica para enfrentar los problemas de la ciencia, las artes, la tecnología, de lo contrario se tendrían personas sólo con capacidad para memorizar y repetir ideas y teorías sin sentido.

En síntesis, como dice Estela Morales desde la ciencia de la información:

[...] el conocimiento, es todo lo que un ser humano ha aprendido, asimilado y organizado de acuerdo con aquellos conceptos, imágenes o relaciones que ha podido dominar; el conocimiento es una abstracción mental que supone cierto razonamiento y enjuiciamiento (Morales, 1998: 2).

Consecuentemente, conocer es un proceso que involucra la comprensión y la interpretación de la información que se recibe, en una reciprocidad constante que permite la generación de más conocimiento. De igual manera, se dice que el conocimiento está conformado por datos organizados con sentido, que conllevan a la presentación de una información que se organiza amparada en la experiencia, en el aprendizaje y en la reflexión.

En el siguiente gráfico se ilustra la relación directa que existe entre datos e información, al igual que el papel central que cumplen el procesamiento y la comunicación entre la información y el conocimiento. 
Hoy en día el hombre, a partir del conocimiento y la información, busca entender y explicar el medio en que vive (Suaiden, 2007). De allí que sucedan procesos continuos de generación y uso del conocimiento, que contribuyen al proceso de aprendizaje social, de acuerdo con su entorno y su realidad; por ello, el conocimiento es tanto instrumento de comprensión e interpretación ${ }^{16}$ de la realidad, como motor de desarrollo social, por lo cual, se apunta que aquellas sociedades que hacen este uso pueden denominarse "sociedades del conocimiento".

\section{GRÁFICO 4}

\section{DE LOS DATOS A LA ACCIÓN COMUNICATIVA}

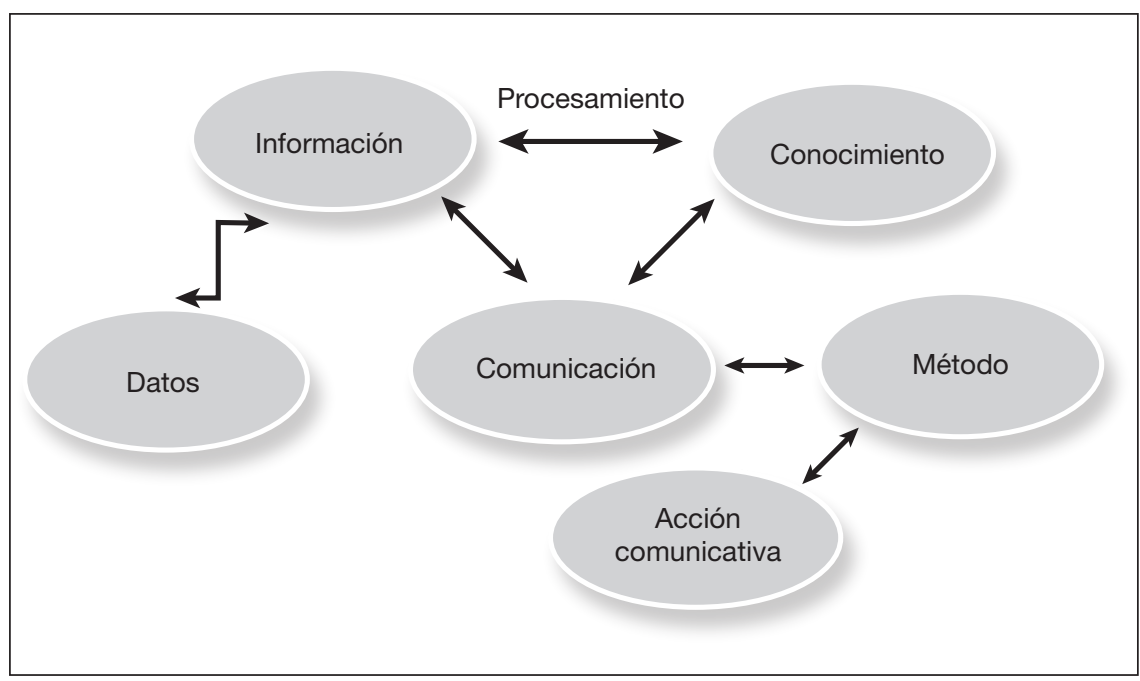

Con los conceptos datos, información y conocimiento, se pretendió encontrar un horizonte que le permitiera a la inves-

16 Como dice Gadamer: "La fundamentación del conocimiento no puede evitar [...] la consecuencia hermenéutica de que la realidad "dada" es inseparable de la interpretación" (Gadamer, 2006b: 327). 
tigadora aportarle algo a la cosa por crear (una estrategia didáctica) y por eso fue necesario diferenciarlos.

Para que un sujeto acceda a un documento debe partir de los datos que lo conforman, como elementos mínimos de éste. Cuándo él los percibe y reconoce pasan a ser información, y luego con el papel que cumple la memoria al albergar experiencias y conocimientos anteriores, ocurren una serie de acciones: algunos valores cambian y se modifican las decisiones y las intenciones en el sujeto; es decir, se transforma el estado del conocimiento de éste o se observa el cambio de la información en conocimiento. Este proceso es el que debe orientarse desde la enseñanza para lograr el aprendizaje con sentido. Se dice que "[...] el conocimiento es información digerida, que puede usarse en la vida, para investigar, para el ocio, para estudiar, para trabajar" (Moreiro, 2006: 44).

Porque "[...] sólo a la luz de la interpretación algo se convierte en 'hecho' y una observación posee carácter informativo [...] en definitiva [...] la interpretación no es un recurso complementario del conocimiento, sino que constituye la estructura originaria del 'ser-en-el-mundo"' (Gadamer, 2006b: 328).

Para finalizar este apartado puede decirse que conocer es siempre aprehender un dato en una cierta función, bajo una cierta relación, en tanto significa algo dentro de una determinada estructura, 'la información'. 


\section{El presente de los SID en la educación superior desde el estado de la cuestión}

9 n este capítulo se presenta el estado de la cuestión sobre el uso de la información mediado por los Sistemas de Información Documental -SID-, y se hace una revisión y análisis crítico desde la documentación que se consultó en los diferentes SID y los recursos de información disponibles, partiendo de un enfoque hermenéutico que adapte o desarrolle la perspectiva teórica que enmarca el uso de los SID como medios didácticos, para facilitar la transformación de datos e información en conocimiento. La revisión y el análisis se centraron, en gran medida, en las unidades de información de carácter universitario y los posibles programas formativos que los respaldan.

El capítulo da cuenta de la labor de búsqueda, recuperación, selección y evaluación de la información que contienen los documentos considerados relevantes para el problema: ¿De qué modo los SID, como medios, posibilitarían la transformación de los datos y la información en conocimiento con fines formativos en la educación superior? Y en cuanto a la hipótesis de la in- 
vestigación: ¿será posible que una estrategia didáctica fundamentada teórica y metodológicamente en los SID, en tanto medios, haya dinamizado la forma (tiempo y espacio) de la enseñanza, y posibilitado la transformación de datos e información en conocimiento, en cuanto contenido, con fines formativos en la educación superior?, y esto haya permitido proceder con el análisis, comparación, comprensión y posterior interpretación.

Uno de los criterios que se tuvo en cuenta para seleccionar los documentos estableció que éstos fueran resultado de la investigación y trataran temas como: el uso de la información en cualquier medio y soporte, los SID como medios y estrategia didácticos utilizados para enseñar a usar los SID. Y otro se centró en el contexto de la educación superior y en los profesores universitarios como usuarios de la información. Este último criterio se convirtió en un filtro clave de las fuentes pertinentes y relevantes.

Para organizar el trabajo se partió de la pregunta e hipótesis que orientaron la tesis; y también, desde el inicio del análisis de la información que se encontró en los diferentes documentos, se procuró ubicar líneas temáticas y de investigación actuales y se detectaron los vacíos, pero también avances en aspectos metodológicos que caracterizaron las investigaciones; por ejemplo, en cuanto a problemas que se investigan y sus respectivas preguntas, las metodologías que se trazan, las hipótesis (si es que se formulan) y los objetivos, sin olvidar el marco conceptual y conceptos que surgen o resultados de las investigaciones, aspectos que se convirtieron en categorías del análisis.

El capítulo se organiza a partir del proceso y las precisiones metodológicas, continúa con el análisis y la comprensión de categorías y finaliza con el proceso hermenéutico de la interpretación, incluyendo las consideraciones parciales, como se lee a continuación. 


\section{PROCESO Y PRECISIONES METODOLÓGICAS}

Para revisar los discursos relacionados con los SID como medios didácticos utilizados por los profesores universitarios con fines formativos en la educación superior, fue pertinente establecer, además de los criterios de que dispone la ficha bibliográfica referencial (Anexo 1), otros que permitieran comprender el valor del contenido de los documentos y delimitar la revisión, los cuales, se describen a continuación.

\section{Pertinencia temática}

Se debe aclarar que no todos los asuntos que se abordan en este proceso, desde los diferentes términos de búsqueda, tales como encabezamientos de materia, palabras clave y descriptores temáticos, se asumen como objeto de interés y análisis para este estudio. Por eso, durante la selección, revisión y análisis de los documentos, los temas centrales fueron:

- El uso de los SID (cualesquiera que fueran),

- Los SID como medios didácticos

- El uso de los SID por parte de los docentes

Además, se buscó aquello que estuviera relacionado con la preparación de los docentes universitarios en el uso de los SID como actividad de las unidades de información (bibliotecas universitarias y centros de documentación) y estrategias didácticas que utilizaron profesores y bibliotecólogos para enseñar a usar estos sistemas. 


\section{Palabras clave, descriptores o encabezamientos de materia}

En un proceso de búsqueda de información se debe tener presente que medios como bases de datos, catálogos y sitios Web tienen características particulares que los diferencian entre sí, especialmente en la forma de presentar los términos de búsqueda. Algunas bases de datos cuentan con su propio tesauro o vocabulario controlado para facilitar la exploración con las palabras que la entidad preparó, de acuerdo con la temática por abordar, como es el caso de: ERIC, Wilson Web, Hapion line e ISI Web.

Para aquellos medios que no cuentan con su propio tesauro se recomienda utilizar el Thesauro de la UNESCO (2007, 2008). Sin embargo, muchas veces al hacer uso de los términos facilitados por éste, es posible que no se obtengan los resultados esperados; por lo tanto, es preciso emplear términos en lenguaje natural a partir de palabras clave y descriptores. Los encabezamientos de materia regularmente se utilizan en los catálogos de las unidades de información.

Cualesquiera que sean los términos que se empleen, es necesario hacer la traducción a otros idiomas, que en este caso fueron inglés y portugués, pues se partió del idioma español como lengua materna. También es importante acudir a términos sinónimos, puesto que no se puede hablar de una terminología normalizada para todos los sitios, lo que permite que unos se conserven y otros se modifiquen de acuerdo con el tesauro de las respectivas bases de datos y orientación de la propia investigación. Los términos se combinaron utilizando operadores booleanos or, and (+, \&, Y), not (-), de acuerdo con las características de las bases de datos, catálogos y sitios Web, limitándolos al rango de fechas entre 2000 y 2008. Algunos de los términos que se emplearon fueron: 


\section{Tabla 1}

Términos de búsqueda

\begin{tabular}{|c|c|c|}
\hline ESPAÑOL & INGLÉS & PORTUGUÉS \\
\hline $\begin{array}{l}\text { Alfabetización en } \\
\text { información }\end{array}$ & Literacy informational & Alfabetização informacional \\
\hline Bibliotecas universitarias & University Libraries & Bibliotecas Universitárias \\
\hline $\begin{array}{l}\text { Desarrollo de habilidades } \\
\text { informativas }\end{array}$ & $\begin{array}{l}\text { Development of } \\
\text { information skills }\end{array}$ & $\begin{array}{l}\text { Desenvolvimento de } \\
\text { habilidades de informação }\end{array}$ \\
\hline Didáctica universitaria & Teaching university & Ensino universitário \\
\hline Docentes universitarios & Teachers university & $\begin{array}{l}\text { Os professores } \\
\text { universitários }\end{array}$ \\
\hline $\begin{array}{l}\text { Educación en el uso } \\
\text { de la biblioteca }\end{array}$ & Education in library use & $\begin{array}{l}\text { Educação no uso da } \\
\text { biblioteca }\end{array}$ \\
\hline Educación superior & Higher education & Ensino superior \\
\hline Estrategias didácticas & Didactic strategies & Estratégias didáticas \\
\hline Formación de usuarios & Users Training & Formação de usuários \\
\hline Medios didácticos & $\begin{array}{l}\text { Teaching aids (media } \\
\text { didactic) }\end{array}$ & Media didático \\
\hline $\begin{array}{l}\text { Recursos didácticos } \\
\text { (herramientas didácticas, } \\
\text { instrumentos didácticos, } \\
\text { material didáctico) }\end{array}$ & $\begin{array}{l}\text { Educational resources } \\
\text { (teaching resources, } \\
\text { teaching tools, } \\
\text { educational tools, } \\
\text { training materials) }\end{array}$ & $\begin{array}{l}\text { Recursos educativos } \\
\text { (ferramentas pedagógicas, } \\
\text { ferramentas educativas, } \\
\text { material didático) }\end{array}$ \\
\hline $\begin{array}{l}\text { Sistemas de información } \\
\text { documental }\end{array}$ & $\begin{array}{l}\text { Information systems } \\
\text { documentary }\end{array}$ & $\begin{array}{l}\text { Sistemas de informação } \\
\text { documental }\end{array}$ \\
\hline Uso de la información & Using information & Uso da informação \\
\hline
\end{tabular}

\section{Recursos y Sistemas de Información Documental seleccionados}

Entre éstos se encuentran: bibliotecas universitarias, centros de documentación, repositorios, bases de datos, buscadores y sitios web, los cuales se detallan a continuación: 


\section{Gráfico 5}

Recursos y Sistemas de Información Documental

\section{BIBLIOTECAS UNIVERSITARIAS Y CENTROS DE DOCUMENTACIÓN}

- Biblioteca Central Universidad de Antioquia

- Escuela Interamericana de Bibliotecología

- Centro de Documentación en Educación de la Universidad de Antioquia

\section{BASES DE DATOS}

- Academic One File

- DOAJ (Directorio de Revistas de Acceso Libre)

- Dialnet

- ERIC

- HAPI (The Hispanic American Periodical Index)

- INFOBILA
- Informe Académico

- LISA

- Scielo

- Science online AAAS

- Springer Link

- Web of Science (ISI Web of knowledge)

- Wilson Web

\section{REVISTAS ELECTRÓNICAS}

- ACIMED

- Anales de Documentación

- Biblios

- Biblioteca Universitaria

- Biblioteconomia \& Ciência da Informação

- Binária

- Boletín de la Asociación Andaluza de Bibliotecarios

- Documentación de las Ciencias de la Información

- EncontrosBibli: R. Eletr
- Informação \& Sociedade

- Investigación y Posgrado

- Perspectivas en Ciência da Informação

- Revista Digital de Biblioteconomia e Ciência da Informação

- Revista Documentación

- Revista General de Información y Documentación

- Revista Iberoamericana de Educación

- Revista Interamericana de Bibliotecología

\section{SITIOS WEB Y OTROS RECURSOS}

- clacso

- IFLA (documentos de Congreso)

- Cybertesis

- E-Lis

- Foro Biblioteca y Sociedad

- Google Académico / Schollar Google
- Jornadas Bibliotecarias de Andalucía

- Redalyc: Red de Revistas Científicas de América latina y el Caribe, España y Portugal

- UNESCO 


\section{Proceso de organización de la información acopiada}

Una vez que se recuperó la información (en resumen o texto completo, impreso o digital), se procedió a valorarla; esto es, a analizar y evaluar su relevancia de acuerdo con el problema y la hipótesis de investigación. Posteriormente se organizó y para ello se utilizó una ficha bibliográfica referencial diseñada para el efecto, donde se consignaron los siguientes datos: tipo de documento, medio físico, ubicación, descripción del documento y las respectivas categorías de análisis. A continuación se explica cada uno de estos apartados:

\section{Total de documentos relevantes}

En la tabla siguiente se relaciona el total de los documentos relevantes, sean éstos parciales o definitivos, encontrados en la búsqueda por recurso o sistema de información.

Se anota que solamente 15 documentos (el 1.6\%) responden a los objetivos de esta investigación o son relevantes para la misma.

Tabla 2

Documentos relevantes por recurso o sistema de información

\begin{tabular}{|c|c|c|}
\hline Recurso o sistema & $\begin{array}{c}\text { Resultados } \\
\text { parciales }\end{array}$ & $\begin{array}{l}\text { Resultados } \\
\text { definitivos }\end{array}$ \\
\hline Web of Science (ISI Web of knowledge) & 463 & 2 \\
\hline $\mathrm{E}$-Lis & 153 & 1 \\
\hline Dialnet & 124 & 2 \\
\hline Google & 75 & 1 \\
\hline WilsonWeb & 71 & 2 \\
\hline Archivo personal & 25 & 2 \\
\hline Cybertesis & 14 & 1 \\
\hline Google Académico / Schollar Google & 9 & 2 \\
\hline $\begin{array}{l}\text { Redalyc: Red de Revistas Científicas } \\
\text { de América latina y el Caribe }\end{array}$ & 4 & 2 \\
\hline Total & 938 & 15 \\
\hline
\end{tabular}




\section{Tipo de documento}

En cuanto al tipo de documento se tuvo en cuenta si era una publicación de un artículo de revista, libro, capítulo de un libro; si eran documentos producto de un trabajo de investigación, sistema de investigación, o ponencia presentada en un evento; y además, si correspondía a educación formal en investigación como monografía, informe de investigación de maestría o tesis doctoral.

\section{GRÁFICO 6}

TIPO DE DOCUMENTO

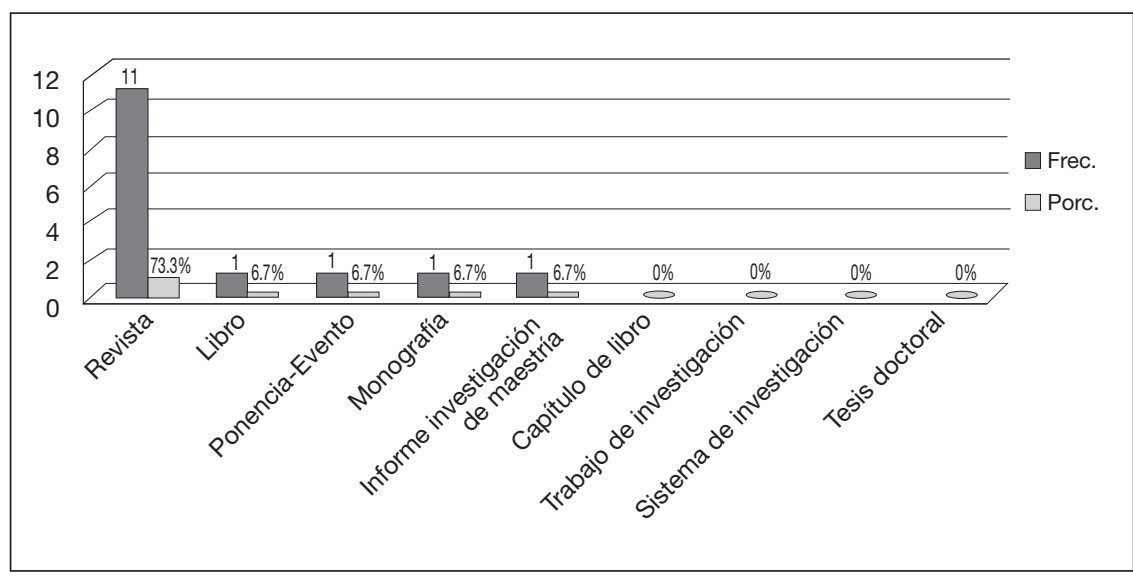

En el Gráfico 6, se observa que la mayoría de los documentos más relevantes aparecen publicados en revistas, con un $73.3 \%$, seguido de un $6.7 \%$ para el libro, la ponencia, la monografía y el informe investigación de maestría.

Sobre los tipos de publicación, que son producto de actividades de educación formal en educación superior, solamente se encontraron relevantes un trabajo en monografía y otro en informe investigación de maestría. No se encontró ninguna tesis doctoral. 


\begin{tabular}{|l|c|c|}
\hline \multirow{2}{*}{$\begin{array}{c}\text { Educación formal } \\
\text { en investigación }\end{array}$} & Monografía & 1 \\
\cline { 2 - 3 } & Informe investigación de maestría & 1 \\
\cline { 2 - 3 } & Tesis doctoral & 0 \\
\hline
\end{tabular}

\section{Medio físico}

Con respecto al soporte o medio físico del documento (Gráfico 7), se encontró que el 87\% (13 documentos) están en formato digital y $13 \%$ en formato impreso.

\section{GRÁFICO 7 \\ MEDIO FÍSICO}

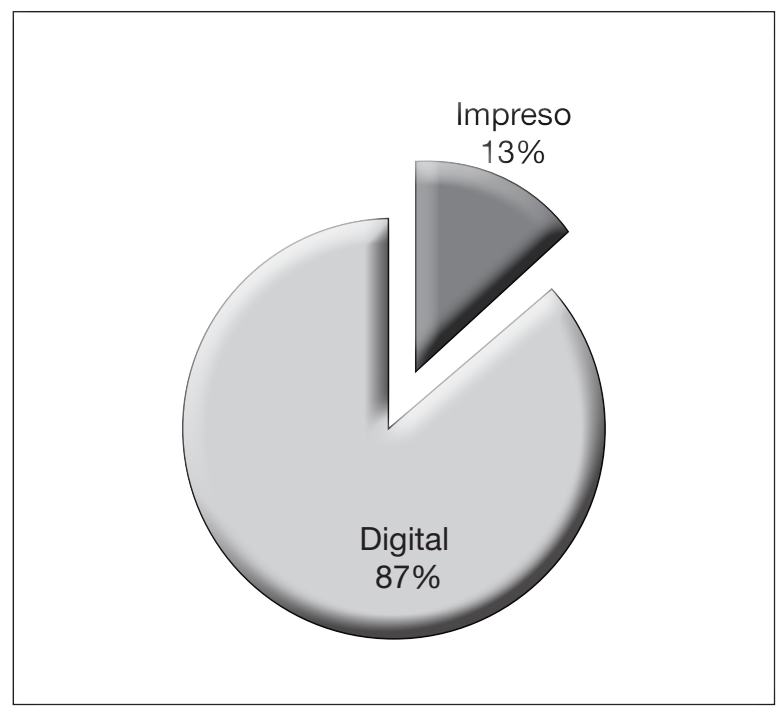

Ubicación del documento en un sistema o recurso de información

La ubicación del documento hace referencia a determinar el lugar donde se encontró, como: bases de datos, bibliotecas, archivo 
personal o un recurso Web; se anota además si el documento se recuperó de bases de datos de texto completo o referencial.

Se observa en el Gráfico 8 que de los 15 documentos relevantes existe una marcada divulgación en bases de datos de texto completo con un $93.3 \%$ (14 documentos), seguido de los recursos web con un $46.7 \%$ ( 7 documentos), en contraste con la ubicación en bibliotecas, donde no se encontró ningún documento.

\section{GRÁFICO 8}

UBICACIÓN DEL DOCUMENTO

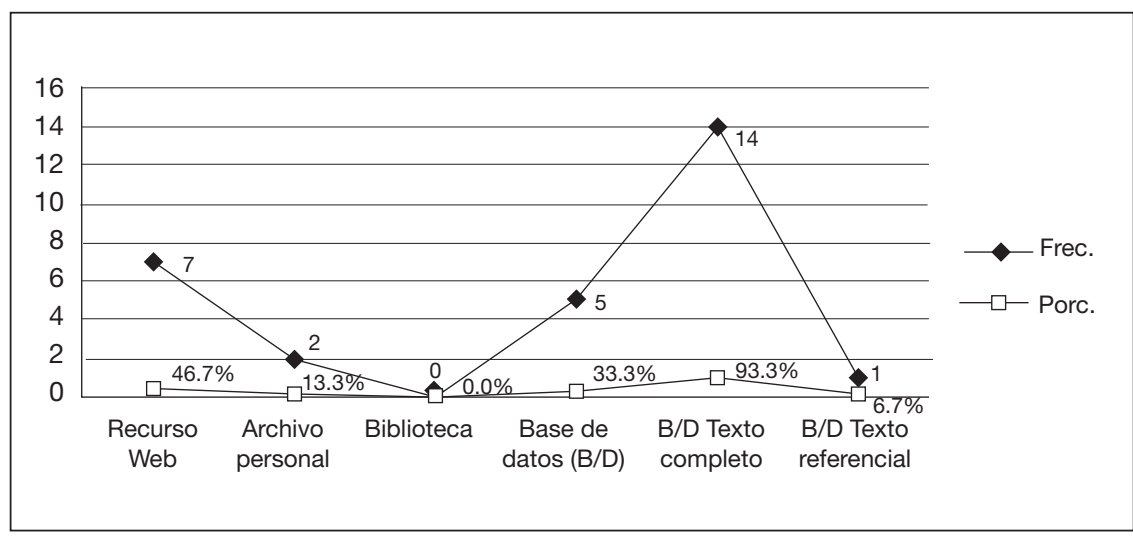

\section{Descripción del documento}

En este apartado se llevó a cabo la descripción bibliográfica del documento a partir del título y subtítulo del mismo, el autor, el título de la publicación, la mención del todo (cuando hace parte de un libro, una revista o un evento), el país, la fecha de publicación, la editorial, la edición, el idioma en que se encontró el texto, el número de páginas y las palabras clave que presentó la publicación.

A continuación se presentan los resultados de la búsqueda por idioma, país y fecha de publicación. 


\section{Idioma del documento}

En cuanto al idioma (ver Tabla 3), el mayor porcentaje, 53.3\%, equivalente a ocho (8) documentos en español, seguido del inglés con un $26.7 \%$ (4 documentos) y del portugués $20.0 \%$ (3 documentos).

Tabla 3

Idioma de los documentos

\begin{tabular}{|l|c|c|}
\hline \multirow{2}{*}{ IDIOMA } & \multicolumn{2}{|c|}{ TOTAL } \\
\cline { 2 - 3 } & Frec. & $\%$ \\
\hline Español & 8 & 53.3 \\
\hline Inglés & 4 & 26.7 \\
\hline Portugués & 3 & 20.0 \\
\hline \multicolumn{1}{|c|}{ Total } & 15 & 100.0 \\
\hline
\end{tabular}

\section{País de publicación}

El mayor porcentaje de documentos, 20\%, se localizó en Brasil, Colombia y España, cada uno con tres (3) documentos, seguido de Inglaterra con un 13.3\%, equivalente a dos (2) documentos, y el resto de países (Canadá, Cuba, Irlanda y Nigeria) con un (1) documento, equivalente al 6.7\%.

\section{GRÁFICO 9}

PAÍS DE PUBLICACIÓN

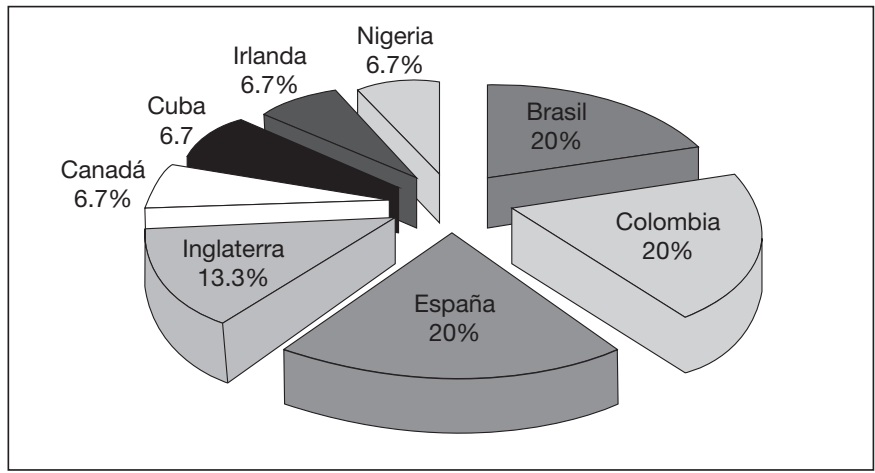




\section{Fecha de publicación}

Como se aprecia en el Gráfico 10, la mayor publicación de documentos relevantes se presentó en el año 2007 con un 47\%, en contraste con los años 2001 y 2002, en los cuales no se encontró ningún documento que fuera notable para el objeto de la investigación.

GRÁFICO 10

FECHAS DE PUBLICACIÓN

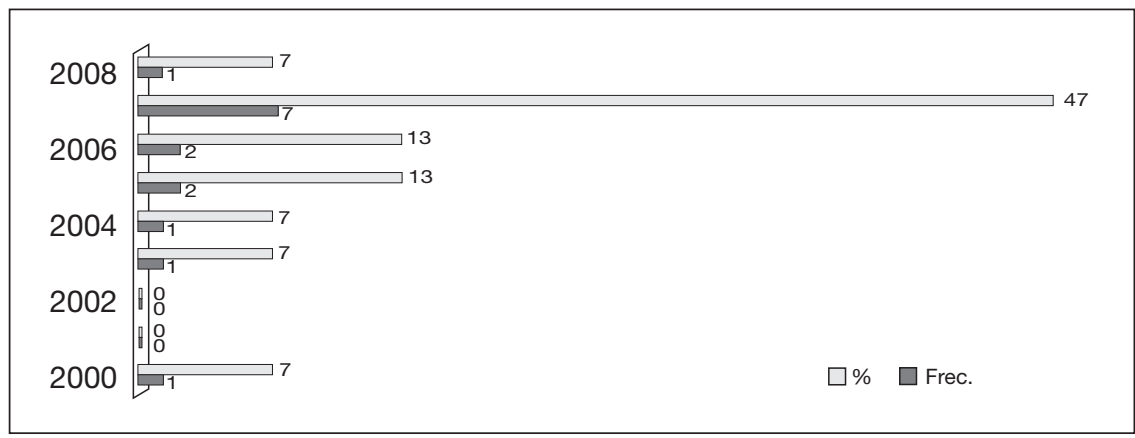

\section{ANÁLISIS Y COMPRENSIÓN DE CATEGORÍAS}

Esta actividad se desarrolló teniendo en cuenta el proceso hermenéutico de la comprensión, el cual parte de la idea de E. González (2006: 49) cuando expresa que "[...] analizar es ir de lo superficial a lo profundo, de la expresión al contenido, de lo que se dice a aquello a lo cual se refiere; es decir, la significación emerge de su propia estructura”. Este análisis requiere de mayor profundidad para que no se quede sólo en la suma de las partes o, en la división de éstas; por lo tanto, se necesita entender esas partes en forma individual, pero también como un todo, de acuerdo con lo estimado desde este enfoque, buscando la comprensión para lograr interpretar la información que se acopió y se organizó en categorías 
Entre tanto, se entiende la interpretación como una proyección de la comprensión, puesto que "[...] la interpretación es en cierto sentido una recreación, pero ésta no se guía por un acto creador precedente, sino por la figura de la obra ya creada, que cada cual debe representar del modo como él encuentra en ella algún sentido" (Gadamer, 2005: 165).

De este modo, se presenta el análisis comparativo con los textos seleccionados, el cual, surge de las categorías seleccionadas y conlleva a la interpretación y síntesis de este estado de la cuestión, como se presenta a continuación.

\section{Problemas de investigación}

De los quince (15) documentos relevantes, sólo seis (6) presentan el problema que dio origen a la investigación que se desarrolló. En esta serie de problemas se visualizaron varias situaciones o concurrencias, de las que se destacan: el hecho de que los profesores encuentren obstáculos para acceder a los canales de información, especialmente porque no saben cómo usarlos (Silva, Souza, Bezerra, Costa y Ramalho, 2007); similar situación establecen Williams y Coles (2007), quienes plantearon el desconocimiento que tenían algunos maestros en el Reino Unido acerca de la importancia de saber acceder y usar la información para llevar a cabo un trabajo de investigación. Igualmente, Vargas y Villegas (2004) cuando expresan que si bien es innegable el papel de la Biblioteca de la Universidad de Antioquia como facilitadora en el desarrollo académico de estudiantes y profesores, ésta no está plenamente articulada con el proceso académico de la Universidad puesto que los docentes no son conscientes de ello y subutilizan algunos servicios y recursos que pueden apoyar significativamente el proceso de enseñanza y aprendizaje de sus alumnos. 
Igualmente, los autores mencionaron que si bien se observa un uso generalizado de Internet por parte de la comunidad universitaria, son pocos los estudios que analizan las habilidades de acceso, organización y uso de la información por parte de ésta (Marzal y Calzada, 2003). Esto coincide con lo planteado por Flores y Torres (2005) en su trabajo de maestría, en el que indican cómo en la Universidad Autónoma de México, sede Xochimilco (UAM-X) no se tienen proyectos para alfabetizar o formar a la comunidad universitaria en el uso y manejo de la información. A estos planteamientos se agrega la mirada de Naranjo, Rendón y Giraldo (2006), quienes observan que, si bien con los programas de formación de usuarios se busca el desarrollo de unas habilidades de información, éstas requieren el autoaprendizaje por parte de los usuarios para poder resolver sus necesidades de formación e información, labor mediada actualmente por las TIC, pero en las bibliotecas universitarias y públicas de América Latina aún no se observa un enfoque pedagógico que permita decir que los usuarios serán autónomos en su proceso de búsqueda, acceso y uso de la información.

\section{Pregunta de investigación}

Ubicándose en contextos específicos, cuatro (4) documentos hacen visibles las preguntas que orientaron la investigación y están relacionados con el comportamiento de los usuarios durante la búsqueda de información, las necesidades de información de los docentes, y los canales, servicios o recursos que utilizan para satisfacer dichas necesidades. A continuación se presentan algunas de esas preguntas:

- ¿Cuáles son los canales de información utilizados por los profesores en su proceso de búsqueda y uso de la información para el desempeño de sus actividades docentes? 
- ¿Cuáles son los obstáculos que se encuentran en ese proceso?

- ¿Qué estrategias-alternativas sugieren los profesores para enfrentar esos obstáculos? (Silva et al., 2007).

- ¿Cuál ha sido el impacto del ABP en el comportamiento de la búsqueda de información y dentro del proceso de la alfabetización en información en los estudiantes? (Dodd, 2007).

- ¿Cuál es el grado de uso de Internet entre los estudiantes?

- ¿Cuáles son los motores de búsqueda que más utilizan los estudiantes o cuál es la combinación más frecuente de éstos para buscar información en Internet, y por qué? (Salako y Tiamiyu, 2007).

Valorando el papel de estas preguntas se destaca una monografía cuyo interrogante es el que más se identifica con la pretensión de este trabajo: ¿cómo articular el proceso docente educativo con la biblioteca para generar nuevas dinámicas en la adquisición del conocimiento en los procesos académicos de la Universidad de Antioquia? (Vargas y Villegas, 2004).

\section{Objetivos}

Entre los objetivos que aparecen en los quince (15) documentos analizados, se resalta el interés de los investigadores por identificar los canales más utilizados por los docentes y los estudiantes para localizar la información; por ejemplo, motores de búsqueda, bases de datos u otros sistemas de información que se encuentren en la biblioteca. También está lo relacionado con las herramientas que brinda Internet para acceder a la información; además de indagar el papel de la biblioteca en las prácticas de enseñanza y de aprendizaje en la universidad. Igualmente se analizó la percepción que tienen los estudiantes frente a sus competencias informativas y lo que esto conlleva para el diseño 
de herramientas de acceso y organización de los recursos Web. Asimismo, se pretendió determinar los enfoques educativos y pedagógicos en que se apoyan los programas de formación de usuarios y proponer, de acuerdo con las características y tendencias de los programas de formación, un modelo pedagógico que contemplara los objetivos, recursos y metodologías.

\section{Hipótesis}

Es la categoría que menos información arrojó. Sólo un documento la presenta y se encuentra dividida así: (a) los motores de búsqueda se necesitan más en la investigación orientada en postgrado que en pregrado y en las actividades de aprendizaje, y por consiguiente, (b) los estudiantes de postgrado (que suelen participar en la investigación orientada a proyectos y cursos de estudio), se encuentran más motivados por utilizar los motores de búsqueda para explorar información sobre diferentes temas, que sus homólogos de pregrado en el mismo establecimiento (Salako y Tiamiyu, 2007).

\section{Tipo de investigación}

Doce (12) de los quince (15) documentos explicitan el método de investigación utilizado. De ellos es posible decir que las investigaciones se realizaron amparadas en diferentes métodos entre los cuales no se observa alguno que predomine. Cuatro (4) utilizaron el método mixto, denominado por otros investigación cuali-cuantitativa; otras cuatro el cualitativo y las restantes cuatro, el cuantitativo. Tres (3) documentos no indicaron el método de investigación que utilizaron. 


\section{Marco conceptual (autores)}

Son varios los conceptos que enmarcan estos resultados de investigación, aunque no todos los documentos que se consultaron los presentan (sólo lo hacen once). Estos conceptos son: aprendizaje basado en problemas, canales de información, tecnologías de la información y la comunicación (TIC), proceso docente educativo, usuario alfabetizado, información, sociedad de la información, teoría general de sistemas, usabilidad, aptitudes para el uso de la información, usuario de la información, formación, formación de usuarios, desarrollo de habilidades informativas y, alfabetización en información, entre otros.

El término alfabetización en información lo abordan varios autores (en seis documentos). Específicamente se refieren al proceso por el que debe pasar una persona para poder identificar y formular su necesidad de información, además de estar en condiciones de buscar, localizar, evaluar y utilizar la información, apoyándose en las TIC.

Se observa cómo las expresiones estrategia didáctica, medios didácticos y espacio didáctico, Naranjo, Rendón y Giraldo (2006), los definen como elementos del sistema didáctico para la formación de usuarios, en otro trabajo sólo se relacionan o mencionan como parte del concepto proceso docente educativo (Vargas y Villegas, 2004); lo que lleva a plantear la necesidad de conceptuar acerca de ellos.

\section{Nuevos conceptos}

Siete (7) de los documentos analizados presentan nuevas miradas para algunos de los conceptos atribuidos a otros autores. Éstos se relacionan con: proceso docente educativo, proceso de enseñanza y alfabetización en información (Vargas y 
Villegas, 2004: 29). A este último, también le hacen su aporte Bernhard (2005), Flores y Torres (2005) y Uribe et al., (2007).

Por su parte, Silva et al., (2007) que se ocupan además del término usuario de la información, exponen brecha digital y asimetría de la información como conceptos definidos por ellos mismos; mientras que Naranjo, Rendón y Giraldo (2006) contemplan los conceptos formación y formación de usuarios.

Se observa, al igual que con la categoría anterior, que tampoco se encuentran aportes para los términos fundamentales por tratar dentro de esta investigación, tales como: transformación del conocimiento, sistema de información documental, información, conocimiento, sistema didáctico y estrategia didáctica.

\section{Resultados de investigación}

Esta categoría se organiza teniendo en cuenta la presentación que de ella hacen los autores de los documentos analizados y los objetivos que se trazaron; los resultados se encuentran en las quince (15) publicaciones y varía la presentación de acuerdo con el tipo de investigación; sin embargo, no se toman en cuenta todos los resultados debido al interés particular de este trabajo investigativo.

En el estudio realizado por Sastre (2007), se encontró que en el 34\% de las bibliotecas universitarias de España, la formación de usuarios aún no se ofrece vía Web y que la formación en el uso de las bases de datos se centra en guías y manuales de consulta.

Para Bernhard (2005) la formación de un usuario lleva una secuencia de aptitudes por desarrollar, entre las que están: identificación de las necesidades de información, creación y organización de la información, estrategias de búsqueda de información, habilidades tecnológicas e informáticas, evaluación y tratamiento 
de la información, utilización y comunicación de la información, aspectos éticos y sociales, actitud activa de cara al aprendizaje durante toda la vida, crítica de los medios de comunicación y, autoevaluación. El investigador resalta, además, que esta formación se debe brindar en colaboración entre docentes y bibliotecarios.

Los resultados de otra investigación española dan cuenta de los contenidos que se programan dentro de los programas formativos de las bibliotecas y arrojan que sólo el 54\% (26 bibliotecas) disponen de una planificación docente de la formación; planificación compuesta por objetivos, contenidos, recomendaciones, prerrequisitos, etc. De allí que les recomiendan a las bibliotecas que no lo hacen, incorporar estos aspectos ya que se incrementaría la calidad de los cursos, así como la visibilidad y comprensión de la oferta formativa. Asimismo, indican que la mayor parte de las bibliotecas utilizan demostraciones prácticas (92\%) y la enseñanza con base en problemas (44\%); solamente tres emplean otras técnicas como el aprendizaje activo, el colaborativo o en grupo. La formación se lleva a cabo con un proyector y prácticas que deben ejecutar los alumnos (42\%), aunque otras bibliotecas optan por una demostración con proyección sin ejercicios (54\%) y clases expositivas con prácticas (38\%) (Somoza y Abadal, 2007).

El trabajo de Marzal y Calzada (2003) muestra que los estudiantes buscan y usan la información para realizar sus trabajos y tareas de curso, y prefieren utilizar Internet, concentrándose en un buscador específico. Estos resultados los corroboró una investigación posterior, Salako y Tiamiyu (2007), donde se expone que el $75.9 \%$ de los estudiantes encuestados usan preferentemente los motores de búsqueda Google y Yahoo.

Continuando con Marzal y Calzada, los estudiantes dedican entre ocho y nueve horas semanales para la búsqueda de información, lo cual, consideran que es demasiado tiempo. Además 
los estudiantes expresan que si bien la búsqueda por medio de los buscadores arroja grandes resultados, no se sienten satisfechos con éstos; esto podría deberse a que son muy limitados en las herramientas que utilizan (sólo un buscador) o que tienen pocas destrezas en el proceso de búsqueda, como lo indicaron años más tarde Salako y Tiamiyu, al afirmar que sólo el 25\% manifiesta que sabe manejar los operadores booleanos. Por otra parte, los estudiantes encuestados muestran cierta inseguridad tanto a la hora de seguir un plan concreto para obtener la información que desean, como al evaluar la información que encuentran o incluso de citarla; lo que podría indicar una necesidad de mejorar su formación en habilidades de acceso, manejo y uso de la información (Marzal y Calzada, 2003).

Respecto a los canales o recursos que más utilizan los docentes para adquirir información se encuentra: la lectura de documentos impresos (95.7\%), la asistencia a eventos técnicocientíficos (84.1\%) y la utilización de las redes de computadores (42.7\%). En tanto que para el $15.9 \%$ de los profesores nunca fue necesario buscar información en bibliotecas localizadas en otras instituciones. El 28\% lo hizo por lo menos de 1 a 2 veces durante el mes. Proporcionalmente, se pudo verificar que tienden a frecuentar mensualmente la biblioteca de otras instituciones, el $6.1 \%$ de 2 a 4 veces, el $4.3 \%$ entre 4 y 8 veces, y el $5.5 \%$ las frecuenta más de 8 veces al mes. (Rosemberg, 2000)

Es interesante destacar que, de acuerdo con la investigación de Dodd (2007), cuando se desarrolla un curso con la estrategia del ABP, los estudiantes hacen mayor uso de la biblioteca. También se expone la necesidad de contar con una metodología para garantizar el desarrollo de las habilidades informativas, incluyendo un proceso de evaluación que indague si se logró el aprendizaje.

Vargas y Villegas (2004) utilizaron una prueba piloto para indagar sobre la participación de los docentes en los cursos de 
formación de usuarios ofrecido por el Sistema de Bibliotecas de la Universidad de Antioquia, y encontraron que sólo una minoría había asistido a ellos y que les era difícil resolver sus necesidades de información.

En cuanto al uso de las fuentes de información, los resultados varían según el público que se pretendió cubrir con la investigación. Por ejemplo, en la Universidad de Antioquia (Vargas y Villegas, 2004) se tiene que los docentes dicen que les recomiendan a los estudiantes el uso de las fuentes documentales para hacer sus trabajos, pero al momento de elaborar ellos el trabajo planteado con el estudio de caso, desconocían estas fuentes y cómo se usaban. En otro estudio, entre las fuentes de información que más utilizan los estudiantes se encuentra Internet, seguida de la familia, los amigos, las bibliotecas y el periódico; la radio y la televisión son poco valorados (Marzal y Calzada, 2003).

En otra investigación que buscaba contribuir a la comprensión del papel de la información en la investigación de los docentes a partir de un proceso de búsqueda, localización y evaluación de la información desarrollado con un programa de alfabetización en información, se reveló que el desconocimiento que tienen sobre cómo se debe llevar a cabo este proceso, les resta confianza para hacerlo y sólo aquellos que se encuentran más motivados por el tema muestran mayor nivel de confianza (60.9\%).

En la investigación Evolución y tendencias de la formación de usuarios en América Latina (Naranjo, Rendón y Giraldo, 2006), se indica que la biblioteca universitaria en América Latina es la unidad de información que más se ha preocupado por la formación de los usuarios en el uso de la información debido, en gran parte, a "[...] la falta de desarrollo de habilidades informativas de los estudiantes antes de su ingreso a la universidad y las necesidades manifestadas por los usuarios en re- 
lación con el proceso de búsqueda, recuperación y uso de la información" (p. 221). A pesar de que las estadísticas mostraron un marcado interés hacia el aprendizaje de las habilidades informativas, se encontraron algunos problemas tales como escasa relación entre contenidos y objetivos de los programas, lo que trae como consecuencia "usuarios con poco desarrollo en sus habilidades para buscar, recuperar, seleccionar, evaluar, utilizar y producir nueva información o conocimiento" (p. 221).

Al estudiar el uso de Internet en la Universidad de Antioquia, más de la mitad de los estudiantes de pregrado dedican entre 1 y 6 horas semanales en promedio al acceso a Internet, actividad centrada en el uso de herramientas básicas como el correo electrónico y la navegación en sitios Web; además, presentan "[...] un total desconocimiento o uso nulo, generalizado de parte de casi todos los estudiantes, de otras herramientas y servicios claves para efectos académicos e investigativos y de aspectos relativos a la calidad de la información" (Uribe et al., 2004: 27).

En cuanto a los profesores, en la misma investigación se dice que en esta población "[...] se presentan segmentos de rechazo o aceptación ante las TIC e Internet, específicamente determinadas por la brecha generacional. En términos generales, la nueva generación docente tiene una actitud positiva frente a estas herramientas y servicios de Internet, pero aún es alto el porcentaje de los que desconocen algunas herramientas y servicios especializados, lo cual, conduce a una relación directa con esta misma situación entre los estudiantes, convirtiéndose así en un ciclo de analfabetismos [digital y en información]" (2004: 28). 


\section{PROCESO HERMENÉUTICO DE LA INTERPRETACIÓN Y CONSIDERACIONES PARCIALES}

Es posible que exista en el mundo algún material bibliográfico que dé cuenta de los resultados de investigación y aborde el tema de los sistemas de información documental y bibliográfico como un medio didáctico con fines formativos en la educación superior, o tal vez, en los que se desarrolle una estrategia didáctica que facilite la preparación de los docentes universitarios en el uso de los mismos, especialmente por el auge de las TIC; pero dentro de las fuentes que se consultaron no se encontró información al respecto. Inclusive, así se desarrolló el proceso de búsqueda, localización y revisión de documentos que se acercaran a estas necesidades con el fin de encontrar posibles respuestas a la pregunta de investigación o una claridad frente a la hipótesis abductiva.

Con la organización categorial se logró hacer el análisis comparativo entre documentos y los resultados indican que el problema planteado no se resuelve todavía, como se expone a continuación:

- El tema de la alfabetización en información es el más recurrente; con él se abordan aspectos de la autonomía del usuario en el manejo de la información desde los variados recursos y sistemas de información que existen; sin embargo, no se hace visible una estrategia o un método para hacerlo y las propuestas formativas están dirigidas a los estudiantes, más que a los docentes.

- No obstante, cuando en un programa académico se desarrolla un curso con la estrategia del ABP (Aprendizaje Basado en Problemas), los estudiantes hacen un mayor uso de la biblioteca, aunque el personal adscrito a la misma no sea consciente de ello ni de la necesidad de contar 
con una estrategia para garantizar el desarrollo de las habilidades informativas que se requieren para responder adecuadamente al ABP.

- A pesar de que en las unidades de información se tienen cursos para hacerlo, no existe la preocupación por saber el resultado del aprendizaje a partir de la formación que se dio para el uso de la información (Dodd, 2007). Desafortunadamente, no se han encontrado documentos que se refieran a otras estrategias didácticas ni se visualiza claramente una propuesta de estrategia relacionada directamente con el uso de los SID.

- Los conceptos que revisaron los investigadores y los que transformaron, aunque es necesario tenerlos en cuenta para el proceso hermenéutico de esta tesis, no incluyen los centrales de la misma y sólo periféricamente se vislumbran en la monografía elaborada por Vargas y Villegas (2004) y en la investigación de Naranjo, Rendón y Giraldo (2006).

- En el trabajo investigativo que se hace con los docentes se observa que éstos son poco participativos y que algunos ni siquiera saben hacer uso de estos medios (Williams y Coles, 2007). Queda así la inquietud de que este problema se debe superar y demostrarles a los docentes la función que cumplen los SID como medios didácticos en los procesos de enseñanza y aprendizaje.

- Existe la preocupación entre los diferentes autores por el poco uso de la información a raíz de factores como: falta de compromiso de parte de los profesores para mejorar su desempeño (Silva et al., 2007), y dificultades para acceder a los canales de información quizás por desconocimiento o subutilización de los mismos (Williams y Coles, 2007); aspecto que también resaltan Naranjo, Rendón y Giraldo (2006).

- En los diferentes documentos se hace referencia al papel que juegan los profesores dentro de los procesos de en- 
señanza y aprendizaje como orientadores y se les indica su grado de responsabilidad en el desarrollo de las habilidades y destrezas de los estudiantes para hacer uso de la información; sin embargo, muy pocos, con excepción de dos (Salako y Tiamiyu, 2007; Vargas y Villegas, 2004), son explícitos al indicar que el profesor también debe capacitarse en el uso de la biblioteca e Internet para enseñar y motivar al estudiante para usarlos.

- En casi todos los documentos se revela la importancia que tiene la información para el aprendizaje y no tanto para la enseñanza. De hecho las investigaciones se relacionan con la función de los recursos y servicios de información para el desempeño de los estudiantes de pregrado y posgrado y sólo en la monografía citada por Vargas y Villegas (2004) se menciona el papel que cumplen los profesores en la motivación de los estudiantes para hacer uso de ellos, con el agravante de que los primeros no saben hacer uso de esos sistemas (Williams y Coles, 2007) o los docentes no tienen confianza para usarlos porque no saben cómo hacerlo, como lo reitera la investigación de Uribe y Otros (2007).

Los SID, con la connotación que se le dio en este escrito, apenas comienzan a ser tratados como medios y espacios didácticos, pues las fuentes de información en las que se habla del uso de la información se centran en gran parte en aquellas que se encuentran mediadas por las TIC con gran énfasis en Internet y los buscadores. De esta manera, con este estado de la cuestión se propuso develar posibles vías de solución a este vacío en el conocimiento. 
Segunda Parte

EL TRABAJO DE CAMPO O CÓMO VEN

LOS ACTORES SU REALIDAD 


\title{
El mundo real con los SID desde el acopio de la información
}

\begin{abstract}
Don los Sistemas de Información Documental -SID- como objeto de estudio, los cuales se sitúan en una institución social como la universidad, y se enmarcan en la didáctica universitaria específicamente en el sistema formativo como campo de acción se planteó la pregunta de investigación, y se formuló la hipótesis abductiva, que lleva a una posible anticipación de respuesta a la misma. Luego se procedió a conocer el estado de la cuestión en el presente a partir de la producción investigativa; de igual manera, se elucidó el pasado con la historia de los conceptos empleados y, con estos elementos aclarados, se llegó al trabajo de campo que se organizó con los elementos metodológicos que enmarcaron el acopio de la información, con el fin de alcanzar los objetivos propuestos.
\end{abstract}

\section{ELEMENTOS METODOLÓGICOS}

El paradigma que orienta la investigación y su enfoque, generalmente tienen relación en la que convergen para lograr los ob- 
jetivos trazados; en esta ocasión se utilizó el paradigma cualitativo $^{1}$ con un enfoque hermenéutico.

Una de las principales razones que permitieron su asiento en este enfoque fueron los sujetos, representados en los profesores universitarios como usuarios de los SID, y los estudiantes como aprendices de éstos, más los bibliotecólogos como formadores de profesores y estudiantes, y la investigadora como sujeto que vivencia el proceso de investigación.

De igual manera se asume el enfoque hermenéutico, pues permite el análisis, la comprensión y la interpretación de los textos, entendiendo por éstos "[...] en sentido amplio, toda acción susceptible de traducción y, en sentido restringido, toda fijación que genera una estructura de sentido" (González, E., 2006: 43); es decir, se interpretó la información registrada, al igual que las acciones de los sujetos partícipes en este trabajo (docentes, estudiantes y bibliotecólogos), para descubrir las estructuras de sentido.

El horizonte de la tradición, basado en la comprensión de los conceptos: dato, información y conocimiento, en tanto partes, se encontró con el presente (el estado de la cuestión), y permitió el diálogo entre el todo; es decir, la didáctica universitaria que modifica las partes y éstas a su vez modifican el todo, en un continuo círculo hermenéutico ${ }^{2}$ que llega así a la fusión de

1 Según Galeano y Vélez (2004: 20) "la investigación social cualitativa apunta a la comprensión de la realidad como resultado de un proceso histórico de construcción a partir de la lógica de los diversos actores sociales, con una mirada "desde adentro" y rescatando la singularidad y las particularidades propias de los procesos sociales".

2 "El [...] describe la comprensión como la interpretación del movimiento de la tradición y del movimiento del intérprete [...] Pero en nuestra relación con la tradición, esta comunidad está sometida a un proceso de continua formación. No es simplemente un presupuesto bajo el que nos encontramos siempre, sino que nosotros mismos la instauramos en cuanto que comprendemos, participamos del acontecer de la tradición y continuamos determinándolo así desde nosotros mismos. El círculo de la comprensión no es en este sentido un círculo "metodológico" sino que describe un momento estructural 
horizontes ${ }^{3}$ la cual se manifiesta en la creación de la cosa; esto es, la fundamentación teórica y metodológica de la estrategia didáctica que posibilita la unidad de sentido investigativo.

Para realizar el trabajo de campo se acudió al estudio de caso ${ }^{4}$ como información adicional para diseñar la estrategia didáctica, pues se partió del trabajo que se ha realizado en los sistemas de bibliotecas de la Universidad de Antioquia, la Universidad Nacional de Colombia sede Medellín y la Universidad CES (localizadas en Medellín, Colombia). Los criterios que se tuvieron en cuenta para seleccionar estas instituciones fueron: la representación del sector público y del sector privado, el reconocimiento de la comunidad académica reflejada en programas acreditados, los grupos de investigación clasificados y la publicación de los profesores, entre otros. Por otra parte, se quizo contar con un sistema de bibliotecas que cumpliera con los estándares internacionales (Association of College and Research Libraries, 2003), entre los que se encuentran: número adecuado de libros por usuario, suscripciones a publicaciones seriadas, suscripciones a bases de datos en línea, sitio Web de la biblioteca, servicios electrónicos, catálogos en línea, personal profesional en el área para atender a los usuarios, políti-

ontológico de la comprensión [...] Sin embargo, el sentido de este círculo que subyace a toda comprensión posee una nueva consecuencia hermenéutica que me gustaría llamar "anticipación a la perfección" [...]" (Gadamer, 2005: 363).

3 El punto de encuentro entre el presente que con sus prejuicios se halla en constante formación y los pone a prueba en un acto de coincidir con el pasado y la comprensión de la tradición; esto indica que el presente está revestido por el pasado. Con la fusión de horizontes se muestra el proceso de la comprensión, como dice Gadamer "comprender es siempre el proceso de fusión de estos presuntos horizontes para sí mismos" (2005: 377).

4 El estudio de caso se entiende como "el estudio de la particularidad y de la complejidad de un caso singular, para llegar a comprender su actividad en circunstancias importantes [donde] el investigador [...] destaca las diferencias sutiles, la secuencia de los acontecimientos en su contexto, la globalidad de las situaciones personales" (Stake, 1998: 11). 
cas escritas y manuales de procedimiento, usuarios organizados por categorías y programas de formación de usuarios ofrecidos por los profesionales del área. Finalmente estaba también la disponibilidad de los coordinadores de programas de formación de usuarios para facilitar la aplicación de la estrategia didáctica, en caso de que ésta se diera.

Entre tanto, las técnicas utilizadas para el acopio de la información del caso como texto, fueron la encuesta de prejuicios realizada a profesores y estudiantes de pregrado, y las conversaciones con bibliotecólogos y usuarios reconocidos (profesores).

\section{ENCUESTA DE PREJUICIOS}

Se dio el acercamiento a un nuevo momento de la experiencia hermenéutica con el que se buscó otra posibilidad para la construcción del conocimiento; es decir, a la creación de la cosa; aproximándose a los casos en tanto textos fijados 5 a partir de la encuesta de prejuicios a profesores y estudiantes universitarios, como una de las técnicas de acopio e interpretación de la información; esto es, se vivió el procedimiento de esa experiencia.

Con la encuesta de prejuicios ${ }^{6}$ se buscó indagar el nivel de apropiación que presentan los docentes y los estudiantes universitarios frente al uso de los SID, a partir de sus prejuicios, sus percepciones y sus sentimientos, y cómo los utilizan en los cursos que ofrecen los profesores (Anexo 2) y que reciben los alumnos (Anexo 3).

Los cuestionarios de la encuesta se diseñaron y organizaron en preguntas que se formularon apoyándose en autores como:

5 Proceso de lectura de lo real... obras que fijan íconos y signos (González, E., 2006).

6 El prejuicio no debe tomarse como una referencia negativa, es una situación que precede a la comprensión. 
Goetz y LeCompte (1988), López (2004), Moscoso (2002) y Moreiro (2006). Igualmente, se trató de conocer sus preconcepciones, y en ocasiones, sus creencias acerca de los SID, y sus ideas de las habilidades de pensamiento ${ }^{7}$ que procuran desarrollar en los estudiantes durante el proceso de enseñanza y cómo los perciben estos últimos. Las preguntas y variantes presentes en el cuestionario relacionadas con la transformación de la información en conocimiento, respondieron a la reflexión basada en autores como Elvia M. González (2005) y Louis Not (1994).

Varias de las apreciaciones de los profesores, y algunas de los estudiantes, desde sus puntos de vista apuntaron hacia una anticipación en la elaboración de la cosa, a partir de las respuestas que dieron en el cuestionario de prejuicios o, como dice E. González (2011b: 11) "[...] es el tipo de pregunta que portan los conceptos ya comprendidos pero que necesitan abrirse a la interpretación, otros asuntos que en la vida diaria expanden las teorías".

En el proceso hermenéutico PRACCIS (en éste tienen presencia los prejuicios, la reflexión, el análisis, la comparación, la comprensión, la interpretación y la síntesis) se establecen varios pasos, unos propios de una técnica como la encuesta y otros retomados del mismo proceso hermenéutico.

En busca de las unidades de sentido que permitieran acercarse a la cosa por crear, se analizaron las respuestas que brindó cada uno de los miembros de la comunidad y se compara-

7 Hacen parte de las habilidades cognoscitivas, estas se refieren a los "tipos de operación que actúan sobre la información que se tiene sobre experiencias anteriores", en tanto las habilidades de pensamiento son "un número de habilidades complejas que se aplican aislada o conjuntamente..." (Ruíz, 2000: 19) 
ron $^{8}$ entre ellas (respuestas entre profesores, estudiantes, y profesores y estudiantes); para lograrlo se organizaron las preguntas hasta convertirlas en unidades de significación que permitieron la claridad frente a las unidades de sentido.

Para ello, se diseñó una tabla en la que se relacionó cada una de las preguntas del cuestionario, que fue resuelto por ambos públicos para la encuesta de prejuicios, con el concepto que se buscó y la proyección de sentido surgida dentro de la investigación? (véase Tabla 4). En ocasiones, tanto el concepto que se buscó como la proyección de sentido, incluyeron varios conceptos y proyecciones, no se limitó a uno solo.

Como una síntesis de este proceso con los profesores se presenta la Tabla 5 (véase Tabla 5):

8 En la comparación se busca tanto lo idéntico como lo diverso; en aquello se encuentra lo común, las concurrencias; en esto, las ocurrencias, esto es, las diferencias (González, E., 2011c).

9 La interpretación de un texto permite actualizar la proyección de sentido; esto indica que al disponer de una posibilidad de anticipación, perteneciente a un preconcepto como parte de un todo, es factible que se dé la comprensión. 


\begin{tabular}{|c|c|c|c|c|c|}
\hline 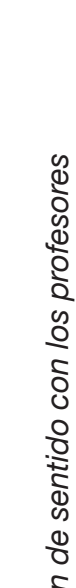 & 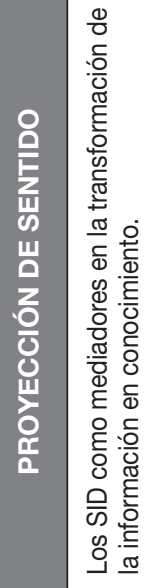 & 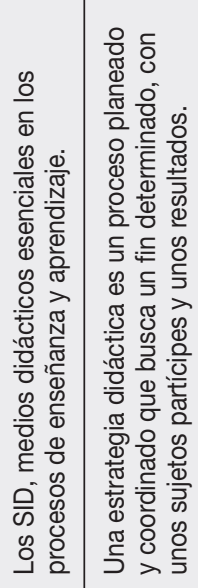 & 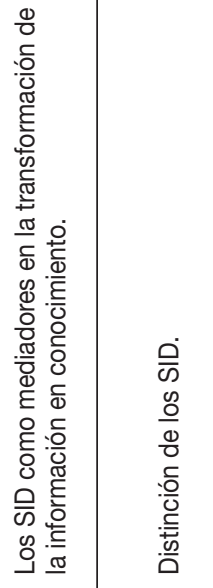 & 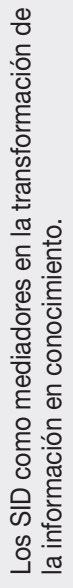 & 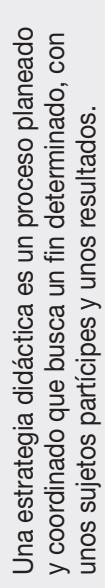 \\
\hline 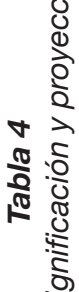 & 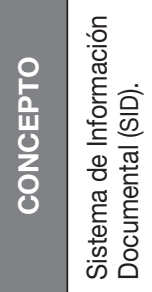 & 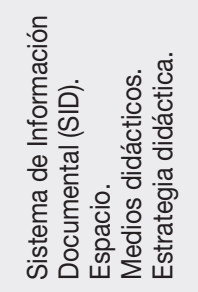 & 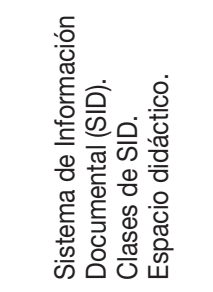 & & 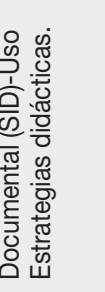 \\
\hline 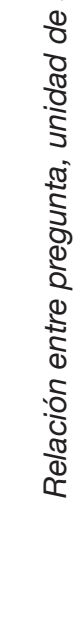 & 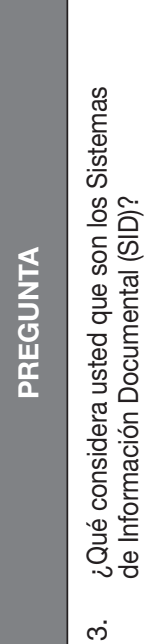 & 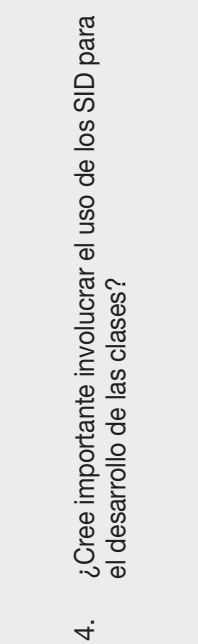 & 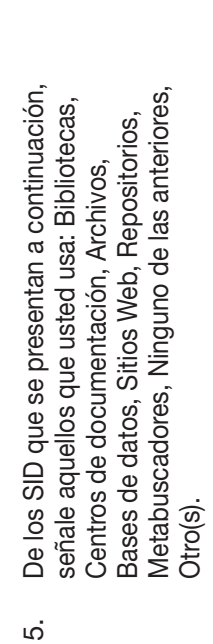 & 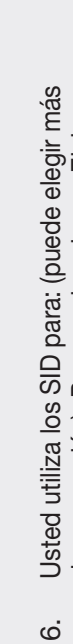 & 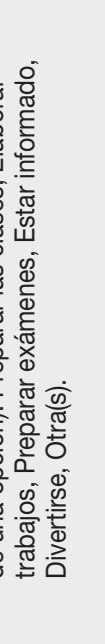 \\
\hline
\end{tabular}




\begin{tabular}{|c|c|c|c|c|c|c|c|}
\hline 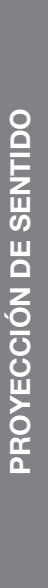 & 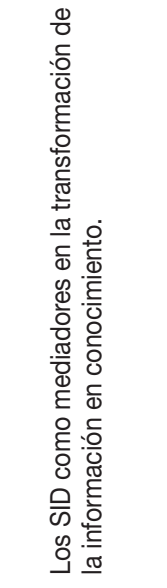 & 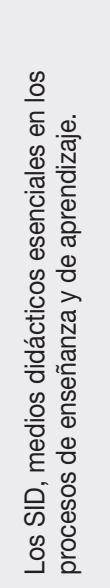 & 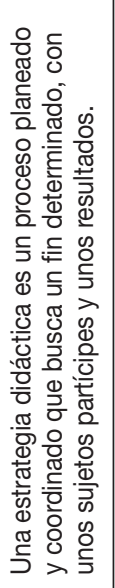 & 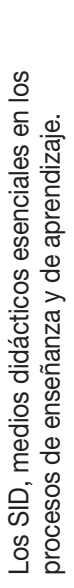 & 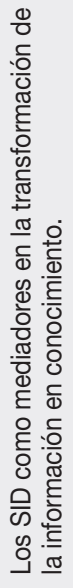 & 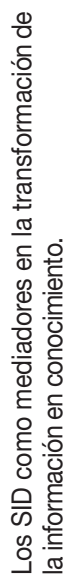 & 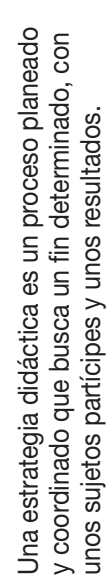 \\
\hline $\begin{array}{l}\frac{0}{b} \\
\frac{1}{0} \\
\frac{0}{z} \\
\text { 은 }\end{array}$ & \multicolumn{2}{|c|}{ 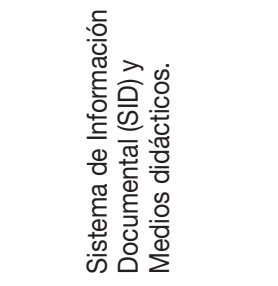 } & \multicolumn{2}{|c|}{ 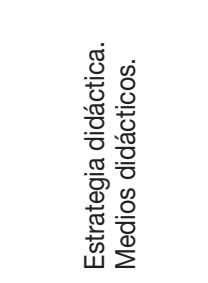 } & 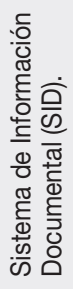 & \multicolumn{2}{|c|}{ 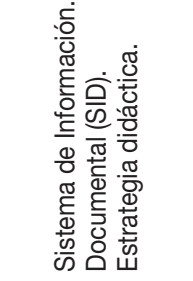 } \\
\hline $\begin{array}{l}\frac{\mathbb{s}}{2} \\
\frac{\mathrm{d}}{\mathrm{d}} \\
\frac{\mathrm{c}}{\alpha}\end{array}$ & 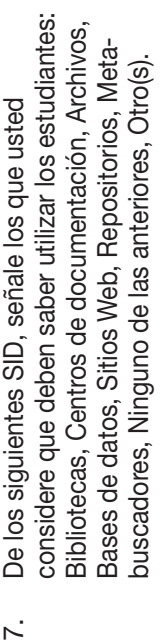 & 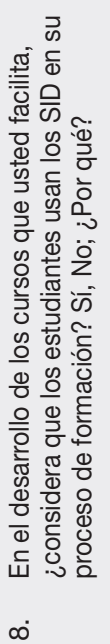 & 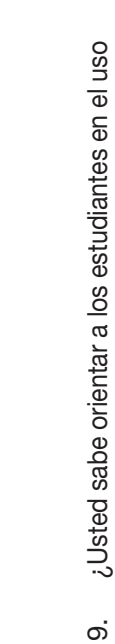 & & 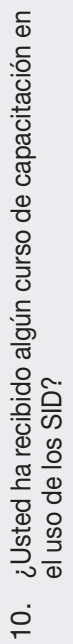 & 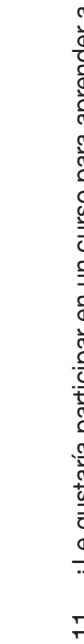 & 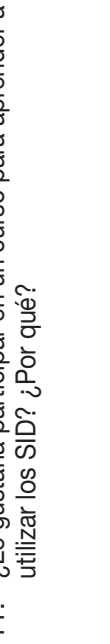 \\
\hline
\end{tabular}




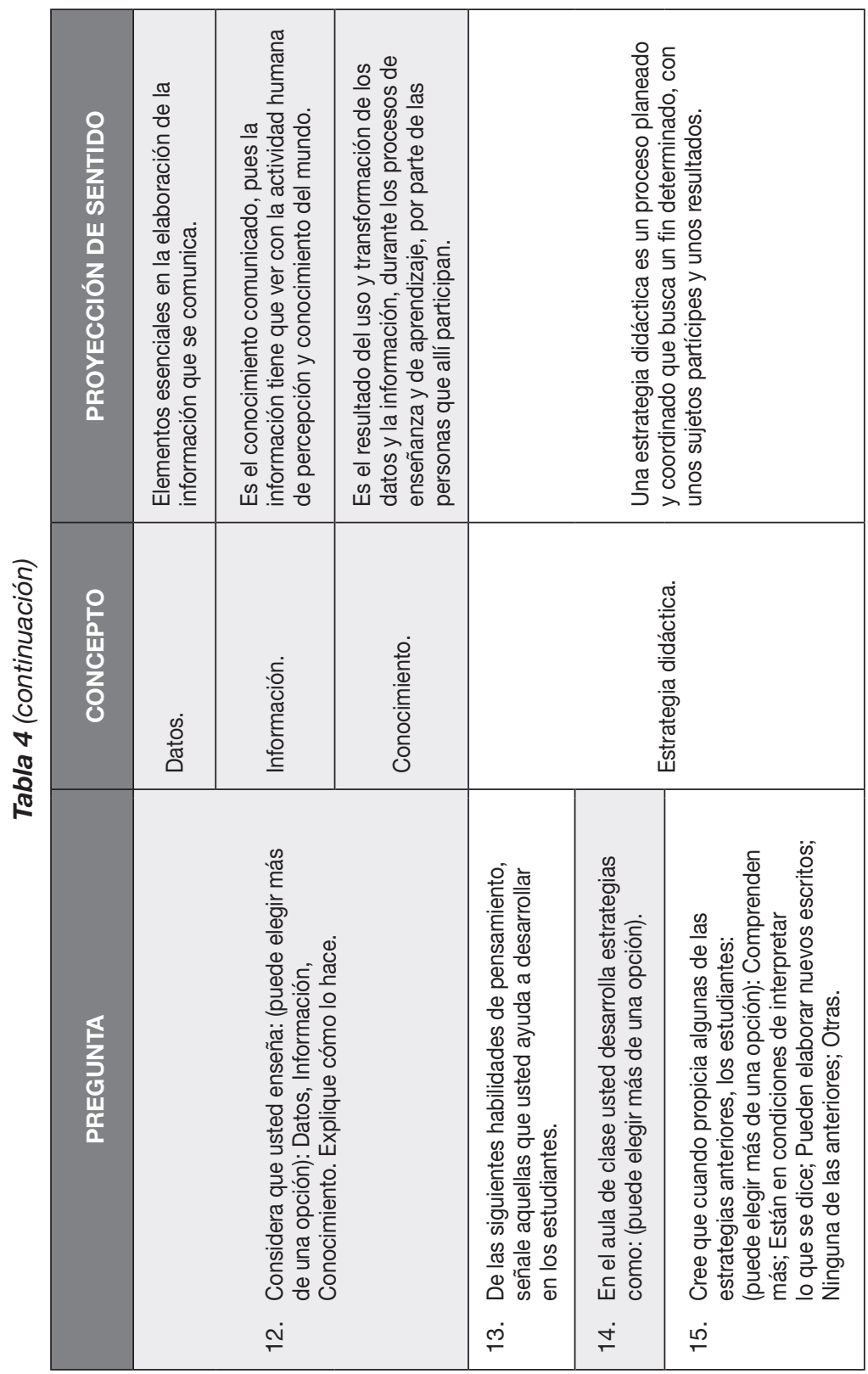




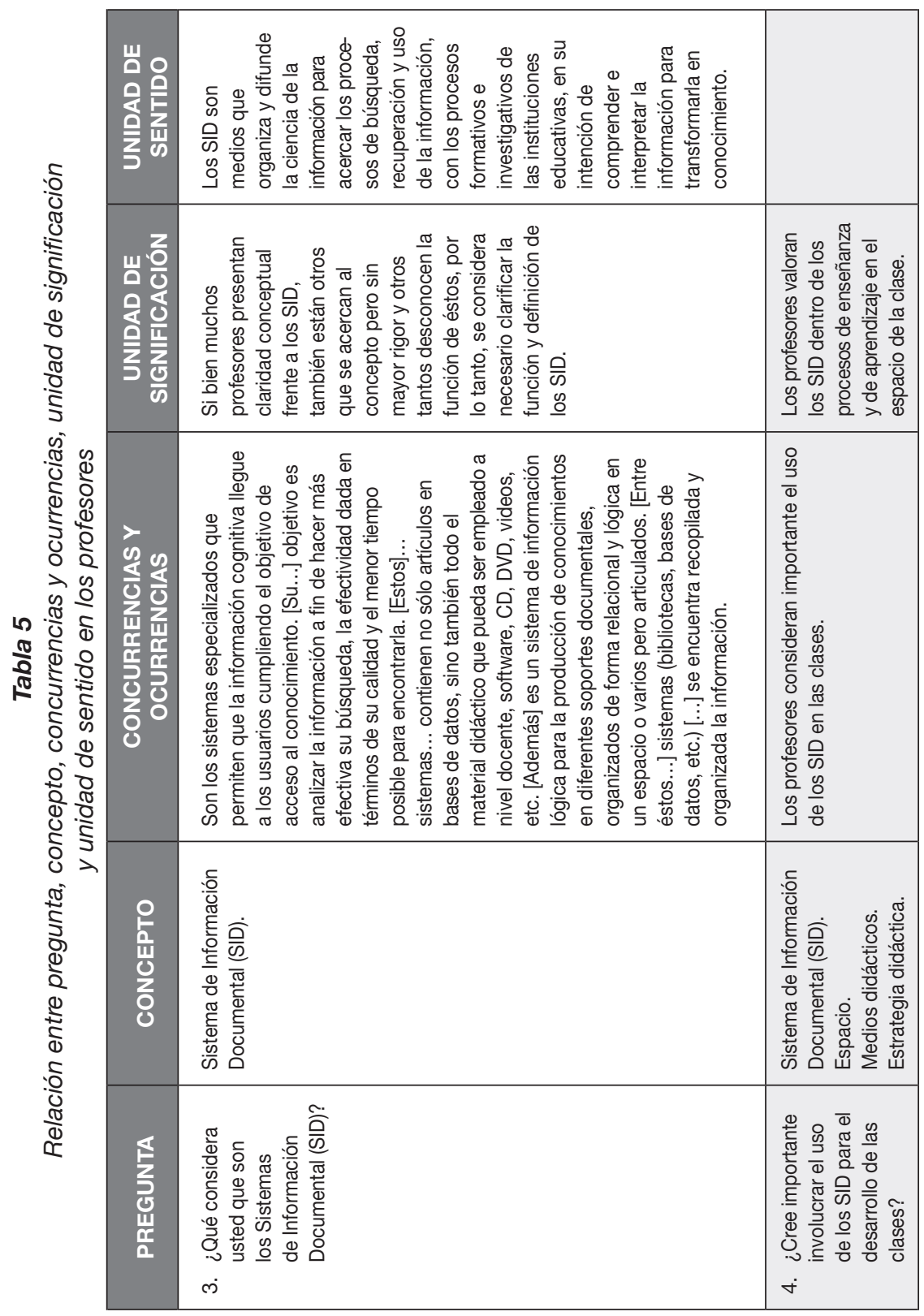




\begin{tabular}{|c|c|c|}
\hline 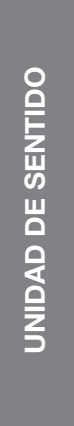 & 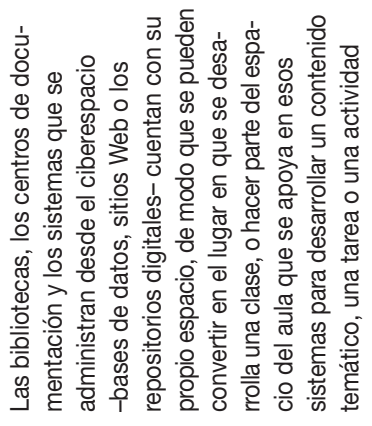 & 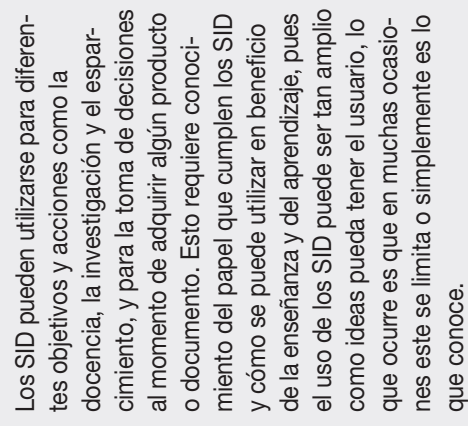 \\
\hline 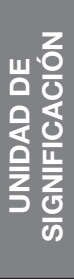 & 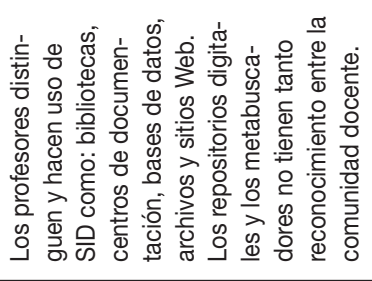 & 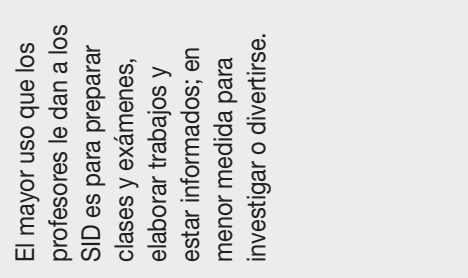 \\
\hline 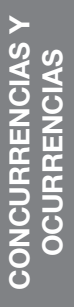 & 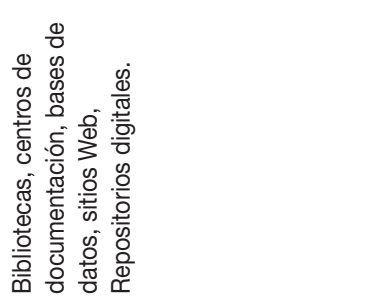 & 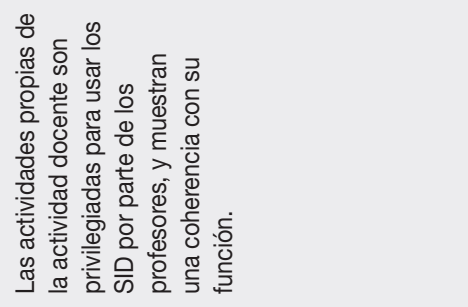 \\
\hline $\begin{array}{l}\text { 은 } \\
\text { 耑 } \\
\text { Z } \\
\text { ㅇ }\end{array}$ & 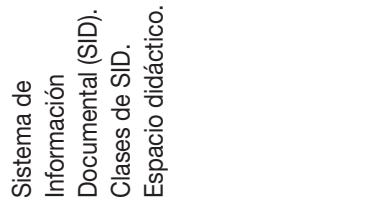 & 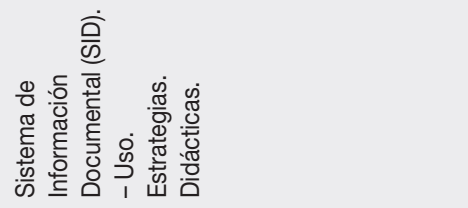 \\
\hline 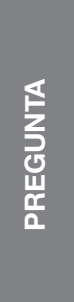 & 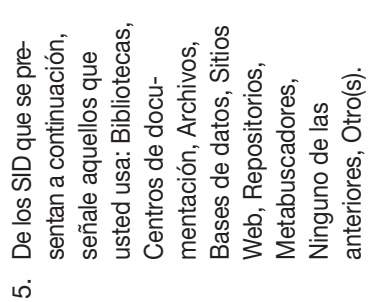 & 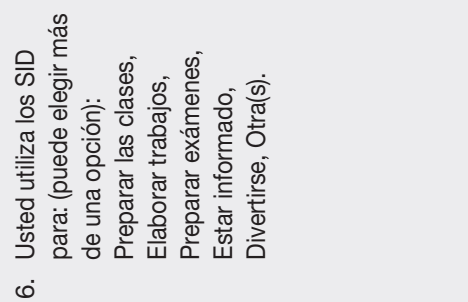 \\
\hline
\end{tabular}




\begin{tabular}{|c|c|c|}
\hline 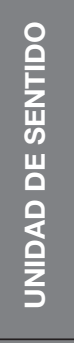 & 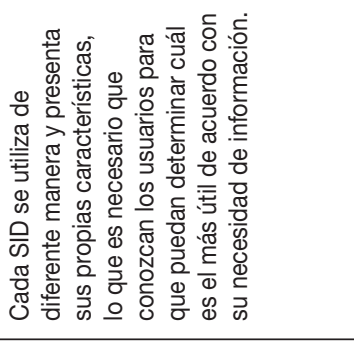 & 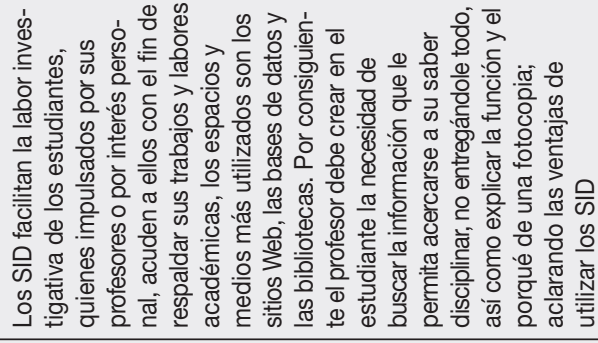 \\
\hline 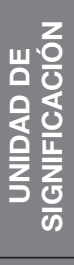 & 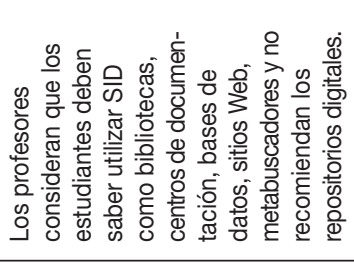 & 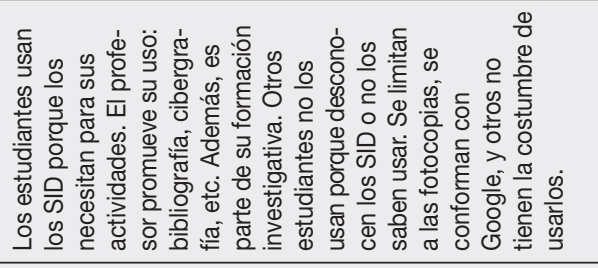 \\
\hline 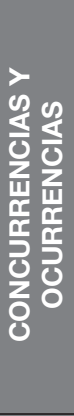 & 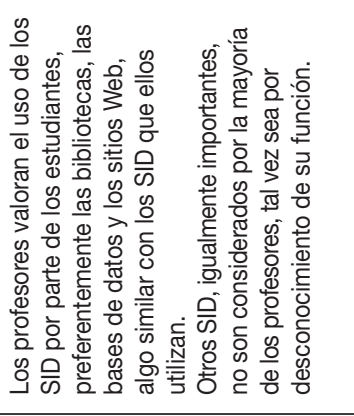 & 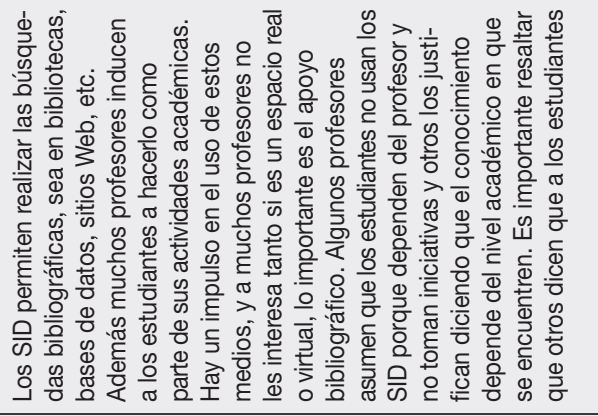 \\
\hline 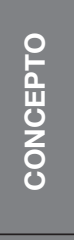 & 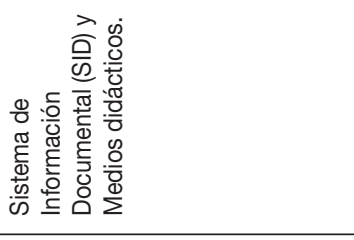 & 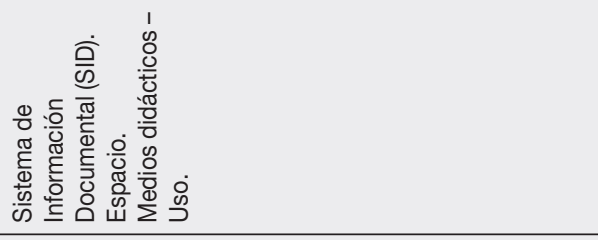 \\
\hline $\begin{array}{l}\frac{5}{z} \\
\frac{\mathrm{d}}{\mathrm{II}} \\
\frac{\mathrm{c}}{\mathrm{a}}\end{array}$ & 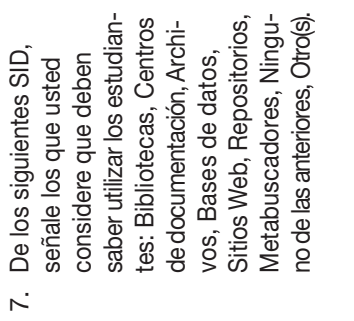 & 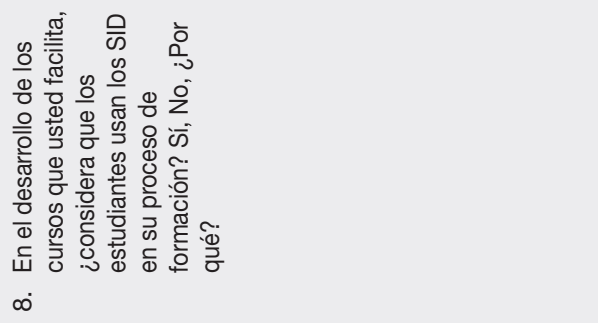 \\
\hline
\end{tabular}




\begin{tabular}{|c|c|c|c|}
\hline$\frac{8}{2}$ & 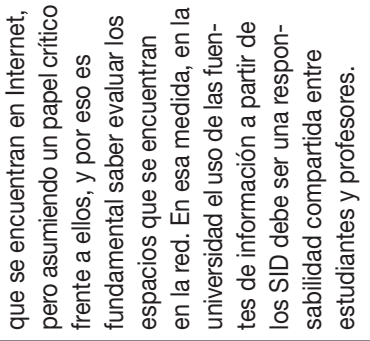 & 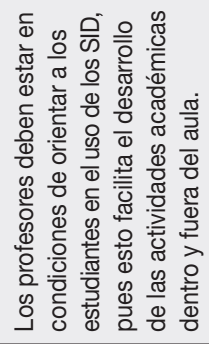 & \\
\hline 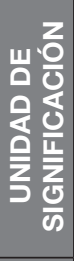 & 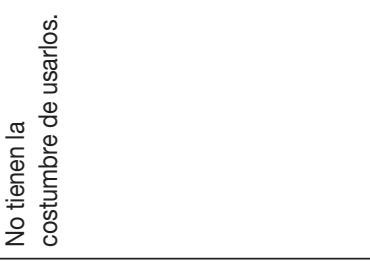 & 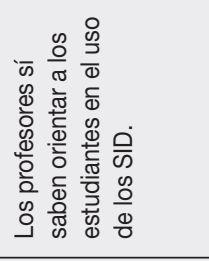 & 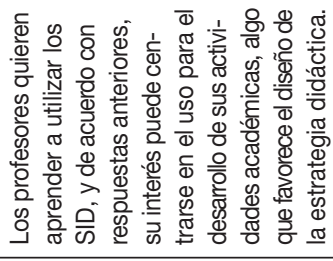 \\
\hline 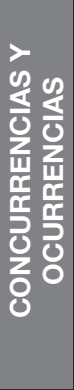 & 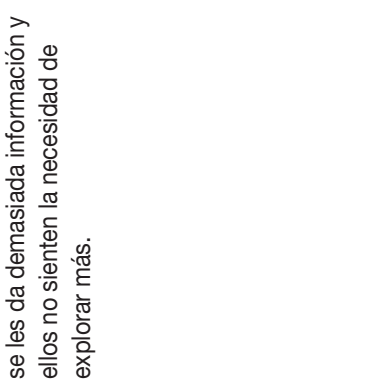 & 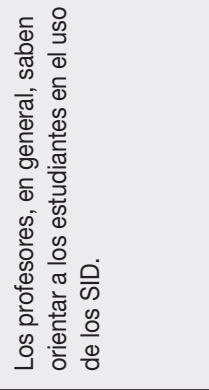 & 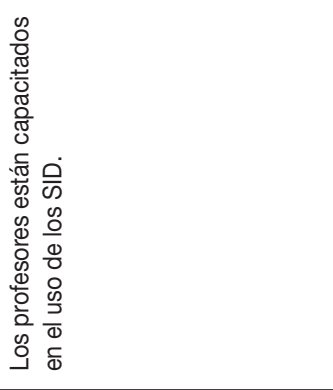 \\
\hline $\begin{array}{l}\text { 음 } \\
\text { 때 } \\
\text { 을 } \\
\text { ㅇ }\end{array}$ & & 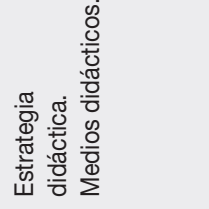 & 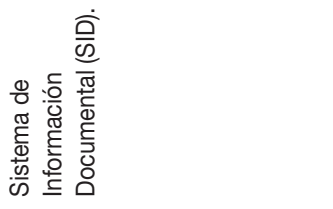 \\
\hline $\begin{array}{l}\frac{\mathrm{K}}{z} \\
\frac{\mathrm{E}}{\mathrm{d}} \\
\frac{\mathrm{II}}{\alpha}\end{array}$ & & 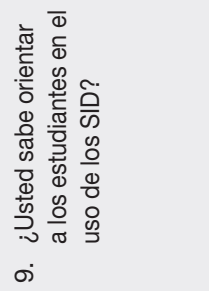 & 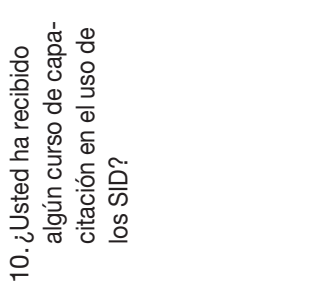 \\
\hline
\end{tabular}




\begin{tabular}{|c|c|c|c|c|c|}
\hline 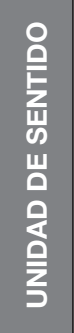 & 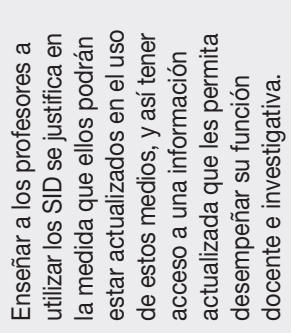 & \multicolumn{3}{|c|}{ 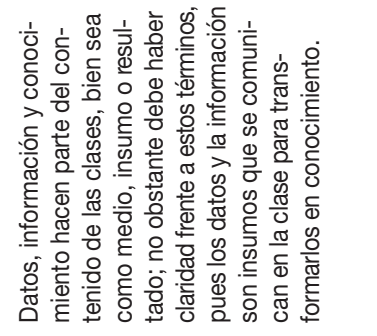 } & \\
\hline 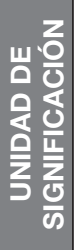 & 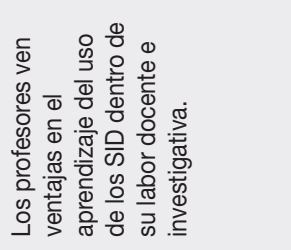 & \multicolumn{3}{|c|}{ 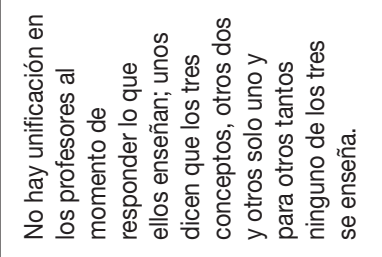 } & 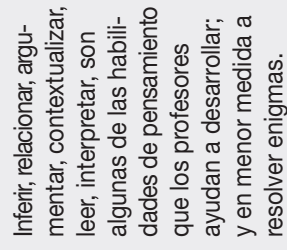 \\
\hline 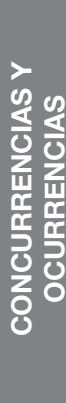 & 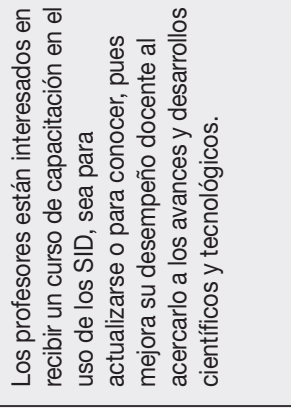 & 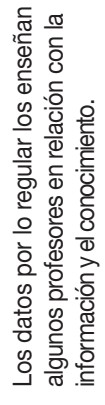 & 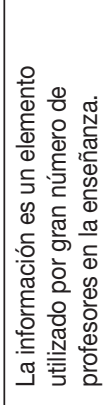 & 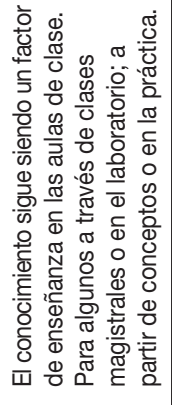 & 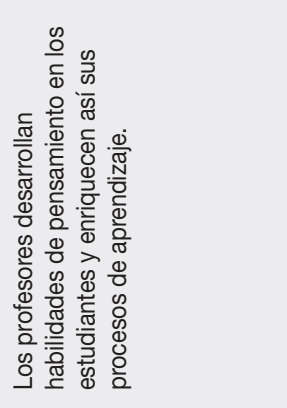 \\
\hline 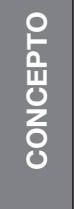 & 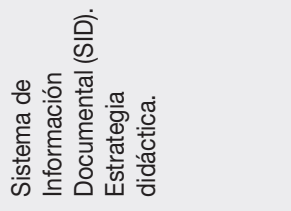 & $\begin{array}{l}\dot{0} \\
\stackrel{ \pm}{\tilde{E}} \\
0\end{array}$ & 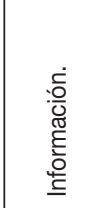 & 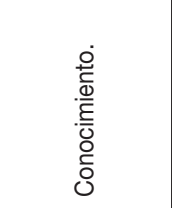 & 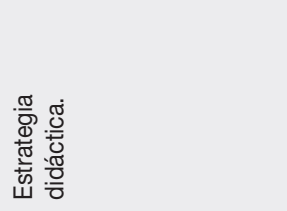 \\
\hline $\begin{array}{l}\frac{\mathbb{E}}{z} \\
\frac{\mathrm{d}}{\mathrm{d}} \\
\frac{\mathrm{c}}{\alpha}\end{array}$ & 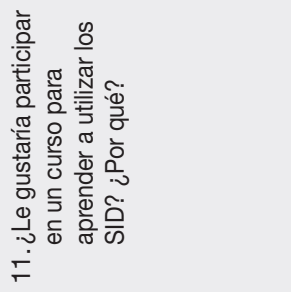 & & 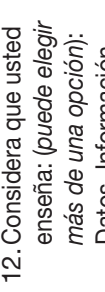 & 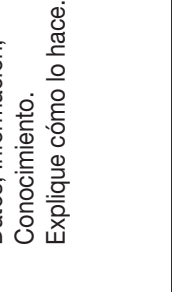 & 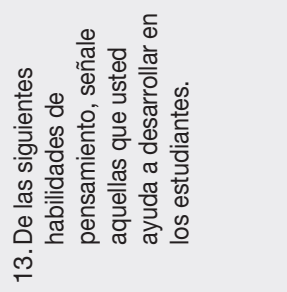 \\
\hline
\end{tabular}




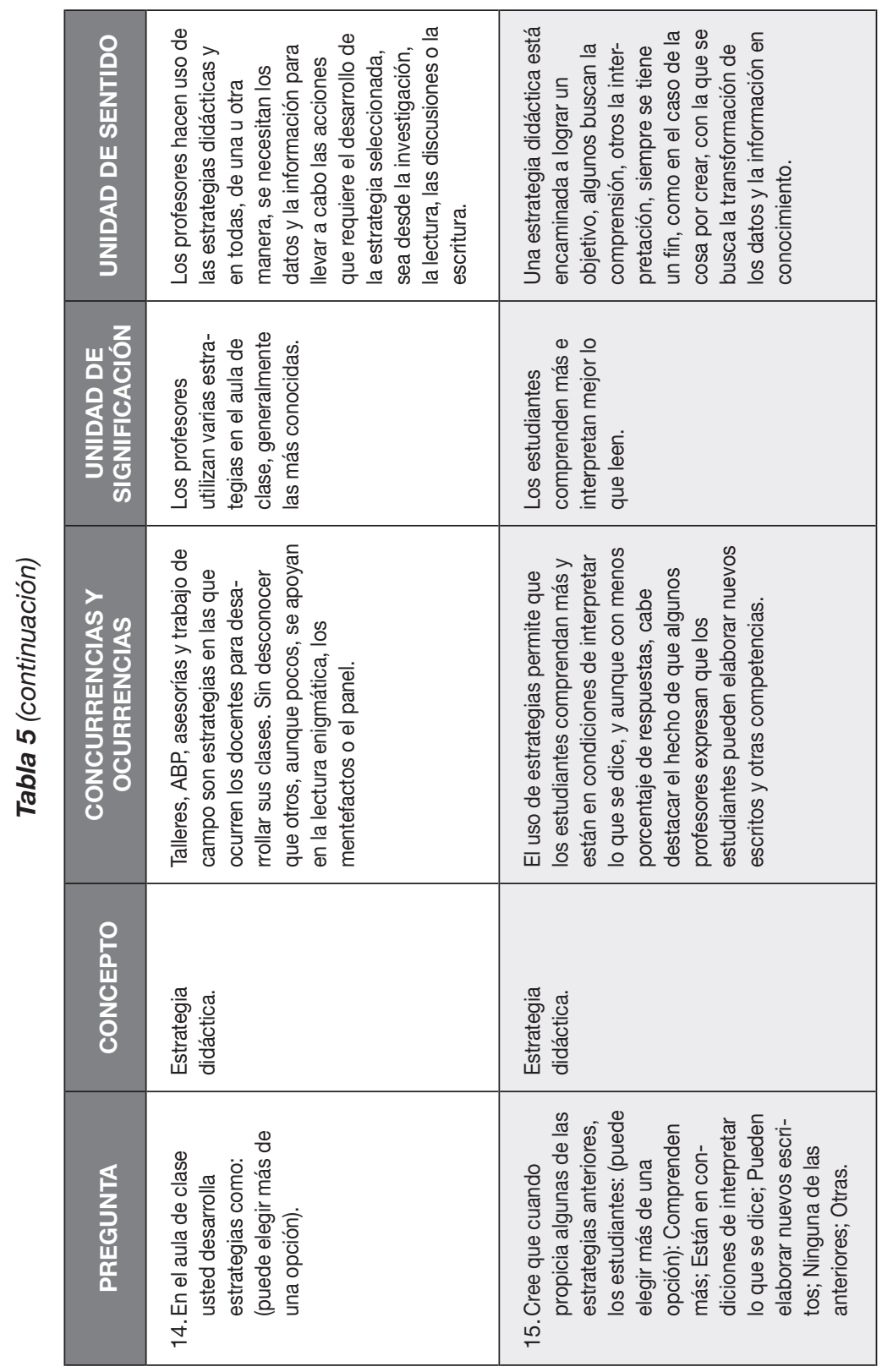


Al igual que con los profesores, se diseñó una Tabla (6) en la que se relacionó cada pregunta del cuestionario con el o los conceptos con los que se vislumbró la proyección de sentido.

Teniendo en cuenta que algunas preguntas de ambos cuestionarios (profesores y estudiantes) fueron similares, a medida que se avanzó en el análisis con estos últimos, se hizo -cuando fue posible- la comparación de las respuestas para afianzar aún más la unidad de sentido perteneciente a la cosa por crear.

Similar al cuestionario de prejuicios de los profesores, el de los estudiantes también se inicia con las preguntas de carácter general: nombre de la Universidad a la que pertenece, y, Facultad, Escuela o Instituto como dependencia de la universidad.

En la tabla siguiente, se sintetizó el proceso con los estudiantes:

Tabla 6

Relación entre pregunta, concepto y proyección de sentido con los estudiantes

\begin{tabular}{|c|c|c|}
\hline PREGUNTA & $\begin{array}{c}\text { CONCEPTO } \\
\text { QUE SE BUSCA }\end{array}$ & PROYECCIÓN DE SENTIDO \\
\hline $\begin{array}{l}\text { 3. ¿Qué considera usted que son los } \\
\text { Sistemas de Información } \\
\text { Documental (SID)? }\end{array}$ & $\begin{array}{l}\text { Sistema de } \\
\text { Información } \\
\text { Documental (SID). }\end{array}$ & $\begin{array}{l}\text { Los SID como mediadores en } \\
\text { la transformación de la } \\
\text { información en conocimiento. }\end{array}$ \\
\hline \multirow{2}{*}{$\begin{array}{l}\text { ¿Cree usted que los profesores } \\
\text { usan los SID en el desarrollo de } \\
\text { las clases?; Sí, ¿Cuáles utilizan?; } \\
\text { No, ¿Por qué cree que no los } \\
\text { utilizan? }\end{array}$} & \multirow{2}{*}{$\begin{array}{l}\text { Sistema de } \\
\text { Información } \\
\text { Documental (SID). } \\
\text { Espacio. } \\
\text { Medios didácticos. } \\
\text { Estrategia } \\
\text { didáctica. }\end{array}$} & $\begin{array}{l}\text { Los SID, medios didácticos } \\
\text { esenciales en los procesos de } \\
\text { enseñanza y de aprendizaje. }\end{array}$ \\
\hline & & $\begin{array}{l}\text { Una estrategia didáctica es un } \\
\text { proceso planeado y coordinado } \\
\text { que busca un fin determinado, } \\
\text { con unos sujetos partícipes y } \\
\text { unos resultados. }\end{array}$ \\
\hline \multirow{2}{*}{$\begin{array}{l}\text { De los SID que se presentan a } \\
\text { continuación, señale aquellos que } \\
\text { usted usa: Bibliotecas, Centros de } \\
\text { documentación, Archivos, Bases } \\
\text { de datos, Sitios Web, Repositorios, } \\
\text { Metabuscadores, Ninguno de las } \\
\text { anteriores, Otro(s). }\end{array}$} & \multirow{2}{*}{$\begin{array}{l}\text { Sistema de } \\
\text { Información } \\
\text { Documental (SID). } \\
\text { Clases de SID. } \\
\text { Espacio didáctico. }\end{array}$} & $\begin{array}{l}\text { Los SID como mediadores en } \\
\text { la transformación de la } \\
\text { información en conocimiento. }\end{array}$ \\
\hline & & Distinción de los SID. \\
\hline
\end{tabular}


Tabla 6 (continuación)

\begin{tabular}{|c|c|c|}
\hline PREGUNTA & $\begin{array}{c}\text { CONCEPTO } \\
\text { QUE SE BUSCA }\end{array}$ & PROYECCIÓN DE SENTIDO \\
\hline \multirow{2}{*}{$\begin{array}{l}\text { ¿Los profesores lo motivan para } \\
\text { que usted utilice los SID? }\end{array}$} & \multirow{2}{*}{$\begin{array}{l}\text { Sistema de } \\
\text { Información } \\
\text { Documental (SID). } \\
\text { Espacio. } \\
\text { Medios didácticos } \\
\text {-Uso. }\end{array}$} & $\begin{array}{l}\text { Los SID como mediadores en } \\
\text { la transformación de la } \\
\text { información en conocimiento. }\end{array}$ \\
\hline & & $\begin{array}{l}\text { Los SID, medios didácticos } \\
\text { esenciales en los procesos de } \\
\text { enseñanza y de aprendizaje. }\end{array}$ \\
\hline \multirow{2}{*}{$\begin{array}{l}\text { Usted utiliza los SID para: (puede } \\
\text { elegir más de una opción): } \\
\text { Estudiar, Elaborar trabajos, } \\
\text { Preparar exámenes, Estar } \\
\text { informado, Divertirse, Otra(s). }\end{array}$} & \multirow{2}{*}{$\begin{array}{l}\text { Sistema de } \\
\text { Información } \\
\text { Documental (SID) } \\
\text { - Uso } \\
\text { Estrategias } \\
\text { didácticas. }\end{array}$} & $\begin{array}{l}\text { Los SID como mediadores en } \\
\text { la transformación de la } \\
\text { información en conocimiento. }\end{array}$ \\
\hline & & $\begin{array}{l}\text { Una estrategia didáctica es un } \\
\text { proceso planeado y coordinado } \\
\text { que busca un fin determinado, } \\
\text { con unos sujetos partícipes y } \\
\text { unos resultados. }\end{array}$ \\
\hline \multirow{2}{*}{$\begin{array}{l}\text { ¿Cree que los profesores deben } \\
\text { saber utilizar los SID? Sí, No, } \\
\text { ¿Por qué? }\end{array}$} & \multirow{2}{*}{$\begin{array}{l}\text { Estrategia } \\
\text { didáctica. } \\
\text { Medios didácticos. }\end{array}$} & $\begin{array}{l}\text { Una estrategia didáctica es un } \\
\text { proceso planeado y coordinado } \\
\text { que busca un fin determinado, } \\
\text { con unos sujetos partícipes y } \\
\text { unos resultados. }\end{array}$ \\
\hline & & $\begin{array}{l}\text { Los SID, medios didácticos } \\
\text { esenciales en los procesos de } \\
\text { enseñanza y de aprendizaje. }\end{array}$ \\
\hline \multirow{3}{*}{$\begin{array}{l}\text { Usted cree que los profesores le } \\
\text { enseñan: (puede elegir más de } \\
\text { una opción): Datos, Información, } \\
\text { Conocimiento. Explique cómo lo } \\
\text { hacen. }\end{array}$} & Datos. & $\begin{array}{l}\text { Elementos esenciales en la } \\
\text { elaboración de la información } \\
\text { que se comunica. }\end{array}$ \\
\hline & Información. & $\begin{array}{l}\text { Es el conocimiento comuni- } \\
\text { cado, pues la información } \\
\text { tiene que ver con la actividad } \\
\text { humana de percepción y } \\
\text { conocimiento del mundo. }\end{array}$ \\
\hline & Conocimiento. & $\begin{array}{l}\text { Es el resultado del uso y } \\
\text { transformación de los datos y } \\
\text { la información durante los } \\
\text { procesos de enseñanza y de } \\
\text { aprendizaje por parte de las } \\
\text { personas que allí participan. }\end{array}$ \\
\hline
\end{tabular}




\section{Tabla 6 (continuación)}

\begin{tabular}{|c|c|c|}
\hline PREGUNTA & $\begin{array}{l}\text { CONCEPTO } \\
\text { QUE SE BUSCA }\end{array}$ & PROYECCIÓN DE SENTIDO \\
\hline $\begin{array}{l}\text { 10. De las siguientes habilidades de } \\
\text { pensamiento, señale las que } \\
\text { considere que los profesores le } \\
\text { ayudan a desarrollar en los } \\
\text { cursos. }\end{array}$ & \multirow{3}{*}{$\begin{array}{l}\text { Estrategia } \\
\text { didáctica. }\end{array}$} & \multirow{3}{*}{$\begin{array}{l}\text { Una estrategia didáctica } \\
\text { es un proceso planeado y } \\
\text { coordinado que busca un } \\
\text { fin determinado, con unos } \\
\text { sujetos partícipes y unos } \\
\text { resultados. }\end{array}$} \\
\hline $\begin{array}{l}\text { 11. Usted considera que los } \\
\text { profesores desarrollan en el aula } \\
\text { de clase estrategias como: } \\
\text { (puede elegir más de una opción). }\end{array}$ & & \\
\hline $\begin{array}{l}\text { 12. Cree que cuando los profesores } \\
\text { propician algunas de las } \\
\text { estrategias anteriores, usted: } \\
\text { (puede elegir más de una opción): } \\
\text { Comprende más, Está en } \\
\text { condiciones de interpretar lo que } \\
\text { se dice, Puede elaborar nuevos } \\
\text { escritos, Ninguna de las } \\
\text { anteriores, Otras. }\end{array}$ & & \\
\hline
\end{tabular}

\section{En la tabla siguiente, se sintetizó el proceso con los estu- diantes:}




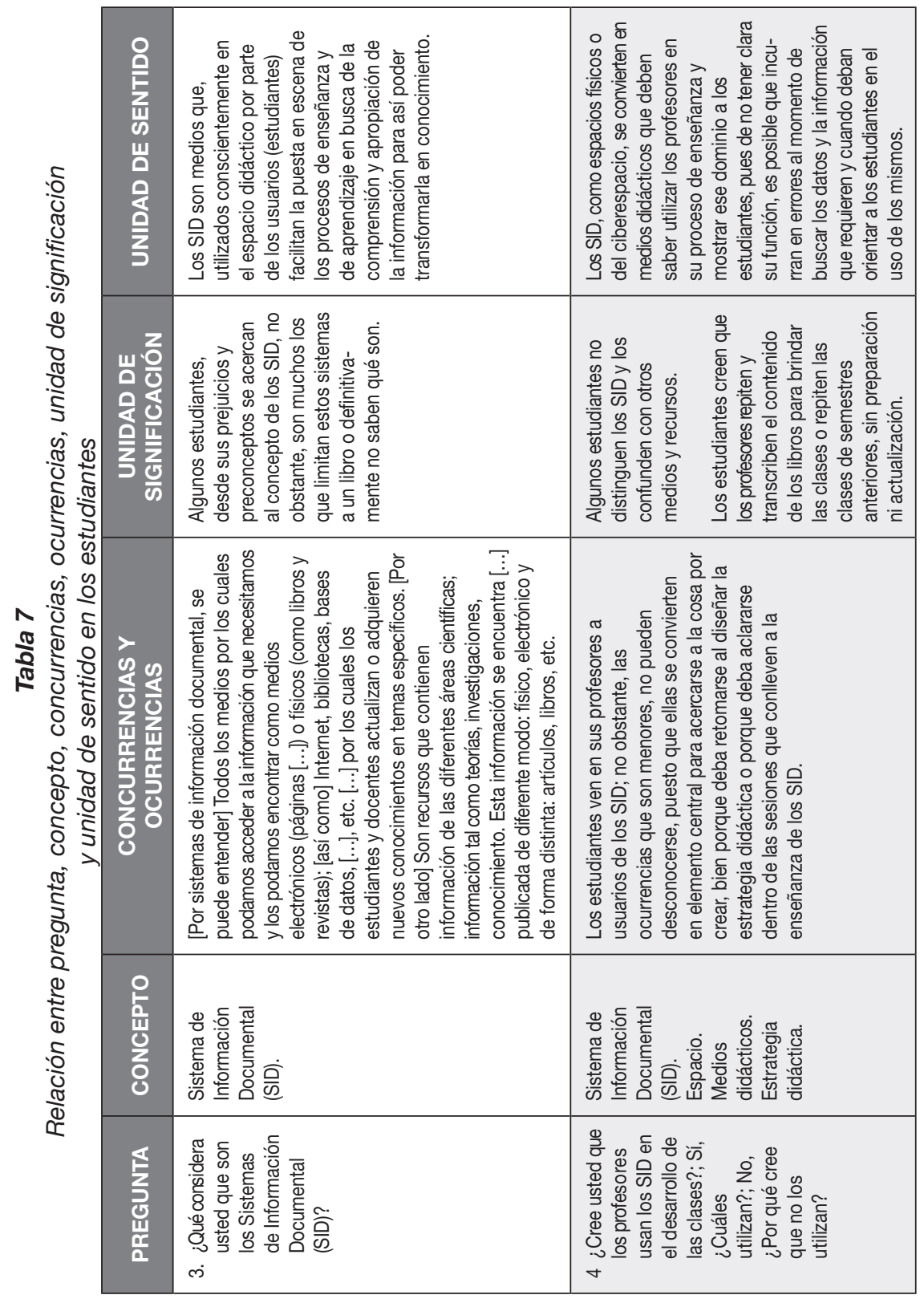




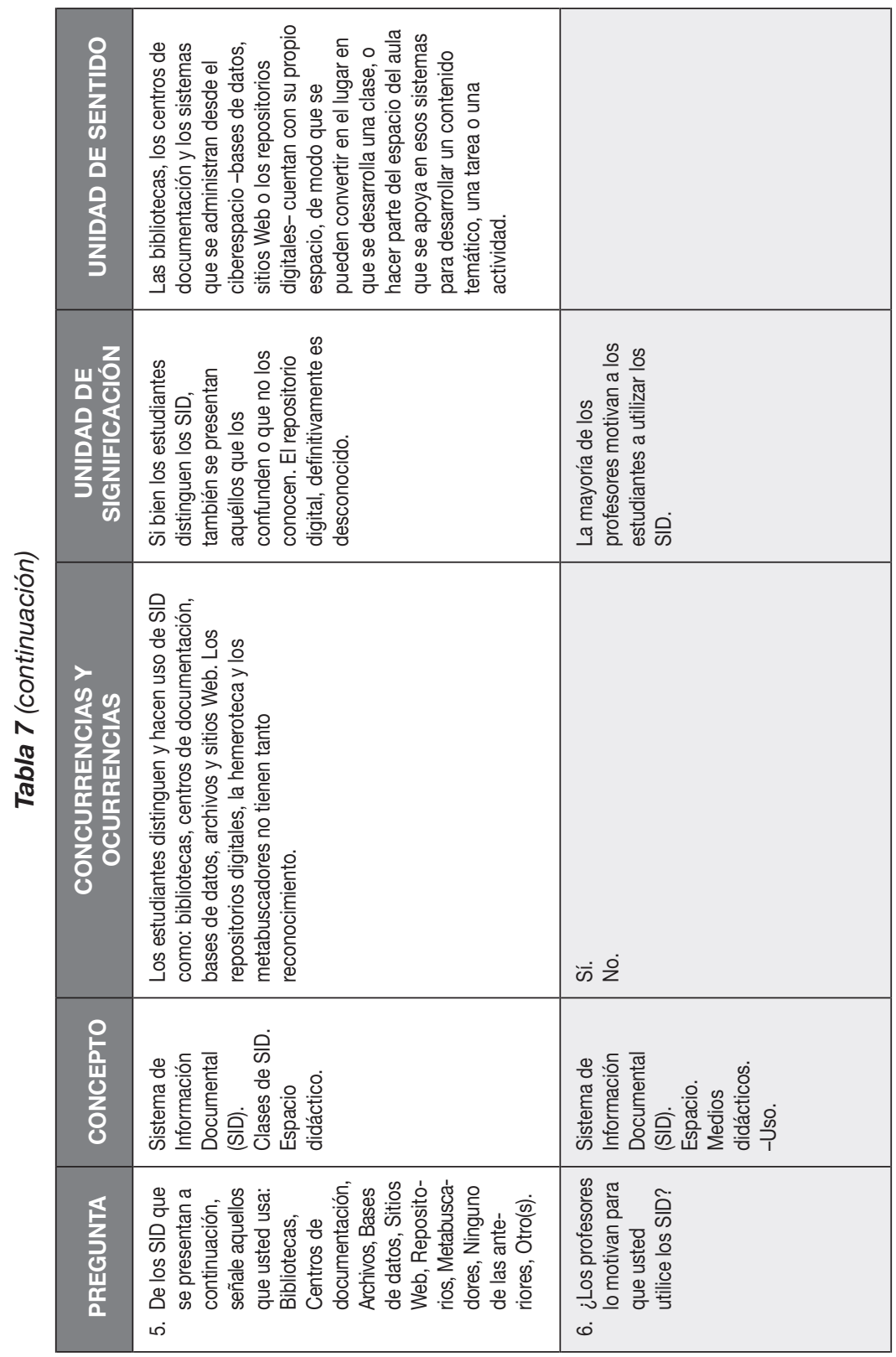




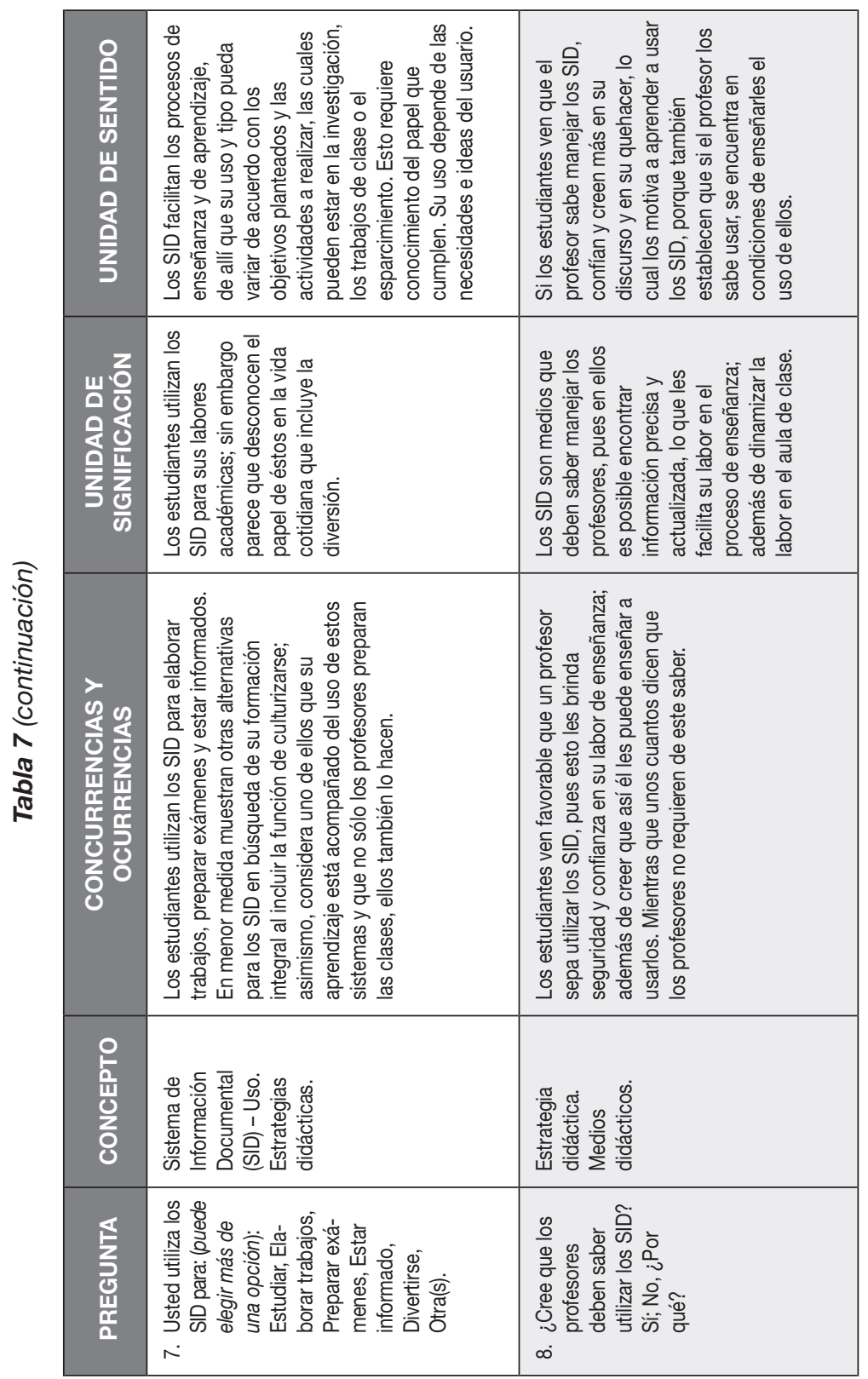




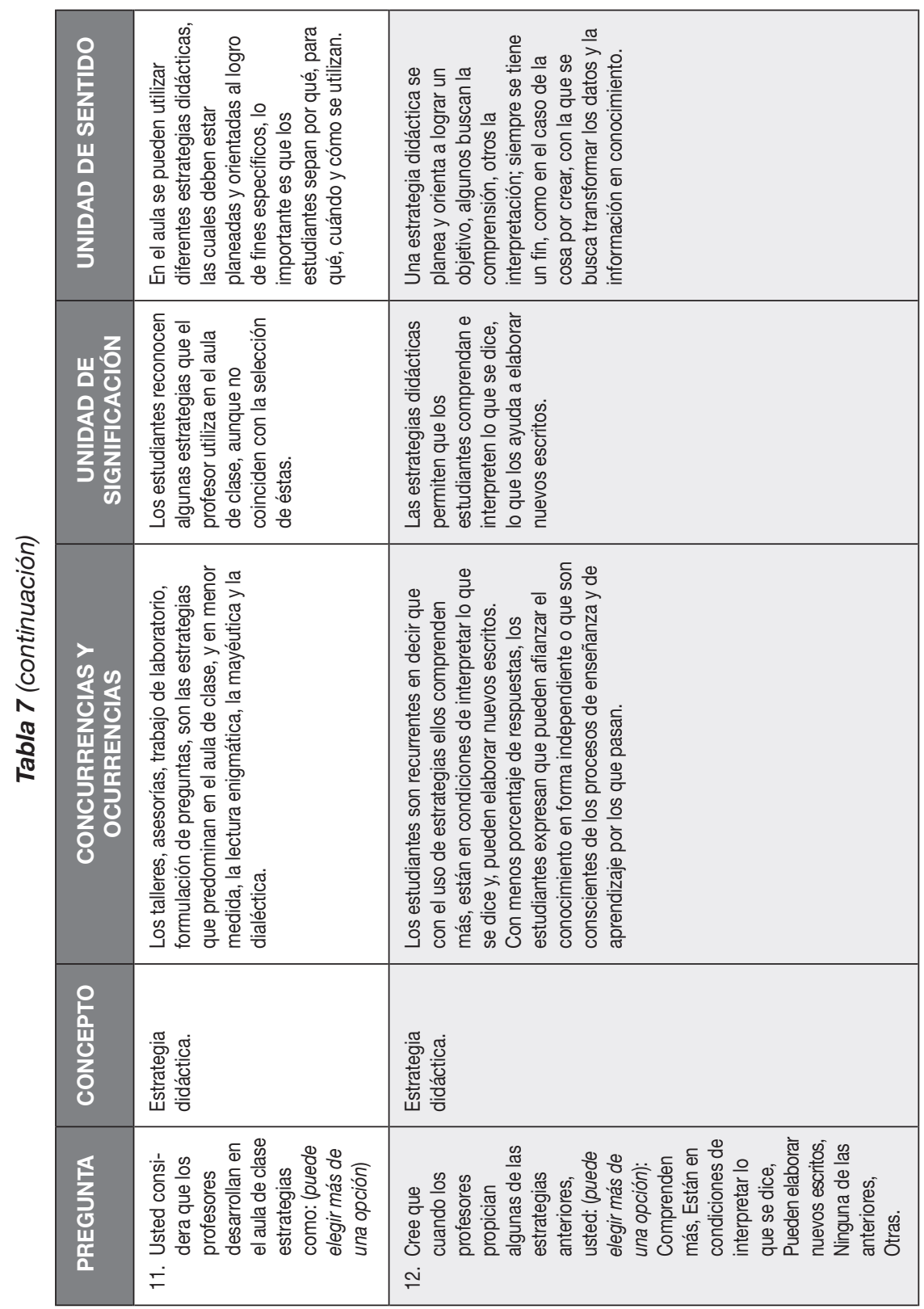




\section{LA CONVERSACIÓN}

Quien quiere saber regularmente se pregunta y les pregunta a otros, que de manera segura le contestarán, aunque no necesariamente lo dejen satisfecho con sus respuestas, y es cuando el primero vuelve a preguntar para que le vuelvan a contestar y así continuar conversando en una dialéctica constante, pues esta última "[...] como arte de preguntar sólo se manifiesta en que aquél que sabe preguntar y es capaz de mantener en pie sus preguntas, esto es, su orientación abierta. El arte de preguntar es el arte de seguir preguntando, y esto significa que es el arte de pensar. Se llama dialéctica porque es el arte de llevar una auténtica conversación" (Gadamer, 2005: 444), y es recordar la presencia de todos y no sólo de quien pregunta, pues prevalece el nosotros al hablar, así como el tema tratado.

De este modo para que la conversación sea fluida, es necesario que los interlocutores estén concentrados en el discurso del contrario y que se escuchen con atención, pues para llevar la secuencia de ésta es necesario "[...] ponerse bajo la dirección del tema sobre el que se orientan los interlocutores" (Gadamer, 2005: 445) y establecer las opiniones sobre el mismo para -de esta manera- fortalecer lo dicho y no buscar la debilidad del otro; por el contrario, se dialoga para encontrar la verdad del tema objeto de la conversación, de la cosa en cuestión, de la cosa por crear. Lo que implica la búsqueda de la comprensión de aquello que expresan los interlocutores, buscando objetivamente develar lo que dice el otro.

Con la conversación se pretende llegar a un acuerdo, lo cual exige la concentración entre quienes lo hacen, lo que conlleva a valorar los puntos de vista de cada uno y a ponerse en su lugar para tratar de entender lo que dice. Así, se busca comprender el fenómeno a partir del punto de vista del otro o de los otros, desde un escrito o desde la oralidad, e interpretarlo 
y llevarlo por la senda de los conceptos que se están elaborando. Lo que bajo la óptica de la dialéctica hegeliana "[...] es un monólogo del pensar que intenta producir por adelantado lo que poco a poco va madurando en cada conversación auténtica" (Gadamer, 2005: 447).

Inicialmente la conversación parece algo sencillo, sin embargo, al momento de abordarla y dependiendo de la cosa por tratar, se puede tornar un tanto compleja, puesto que allí se encuentra el punto de vista del otro, sus observaciones, sus objeciones, sus refutaciones, y también su aprobación y los malentendidos, todo lo cual lleva a ampliar la visión del tema y a contemplar un posible acuerdo. Como dice Carlos Vásquez "[...] sin la sustancia viva de los conversadores el saber se vuelve neutro, sin voz. El fuego se apaga y el conocimiento se hunde en fórmulas huecas" (2011).

Esta técnica se llevó a cabo con diferentes grupos, siendo éste otro de los momentos del proceder de la experiencia hermenéutica. Entre estos grupos estuvieron los bibliotecólogos y los usuarios reconocidos; estos últimos, profesores que en los sistemas de bibliotecas de las universidades de este caso, son considerados como conocedores del tema que se estudia por su relación con la información.

Con ellos se conversó sobre las estrategias didácticas, el uso de los SID, y conceptos conocimiento e información. En la selección de los primeros (bibliotecólogos) se tuvo en cuenta su experiencia laboral con la temática (programas y cursos relacionados con la preparación de los usuarios en el uso de la información en bibliotecas universitarias) o por su experiencia como profesores en la enseñanza de este saber, también se tuvo presente su producción bibliográfica en el tema. Mientras que los segundos se escogieron por el reconocimiento que tienen entre los empleados de los sistemas de bibliotecas, como usuarios que hacen uso consciente y frecuente de los SID, al 
igual que por el interés que muestran para que los estudiantes también sepan utilizar éstos.

Para organizar los encuentros con estos profesionales se diseñaron dos tipos de comunicaciones (Guía de conversación), una para los bibliotecólogos (Anexo 4) y otra para los usuarios reconocidos (Anexo 5). La Guía se convirtió en el instrumento que orientó la conversación y no se formuló con preguntas sino con temas que emergieron de la revisión conceptual que hizo parte del proyecto de la tesis y del estado de la cuestión, arrojando luces acerca de los temas esenciales sobre los que se pretendió indagar a fondo; esta información se les hizo llegar vía correo electrónico. Parte de los aportes de los dialogantes se reflejó en el análisis de las encuestas de prejuicios que se les aplicaron a estudiantes y profesores.

Si bien la Guía sirvió para iniciar el diálogo, no se desplegó en ese orden estricto, sino que en muchos momentos éste se modificó de acuerdo con el desarrollo que tuvo la conversación. Tampoco se limitó la Guía a la formulación de preguntas, sino que los interlocutores (usuarios reconocidos, bibliotecólogos e investigadora) presentaron sus apuntes, expresaron sus prejuicios y la conversación fluyó libremente, lo cual, no interfirió en los resultados, pues como apunta Gadamer:

...cuanto más auténtica es la conversación, menos posibilidades tienen los interlocutores de 'llevarla' en la dirección que desearían. De hecho la verdadera conversación no es nunca la que uno habría querido llevar. Al contrario, en general sería más correcto decir que 'entramos' en una conversación, cuando no que nos 'enredamos' en ella. Una palabra conduce a la siguiente, la conversación gira hacia aquí o hacia allá, encuentra su curso y su desenlace, y todo esto puede quizá llevar alguna clase de dirección, pero en ella los dialogantes son menos los directores que los dirigidos. Lo que 'saldrá' de una conversación no lo puede saber nadie por anticipado (Gadamer, 2005: 461). 
La información que se obtuvo de los participantes se analizó inicialmente con el apoyo del programa Atlas.ti, y posteriormente se realizaron matrices con las categorías y los códigos o conceptos organizados con el software mencionado ${ }^{10}$ (unificados en la Tabla 8), lo que permitió resaltar concurrencias y ocurrencias en las dos clases de públicos, incluso, en algunos momentos se resaltaron los acuerdos y diferencias entre las apreciaciones que surgieron entre bibliotecólogos y usuarios reconocidos. Algunas de las apreciaciones de los dialogantes se reflejaron en las unidades de significación, debido a que el aporte fue amplio y no limitado a una pregunta cerrada.

\section{Tabla 8}

Unificación de categorías y conceptos de la conversación con bibliotecólogos y con usuarios reconocidos (profesores)

\begin{tabular}{|l|l|}
\hline CATEGORÍA & CONCEPTO \\
\hline Conocimiento & Conocimiento \\
\hline \multirow{4}{*}{ Didáctica } & Contenidos \\
\cline { 2 - 2 } & Estrategia didáctica \\
\cline { 2 - 2 } & Medios didácticos \\
\hline Enseñar a usar la información & Búsqueda de información \\
\hline \multirow{4}{*}{ Información } & Transformación de la información \\
\cline { 2 - 2 } & Transmisión de la información \\
\cline { 2 - 2 } & Uso de la información \\
\hline \multirow{4}{*}{ Sistemas de información documental -SID- } & Biblioteca universitaria \\
\cline { 2 - 2 } & Internet \\
\cline { 2 - 2 } & SID \\
\cline { 2 - 2 } & Web social (Web 2.0) \\
\hline \multirow{4}{*}{ Usuarios de la información } & Características de los estudiantes \\
\cline { 2 - 2 } & Características de los profesores \\
\cline { 2 - 2 } & Características de los usuarios \\
\cline { 2 - 2 } & Necesidad de información \\
\hline
\end{tabular}

10 En este software (Atlas.ti) se habla de códigos que, llevándolos a la experiencia hermenéutica se refieren a las unidades de significación. 
Con la conversación se desarrolló el proceso de la experiencia hermenéutica, al apoyarse en el proceder PRACCIS (prejuicios, reflexión, análisis, comparación, compresión, interpretación y síntesis) partiendo de los prejuicios de la investigadora. En este documento no se presenta el proceso de cada conversación, por lo extenso del mismo, y sólo se muestran dos ejemplos de su aplicación (Tablas 9 y 10), uno con un bibliotecólogo y otro con un usuario reconocido. No obstante, este proceso con las conversaciones permitió configurar y afianzar las unidades de significación y las unidades de sentido en una fusión de horizontes que orientó la estrategia por crear.

El proceso hermenéutico de este momento se ejemplifica a continuación: 


\section{Tabla 9 \\ Ejemplo de proceso hermenéutico con una bibliotecóloga}

\begin{tabular}{|c|c|}
\hline Prejuicios & $\begin{array}{l}\text { Los bibliotecólogos tienen claridad frente a las trasformaciones por las que pasa la } \\
\text { biblioteca y admiten que su quehacer se ha ampliado a otros espacios. } \\
\text { Los bibliotecólogos comprenden la organización y función de los SID y no lo limitan } \\
\text { a las aplicaciones de las TIC. } \\
\text { EI SID es un concepto que aún no es de dominio total entre los bibliotecólogos. }\end{array}$ \\
\hline Análisis & $\begin{array}{l}\text { Los SID como concepto incluyen personas, recursos como los documentos y la } \\
\text { información, equipos, procesos sistémicos, espacios reales y virtuales que pre- } \\
\text { tenden facilitar a las personas el acceso a la información, como se expresa en su } \\
\text { concepto: los SID se entienden como el conjunto de personas, máquinas y proce- } \\
\text { dimientos que transforman la información documental en una información que se } \\
\text { puede buscar, recuperar y usar para la toma de decisiones. Entre ellos se encuen- } \\
\text { tran las unidades de información como bibliotecas, centros de documentación, } \\
\text { archivos y museos, así como bases de datos, centros referenciales y de recursos, y } \\
\text { herramientas como Internet, portales, buscadores, metabuscadores, repositorios } \\
\text { y sitios Web que facilitan el acceso a la información y al conocimiento por parte de } \\
\text { los miembros de la sociedad. } \\
\text { La bibliotecóloga presenta su punto de vista de lo que ella considera que es un SID, } \\
\text { pero no lo expresa con certeza sino desde lo que ella se imagina que éste es e inclu- } \\
\text { ye los sitios que se han planteado teóricamente como un SID, pero no menciona el } \\
\text { papel de las personas ni la función que cumplen estos sistemas en la sociedad. }\end{array}$ \\
\hline Reflexión & $\begin{array}{l}\text { ¿Por qué la bibliotecóloga no hace alusión al papel que juegan las personas en } \\
\text { ellos? Y también, ¿por qué no menciona la función que cumplen estas personas } \\
\text { para facilitar el acceso a la información? ¿Será que ella y muchos otros } \\
\text { bibliotecólogos siguen imaginándose la concepción de los SID y no tienen un } \\
\text { manejo teórico de los mismos? }\end{array}$ \\
\hline Comparación & $\begin{array}{l}\text { La bibliotecóloga, tiene apreciaciones muy válidas de lo que es un SID, aunque le } \\
\text { faltan elementos característicos de los mismos; no obstante, su apreciación es válida } \\
\text { dentro de la concepción teórica que se tiene del término. Es importante leer las } \\
\text { apreciaciones de otros colegas, uno de los cuales presenta una concepción muy } \\
\text { completa del término. }\end{array}$ \\
\hline Comprensión & $\begin{array}{l}\text { La bibliotecóloga resalta el papel de los sistemas de información organizados a } \\
\text { partir de las TIC y menciona metabuscadores de reconocida trayectoria como } \\
\text { Google, sin desconocer el papel que juegan las bibliotecas y los documentos } \\
\text { impresos. Esto nos lleva a ver que los SID cumplen la función de facilitar el acceso } \\
\text { a la información, independientemente del soporte y el formato en que ésta se } \\
\text { encuentre y donde el espacio ya no es una barrera para su acceso. }\end{array}$ \\
\hline Interpretación & $\begin{array}{l}\text { Apropiarse de los SID requiere de un manejo teórico y práctico de éstos por parte } \\
\text { de los bibliotecólogos, para que ellos les faciliten su aprendizaje a los usuarios } \\
\text { universitarios: estudiantes, profesores e investigadores. }\end{array}$ \\
\hline Síntesis & $\begin{array}{l}\text { El bibliotecólogo es el profesional indicado para acompañar al profesor en la } \\
\text { enseñanza del uso de los SID en el aula de clase, y así facilitar la transformación de } \\
\text { la información en conocimiento para los estudiantes. }\end{array}$ \\
\hline
\end{tabular}




\section{Igualmente se ejemplifica el proceso hermenéutico que se siguió en la conversación con los profesores universitarios:}

\begin{tabular}{|c|c|}
\hline \multicolumn{2}{|c|}{$\begin{array}{c}\text { Tabla } 10 \\
\text { Ejemplo de proceso hermenéutico con usuario reconocido-profesor }\end{array}$} \\
\hline Prejuicios & $\begin{array}{l}\text { Los profesores como usuarios reconocidos consideran a los SID como } \\
\text { elementos fundamentales para el desarrollo de las clases. } \\
\text { A pesar de que los profesores valoran la función de los SID, no cuentan } \\
\text { con estrategias didácticas que motiven a los estudiantes a utilizarlos. }\end{array}$ \\
\hline Análisis & $\begin{array}{l}\text { Los SID compuestos por bibliotecas, centros de documentación, bases de } \\
\text { datos, archivos, repositorios digitales, etc. facilitan el acceso a los datos y } \\
\text { la información que se discute en el aula de clase. } \\
\text { De acuerdo con el profesor, en la biblioteca se encuentra todo lo que se } \\
\text { publica, los avances, los desarrollos científicos; por consiguiente, quien } \\
\text { vaya a preparar un tema de clase debe ir primero a estos sitios para } \\
\text { conseguir la información de punta y así motivar a los estudiantes para } \\
\text { buscar las novedades bibliográficas en el área de interés. }\end{array}$ \\
\hline Reflexión & $\begin{array}{l}\text { ¿Por qué si se cuenta con personas conscientes del papel que cumple la } \\
\text { biblioteca en el desarrollo de las clases, aún hay profesores que sólo } \\
\text { utilizan sus notas de clases elaboradas de tiempo atrás para desarrollar el } \\
\text { proceso de enseñanza? } \\
\text { ¿Será que algunos profesores creen que con los documentos que dejan en } \\
\text { las fotocopiadoras es suficiente para que los estudiantes conozcan el } \\
\text { desarrollo científico y tecnológico reciente? } \\
\text { ¿Cómo podría actualizarse a los profesores en el desarrollo y avance de } \\
\text { los SID, de manera que no limiten su consulta a las bibliotecas o a Internet? }\end{array}$ \\
\hline Comparación & $\begin{array}{l}\text { Entre los profesores reconocidos como usuarios frecuentes de las bibliote- } \\
\text { cas universitarias, existen diferentes maneras de ver los SID en los pro- } \\
\text { cesos de enseñanza y aprendizaje; unos tienen miradas más críticas, otros } \\
\text { conocen más los servicios y beneficios que se obtienen de ellos y otros } \\
\text { manejan propuestas que presentan mayor provecho para los estudiantes. }\end{array}$ \\
\hline Comprensión & $\begin{array}{l}\text { Para lograr que los estudiantes transformen los datos y la información en } \\
\text { conocimiento en el aula y guiados por el profesor, se requiere de un manejo } \\
\text { adecuado y consciente de los SID, no basta con valorar el papel de éstos. }\end{array}$ \\
\hline Interpretación y síntesis & $\begin{array}{l}\text { Lograr un manejo adecuado de los SID por parte de profesores y estu- } \\
\text { diantes, implica el diseño de una propuesta formativa al respecto. Esta } \\
\text { propuesta no debe estar aislada del programa educativo; por el contrario, } \\
\text { debe apoyarse en él y desarrollarse dentro de uno o varios cursos a partir } \\
\text { de una estrategia didáctica en la que el uso de las fuentes de información } \\
\text { sea necesario para elaborar la actividad académica. }\end{array}$ \\
\hline
\end{tabular}


El proceso hermenéutico que se aplicó a la conversación que se sostuvo con cada público acerca de sus vivencias con los SID, generó las unidades de significación de cada concepto.

Estos conceptos y sus unidades de significación se compararon y -cuando se pudo- se organizaron en una unidad de sentido. Esta actividad se observa a continuación en un ejemplo con uno de los conceptos (Tabla 11). 


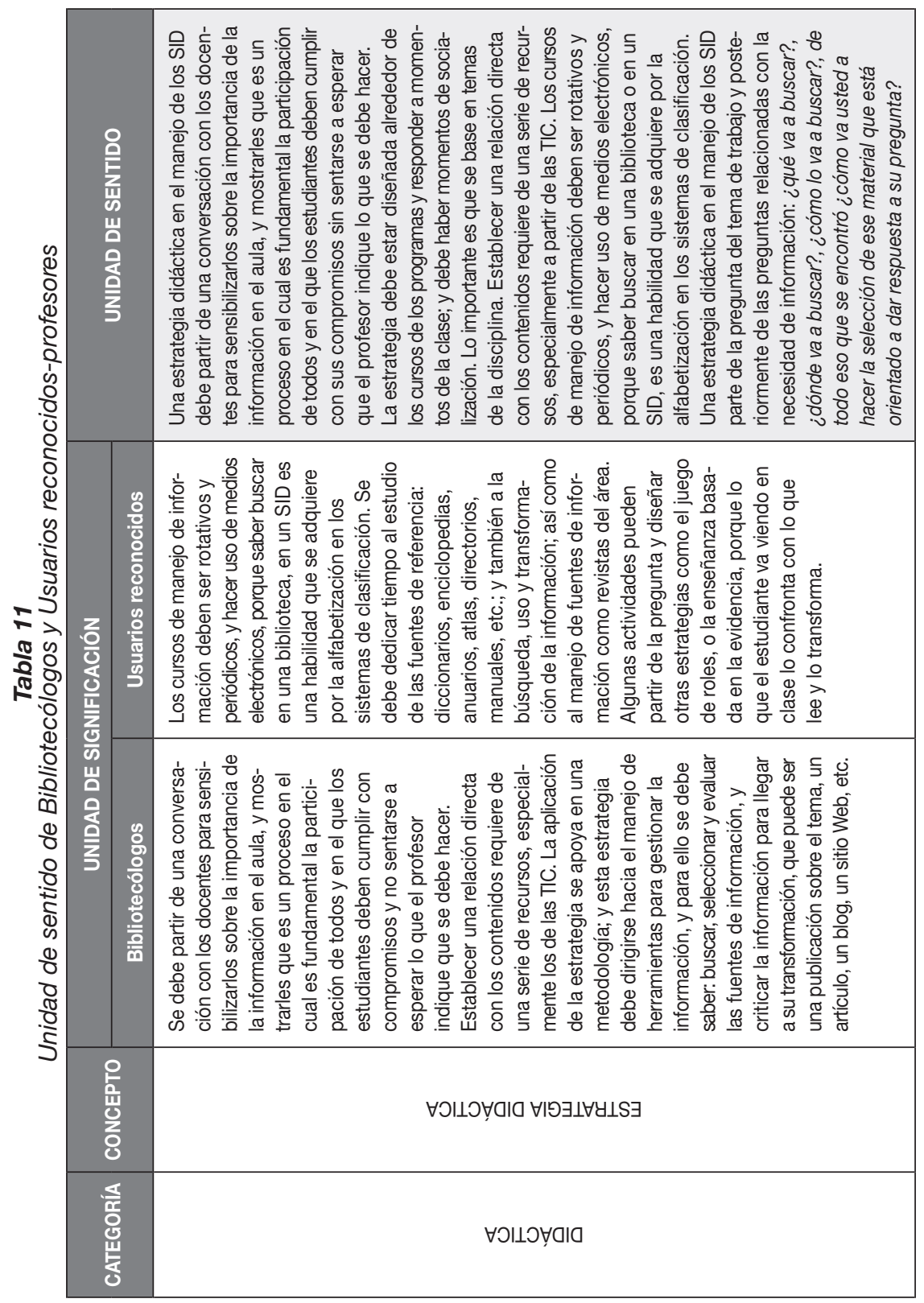




\section{Tercera Parte UNA SENDA HACIA LA COSA CREADA}




\title{
Estrategia didáctica TRINCO: transformación de la información en conocimiento
}

\begin{abstract}
C presenta este discurso producto de un proceso de inter- pretación teórica y vivencial sin la pretensión de ser totalitario, y conscientes de que otros, tal vez por azar o por conciencia, pueden encontrar contradicciones, incertidumbres, des-orden y ambigüedad, lo que es posible en la medida de lo complejo que resulta crear la estrategia didáctica desde la mirada interdisciplinar; es decir, se hace un esfuerzo contextual e intelectual para lograr una "transformación multidimensional" (Morin, 1994: 77), sin salirse completamente del parcelamiento disciplinar, desde el amparo en la teoría de la complejidad (con Morin), la didáctica y la ciencia de la información.
\end{abstract}

\section{LA DIDÁCTICA, LAS ESTRATEGIAS Y EL SISTEMA DIDÁCTICO TIENEN UN LUGAR EN LA UNIVERSIDAD}

El padre de la didáctica, Jan Amos Komenski, conocido como Comenius, en su obra Didáctica magna (2007) destaca el papel 
que juega la metodología dentro de los procesos de enseñanza y aprendizaje, y para ello consideró necesario partir de un estudio del desarrollo psicológico del estudiante que generara los pasos para una enseñanza individualizada. En esa medida, la didáctica enfatiza, por un lado, la idea y la necesidad de una acción metodológica en la que el modo de enseñar logre los fines buscados y, para ello, privilegia al alumno, quien se encuentra bajo la responsabilidad del profesor; mientras que por el otro, se interesa y centra su reflexión teórica y metodológica en los intereses y necesidades del sujeto que aprende.

Esto de acuerdo con Zuluaga, indica que la didáctica "[...] es el conjunto de conocimientos referentes [a los procesos de enseñanza y de aprendizaje] que conforman un saber" (1999: 11). Procesos en los cuales se relacionan profesor y alumno como sujetos sociales que comparten una cultura; donde se encuentran conceptos teóricos y operativos que permiten afirmar que la didáctica supera fórmulas y recetas.

Por lo tanto, se infiere que la didáctica es un campo del conocimiento o disciplina preocupada por hacer explícitos, en forma teórica y práctica, los procesos de enseñanza y de aprendizaje encaminados hacia un fin educativo.

Esto lleva a pensar que se requiere de una mediación; es decir, de alguien que lidere el proceso de enseñanza y facilite el aprendizaje del alumno. De allí que Not exprese, frente a la mediación didáctica que ésta "[...] consiste en suministrar al alumno la información de la que no dispone y que no podría procurarse por sus propios medios; y después, en ayudarle a transformar esa información en conocimiento" (1992: 83). Apreciación que deja ver la transformación de un sujeto con la anuencia de otro que lo ayuda a lograr su propósito. Como expone Olga Lucía Zuluaga: "[...] los parámetros de las conceptualizaciones en la didáctica se refieren a la forma de conocer o de aprender del hombre, a los conocimientos objeto de la ense- 
ñanza, a los procedimientos para enseñar, a la educación, y a las particularidades, condiciones o estrategias bajo las cuales debe ser enseñado un saber específico" (1999: 11).

En los inicios del siglo XX se empezó a hablar de la didáctica especial en consonancia con el contenido. Rein, discípulo de Herbart, se refería a ésta a partir del plan de enseñanza, al indicar que la didáctica especial se refiere a la enseñanza de especialidades (Rein, cit. por Ríos, 1997). Esto muestra una relación entre contenido y método de enseñanza para logar un acercamiento a la producción del conocimiento. "Pero dado que cada área de conocimiento tiene su propio método, fue necesario pensar en una didáctica especializada para cada una de ellas, surgiendo de este modo la didáctica de las matemáticas, de las lenguas, de las ciencias, de la música, entre otras. Estas didácticas especiales o especializadas [...] hoy en día se catalogan como didácticas específicas." (Grisales, 2011: 67)

La didáctica especial, además de caracterizarse por los contenidos específicos en determinadas áreas del conocimiento, también incluye las características de las personas, el tipo de institución y los niveles educativos, entre otros (Camilloni, 2008), lo que ratifica a la didáctica específica.

Frente a esto Bolívar expresa:

[...] se suele distinguir, de una parte, la didáctica general (Allgemeine Didaktik) como el estudio del proceso de enseñanza en general en el marco de la institución escolar, de la didáctica especial (Spezialdidaktiken) diferenciada según los tipos de escuela, la edad o características particulares de un grupo de alumnos o los campos específicos de contenido (materias disciplinares). En este sentido, las didácticas específicas (Fachdidaktik o didácticas de los contenidos disciplinares) forman parte, relevante y diferenciada, de la didáctica especial (2005: 10).

Se observa de esta manera que la especificidad es parte, de alguna manera, de la especialidad, o como expone Camilloni: 
"[...] las didácticas específicas desarrollan campos sistemáticos del conocimiento didáctico que se caracterizan por partir de una delimitación de regiones particulares del mundo de la enseñanza" (2008: 23), las cuales, se diferencian por diversos criterios, que la misma Camilloni organiza de acuerdo con los niveles educativos (preescolar, primaria, secundaria, superior, posgrado), según las edades de los alumnos, y a partir de las disciplinas; por el tipo de institución (formal, no formal y en éstas las rurales, urbanas, para el trabajo, la recreación, etc.); y por último, de acuerdo con las características de los sujetos, en éstas se encuentran las minorías y quienes tienen necesidades especiales.

De acuerdo con esta mirada, puede decirse que la didáctica universitaria es especial, en la que se distinguen ciertos procesos de enseñanza y aprendizaje circunscritos en un nivel de educación superior, para un público particular, y en un rango de edad adulta que busca resolver los problemas sociales desde diferentes áreas del conocimiento.

Con base en esta didáctica universitaria, también se le da cabida a las reflexiones teóricas y prácticas relacionadas con las maneras de planear o concebir la clase, las estrategias de enseñanza, planteamiento de problemas, evaluaciones y viabilidad de utilizar ejemplos y casos reales. Esto hace ver cómo la didáctica requiere de un trabajo consciente y constante del profesor para lograr el aprendizaje de los estudiantes. En este proceso se tienen profesores con su estilo propio, como dice Edith Litwin (2009, en línea):

En algunas oportunidades, se trata de estilos deslumbrantes para desarrollar una clase, genuinos maestros que enseñan una manera de pensar y, otras veces, más silenciosa, es una clase que provoca que los estudiantes decidan una manera de encarar y solucionar problemas de la disciplina o de las prácticas profesionales. La presencia del profesor, más humilde y menos omnipotente, en esos casos, se 
inscribe en acompañar y proteger el proceso de descubrimiento del estudiante.

Es decir, esta didáctica universitaria se centra en el profesor como creador, transformador y, por lo tanto, autor de un acto pedagógico, de un proceso de enseñanza de acuerdo con su área y en donde su experticia le permitirá diseñar un proceso para la transformación de la información en conocimiento durante la clase, lo cual, requiere de un diálogo permanente entre profesor y estudiante, lo que lleva a concebir como didáctica universitaria el planteamiento de la profesora Elvia M. González (2011a: 1):

La didáctica [universitaria] es [...] un acto comunicativo, en el cual el profesor establece una conversación con sus estudiantes, sobre asuntos inacabados del conocimiento. El diálogo se inicia, quizás en otros espacios de lecturas previas, con preguntas que dejan las lecturas inciertas, sobre ese saber que no se sabe, sobre eso que nos asombra, que nos inquieta, que no nos deja tranquilos, y eso se va constituyendo en un proyecto de conocimiento diferente para cada uno de los estudiantes. El profesor abre las posibilidades, su experiencia le permite ver otros mundos posibles y sugerir caminos, está siempre en estado de enunciación y genera actos perlocutivos.

Aquí se percibe la presencia de la información que permite la acción comunicativa entre los sujetos partícipes del proceso educativo, momento que además requiere organización y planeación; por eso, con la intención de comprender el sentido de la estrategia didáctica diseñada para que los profesores enseñen a los estudiantes a utilizar los SID en la transformación de los datos y la información en conocimiento, se presenta un panorama de este concepto.

En la didáctica universitaria están presentes las estrategias para facilitar la enseñanza de un saber, como parte o manifestación del método; sin embargo, es necesario profundizar en 
este sentido, puesto que las estrategias no sólo son aplicaciones para una actividad, de ser así se limitaría a una técnica ${ }^{1}$ para enseñar.

La preocupación del docente por comprender el método y los pasos para enseñar, entre los cuales se encuentran las estrategias didácticas, ha existido desde épocas pretéritas, preocupación que ha variado con la época y las circunstancias vividas, y que se vuelve compleja si se tiene presente que esto involucra los sistemas social, educativo, pedagógico y didáctico, y una serie de sujetos que se distinguen por sus intereses, deseos y necesidades particulares.

Para Navaridas (2004), el interés por el saber estratégico se ha vuelto novedoso y actual; no obstante, no sólo se trata de acumular conocimiento relacionado con el saber cómo, sino también, de comprender la razón de las acciones, reflexiones y actos que se llevan a cabo en este interés por enseñar bien y lograr que los estudiantes aprendan, razón para acercarse al concepto en cuestión, a fin de reflexionar la práctica didáctica en la universidad.

Estrategia, palabra que se toma -inicialmente- como una serie de acciones que se realizan para alcanzar un fin específico; surge de las primeras definiciones que se dieron al término, el cual viene del latín strategema, y éste del griego strategía $\Sigma$ TPAТНГІКН $\Sigma$ Stratos $=$ Ejército y hégeoma $i=$ yo conduzco, yo guío o dirijo; por eso se dice que el ámbito militar fue el primer espacio en que se usó, pues éste abarcaba los medios y su uso adecuado para alcanzar el fin militar, esto es, ganar las batallas; por lo tanto, para lograrlo, se requiere de un conductor

1 La técnica se caracteriza por ser un conjunto de actividades organizadas en forma secuencial, que buscan un fin preciso y concreto para que los resultados se puedan predecir (Monereo, 1998), esto significa que son rutinas que se aprenden, se interiorizan y se vuelven automáticas. 
que dirija tanto las acciones a implementar como del ejército (strategos = estratega), de allí que, como lo expresara Monlau, ésta se considera "[...] la ciencia de los movimientos militares que se ejecutan fuera del rayo visual recíproco de dos ejércitos enemigos, o fuera del alcance de la artillería" (1856: 270).

El concepto se difunde en el ámbito mundial después de la Segunda Guerra Mundial. Es en las décadas de los sesentas y setentas cuando hace parte del discurso social, político y económico y a partir de los ochentas se involucra en el discurso de las ciencias administrativas; cuando se introduce en el campo pedagógico ya ha perdido su sentido militar (Torre y Barrios, 2002).

La estrategia conlleva un acto, pues es dinámica y por consiguiente genera la acción de los sujetos, quienes -en el caso de la educación superior- buscan una realización personal y profesional. Al respecto expresa Morin: “[...] la acción es una decisión, una elección, pero es también una apuesta” (1994: 113), apuesta en el sentido de que el pronóstico del logro es impredecible, lo que implica riesgo y genera incertidumbre. Y es que la acción denota estrategia, pues parte de una decisión que es factible de ejecutarse en diversos escenarios que, como dice Morin en el mismo texto, "[...] podrán ser modificados según las informaciones que nos lleguen en el curso de la acción y según los elementos aleatorios que sobrevendrán y perturbarán la acción" (p. 113), pudiendo presentarse problemas y dificultades mientras se aplica la estrategia. Por lo cual, profesores y bibliotecólogos que apliquen la estrategia deben reflexionar sobre la complejidad de la misma, ya que se viven una serie de interacciones en las que el ambiente puede interferir y modificar la intención original y generar incertidumbre y zozobra; situación que puede vivirse al interior de la clase. Por lo tanto, es necesario prepararse para reaccionar ante lo nuevo o inesperado, de manera que se facilite su integración a la acción 
prevista, lo que, tal vez, genere modificación y enriquecimiento a la propuesta inicial. Quizás el éxito de una estrategia resida en la combinación compleja de pensamiento, reflexión y dominio de las cosas simples que incluye la acción (Morin, 1994).

La citada Olga Lucía Zuluaga manifiesta que la estrategia

debe entenderse como las determinaciones de poder y de saber que actúan en un campo complejo y heterogéneo de fuerzas diseminadas en las prácticas sociales (incluyendo entre éstas las prácticas discursivas); tales determinaciones requieren para su despliegue de una red de instituciones, sujetos y discursos (saberes), atravesados por sus fines o delimitados para sus fines, y para introducir mecanismos estables de dominación en el conjunto de fuerzas (Zuluaga, 1999: 141).

Indudablemente, los procesos de enseñanza y aprendizaje tuvieron un principio de inspiración en la milicia; pero no puede desconocerse que en el hombre siempre ha existido la necesidad de encontrar la mejor forma de proceder; es decir, el cómo para lograr el conocimiento y su perfeccionamiento. Morin se refiere así a la inseparabilidad del conocimiento y de la acción: "[...] como todo el conocimiento cerebral, el conocimiento humano es, en su origen y en sus desarrollos, inseparable de la acción; como todo conocimiento cerebral, elabora y utiliza estrategias para resolver los problemas puestos por la incertidumbre y la incompletud del saber" (Morin, 1986: 192).

Las características conceptuales de la didáctica indican que en ésta, prima la comprensión de la forma como el hombre aprende y conoce; de los conocimientos artísticos, científicos, técnicos y tecnológicos del objeto de la enseñanza; de los procedimientos que se utilizan para enseñar, así como de las estrategias que facilitan la enseñanza y el aprendizaje de los saberes ( $\mathrm{Zu}$ luaga, 1999).

Unas estrategias que no deben confundirse con las técnicas para enseñar, puesto que aquéllas son aplicaciones para la acción 
más que para una actividad. Como dice Torre (2002: 117), las estrategias son un "conjunto de procedimientos adaptativos por los que organizamos secuenciadamente la acción en orden a conseguir las metas previstas". Lo que posibilita la acción formativa y el desarrollo de habilidades, valores y conocimientos, entre los que se encuentra la reflexión, la interrogación, el debate, la metacognición y el error.

Esas acciones de las estrategias son complejas y son útiles para la labor del docente, quien al planearlas a conciencia está preocupado por ofrecer una buena enseñanza para lograr que los estudiantes se apropien -también conscientemente- del conocimiento transformado que les presentó, y para ello se ampara en las labores que le permiten los temas que va a presentar en el espacio educativo.

Continuando con las secuencias de las acciones, Rajadell (1995: 404) define las estrategias didácticas como "[...] formas secuenciales de proceder para alcanzar unos objetivos formativos"; otros indican que son un "[...] conjunto planificado de acciones y técnicas que conducen a la consecución de objetivos preestablecidos durante el proceso educativo." (Benedito, Ferreres e Imbernón, 1999: 759). A su vez Pozo (1999: 300-301) expone la estrategia como "[...] un uso deliberado y planificado de una secuencia compuesta de procedimientos, dirigida a alcanzar una meta establecida." Asimismo, Beltrán relaciona las estrategias con un "conocimiento llamado procedimental (conocimiento cómo), que hace referencia a cómo se hacen las cosas (por ejemplo, cómo hacer un resumen), de esta forma se distingue de otra clase de conocimiento llamado declarativo (conocimiento qué), que hace referencia a lo que las cosas son (qué es un resumen)" (1996: 393).

Se observa cómo esa secuencia se establece para alcanzar los objetivos fijados; no obstante, la estrategia requiere del proceso de la reflexión que le da el carácter de estrategia, al realizar 
la planificación y determinar cuándo, dónde y cómo utilizarla. Navaridas lo expone así:

[...] la finalidad supone un primer proceso de reflexión y diagnóstico en cuanto puede justificar y sustentar en parte la toma de decisiones durante el diseño del plan de acción. Los objetivos (docentes/ discentes) conducen al sujeto protagonista, influenciado por una serie de factores personales (estilo de enseñanza/aprendizaje, experiencia previa, motivación, formación, etc.) y socio-culturales de la realidad contextual donde se ejercita (clima relacional, naturaleza del contenido de la materia, recursos y medios disponibles, etc.), a adoptar determinadas estrategias durante su actividad didáctica. La puesta en práctica de estas estrategias supone la planificación reflexiva (antes de emprender la acción).

Y el control activo (durante y después de la propia acción formativa) de un conocimiento (procedimiento) más o menos complejo (métodos y técnicas) según la situación y los resultados deseados de la tarea educativa (Navaridas, 2004: 20).

De esta forma, Navaridas presenta la acción reflexiva por la que pasa la estrategia, puesto que se deben tomar decisiones sobre los procedimientos que se requieren en las fases de la estrategia, o en la teoría de sistemas, de un plan de acción.

Fases que, desde el interés de la estrategia didáctica propuesta, llevan una secuencia, a partir del orden, y se relacionan con los objetivos para lograr el fin último de la acción docente en la que el estudiante comprenda

lo que se le ha enseñado, lo interprete y pueda transformarlo en un conocimiento que él pueda "digerir" y aplicar; es decir, se vive un proceso de transformación de la información en conocimiento?

Como dice Not "[...] la reflexión se inserta en la acción para apreciar su grado de conformidad" (Not, 1992: 45), o en el caso de Heidegger (1971), la reflexión es la meditación que permite 
percatarse de lo que acontece en un proceso, en la medida en que "[...] el comportamiento hacia sí mismo y de que el decirse sea una reflexión" (p. 311).

Las estrategias didácticas proporcionan conocimientos, habilidades, actitudes y valores para que los estudiantes comprendan y reflexionen el proceso de transformación de la información en conocimiento, al igual que los medios y procedimientos que se requieren para abordar acciones académicas; "[...] donde los aspectos contextuales (experiencias previas de los estudiantes, el ambiente de la realidad educativa, el tipo de enseñanza recibido por el sujeto que aprende, la propia percepción, los estilos cognitivos personales, etc.) adquieren un gran protagonismo para la comprensión y mejora de los procesos de enseñanzaaprendizaje" (Navaridas, 2004: 13).

En el entorno se encuentran varios tipos de estrategias: de enseñanza, de aprendizaje, metodológicas, cognitivas y didácticas, cuyo objetivo común (bajo estas diferentes denominaciones) es: "[...] perfeccionar el proceso de enseñanza-aprendizaje que en el ámbito universitario se traduce en desarrollar las potencialidades de los futuros profesionales, a través de un proceso donde aprendan a pensar, a participar activa, reflexiva y creadoramente" (Rujano, 2006, en línea). También se mencionan estrategias por descubrimiento y estrategias creativas, en las cuales se pretende que el estudiante alcance el conocimiento, indicando que lo que él sabe lo logró porque hubo un proceso de comprensión e interpretación.

Las estrategias de enseñanza dan cuenta de las concepciones generales de cada profesor; e igualmente muestran el punto de vista psicopedagógico de éste y revelan su saber y desempeño didáctico, de allí que las estrategias que él escoge no deben considerarse como la serie de actos que, de acuerdo con sus conocimientos personales, él organiza, sino que conlleva una labor compleja en la que se encuentra en juego la relación 
de la teoría y la práctica, con el fin de que los estudiantes aprendan. Para Díaz estas estrategias las conforman "[...] el conjunto de intencionalidades, procesos, recursos, secuencias que se organizan para promover distintos tipos de conocimientos y distintos tipos de aprendizajes" (Díaz, 2001: 70). Que en palabras de Edith Litwin:

[...] significa, por parte de los docentes, una reconstrucción de las relaciones entre los contenidos desde la problemática del aprender. La utilización de los medios incluidos en las estrategias metodológicas constituyen, en el caso de las prácticas universitarias, resoluciones personales que dan cuenta del pensamiento del docente en relación con la construcción del conocimiento, razón por la que entendemos que se deberían plantear como una necesaria dimensión de análisis (1997: 65).

Igualmente, las estrategias de aprendizaje se consideran procedimientos mentales por parte del estudiante que está en búsqueda de su aprendizaje, proceso en el que desarrolla una serie de operaciones cognoscitivas a fin de procesar la información y así aprenderla de acuerdo con el valor y significado que le asigne su proceso de aprendizaje. Otros como Gagné las denominan estrategias cognitivas (Rujano, 2006).

Como se ha expuesto, las estrategias didácticas son sistemas de acciones y operaciones, tanto físicas como mentales, que facilitan la confrontación (interactividad) del sujeto que aprende con el objeto de conocimiento, a esto se le agrega que estimulan la relación de cooperación durante el proceso de aprendizaje con el docente y otros estudiantes (interacción) para realizar una labor. Constituyen una herramienta de mediación entre el sujeto que aprende y el contenido que el docente emplea conscientemente para lograr determinados aprendizajes (Rujano, 2006).

Además, las estrategias didácticas incluyen los medios de los que se vale el profesor para lograr que los estudiantes realmente puedan aprender y aprehender los contenidos. Razón que lo 
lleva a enseñarles variadas estrategias, como los mapas mentales, los mapas conceptuales, los debates, las mesas redondas, los proyectos de aula, la resolución de problemas, los estudios de casos y el método de proyectos.

De acuerdo con Carvajal (2002: 28) "[...] el concepto de estrategia siempre se ha enfocado desde la perspectiva del método"; es más, la estrategia es una propuesta relacionada con la enseñanza que busca el logro de metas y resultados, lo que podría asumirse como un procedimiento que enlaza y relaciona los componentes del sistema didáctico: problema, objetivo, objeto, contenido, método, medio, forma, evaluación, resultados.

De las encuestas que se aplicaron a profesores y estudiantes que participaron en esta investigación, se sintetiza lo siguiente: una estrategia didáctica se planea y orienta para lograr un objetivo, algunos buscan la comprensión, otros la interpretación, siempre se tiene un fin, como en el caso de la cosa por crear, con la que se busca la transformación de los datos y la información en conocimiento. Por lo tanto, la estrategia didáctica debe impulsar el desarrollo de determinadas habilidades en las personas que participan de ella.

Por consiguiente, se propone y se asume (como aporte de esta investigación) que

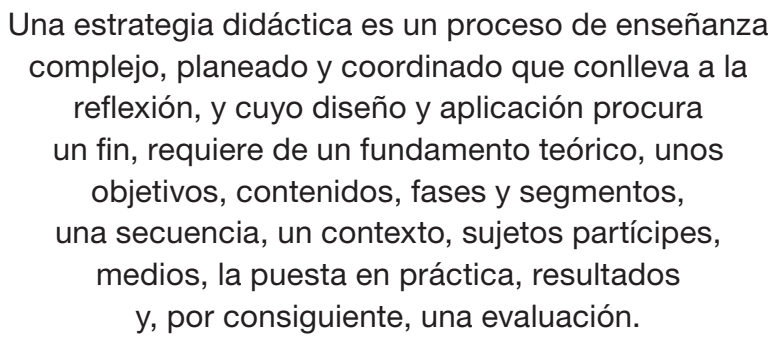


A medida que se avanza en la construcción y fundamentación teórica de esta tesis, surgen factores que deben ampliarse, como es el caso de los componentes del sistema didáctico mencionado, pues permiten la comprensión del discurso que enmarca la estrategia didáctica creada.

Es así como la didáctica universitaria, revestida de varios elementos, requiere de un sistema denominado sistema didáctico, que permita su combinación, su interrelación y su interacción. De acuerdo con González y Díaz el sistema didáctico está compuesto por varios componentes: "[...] el problema, la situación de un objeto que genera una necesidad en un sujeto que desarrolla un proceso para su transformación. El objeto, o parte del mundo real que se va a estudiar. El objetivo que el sujeto se propone alcanzar en el objeto para que, una vez transformado, satisfaga su necesidad y resuelva el problema. [...] El producto o resultado académico del aprendizaje. La evaluación, constatación periódica del desarrollo del proceso." (González y Díaz, 2008: 88-89). Otros componentes corresponden al contenido, el método, la forma y los medios, los cuales son de interés central en este trabajo, razón por la que tienen un tratamiento más amplio.

\section{El contenido: un componente revestido de información}

Hablar de contenido es referirse al concepto que engloba "[...] todo lo que se quiere enseñar" (Camilloni, 1998: 79), lo que comprende: informaciones, datos, conceptos, leyes, normas, principios, procedimientos, hábitos, destrezas, valores, actitudes; es decir, elementos y aspectos que se organizan con la intención de que los estudiantes aprendan, además de que comprendan, que ese contenido es importante y porta un significado en su futuro desempeño profesional y personal, de manera que sean cons- 
cientes de que su formación abarca tanto el saber científico, artístico, tecnológico o técnico, como los valores y las actitudes, desde una concepción filosófica, ética, política, estética y física. Por lo tanto, es posible organizar los contenidos formativos en conocimientos (objeto de estudio), habilidades (la correspondencia entre sujeto y objeto) y las actitudes y valores (importancia y significado que el estudiante les otorga a los objetos de conocimiento) (Álvarez, 1999), una serie de sistema complejo.

Se dispone de contenidos seleccionados, diseñados y organizados desde la información y que constituyen temas que involucran conceptos, ideas, principios, etc. Es en el espacio áulico donde se le da un significado, un sentido a esa información; además de valorizarla en su nivel de importancia. Se traducen las formas de pensar de los autores en un campo del conocimiento o en una temática determinada, con el fin de lograr su comprensión e interpretación para ampliar los aprendizajes y conocimientos de los estudiantes y que ellos puedan dirigirse, con esta transformación y apropiación, a otros espacios. Es recomendable que se priorice lo importante ante lo ligero; además, en concordancia con Litwin (2001): “[...] la tarea docente consiste en reconocer las características de esa información, el sentido con que se la dispuso [...] y, fundamentalmente, la construcción de criterios para reconocer esas características y el sentido original".

La selección, organización y comunicación de los contenidos son decisiones que deben tomarse en función del proceso didáctico y de criterios pedagógicos, y es en la institución educativa, concretamente en la figura del profesor -como académico y profesional- en quien recae esta función, al igual que el diseño del método y de las estrategias didácticas.

Los contenidos portan "[...] datos, informaciones, referencias" (Zabalza, 2004: 142) y modos, como métodos de investigación o enfoque de problemas que permiten acercarse a la 
realidad social desde las materias pertenecientes a las disciplinas, lo que lleva a la apropiación del estudiante de un conjunto de saberes y al desarrollo de habilidades intelectuales y estrategias de aprendizaje, pues los contenidos, más que un fin son un medio para acrecentar las capacidades y los procesos comprensivos.

No obstante, la comprensión real de un tema, de un dato, de una información, de un procedimiento, etc., requieren del conocimiento del contexto en que se inscribe ese contenido, puesto que las circunstancias y condiciones en que se presenta permiten explicar o justificar las razones de un evento; además que le dan sentido a un hecho o facultan su reconceptualización o posibilitan la visualización de las dificultades que rodearon el evento. Como sostiene Morin: "[...] hay que situar la información y los datos en su contexto para que adquieran sentido. Para tener sentido la palabra necesita del texto, que es su propio contexto, y el texto necesita del contexto donde se enuncia" (Morin, 2001: 44).

\section{El método: un recorrido entre la información y el conocimiento}

Desde la etimología, el método se retoma como un camino, y desde esta investigación se asume como un caminar de los sujetos involucrados en el acto educativo, que buscan transformar la información en conocimiento, realizando un recorrido por los SID, apoyados en una estrategia didáctica que, como dice el profesor Carvajal (2002), es un enfoque del método, o como lo expresa Díaz "[...] el método tiene que ver con una perspectiva global de las estrategias de enseñanza que sintetizan tanto las concepciones generales que tiene cada docente, como su punto de vista psicopedagógico; esto supone una visión cognoscitiva, humanística, genética y psicoanalítica que busca la 
apropiación del conocimiento, o bien, el descubrimiento y la construcción del mismo" (1997: 68).

Otra mirada explica que el método es una forma de enseñar los contenidos, en la cual se destacan el orden y la sistematicidad, y con estas características también se le llama construcción metodológica o se le inscribe en las estrategias de enseñanza (Litwin, 1997). Lo cierto es que se trata de un proceso reflexivo que organiza las situaciones de la enseñanza apoyándose en los medios en forma progresiva, hasta alcanzar un fin o, como argumentan Álvarez y González "[...] el método es la organización interna del proceso docente educativo. En él se manifiesta la lógica de este proceso cuya esencia es la comunicación entre los sujetos participantes para generar acciones en el mundo de la vida" (Álvarez y González, 2002: 52).

¿Qué se ve de nuevo en esta última visión?, la presencia de la comunicación como algo esencial en las acciones de profesores y estudiantes, lo que permite agregar que el método, además de ser la organización de una forma de enseñar, entraña un modo de comportamiento kinésico, social, intelectual y moral de estas personas.

¿Qué hay en el fondo de estas miradas? La complejidad de la variedad de formas para abordar el método, pues en ellas están presentes el modo como se construye una disciplina en el espacio de la clase, el papel de las teorías del aprendizaje y las estrategias didácticas como forma de concretar el ordenamiento de las etapas y los contenidos de la enseñanza entrelazados por la comunicación. En esas formas de hacer en el aula también participan el contexto, los intereses y las motivaciones de estudiantes y profesores, los saberes disciplinares, las relaciones interpersonales, la elaboración y transformación del conocimiento, y los fines educativos que se pretenden alcanzar.

En consecuencia, debe entenderse que el método no es estático, no es una receta que se limita al acto de enseñar, pues 
cada acto antes, durante y después de su ejecución debe reflexionarse como una vía que permite estructurar el proceso y superar la rigidez. En este sentido, es posible concebir métodos que favorezcan procesos de enseñanza y de aprendizaje conscientes de la realidad, que propugnen por su transformación desde los sujetos en formación con su actuar basado en conocimientos, habilidades, valores y actitudes. En palabras de Gadamer (2005: 36) esto significa que "[...] el método es más una puesta en práctica del saber, es decir, posibilita la formación; no es tanto llegar a tener un conocimiento de las cosas mismas sino llegar a tener una comprensión de la manera como hemos llegado a ser lo que somos, en una individualidad singular y concreción plena”.

Por lo tanto, en los espacios de las clases y las prácticas es necesario confrontar los contenidos con la información disponible en los sistemas de información documental, en tanto los textos se escribieron y publicaron en respuesta a una variedad de necesidades o sentidos, y son los espacios áulicos los lugares en los que se estimulan y fomentan los criterios relacionados con la crítica, la confrontación y la duda de los saberes enseñados con lo expuesto en los documentos; es decir, se dispone de un "[...] producto necesario e inherente al trabajo con la información. Esto quiere decir que la utilización de [estos SID] puede, al igual que cualquier herramienta, o bien potenciar la propuesta educativa o bien banalizarla al no reconocer que información no es igual a contenido para la enseñanza y para el aprendizaje" (Litwin, 2001).

Luego, ¿cómo se da el proceso de comunicación entre los sujetos educativos?

El proceso de comunicación se da entre varias personas que, como seres humanos, se destacan porque su expresión se encuentra poblada por una serie de hábitos, sentimientos y pensamientos (Peirce, 2005) que crecen en su interacción comunicativa 
y que se manifiestan a través de los signos, unos externos y otros interiorizados; el principal de ellos, para este caso, lo constituye el lenguaje, sea para comunicarse con otras personas (externalización) o consigo mismo (internalización) (Talizina, 1988).

La comunicación también se vive en el ambiente educativo, es inherente y punto central de los procesos de enseñanza y de aprendizaje en los que se da apertura a la participación, la discusión y el diálogo, pues como lo plantea Fernando González "[...] la base de la educación es precisamente la comunicación. A través de la comunicación se brinda la enseñanza y a su vez se ejerce una influencia educativa sobre el [educando] en un medio participativo" (1995: 2). Aquí se evidencia la existencia de la reflexión, los conocimientos previos y los prejuicios de los estudiantes, pero también los saberes que dominan, que comprenden; es decir, sus miradas y significados adquiridos en el contexto en el que se mueven. Estas comprensiones pueden diferir de las que porta el docente, es en ese momento cuando éste propicia el intercambio de saberes entre los participantes, incluyendo los suyos y los generados por la cultura, dando oportunidad a la crítica, al cuestionamiento. En este proceso de comunicación se da un intercambio y aprehensión de significados, de comprensiones e interpretaciones, en ocasiones, en forma espontánea, en otras planificada, lo cual, incide en los contenidos pero también en el aprendizaje, en las actitudes, en el pensamiento y en las expresiones de los partícipes.

En esta concepción, en la que la comunicación es un eje central del proceso educativo, se observa un modelo comunicacional dialógico (Pasquali, 1979), en el cual, los sujetos son activos, tienen voz y participan en la transformación de la información en conocimiento; es decir, se consideran interlocutores, lo que exige partir del otro en relación con el yo, y esto significa escuchar atentamente las inquietudes, intereses, experiencias, esperanzas, 
temores, etc. (Kaplún, 1998) de aquél, de ese otro para llegar a ser no un nosotros, sino dos tú, que se identifican, se escuchan y se respetan como un resultado de su formación y autonomía. Lo que significa "[...] que el acto educativo es eminentemente un acto comunicativo donde convergen múltiples lenguajes para generar acciones que abren las fronteras de la escuela hacia la vida y de la vida hacia la escuela" (González, E., 1998: 45). ${ }^{2}$

En el proceso de comunicación se encuentran tres tipos de lenguaje: el cotidiano, el científico y el estético (González, E., 1998); el primero es parte del lenguaje que representa al estudiante en formación, quien -se espera- se encuentra interesado por ampliar su léxico y su bagaje social, cultural y científico; los textos, los contenidos portan el lenguaje científico que, sin perder la rigurosidad y cientificidad, el profesor traduce a un lenguaje más comprensible para el educando, y el tercero es la producción que surge del aprendiz, lo que este sujeto en formación presenta como su producción en un lenguaje también científico, en virtud de haber vivido unos procesos de comprensión e interpretación surcados por el diálogo, por la conversación en el espacio áulico; este proceso lo habilita como un interlocutor válido para que se comunique con autoridades del objeto de estudio.

En consonancia, si bien en el diálogo se pretende llegar a un acuerdo en medio de la singularidad, también es cierto que reúne la multiplicidad, la diferencia y la divergencia, ya que el habla "[...] es un ejercicio despierto, activo, actual" (Vásquez, 2010, en línea) que genera calma con la discusión, haciendo de la conversación una vivencia del lenguaje, atributo de la humanidad, ya que "[...] el hombre es hombre en tanto que hablante" (Heidegger 1990: 11).

2 Se toma la escuela en sentido general y se deja el término para no alterar la cita; no obstante, se recuerda que esta investigación se enmarca en las instituciones de educación superior. 
Se constata la acción comunicativa que, en palabras de Habermas (1989: 137-138)

[...] presupone el lenguaje como un medio de entendimiento sin más abreviaturas, en el que hablantes y oyentes se refieren simultáneamente -desde el horizonte preinterpretado que su concepción del universo representa-, a algo en el mundo objetivo, en el mundo social y en el mundo subjetivo, para negociar definiciones de la situación que puedan ser compartidas por todos.

Esto significa que el proceso de comunicación no es simple, al contrario, es bastante complejo, y es de esta complejidad de donde surgen acciones significativas, con sentido para los sujetos que intervienen en él, facilitando el surgimiento o reafirmación de valores, principios, convicciones y actitudes que se reflejan durante la conversación, la discusión; esto es, la comunicación.

Cuando el diálogo entra al aula de clase (real o virtual), como un atributo del método, muestra la esencia del hombre, en el sentido de que él es un ser en conexión con el mundo, que busca contribuir a la historia, generar cultura y transformar la sociedad, realidad que Freire expresa de la siguiente manera: "el hombre no solo está en el mundo; está con el mundo... lo que lo hace ser un "ente de relaciones"” (Freire, 1972: 5). Relaciones en las que se aprende a hablar escuchando, lo que indica que se da un reconocimiento al otro como sujeto, puesto que "[...] quien tiene algo que decir debe asumir el deber de motivar, de desafiar a quien escucha, en el sentido de que, quien escucha diga, hable, responda" (Freire, 1997: 112), pues en estos actos se reflexiona para comprender e interpretar la realidad, superando la transferencia de la información y de contenidos, logrando en última instancia, comunicar lo que ha transformado; es decir, la síntesis. 


\section{La forma: entre el espacio y el tiempo}

La forma se refiere a los elementos organizativos (Álvarez, 1999) de los procesos de enseñanza y de aprendizaje que son esenciales para el desenlace del sistema educativo. El espacio en que se desarrolla la acción formativa y el tiempo en que ésta transcurre son los aspectos esenciales; cada uno con sus particularidades, lugares y momentos, en los que estudiantes y profesores interactúan para elucidar los problemas sociales que les atañen.

En el espacio tienen lugar una serie de interacciones e interrelaciones entre estudiante(s)-profesor(es), estudiante-estudiante, profesor-profesor, que generan diversos grupos de sujetos partícipes (Arroyave, 2001); y en éstas el profesor puede cumplir la función de acompañante, guía, asesor y/o tutor a partir de la comunicación dialógica con los otros actores del proceso, con el fin de que el problema social se asuma desde la individualidad (cada sujeto) y la colectividad (los grupos que se conformen).

En el proceso didáctico se proponen acciones intencionadas que buscan aprendizajes de responsabilidad netamente individual y otros de carácter grupal, por lo tanto, se proponen trabajos en parejas o grupos pequeños, se formulan proyectos de manera que se propicie la discusión, se presentan diferentes puntos de vista para incentivar la confrontación de opiniones y que los estudiantes perciban la solidez, o no, de sus fundamentos y argumentos. Con los avances tecnológicos es fácil que estas discusiones no se terminen en el aula de clase (cuando el proceso se desarrolla en la modalidad presencial), sino que se continúen en el ciberespacio con los foros de discusión, los chats y el mismo correo electrónico. Se recomienda que el trabajo con el otro o en grupo, en donde se viven momentos de confrontación del saber y de manejo argumentativo, se organice para que se dé la posibilidad de aprender a con-vivir (Arro- 
yave, 2001), pues el trabajo con el otro conlleva el proceso de comunicación, el diálogo; es decir, que el hombre además de estar en el mundo, esté con el mundo, ya que es un ser de relaciones y de interacción.

El componente tiempo hace referencia a las diferentes modalidades de interacción temporal; se habla de educación presencial, semipresencial, semiescolarizada, a distancia, virtual. Estos encuentros se estructuran en periodos de tiempo lectivo: anual, semestral, cuatrimestral, trimestral, semestral, mensual y en éstos, cada quince días, por semanas, por días y por horas, en jornadas diurna, nocturna o mixta, en forma sincrónica o asincrónica.

En el espacio áulico tanto el docente como los estudiantes se apoyan en medios didácticos como los SID, los cuales, a la vez que son medios didácticos, albergan espacios reales y virtuales distribuidores de información al servicio de la sociedad, bien para traducir el saber sabio en un saber por enseñar (el profesor), como para realizar la labor o acción que muestre su comprensión e interpretación de ese saber enseñado, es decir, su apropiación por parte del estudiante.

El espacio educativo ha sido subvertido por las TIC, pues su incursión ha modificado el quehacer cotidiano, así como el ambiente, el espacio y el tiempo de interacción e interrelación de las personas y, en ocasiones, de quienes participan en los procesos de enseñanza y de aprendizaje. Se habla de otro mundo, de un mundo nuevo, resultado de la informatización de la sociedad y que denominan ciberespacio, "[...] este ciberespacio es un nuevo entorno abstracto e invisible en el que circulan ideas e informaciones en forma de textos, sonidos e imágenes; es un espacio virtual y complejo de comunicaciones que diluye las barreras de tiempo y espacio; es una esfera social que cambia el destino de la humanidad" (Lopera, 2010: 42), impulsado por los microprocesadores, la fibra óptica, las telecomunicaciones. 
En él se tiene acceso a gran variedad de fuentes de información, además de que las personas logran comunicarse fácilmente, debido a que el usuario de un computador puede acceder a los de los demás; allí también tienen cabida los SID, pues se dispone de documentos virtuales ubicados a grandes distancias, pero que se pueden recuperar con un buen uso de los medios de búsqueda y localización de la información que necesitan los usuarios, a partir de una buena comunicación.

Esto indica que el mayor auge del ciberespacio se da por ser un espacio relacional que promueve el intercambio de información y facilita la comunicación e interacción de los usuarios de la red, lo que permite afirmar que es espacio, y que también es un medio; por lo tanto, en palabras de Aguirre (2001, en línea) se trata de "[...] un espacio que se genera cuando se producen ciertos tipos de comunicación". Acorde con esto, se puede decir, finalmente, que la constitución de este espacio ocurre por la interacción de los miembros de la sociedad, mediados por su capacidad de comunicación.

\section{Los medios didácticos ¿qué cohesionan?}

Los profesores se enfrentan día a día a un desafío: lograr la comprensión e interpretación de contenidos; es decir, una ampliación, y, a su vez, una fusión de horizontes por parte de los estudiantes ante un fenómeno, problema o acontecimiento y para ello se apoyan -en ocasiones- en dispositivos y materiales (Litwin, 2008), cuyo uso se puede planear en una estrategia didáctica; estos materiales y dispositivos se conocen como medios de enseñanza o medios didácticos. Cuando se persigue un objetivo se eligen y se adoptan, los que se cree, son los medios adecuados para alcanzarlo; esto muestra que la contemplación de los medios es algo previo al uso de los mismos, pues se busca "[...] la congruencia recíproca de todas las partes entre sí" (Gadamer, 2005: 550). 
Los medios, en general, se utilizan con el fin de acercar dos extremos o acercar dos cuerpos a partir de una acción física (Lalande, 1953) o mental, como sucede en el caso del proceso didáctico, en el que se busca que el educando comprenda e interprete un problema, un fenómeno o un suceso de su disciplina. Un extremo es el estudiante con sus prejuicios, los conocimientos previos, la reflexión, las experiencias, y el otro es el problema de la disciplina; entre ambos se encuentra el profesor quien es un puente, un mediador que se apoya en un medio (como los SID) para que esos dos extremos se acerquen y así contribuir al logro del objetivo.

Los medios se utilizan para guiar en forma organizada el aprendizaje de los estudiantes, desde los contenidos hasta su manejo. Además, se tiene el propósito de llamar la atención de los estudiantes, de conservar su interés en el tema; es decir, se busca motivarlos. Tratando de conservar esta motivación, los docentes se han adaptado a los cambios de los medios generados por los avances científicos y tecnológicos, como es el caso de los SID, que de los espacios físicos en bibliotecas han migrado a páginas web, bibliotecas electrónicas, repositorios digitales y bases de datos, entre otros.

Los SID, organizados para albergar la información que requiere la sociedad para avanzar en sus desarrollos científicos, artísticos y tecnológicos, se convierten en un medio dentro de los procesos de enseñanza y de aprendizaje, puesto que a ellos acuden tanto profesores como estudiantes para encontrar la información que les permitirá prepararse con anticipación para participar en el espacio áulico; participación que se da con los contenidos traducidos, con el saber enseñar por parte del profesor, y con las lecturas del estudiante, que lo habilitarán para discutir con sus compañeros y el mismo profesor, ese saber sabio que caracteriza al objeto de estudio de su disciplina. Si bien es posible discutir y confrontar un contenido desde los 
prejuicios, las experiencias, los conocimientos previos y la reflexión, no será igual esta acción si los estudiantes han abordado la temática basándose en los documentos que dan cuenta del conocimiento elaborado por otros y que para ellos, hasta ese momento, sólo es información.

Para la elaboración de gran cantidad de compromisos y labores académicas, sean en el aula o fuera de ella, también se necesita este medio, ya que en el ambiente universitario la apropiación de los saberes disciplinares requiere del conocimiento de los antecedentes (investigaciones, teorías, leyes, principios), del presente y de las tendencias; labor realizada por los científicos, académicos e investigadores y que se encuentra en los documentos. Pero, es tanta la información disponible que se requiere de un sistema que la albergue para que las personas sepan dónde acudir con el objetivo de localizar y poder así cumplir con sus compromisos de transformar la información en conocimiento, al tiempo que consolidan sus actitudes y valores. Los SID son medios didácticos que unen al estudiante y al profesor -en sus procesos didácticos- con la información que contienen los documentos; y también unen el acto de leer esa información (que incluye reflexión, análisis, comprensión e interpretación) con el acto de transformar ésta en conocimiento.

Luego de estas apreciaciones conceptuales, se presenta la cosa creada: la estrategia didáctica TRINCO, como unidad de sentido que surge de la fusión de horizontes de los capítulos que preceden a éste: la mirada histórica de los conceptos dato, información y conocimiento; el estado de la cuestión y el trabajo metodológico con los sujetos que viven la realidad a partir del acopio de la información. 
ESTRATEGIA DIDÁCTICA TRINCO:

TRANSFORMACIÓN DE LA INFORMACIÓN

EN CONOCIMIENTO

Esta estrategia se explica paso a paso, de acuerdo con el concepto creado y aportado por esta investigación; no obstante, la estrategia didáctica TRINCO es un todo complejo y como tal está conformada por las partes, las cuales, se interrelacionan entre sí y con el todo; y van de un lado a otro, así como éste va y viene. La estrategia - el todo- está conformada por fases y segmentos -las partes-, que a su vez son el todo de otras partes, como podrá leerse en este apartado.

Los datos son una parte de la información y ésta del conocimiento, es su insumo, puesto que es conocimiento comunicado, y en la educación universitaria se pretende que las personas que pasan por las aulas de clase egresen con el dominio conceptual, teórico, filosófico, epistemológico y práctico de un saber disciplinar determinado. Ese dominio es el conocimiento que ha pasado por un proceso de reflexión, análisis, comprensión e interpretación, cuando el estudiante en compañía de sus profesores y compañeros lo transforma, partiendo de los datos y la información como insumos básicos, y logra una síntesis. Para obtener esa transformación y síntesis, el profesor, en compañía de los bibliotecólogos, aplica una estrategia orientada hacia el desarrollo de habilidades, la apropiación del conocimiento y el despliegue de valores y actitudes en el manejo y uso de los SID, con la intensión de que el estudiante los use como medios en los que se encuentran las fuentes de información (impresas y electrónicas), que contienen la información del saber disciplinar y cultural que requiere en su proceso de formación como futuro profesional.

En la síntesis elaborada por el estudiante a partir de una fusión de horizontes con todas las partes de este proceso, se presenta un acto transformador de la información en conocimiento 
y del estudiante en profesional, al que contribuye la estrategia didáctica.

\section{Una organización para la estrategia didáctica: fases y segmentos}

El desarrollo de las acciones que se realizan en un proceso de enseñanza, enmarcadas en una estrategia didáctica, se denomina en primera instancia fase y son en total tres; a su vez, cada una de estas está comprendida por varios componentes, que se identifican como segmentos.

Las fases comprenden los estados sucesivos en que se organiza la estrategia; una fase es una parte o etapa de la estrategia que se organiza siguiendo el recorrido de un proceso de enseñanza con el que se pretende acercar a los estudiantes al manejo y uso consciente de los SID, hasta lograr que ellos, a partir de las fuentes de información que obtengan en esos SID, transformen la información en conocimiento como parte de su proceso de aprendizaje (objetivo). El recorrido de las fases está compuesto por una serie de pasos que conllevan un contenido cognitivo y sucesión de acciones, lo que permite referirse a los segmentos pertenecientes a la fase de la estrategia; es decir, se hacen presentes las partes de un todo (los segmentos son las partes de la fase, y las fases las partes de la estrategia). En palabras de Litwin, los segmentos se entienden "[...] como secuencias que aluden a un modo de interacción o tratamiento del contenido. La cantidad de segmentos está estrechamente vinculada con los contenidos que se desarrollan" (Litwin, 2008: 25).

Se comprende, las fases en su recorrido implican acción, y si la acción es estrategia, como lo dijo Morín (1994), entonces se confirma el desarrollo de los procesos relacionados con la enseñanza y el aprendizaje. 
La estrategia didáctica TRINCO, como se observa en el Gráfico 11, se organiza en tres fases; a saber, primera o Fase de Prejuicios e Indicios, segunda llamada Fase de Recuperación y Análisis, y tercera denominada Fase de Transformación y Síntesis. En tanto, los segmentos o las partes en que se divide cada fase conforman otro horizonte u otro todo, y se presentan en orden secuencial dentro de las fases de la estrategia didáctica, el cual puede ser alterado de acuerdo con las circunstancias; esto es, los segmentos pueden adaptarse a las condiciones de cada institución educativa, y a las características de los usuarios y de los cursos en los que se pretenda utilizar esta estrategia.

\section{GRÁFICO 11}

FASES Y SEGMENTOS DE LA ESTRATEGIA DIDÁCTICA TRINCO

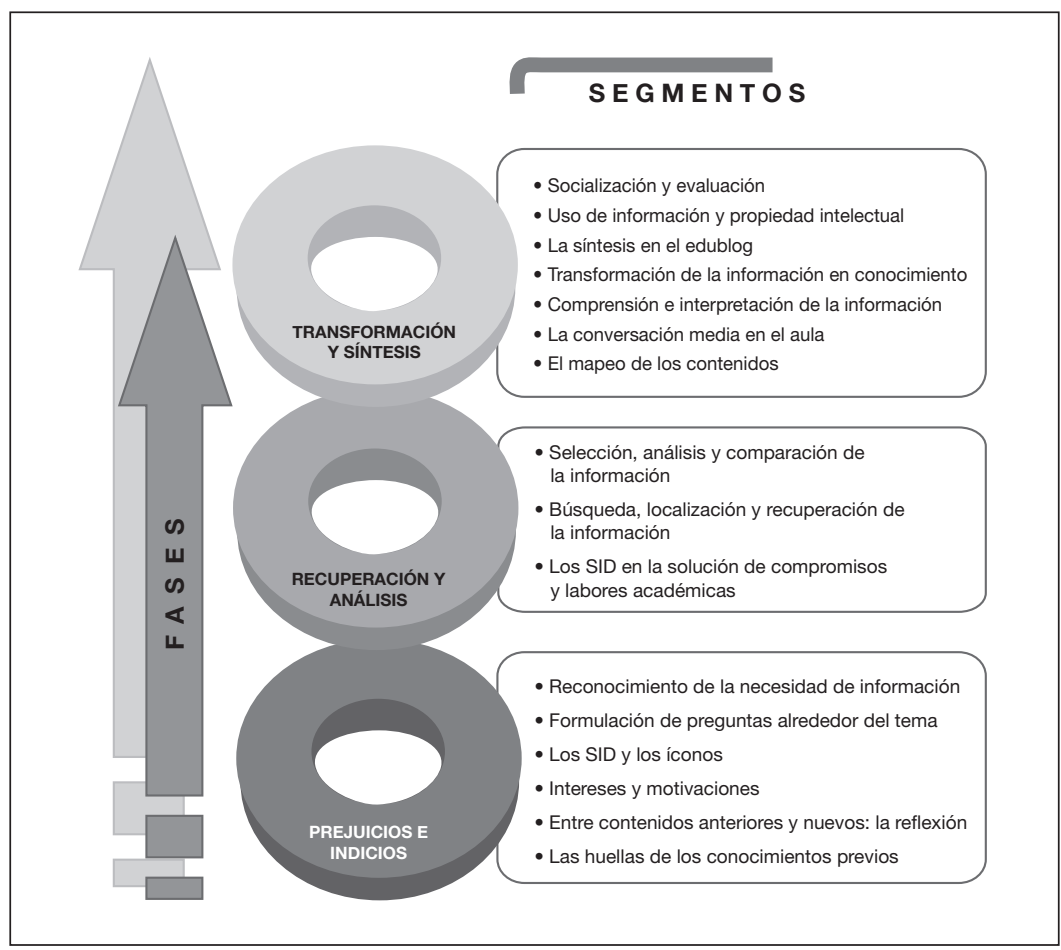


Para cada segmento se formulan preguntas o cuestionamientos a resolver que permiten definir los contenidos específicos de la fase, los cuales, se podrán modificar de acuerdo con las características institucionales de los sujetos y los objetos de estudio de las disciplinas; de igual manera en cada segmento se indican habilidades, conocimientos, actitudes y valores que adquirirán estudiantes y profesores como usuarios de los SID. Las preguntas permiten develar lo que está oculto o, por lo menos abren el camino para acercarse al tema y con ellas se puede vislumbrar lo que vendrá, lo que se abordará. En tanto las habilidades, los conocimientos, las actitudes y los valores surgen en los sujetos del proceso que, conscientemente toman esta acción como algo necesario en su proceso formativo para poder asumir la función de transformar la información en conocimiento.

\section{Fundamentación metodológica}

Desde la pedagogía se ha dicho que el modelo pedagógico es la representación ideal de un proceso didáctico compuesto por varias teorías y que éste se implementa a partir de un acto práctico que se materializa, entre otros, en un programa, un método o una estrategia. En el caso de TRINCO, su diseño y aplicación dependen de lo que se vaya a enseñar con el fin de que otros aprendan, ya que lo importante estriba en que el sujeto quiera aprender, sin desconocer que tantos métodos, como medios y forma (tiempo, espacio) alrededor de los contenidos, facilitan la comunicación entre los sujetos partícipes en los procesos de enseñanza y aprendizaje.

Igualmente, las acciones didácticas no son exclusivas del aula, esto permite decir que la identidad socio-cultural se recrea y crea en el contexto en el que se realiza la acción educativa, por lo tanto, las prácticas culturales hacen que los estudiantes se aproximen en forma diferente al conocimiento formal de las 
aulas (previsto en los contenidos). Luego, cabe preguntarse: ¿cómo demostrar que la estrategia didáctica es una alternativa que favorece la cultura de la información y posibilita la autonomía de los sujetos sociales que viven este proceso?

De acuerdo con Navaridas (2004: 2), "[...] la estrategia didáctica es una actividad docente centrada en el aprendizaje”. Por eso, cuando el profesor prepara la clase está realizando una labor reflexiva, intelectual y cognitiva; en tanto el estudiante realiza esta acción cuando busca comprender la información que le ha sido comunicada con los contenidos a partir de la enseñanza del profesor. Consecuentemente, con esta estrategia se intenta que profesores y estudiantes estén en condiciones de transformar los datos y la información en conocimiento, como un proceso que se lleva a cabo en los espacios áulicos universitarios (aulas, unidades de información, laboratorios, ciberespacio, etcétera.).

Con esta estrategia se pretende darles solución a varios problemas que se hicieron visibles con el acopio de la información en el trabajo de campo y que por su recurrencia se vuelven unidades de significación, en tanto otros surgen porque, a pesar de ser poco recurrentes las respuestas, no dejan de ser significativos. Entre los problemas a superar se encuentran:

- El desconocimiento que tienen varios profesores y estudiantes sobre los SID, lo que se refleja en que no los distinguen entre sí porque no presentan una definición aceptable de éstos, a pesar de que los consideran valiosos para el desarrollo de las clases.

- Es necesario concientizar a profesores y estudiantes de que los SID se pueden utilizar para divertirse, pues la literatura, las películas, la música también se obtienen a través de estos medios. 
- Entre la gama existente de SID, profesores y estudiantes utilizan básicamente las bibliotecas, las bases de datos y, en menor medida, los centros de documentación y los metabuscadores, y prácticamente nadie utiliza los repositorios digitales.

- Los estudiantes no hacen uso de los SID porque sus profesores les entregan los documentos que deben consultar para que los fotocopien, en esa medida no sienten necesidad de acudir a ellos para solucionar su necesidad de información cognitiva.

- El uso consciente de los SID por parte de los estudiantes es una responsabilidad conjunta que atañe tanto a estudiantes como a profesores y a bibliotecólogos, pero no se está asumiendo en conjunto.

- En el aula de clase se transmiten datos e información que se memorizan y repiten a modo de apropiación del conocimiento, pero realmente no se logra la transformación de aquéllos en conocimiento.

- En el aula de clase se desarrollan varias habilidades, no obstante algunas no se logran completamente, como las de escribir, refutar, clasificar, sintetizar y hablar, entre otras, que son esenciales en el proceso formativo de la educación superior.

Para superar estos problemas es necesario que con la estrategia didáctica TRINCO los sujetos que participan en el proceso educativo como usuarios de los SID, obtengan y desarrollen conocimientos, habilidades, actitudes y valores para su desempeño académico y profesional, desenvolviéndose ante situaciones y contextos diferentes, sin pensar en la existencia de verdades absolutas y dialogando con la incertidumbre. Como se infiere de lo que expresan los estudiantes en la encuesta de prejuicios: La estrategia didáctica debe impulsar el desarrollo 
de determinadas habilidades en las personas que participan de ella. Y, por consiguiente, en quienes pretenden transformar los datos y la información en conocimiento.

Si bien la estrategia TRINCO fue diseñada para enseñarles a los profesores a usar los SID para que los utilicen como medios didácticos en el espacio áulico, los beneficiarios finales serán los estudiantes, de allí que en las fases y los segmentos se mencionen éstos constantemente.

\section{Desarrollando las fases de la estrategia didáctica TRINCO}

\section{Fase de prejuicios e indicios}

Prejuicio: El hombre, un ser falible y finito (Gadamer, 2005), es un intérprete de su realidad y su quehacer, y por ello pretende aprender y conocer aquello que le genera inquietud por ser nuevo, diferente o incomprensible, independientemente de que sea contrario a sus ideas, creencias o prejuicios. Esa inquietud lo lleva a reflexionar y esta actitud a buscar en el horizonte lo extraño, lo nuevo, aunque para ello el intérprete deba estar atento a la forma como interfieren sus conocimientos previos y sus prejuicios, atención que también corresponde a la manera en que acepta que lo nuevo le modifique esas precomprensiones y esos prejuicios.

Los prejuicios, creencias, conocimientos previos y precomprensiones son un indicio de la historia del ser, modificada en el presente con base en la tradición que lo habita; es decir, son un horizonte en el que se fusionan pasado y presente, que impulsan una anticipación de la comprensión. Esto genera un cotejo entre lo conocido y lo nuevo, y lo extraño o incomprensible que se le presenta al ser y en lo que necesita encontrar un equilibrio (con sus prejuicios) para acercarse a la comprensión (Flores, 2009). 
Para llegar a este equilibrio, el ser debe estar dispuesto a dejarse modificar por el texto o por otros, y esos otros lo pueden hacer a partir de la conversación, en la que está presente la crítica como elemento indispensable de la elaboración de un saber, de manera que la comprensión lleve a formar un juicio, amparado en la discusión, donde tengan presencia diferentes puntos de vista los prejuicios, los conocimientos previos y las precomprensiones, que en la confrontación llevan a asumir la alteración del pasado en el presente.

Se trata del diálogo de raigambre socrática, en el que las preguntas van por delante, y en el que, al irnos haciendo conscientes de nuestros prejuicios y condicionamientos, lo otro y los otros dejan de ser invisibles y se hacen valer por sí mismos. Y puesto que darles la razón a los otros es sin duda algo difícil de aceptar, hay entonces que aprender siempre de nuevo, contra uno mismo muchas veces, a estar equivocado, a perder en el juego de la comprensión (Gutiérrez, 2008: 72).

Este punto muestra una de las condiciones inherentes de la comprensión, los prejuicios. No obstante, en muchas ocasiones, éstos no son reconocidos por el intérprete, o, a veces, éste no está en condiciones de reconocer cuáles son útiles o cuáles interfieren en la comprensión. Esto indica, como expone Gadamer, que el prejuicio

[...] quiere decir un juicio que se forma antes de la convalidación definitiva de todos los momentos que son objetivamente determinantes. [...] Prejuicio no significa pues en modo alguno juicio falso, sino que está en su concepto el que pueda ser valorado positivamente o negativamente (Gadamer, 2005: 337).

El término prejuicio más que una referencia negativa, se relaciona con una condición precedente a la comprensión; es la vía para la anticipación, para llegar a una interpretación, una vez que se completen los datos y la información que falta. En términos 
de Gadamer, el prejuicio le indica al sujeto "[...] la realidad histórica de su ser" (2005: 344) o como expresa Muñoz "[...] un prejuicio es una anticipación, un concepto formado antes de haber reunido y examinado la información pertinente [...] basado en pruebas insuficientes e incluso imaginarias [...] Se trata de ideas, emociones o creencias" (2001: 196) de intuiciones.

Indicio: El término tiene su origen en el latín "indič̌um", se refiere a un signo o hecho pasado y probable de que exista alguna cosa y del cual no se tiene un conocimiento directo. También se asume como un fenómeno o hecho que facilita inferir la existencia de otro que aún no se ha percibido. El indicio puede ser un simple dato objetivo que permite vislumbrar el descubrimiento de un hecho.

$\mathrm{El}$ indicio se reconoce también con sinónimos como objeto, huella, marca, rastro, señal, vestigio. Otros lo enmarcan como las evidencias físico-materiales que conducen al descubrimiento de un determinado hecho. Con los indicios es posible llegar a concluir la existencia o no de un hecho. Los indicios permiten descubrir hechos desconocidos.

De acuerdo con Peirce, el indicio (índice) es un signo en el que hay una relación de contigüidad con lo representado, con el objeto. Para asumirlo como indicio se requiere de un intérprete que comprenda si es una referencia o si se refiere a una relación existencial (Peirce, 2005). En palabras de Eco: “[...] en el reconocimiento de los indicios se individuan [...] ciertos objetos dejados por el agente causador en el lugar del efecto, de modo que pueda inferirse la presencia del agente a partir de su presencia pasada" (1991: 327), los indicios permiten, entonces, analizar las circunstancias que rodean al hecho.

En esta fase se contempla la búsqueda del pasado que acompaña al usuario (profesores y estudiantes), pues comprende los pasos iniciales para enfrentarse a la labor académica del 
tipo que es necesario resolver, reconociendo los indicios como elementos de comprobación de conocimientos previos, de prejuicios o de creencias que acompañan a la persona. El proceso de preguntar se vuelve central para discurrir por estos caminos y mostrarle al usuario que él ya ha pasado, en alguna medida, por los procesos de búsqueda y localización de la información; al igual que por algunos elementos del tema o actividad que pretende desarrollar para aprender a distinguir qué es una necesidad de información y cuál es la suya; unido a éstos, se encuentran los íconos, los cuales hacen parte de ese sistema que permite representar visualmente la palabra (Cohen, 1964).

Con esta primera fase de la estrategia didáctica TRINCO, se pretende sensibilizar y motivar a profesores y estudiantes frente al papel que cumple la información en su vida académica, profesional y personal como sujetos sociales.

GRÁFICO 12

FASE DE PREJUICIOS E INDICIOS

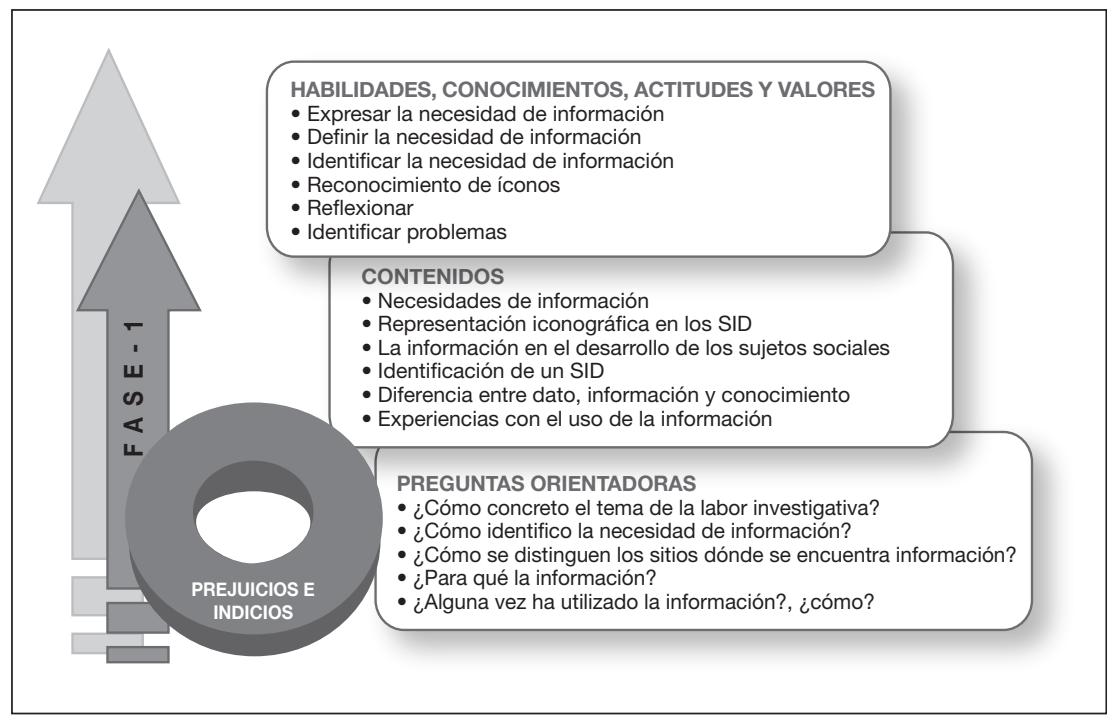


En el Gráfico 12 se presentan las preguntas que orientan los contenidos del segmento, los contenidos a desarrollar y las habilidades, conocimientos, actitudes y valores que, se pretende, lograrán los usuarios una vez finalice la fase. Posteriormente se explica cada segmento de la fase; este orden se conserva en las otras fases.

Las huellas de los conocimientos previos.

Cuando se habla de conocimientos previos se va tras las huellas de la historia cognitiva que acompañan al estudiante y al profesor, en concreto, al usuario, para enfrentarse a un compromiso o una labor académica. En esto es necesario que ellos tengan claridad sobre los prejuicios que los acompañan para abordar las lecturas de la información que pretenden acopiar, y de la misma labor que deben realizar. Como se dijo en párrafos anteriores, los prejuicios no son aspectos negativos sino que se dan como elemento que precede a la comprensión, por eso se dice que son juicios previos, elementos anticipatorios que permitirán llegar a la interpretación de la información. Igualmente, se propicia la revisión de los conocimientos previos sobre los SID que distinguen y manejan, y sus insumos esenciales: datos, información y conocimiento.

En el momento de abordar la estrategia, de vivenciarla, la pregunta es sobre la experiencia que se ha tenido con la información, lo que piensan de ella y cómo se imaginan que se puede llegar a ella.

En el diálogo que se sostiene en el espacio áulico se indaga por los conocimientos que poseen sobre el tema que pretenden abordar con el uso de la información y cómo creen que la información les puede ayudar a resolver la labor académica. 
Entre contenidos anteriores y nuevos: la reflexión.

Iniciar una sesión, clase o segmento de la clase, en la que se abordará una temática reciente o nueva, requiere de un proceso en el que se enlace este nuevo tema con lo visto en otras sesiones o contenidos, o que tenga una relación directa con lo que se incorporará. Para ello, se inicia con preguntas que activen los recuerdos ligados al tema propuesto, con el fin de reflexionar sobre éstos y darle sentido a lo nuevo dentro del proceso de aprendizaje, integrando la nueva información con las estructuras de conocimiento que ya poseen los estudiantes, al buscar la comprensión. La primera pregunta -más general- estará conectada con el objeto de estudio, o con la acción que se pretende llevar a cabo, posteriormente se formularán preguntas que orienten el rumbo por las particularidades del tema en cuestión de ese objeto de estudio.

Durante el desarrollo de la estrategia se trazan otras preguntas que van enlazando lo nuevo con lo que ya saben los estudiantes, con el fin de profundizar en el tema y de hacer referencia a las diferencias y semejanzas que se manifiestan entre lo nuevo y lo anterior. Este acto posiblemente requiera mayor claridad sobre las diferencias, lo que conduce a un proceso de búsqueda en fuentes de información que se encuentran en diferentes SID, o que están disponibles en el espacio áulico. Es posible que esta búsqueda lleve a modificar la secuencia de la clase, pues cuando se formulan preguntas motiva a buscar respuestas y soluciones, en ese momento o más adelante.

Asimismo, se da cuenta de lo nuevo que incursionará en la estructura de los sujetos en relación con los SID, aunque no se pueda establecer abiertamente cuáles han de ser esos nuevos saberes por depender esto del nivel en que se encuentren los usuarios. Unos requerirán mayor énfasis que otros, y así se tendrá que organizar el acto académico; con algunos usuarios será necesario empezar explicando qué es un enlace o link, o 
qué es un catálogo de acceso público (OPAC); mientras que con otros se procederá a aclarar que el conocimiento nuevo se relaciona con el uso de los lenguajes de interrogación, con los operadores booleanos, o el papel de los metabuscadores y directorios, o las bases de datos, entre otras cosas.

\section{Intereses y motivaciones.}

Estos aspectos son recurrentes para explicar el rendimiento académico y el aprendizaje en los estudiantes. En psicología se entiende por motivación "[...] un proceso psicológico que supone la activación de procesos cognitivos, afectivos y emocionales que dirigen la acción en forma deliberada o intencional hacia un objetivo" (Huertas, 2009: 165); es decir, se trata de una fuerza interior o empuje que lleva a alguien a actuar para alcanzar su meta o su objetivo. En tanto desde la ciencia de la información se dice que el interés por la información "[...] es el reflejo en la conciencia, colectiva e individual, de las necesidades de información. Presenta un carácter cognoscitivo, mezclado con la carga afectiva de la necesidad manifestada conscientemente" (Naranjo Álvarez, 2003: 18).

Una de las necesidades que generan mayor motivación en el sujeto es la necesidad de equilibrio, que presenta una relación directa con la acción cognoscitiva, puesto que son "[...] las contradicciones suministradas a nuestras representaciones bien por los otros o por las cosas, o bien por nuestra propia reflexión las que nos hacen experimentar la necesidad de aprender, metiéndonos en una especie de desafío para establecer una adecuación; es decir, un equilibrio entre nuestro saber y el mundo." (Not, 1992: 36-37), confrontación que sirve para dinamizar el proceso de aprendizaje.

El interés es otro elemento esencial en los procesos didácticos. En éste, el yo juega un papel central, esencialmente cuando se realiza una acción en la que se desplegará energía que impulsa 
a formular, a confrontar, a sustentar ideas, a desarrollar propuestas y objetos en relación con la comprensión del conocimiento que se quiere apropiar, pues allí el yo se vuelve consciente de quién es, muestra su carácter emocional y da cuenta de la importancia que tiene la valoración de la acción, pues ésta le indica lo que le espera en su desempeño dentro de un contexto diferente al de la institución educativa; además, parte de su realización como sujeto social y profesional, motivándolo a asumirla como un compromiso personal.

Entre el proyecto de vida del estudiante y el plan académico de su objeto de estudio (o en el caso del profesor: su proyecto de vida y su compromiso docente) se presentan nexos dialécticos que pueden incentivar su interés en el aprendizaje de los saberes y desempeños propios de la disciplina. De igual manera, las actividades que se desarrollan como parte de la acción metódica de los procesos de enseñanza y de aprendizaje llevan al estudiante a verificar las fortalezas que posee, así como sus deficiencias, aunque también descubre medios que desconocía o de cuya existencia sólo sabía parcialmente, y el uso de los cuales le hará más fácil el recorrido hasta alcanzar las metas que se trazó para ir desarrollando su proyecto de vida.

Es fundamental conocer estos aspectos del usuario, a quien se le va a enseñar a utilizar los SID, y si no es posible conocerlos se deberá generar un ambiente que ayude a su clarificación, para lo cual se debe partir del conocimiento de sus metas y objetivos; y organizar la acción en forma secuencial, exponiendo lo que deberá dominar y cómo proceder para lograrlo; habrá que fomentar la participación del usuario en las diferentes fases y "provocarlo" a resolver los compromisos académicos que incluyen diferentes grados de dificultad, y motivarlo a asumir los retos. La coherencia y el dominio en el discurso de quien enseña es fundamental para incentivar el aprendizaje, al igual que manifestar la relevancia y utilidad de lo que se va en- 
señar, señalando las relaciones de los conocimientos y las habilidades de lo se va a aprender para el futuro desempeño profesional.

Los SID y los íconos.

Los íconos, desde la semiótica y de acuerdo con Peirce (1988) son una clase de signos en los que se da una estrecha relación entre el significante y el objeto de la realidad significada por tal signo; es el signo que identifica una idea o un objeto.

El uso de los íconos muestra y recrea la posibilidad óptica que los sujetos poseen en contraposición a un alfabeto que es limitado (Ricoeur, 2006). Se define la iconicidad como "[...] la revelación de una realidad más real que la realidad ordinaria" (Ricoeur, 2006: 54), pues los íconos, al contraer y expresar la realidad en miniatura, la están re-escribiendo.

Esta reescritura icónica en la informática se asume con las imágenes gráficas pequeñas, utilizadas para acceder rápido y directamente a los programas, las aplicaciones, los archivos y las acciones que se ejecutan, íconos como las unidades de disco, las aplicaciones y los documentos, los emoticones, el procesamiento de la información, todo ello dentro de los entornos gráficos. Se logra establecer así una relación entre el ícono y lo que representa "[...] por ejemplo, el ícono de un diskette sustituye a la orden de "guardar", el de una lupa, a la orden de "buscar" y el de una carpeta, representa a "los archivos»" (Lanzillota, 2005, en línea).

Por lo tanto, los usuarios expresarán cuáles íconos de los diferentes SID distinguen y saben interpretar, de manera que los entornos gráficos se vuelvan familiares al momento de iniciar los procesos de búsqueda y localización de la información. 
\ Formulación de preguntas alrededor del tema.

La pregunta en sí es un medio que permite un acercamiento cauteloso y hábil para descubrir lo que está oculto; es decir, los indicios para acercarse a un objeto susceptible de ser conocido, los documentos y los SID en los cuales se encuentran aquéllos.

Todo preguntar es buscar. Todo buscar tiene su dirección previa que le viene de lo buscado. Preguntar es buscar conocer 'qué es' y "cómo es" un ente. El buscar este conocer puede volverse un «investigar» o poner en libertad y determinar aquello por lo que se pregunta. (Heidegger, 1971: 14).

Con la pregunta y sus posibles respuestas, se abre paso al horizonte de la comprensión de lo que se pretende hacer. Es preguntarse por el tema en cuestión, por el contexto en que se desarrolla, por los intereses del usuario, por la importancia dentro de la disciplina y la ciencia, por la delimitación del problema, por la forma como se debe presentar la labor académica, por la forma como se acerca el usuario a los SID y cómo los utiliza, por el modo en que usa el lenguaje de búsqueda y cómo reconoce su necesidad de información.

Con esta mirada se ubica al usuario en el tema o labor que intenta resolver, preguntando los detalles específicos, de manera que él comprenda cómo manejará el tiempo que necesita en la solución y las acciones que debe ejecutar, como la búsqueda de información, y también la lectura y la preparación de los resultados.

Reconocimiento de la necesidad de información.

La necesidad se entiende como la situación de carencia interna o externa que experimenta un sujeto. En éste se presentan necesidades de información porque la existencia de ésta tiene un propósito que la lleva a ser necesaria (Prasaad, 1992), propósito que puede estar ligado con la solución de un problema, 
la ejecución de una acción, la preparación para realizar una práctica, la comprensión de un contenido, el manejo de un medio didáctico, etc., esto depende del ambiente y del contexto en el que se mueve el sujeto.

Una necesidad de información es aquella en la que el sujeto manifiesta la situación problemática en la que se encuentra, de allí que muchas veces sea él quien deba buscar la información la cual permita satisfacer esa necesidad. A menudo, ésta se comprende cuando se toma conciencia del vacío que hay en una explicación, exposición, presentación o disertación, y se admite que esa situación hay que transformarla con ayuda de la información que se encuentra en diferentes SID.

Volviendo a Not (1992), éste describe en forma precisa las necesidades que pueden manifestarse en un sujeto que participa en el proceso didáctico:

Por una parte, está la necesidad de expresarse, de decir lo que uno sabe y que viene a completar o a cuestionar lo que los otros creen o ven; es tan viva que ni el temor, ni la desconfianza o la envidia la han sofocado. Por otra parte está la necesidad de informarse o estar informado. Los medios adoptados para satisfacerla no son siempre de orden social. Suscita la necesidad de interrogar las cosas, es decir, la necesidad de observar y de experimentar, aunque esto fuese sin plegarse a los cánones de la observación y de la experimentación científica. De ella procede el deseo de interrogar al otro para compartir con él el conocimiento que domina y, aunque menos espontánea, la necesidad de interrogar los documentos entre los cuales están los textos. Quizás se encuentra aquí una de las raíces profundas de la curiosidad (Not, 1992: 41).

De esta cita se infiere la necesidad de información como el reconocimiento, por parte del sujeto, de una carencia o la aceptación de incertidumbre frente al conocimiento o la información en relación con un acontecimiento, fenómeno, situación, objeto, problema, acción o tema; situación que se crea por factores externos (ambiente, contexto) o internos (habilidades, cono- 
cimientos, valores, actitudes), lo que genera una sensación de insatisfacción que mueve al individuo a actuar para satisfacer la necesidad cognoscitiva.

El hombre siempre ha tenido una necesidad de información y eso ha permanecido incólume; no obstante, las necesidades de información son muy específicas y en esa medida es preferible que la búsqueda de información la realice cada uno.

En ese momento es necesario que el usuario aclare por qué y para qué necesita la información, el nivel de profundidad de ésta, los idiomas, la cobertura geográfica, los periodos de tiempo, etc., todo aquello que requiere de acuerdo con la acción por realizar.

\section{Fase de recuperación y análisis}

Recuperación de la información. Si recuperar se entiende como volver a tener algo, recuperar información se refiere a disponer de nuevo de una información que en un tiempo pasado (minutos, horas, días, meses, años, siglos) alguien produjo (terceras personas o uno mismo); es un proceso en el que se realizan una serie de acciones orientadas a buscar y encontrar información relevante de los fondos documentales de los SID, para solucionar las necesidades de información de los usuarios. Esta acción es un proceso que se conoce en la ciencia de la información como Recuperación de Información (en adelante RI).

Los SID son los entornos adecuados para lograr la RI, pues en ellos se dispone de documentos de apoyo para una función institucional (los SID universitarios que apoyan a estudiantes, profesores e investigadores) o porque albergan documentos multigenéricos, caso de algunas aplicaciones tecnológicas como la Web que se hacen visibles por Internet y que alojan centenares de documentos. 
Para la RI se necesitan recursos como las computadoras, pues ellas ayudan a agilizar la recuperación desde, por ejemplo, las bases de datos que son SID completamente automatizados, o desde los OPAC (catálogos de acceso público en línea) de las unidades de información; además, la computadora es la herramienta para consultar las Web. No obstante, algunos SID también cuentan con sistemas manuales para la RI, catálogos por tarjetas, tesauros e índices impresos, entre otros.

Una de las características de la RI es el lenguaje de recuperación que es -por ahora- eminentemente alfabético y en ocasiones alfanumérico, y la descripción de los documentos que se obtienen se hace también en un lenguaje textual aunque se busquen documentos no textuales como fotografías, películas, etc. (Abadal y Codina, 2005). El objetivo de la RI es solucionar las necesidades de información cognitiva que expresa el usuario.

Las acciones de este proceso son:

- El uso de términos y descriptores, con los que se representa el contenido semántico de los documentos (Codina, 2002) y las necesidades de información; se pueden utilizar términos del lenguaje natural (indización) o descriptores que son los términos del lenguaje documental (autor, título, materia, palabras clave, etc.). Éstos se pueden combinar haciendo uso de los operadores lógicos, concretamente los booleanos (or, and, not, \&, entre otros)

- La selección de la información es, en esencia, la recuperación: se escogen los documentos más relevantes para solucionar la necesidad de información, teniendo en cuenta los contenidos o temas tratados o algunos elementos del texto; esto es, fecha de publicación, idioma, país productor, país editor, o la combinación de estos factores.

- La ordenación de documentos seleccionados de acuerdo con su relevancia para satisfacer la necesidad de información. 
- La interconexión e hipertextualidad, en relación con los caminos y las estructuras de navegación dentro del mismo documento o entre documentos, puede hacerse por secciones (problemas, metodología, antecedentes, objetivos, conclusiones, resultados, citas bibliográficas, bibliografía, etc.), títulos y subtítulos, etc. (Abadal y Codina, 2003).

- La "Categorización: asignación de cada documento a un grupo, clase o subclase de un cuadro de clasificación, taxonomía u ontología" (Abadal y Codina, 2003, en línea).

- El resumen, con la información principal del documento, para-cuando se pueda- evitar la lectura completa.

- La representación gráfica, en ésta se incluyen y relacionan los principales términos, conceptos o procesos que contiene el documento, por ejemplo cuadros sinópticos. Esta representación también puede hacerse en una cartografía mental: mapa conceptual, mental, nocional, proposicional, etc.

La RI se realiza en los OPAC, las bases de datos en línea, las bases de datos en CD-ROM y las aplicaciones en Internet (páginas Web, buscadores, metabuscadores, etc.). Este proceso permite desarrollar habilidades y adquirir conocimientos para buscar y utilizar eficazmente recursos de información y para saber usar las tecnologías y aplicaciones donde se almacena la información; esto implica saber cómo preguntar, buscar, acceder, localizar, analizar, comparar de forma crítica la información, así como organizarla con miras a su transformación en conocimiento (Salvador, 2002).

Se busca que el usuario sea autónomo en su búsqueda, que utilice eficazmente los diferentes SID para la RI y que esté en condiciones de seleccionar la información de calidad para resolver su necesidad informativa, sin desconocer que puede buscar asesoría con el bibliotecólogo, porque, como lo expone 
Salvador (2002: 192) "[...] la aparición y el uso de las tecnologías de la información facilitan el acceso a la información por parte de cualquier usuario que, paradójicamente, se enfrenta a una situación donde cada vez hay más información, fragmentada en diferentes formatos y medios, y almacenada en múltiples fuentes de información".

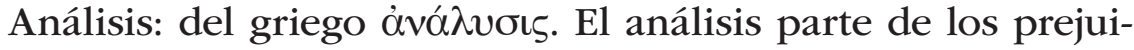
cios y la reflexión de los conocimientos previos para acercarse a la comprensión.

Se entiende por análisis la desintegración de un todo (una obra de arte o de literatura, un tema, documento, sistema, campo de estudio) en las partes que lo conforman (principios, elementos, entradas, salidas, trazos, aspectos, estructura, naturaleza, significados, funciones, etc.), para identificarlas, clasificarlas, distinguirlas y así estudiar las relaciones que guardan, y observar lo que ocurre con el todo en caso de que se modifiquen o eliminen algunas de esas partes, o como lo expresó Comenio en el siglo XVI:

El análisis consiste en dividir una cosa en todas sus partes; es el fundamento primero y más profundo de todo conocimiento. Las cosas antes de dividirse son indistintas y confusas no presentándose bien, sino perturbando a los sentidos y al entendimiento. Una vez se distinguen sus partes se produce luz. El análisis será triple: 1 . La distinción o discriminación de un todo en relación a los otros todos. 2. La partición que separa o divide a un objeto en partes. 3. La distribución, que divide los objetos en especies (Comenio, 1992: VII: §16).

Cuando se realiza con los textos o documentos, los prejuicios (por tradición, por conocimientos previos, por creencias, por vivencias, etc.) facilitan el encuentro. El análisis de las estructuras facilitará encontrar los sentidos en relación con los prejuicios de quien aborda el texto, puesto que "[...] analizar es 
ir de lo superficial a lo profundo, de la expresión al contenido, de lo que dice a aquello a lo cual se refiere; es decir, la significación emerge de su propia estructura" (González, E., 2006: 49).

El acto de analizar lo realiza un sujeto revestido de su experiencia, de su vivencia, es decir, del mundo de la vida; ahí se mueve en un contexto determinado que le facilita leer un texto y descomponerlo en sus partes, en sus estructuras, identificando los temas y conceptos más relevantes de los documentos que se localizaron, para compararlos en procura de su interpretación, poniendo a prueba sus prejuicios, sus conocimientos previos y sus reflexiones, de modo que pueda apropiarse del texto.

Con esta referencia conceptual, en la práctica es válido acercarse a Not (1992) cuando haciendo alusión a lo que escribiera Rousseau en Emilio, expresa que algunos profesores pretenden que los estudiantes realicen tareas excelentes de investigación, sin que éstos se encuentren preparados para recolectar la información que requieren, y quienes, además, ignoran dónde están las fuentes de información más idóneas, pues no conocen el proceso que exige esta recuperación; e igualmente, desconocen los tipos de fuentes de información que les pueden servir y los criterios de selección para determinar si son adecuados para su tarea.

De allí que con la estrategia didáctica TRINCO, el usuario tiene un acercamiento directo a los SID, sean éstos electrónicos o físicos, y comprende cómo con ellos puede empezar a resolver su labor académica; para ello se le enseñan estrategias de búsqueda, localización, recuperación y análisis de información que lo habilitan para que él, posteriormente, haga todo sólo. En esta fase se orienta y enseña al usuario en la recuperación y el análisis de la información (desde el punto de vista de la ciencia de la información), para lo cual se utilizan los recursos y medios que sean necesarios. 


\section{GRÁFICO 13}

FASE DE RECUPERACIÓN Y ANÁLISIS

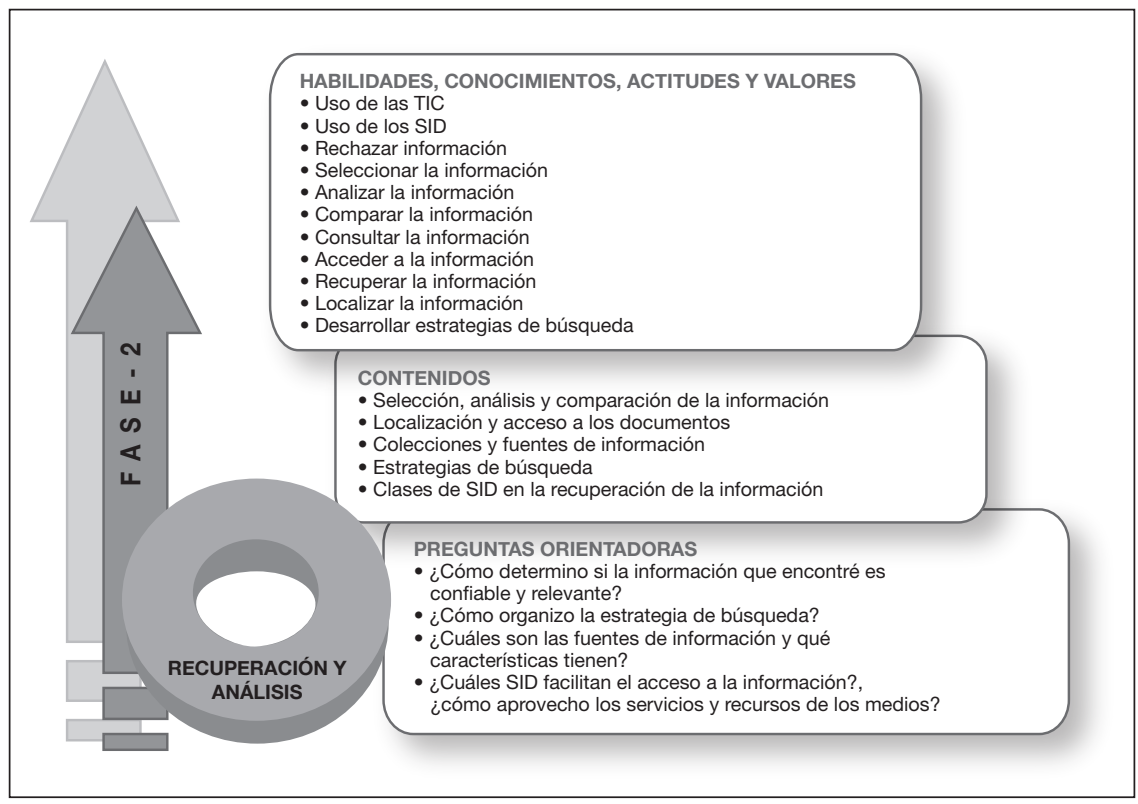

En este gráfico se observan las preguntas que orientan los contenidos del segmento, los contenidos a desarrollar; las habilidades, conocimientos, actitudes y valores que alcanzarán los usuarios una vez finalice esta fase.

Los SID en la solución de compromisos y labores académicas. Las labores y los compromisos académicos que adquieren los sujetos partícipes del proceso didáctico forman parte del método y pueden ser de carácter práctico o de reflexión.

En ambos casos es necesario pensar cómo resolverlos, lo que contribuirá a la comprensión de su nivel de complejidad (Litwin, 2008). Esto permite ver las acciones que realizan los estudiantes en su interés por cumplirlos y lograr el aprendi- 
zaje, además de prever las habilidades, los conocimientos y las actitudes que obtendrán.

Los profesores, por su lado, también deberían realizar previamente los compromisos o las labores académicas que les solicitan a los estudiantes, a fin de comprender los errores y las dificultades de las mismas, de esta forma será posible orientarlos para obtener mejores resultados.

La realización de las labores conlleva, regularmente, un trabajo independiente con la orientación del profesor, aunque esto se pueda realizar en forma individual, en parejas o en grupos. "La determinación de la [acción] implica delimitar aspectos como la secuenciación, el tiempo, los materiales a utilizar, etc." (Zabalza, 2004: 58). Estos compromisos pueden requerir de medios didácticos que faciliten su cumplimiento, como es el caso de los SID, cuando se precise de normas, leyes, conceptos, proposiciones, resultados de otras investigaciones, etcétera.

Finalmente, es claro que los compromisos y las labores académicas favorecen la ampliación de la experiencia de vida y del aprendizaje en los estudiantes, pues les brinda espacios y momentos de interacción con los saberes, con los medios didácticos, con otros sujetos y con ellos mismos.

Los usuarios en los segmentos anteriores debieron referirse a los SID que utilizan y a cómo lo hacen, este es el momento de profundizar en ellos y de mostrar, de acuerdo con la información que se acopió anteriormente, las características de estos sistemas y concentrarse en aquéllos que permiten optimizar los procesos de búsqueda, localización y recuperación de la información de acuerdo con la necesidad que se detectó.

Frente a este uso de los SID se presenta la unidad de sentido que surgió con una de las preguntas de la encuesta de prejuicios aplicada a los estudiantes, y que permite ver una de las funciones de éstos: los SID facilitan los procesos de enseñanza y de aprendizaje, de allí que su uso y su tipo pueda variar de acuerdo con 
los objetivos planteados y las actividades a realizar, las cuales pueden estar en la investigación, los trabajos de clase, el esparcimiento y la cultura. Esto requiere conocimiento del papel que cumplen; su uso depende de las necesidades e ideas del usuario.

Búsqueda, localización y recuperación de la información. En este proceso se aclara lo que es una búsqueda simple; además de profundizar en lo que es una búsqueda más elaborada, reflexionando y argumentando en la importancia y necesidad de ésta haciendo uso de los operadores booleanos, así como el papel que juegan éstos dentro del proceso. Aquí se analiza detalladamente el proceso de búsqueda ejecutado por cada uno, que consiste en comparar las diferentes indagaciones que se han realizado, incluyendo operadores y búsquedas simples.

Lo más indicado es enseñar a planificar una búsqueda: determinar los idiomas en los que se puede realizar y recuperar la información; reconocer los recursos de que se dispone y las características del contexto en el que se encuentra, esto implica dónde buscar: espacio tradicional físico: biblioteca, centro de documentación, mediateca, archivo, hemeroteca; entorno digital o electrónico haciendo uso de CD o DVD, Internet y sus aplicaciones: motores de búsqueda, bases de datos, directorios, webs específicas, directorios especializados, etc. Como indica Monereo (2009: 94) "[...] adoptar uno u otro dispositivo de búsqueda dependerá [...] de distintos parámetros como: la interactividad que ofrece el medio, la facilidad para modificar la búsqueda, la necesidad de dispositivos especiales para el acceso, la permanencia de la información [...]", además del tiempo y el esfuerzo que implique.

Una vez aclarada esta situación, se elegirá el recurso de búsqueda (catálogo en línea, web, base de datos, etc.), el uso de palabras clave generales o específicas y precisas, el establecimiento 
de categorías semánticas relacionadas (construcción de un árbol) y el uso de operadores booleanos.

Se explica cómo los SID se caracterizan por la variedad de fuentes de información que se pueden localizar; las cuales, en bibliotecas, centros de documentación y bases de datos, se organizan de acuerdo con las características de contenido, periodicidad en su publicación y en la función que cumplen. Asimismo, se pueden localizar en distintos soportes y responder a diversas temáticas. Las fuentes de información son los materiales y productos bibliográficos que existen en los SID para acceder al conocimiento generado por el hombre. Igualmente, se explica la diferencia entre las fuentes de información y las diferentes colecciones de las que se dispone en los SID.

Se especifica cómo:

- Planear una estrategia de búsqueda de acuerdo con la necesidad de información.

- Organizar jerarquías y relaciones de subordinación entre los distintos términos y palabras de los conceptos.

- Precisar los términos de la búsqueda.

- Comprender el papel que juegan las fuentes de información de referencia para precisar la búsqueda.

También se elucida cómo acceder a las fuentes de información que no se localizan en la unidad de información o en las bases de datos, a partir de los servicios que se tienen en el SID de la institución educativa para recuperar estos documentos.

४ Selección, análisis y comparación de la información. Con el segmento anterior se dio inicio a éste al realizar la comparación a partir de los parámetros establecidos, pues la búsqueda arroja resultados que muestran dónde localizar las fuentes y los procesos que se deben seguir para su recuperación (si es 
de acceso abierto, si requiere de suscripción, o si se debe solicitar desde la unidad de información o se encuentra disponible en papel). No obstante, antes de recuperarla se verifica que la información encontrada sea correcta (confiable por su procedencia y autoría, que no haya caducado, que sea original) y que responda a la necesidad detectada.

Otros parámetros que permiten evaluar la relevancia y pertinencia de la información son: el orden que ocupa en el listado recuperado; el índice de afinidad que muestran algunos buscadores; la similitud entre el tema y el título del documento; la cercanía con el resumen del documento o con los primeros párrafos del mismo, y la extensión y profundidad del tema en cuestión. También se debe tener en cuenta el tono, la sintaxis, el vocabulario, el formato, a quién va destinado, la relevancia de los enlaces que incluye y su facilidad de acceso, así como otras opciones de búsqueda que presente. No debe desconocerse la reputación de los autores y el acceso a su dirección electrónica, esta reputación también cobija a los sitios donde se aloja la información en Internet; la citación del documento en sitios de calidad reconocida, la actualidad de la temática (si así se requiere), coherencia y claridad, número de consultas, etc. (Monereo, 2009).

Estos elementos permiten seleccionar la documentación pertinente. Posteriormente, para evaluar en forma rápida su idoneidad se recomienda llevarla a un nuevo documento, el cual se organiza con los aspectos planificados por el usuario cuando inició la búsqueda y se verifica que responda a estos, de manera que se pueda empezar el proceso hermenéutico para transformar la información en conocimiento. De igual manera, se evalúa también al usuario y al proceso de búsqueda, los que permitirán mostrar errores y aciertos; y se contrasta el plan inicial con los cambios que se dieron durante el proceso y los resultados que arrojó, en lo cual se incluye la eficacia de los procedimientos. 
En este segmento el usuario debe ser consciente de que no toda la información que recuperó será útil, por eso él debe empezar el proceso de selección preguntándose lo siguiente: ¿qué información ofrece la fuente?, ¿qué obtuve?, ¿qué es lo importante de la información que hallé?, ¿responde a mi necesidad de información? Además, tendrá en cuenta las siguientes pautas para el análisis y la comparación:

- Determinar si la información presenta datos, opiniones, propaganda, punto de vista, resultados de investigación, reflexión sobre un tema, etcétera.

- Revisar las ideas principales y las palabras clave que permiten determinar la pertinencia y relevancia de la información.

- Actualizar la información, y para ello se observa si la fecha de publicación es reciente o muy antigua.

- Averiguar si se trata de una fuente primaria, secundaria o terciaria.

- Indagar si la información se encuentra sólo en obras de referencia o hace parte de otra clase de fuentes.

- Averiguar la autoridad de quien escribe, lo que permite determinar si la fuente y la información son confiables o no.

- Saber si la obra presenta diferentes puntos de vista sobre el mismo tema.

- Verificar si la obra tiene claros los objetivos que persigue.

\section{Fase de recuperación y sintesis}

Transformación y síntesis. Los recuerdos, las remembranzas son parte del sujeto, del ser en la tradición y acompañan al objeto de conocimiento; en tanto sujeto intérprete, el objeto es susceptible de ser conocido. Esas remembranzas y tradiciones implican transformación en ambas, se recupera y transforma el pasado y con él los prejuicios, conocimientos previos y las re- 
flexiones del sujeto. Ese horizonte de la tradición conversa con el presente para recuperar e incorporar el pasado en lo nuevo "[...] lo cual no implica ni su reconstrucción ni su recuperación sino, precisamente, su distorsión y transformación" (González, M., 2003: 90). Es decir, la cosa vive una transformación continua, permanente.

Como ser finito el sujeto vive en y con las tradiciones, unas veces conocidas y otras no; por momentos es consciente de su existencia y en otros ésta pasa desapercibida; esas tradiciones conforman las creencias, los prejuicios del ser ahí y están presentes para lograr la transformación, pues el horizonte del pasado con sus prejuicios, conocimientos previos y precomprensiones, como parte del ser que se transforma, está en movimiento apuntalando una interpretación en el presente; es decir, mana la fusión de horizontes con un nuevo sentido.

No hay nunca un acercamiento limpio y objetivo a la tradición: el intérprete se acerca con todo y sus prejuicios, con su propia tradición, con su propio ser, con su propio estado de ánimo, con su propio comprender, con su propia conciencia. Por tanto, cada acercamiento y cada comprensión de la tradición es diferente, no sólo porque cada intérprete es distinto y varía la interpretación de intérprete a intérprete, sino porque incluso él no se mantiene idéntico a sí mismo: en tanto ser ahí cambia y deviene constantemente (González, M., 2003: 95).

En esa medida es posible decir que la interpretación del texto es inagotable, y en consonancia con esto pervivirá en una constante creación, formación y transformación. Por lo tanto, la interpretación se dirige a un espacio abierto que se puede llenar de diversos modos (Gadamer, 2006a).

En esa interpretación que lleva a la transformación está presente la estructura dialógica, allí conversa la tradición del pasado con el presente, acompañados por los prejuicios y creencias, logrando mediante la comprensión la transformación de ambas partes; esto es, se da una metamorfosis en ellas. Catoggio, dice 
al respecto "[...] la fusión de horizontes lo que hace es transformar mediante un evento temporal, el horizonte de sentido; sus elementos constituyentes, si se quiere, del sujeto comprensor y el objeto comprendido, creando una nueva obra" (Catoggio, 2008: 121). Se presentan, por consiguiente, dos momentos: en el primero el ser intérprete se une con lo que comprendió, y en el segundo surge un nuevo texto, un nuevo horizonte, la cosa nueva, como resultado del primer momento.

De la conversación que se sostuvo con los bibliotecólogos y los profesores usuarios durante el trabajo de campo, en relación con estos conceptos, surge la siguiente unidad de sentido: la transformación la hace el individuo; y quien hace la transformación sufre repercusiones en su propio yo, esto es, se reconstruye. Para realizar la transformación de la información en conocimiento es necesario saber cómo, puesto que para tener conocimiento se debe disponer de información, pero la información no constituye el conocimiento. La información se transforma cuando el sujeto, mediante una labor cognoscitiva que implica lectura, análisis, comprensión crítica e interpretación, la ubica en un contexto temático, problemático, social, real y realiza una nueva síntesis en un contexto actual, en un espacio geográfico real; en ese momento se transforma en conocimiento. La nueva producción, el nuevo texto y su socialización se caracterizan por los argumentos, los puntos de vista, la posición crítica, el análisis y las conclusiones. Es un compromiso tanto del profesor como del estudiante.

Ese nuevo texto, el nuevo horizonte, E. González (2011b) lo denomina síntesis y se refiere a él como una re-creación de algo que ya existía, pero que se modificó; amplía esta apreciación citando a Betti: "[...] el intérprete es llamado a recorrer una experiencia de vida que pertenece al pasado, es la síntesis, donde reconoce y reconstruye" (Betti, 1971: 38, cit. por González, E., 2011b: 54). 
La síntesis muestra la nueva composición elaborada por el lector, enmarcada en el proceso hermenéutico: prejuicios, reflexión, análisis, comprensión, interpretación y escritura. En consonancia, puede decirse que el lector asume el papel de autor en una comunidad, con un código específico de comunicación reflejado en el lenguaje. O como lo expresó Comenio "[...] la síntesis es la recomposición de las partes en un todo" (Comenio, 1992: VII: §16), como una ventaja para el conocimiento, en su consolidación y transformación.

La transformación de la tradición del pasado en fusión con el presente la realiza el ser que se deja decir al confrontar sus prejuicios, precomprensiones, conocimientos previos y creencias con el texto que lo aborda; reflexiona y para ello lo desglosa, lo descompone en sus partes más simples y las compara hasta llegar a comprender cada una de ellas en sus relaciones internas, lo cual, le permite interpretar el sentido de lo expresado allí para llegar a un nuevo texto, la síntesis que muestra su modificación.

En esta fase se presentan los momentos de trabajo directo con la información acopiada para proceder a su transformación desde el proceso que facilita la hermenéutica: comprensión, interpretación y síntesis, pues reflexión, análisis y comparación se realizaron en las fases previas.

En palabras de Not esta mirada en un contexto educativo se presenta de la siguiente manera:

El alumno trabaja en mensajes portadores de información, como el carpintero trabaja la madera o el herrero [le] da forma al metal. Los analiza, transforma sus elementos, prueba ciertas composiciones, las disocia para probar otras, etc. Ésta es la razón por la que la transmisión oral es poco adecuada; toda la información que constituye la materia prima debería beneficiarse de apoyos concretos: textos, grabados, cartas, esquemas, cuadros de datos, muestras materiales, etc.; observándola y "manipulándola» mentalmente es como el alumno la transforma en conocimiento (Not, 1992: 85). 
En esta última fase de la estrategia didáctica TRINCO el usuario (profesor, estudiante) adquiere y afianza conocimientos y habilidades para organizar en esquemas la información que le sirve para su necesidad de información, conversar sobre la experiencia y los resultados. Realiza la comprensión y la interpretación de la información que se seleccionó, así como la transformación y síntesis de esta. Naranjo y Álvarez presentan esta fase como "[...] el proceso de intercambio de experiencias significativas sobre la información y su uso a partir de la estructura cognoscitiva de los sujetos, en una búsqueda continua de transformación" (2003: 23). De allí que surjan preguntas: ¿cómo puedo transformar la información?, ¿cómo la aplico?, ¿cómo la presento?, ¿en qué fuentes y autores me apoyé?, ¿qué aprendí?

En esta fase se prepara al usuario para que redacte y presente sus trabajos y los resultados de su proceso de búsqueda y uso de la información, bien sea en forma escrita, visual, oral o audiovisual en diferentes espacios, formatos y soportes; además de que sus presentaciones estarán respaldadas por las bibliografías que elabore, entre otras acciones.

Continuando con la explicación de cada fase, se presentan en el Gráfico 14 las preguntas que orientan los contenidos del segmento, los contenidos a desarrollar y las habilidades, conocimientos, actitudes y valores que, se pretende, lograrán los usuarios al finalizar la tercera fase. Luego se explica cada segmento de ésta. 
GRÁFICO 14

FASE DE TRANSFORMACIÓN Y ANÁLISIS

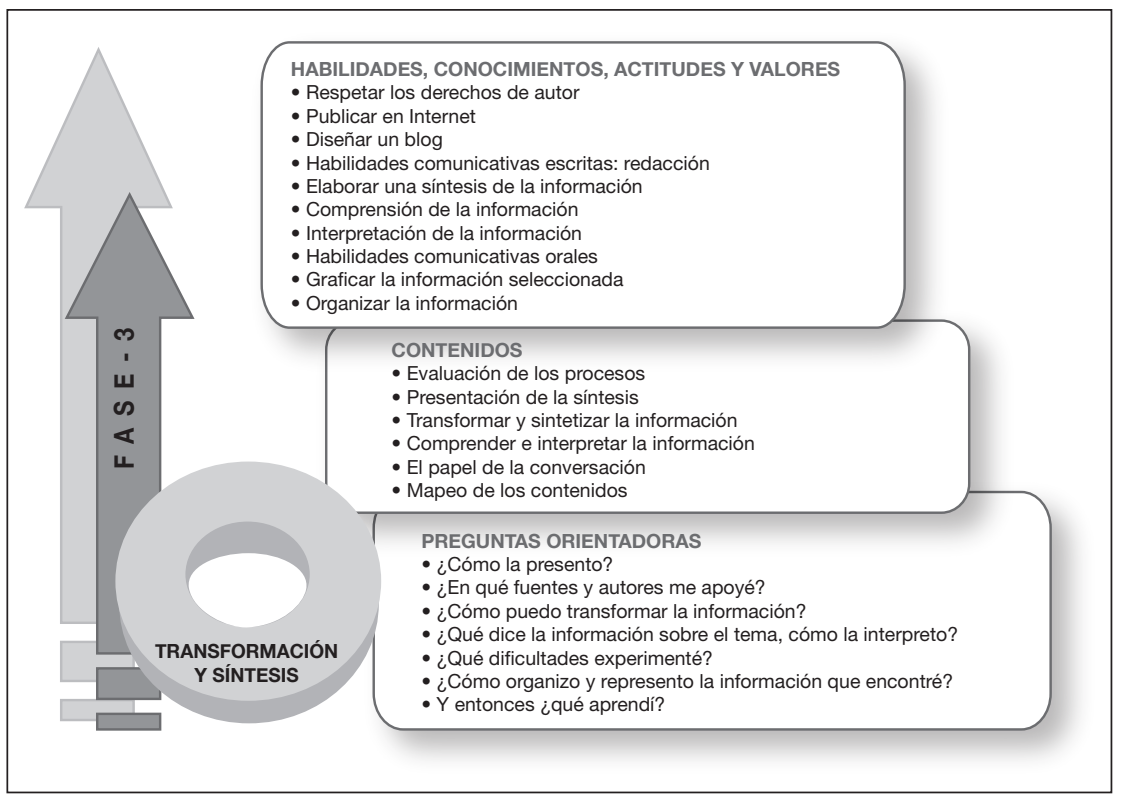

El mapeo de los contenidos.

Las representaciones gráficas de la información le permiten a la mente darle un sentido y un significado a lo que lee, son una muestra de su comprensión, por eso se presenta este segmento, de manera que el usuario empiece a transformar la información en conocimiento y que lleve hacia un mapa (conceptual, mental, icónico, etc.) el contenido de los documentos que seleccionó y analizó para su actividad y mostrar así lo que comprendió de ellos y "[...] que ha tenido lugar una auténtica reorganización cognitiva" (Novak y Gowin, 1988: 125). Cada usuario elabora su mapa, lo que le permite verificar las relaciones erróneas, los aciertos y los conceptos que sobran o faltan. Esta forma de mapear lo que se analizó y comprendió facilita el volver a reflexionar, pro- 
ceso de la no inmediatez sino de la meditación. En la reflexión se percibe lo que ha sucedido. La reflexión, además de aplicar su propia comprensión, está revestida de la realidad vital y toma en cuenta la tradición, pero no ingenuamente sino en forma crítica, es una forma de autoconocimiento. La reflexión lleva a encontrar el verdadero sentido de las ideas y superando las generalidades, se aproxima a la comprensión. Una vez que se tiene el mapa se reflexiona sobre sus errores y aciertos, sobre lo que sobra y lo que falta, lo que da una muestra de la comprensión lectora.

En este segmento y para lograr plasmar en un gráfico los elementos que permiten distinguir las características esenciales del contenido de los documentos que se seleccionaron, se debe tener en cuenta:

- La ubicación del tema.

- Una determinación de la lógica de ordenación que tendrán las fuentes de información propuestas.

- La valoración del lenguaje que se utiliza: general o especializado.

- Qué se muestra, separando los temas básicos y complementarios del documento.

- Los propósitos del documento.

$\downarrow$ La conversación media en el aula.

Con la conversación se pretende llegar a un acuerdo, mas no a un consenso, lo cual, exige la concentración entre quienes lo hacen, y así valorar los puntos de vista de cada uno y ponerse en el lugar del otro para tratar de entender lo que dice. Esto es, se busca comprender el fenómeno a partir del punto de vista del otro o de los otros, a partir de un escrito o de la oralidad para su interpretación. Por consiguiente, la conversación se debe realizar constantemente en el aula o en el espacio en que se esté llevando a cabo el aprendizaje sobre el uso de los SID. Se 
conversa sobre los resultados obtenidos, las dificultades, los aciertos y la estrategia en general. De este proceso dialógico pueden inspirar sugerencias para modificar la estrategia o los compromisos y las labores académicas.

Como la conversación es un acto que despliegan los seres humanos para plantear sus puntos de vista, creencias, comprensiones y vivencias, en ésta se discute cuando surgen posiciones divergentes que amplían la comprensión de los temas tratados. En consecuencia, los resultados de los procesos que han ejecutado hasta el momento y las experiencias que han vivido los estudiantes y profesores como usuarios, serán uno de los temas de conversación; por lo tanto, se enfatiza en la necesidad de escuchar atentamente y preparar con cuidado el discurso que se presenta; aun así, la conversación no se limita a esta fase, pues ya se vio cómo la comunicación fluye en todos los segmentos de las fases y estará presente hasta que se termine de aplicar la estrategia didáctica TRINCO.

Comprensión e interpretación de la información.

Encontrar el sentido de las palabras, más que entender su significado literal, puede denominarse comprender (Gadamer, 2005) y para ello se integran la tradición y los prejuicios a lo actual, buscando un nuevo enfoque, superando las miradas anteriores que se tenían del mundo. Por lo tanto, la comprensión es el proceso de la fusión de horizontes, en el que se encuentran el pasado o la tradición y el presente, al igual que los horizontes del intérprete y de lo que procura interpretar a partir de las preguntas que se hizo en las fases anteriores y de las respuestas que dio.

Buscarle al texto sus múltiples sentidos implica la interpretación como proyección de la comprensión. Así ella permite asociaciones inéditas, nuevos modos de ver y de ser en el campo del sujeto, facilita la transformación de sí mismo y lleva a asumir una posición crítica, ética y propositiva en relación con 
esas transformaciones y nuevos modos de ver. El intérprete crea un nuevo texto producto de su proceso hermenéutico, el cual, se va encadenando a los conocimientos anteriores previstos en textos, conversaciones, experiencias e historias de vida; es decir, la historia, la tradición. Se comprende la interpretación como una proyección de la comprensión, puesto que "[...] la interpretación es en cierto sentido una recreación, pero ésta no se guía por un acto creador precedente, sino por la figura de la obra ya creada, que cada cual debe representar del modo como él encuentra en ella algún sentido" (Gadamer, 2005: 165).

- En este segmento se deberá:

- Leer cuidadosamente el contenido de los documentos seleccionados.

- Realizar un trabajo crítico con su contenido.

- Determinar si el contenido de los documentos responde a las preguntas formuladas o a la necesidad de información que se planteó.

- Definir si el contenido es coherente, presenta cohesión en su redacción, y si es pertinente e imparcial.

- Determinar si se omitió alguna información.

- Establecer la relación que existe entre los conceptos más importantes de los documentos.

- Identificar los puntos de acuerdo y desacuerdo en la información de los documentos.

Posteriormente, se realiza un esquema categorial de acuerdo con el tema y la actividad que se está desarrollando; los documentos se leen seleccionando los párrafos y las ideas se ubican en las diferentes categorías y subcategorías para determinar las concurrencias o coincidencias y las ocurrencias o aspectos que sólo aparecen en un documento, pues esto que lo hace diferente puede ser clave para comprender e interpretar la información. 
$\checkmark$ Transformación de la información en conocimiento.

Esta re-creación se ve en un nuevo texto: la síntesis, esto es, el texto adquiere un nuevo sentido. O como dice E. González (2006: 57) "[...] la síntesis es una composición que muestra los prejuicios de un intérprete, su estilo de analizar, de comprender, de interpretar y de escribir". En la síntesis el usuario (profesor o estudiante) asume el papel del autor que escribe para una comunidad en particular con un lenguaje que lo relaciona con ella y lo distingue de otras, de acuerdo con un sistema de creencias. La síntesis es la traducción del intérprete, no sólo la que él hace sino la traducción de él mismo; es decir, realiza una traducción del pensamiento y conocimiento registrado por otros, es lo que se denomina la transformación de la información en conocimiento.

Aquí ya se sabrá si la mediación de la que habla Not (1992) logró su cometido: transformar la información en conocimiento. La transformación y síntesis hace referencia a la reelaboración que realiza el usuario con la información que acopió, procurando entregar un producto nuevo o por lo menos modificado que dé cuenta de la calidad de su comprensión e interpretación. La síntesis puede ser simple o compleja de acuerdo con el público al que va dirigido, el nivel del usuario y el objetivo que se busque.

Para realizar la transformación es fundamental llevar a cabo varios pasos: permitirle al estudiante hacer un trabajo independiente; el profesor debe mostrar el tema en el mundo real, ya que el estudiante valora mucho la evidencia, y esto le permite confrontarlo con lo que está leyendo y con lo que está viviendo en la práctica. En esa transformación se debe saber combinar la información, razonarla, contrastarla, hacer abducción, inferir y proponer hipótesis, proponer ideas, diseñar métodos. 
La síntesis en el edublog.

Un edublog es el blog que se utiliza con fines educativos (Monzón, 2011). Con este sistema es posible que profesores y estudiantes participen en una discusión por escrito, lo cual conlleva a desarrollar habilidades de escritura, de pensamiento analítico, reflexivo y crítico, de argumentación y, quizás una de los mayores aportes, el trabajo colaborativo. El blog es en realidad una bitácora o diario que se publica en la Web y allí, de acuerdo con una temática establecida, se aloja cronológicamente la producción de uno o varios autores. Como lo expresa Ricoeur (2006: 40) "[...] sólo por extensión es como fijamos mediante inscripción el alfabeto, el léxico y la gramática, todos los cuales sirven para aquello que ha de fijarse: el discurso [...] Sólo el discurso ha de ser fijado, porque el discurso como acontecimiento desaparece [...] porque lo que la escritura realmente fija no es el acontecimiento del habla sino lo dicho del habla".

El blog, como medio de comunicación, facilita la comunicación de la información, el poder compartirla; su uso depende de la actividad que se vaya a realizar. Los blogs, así como algunos sitios web, permiten alojar acervos bibliográficos, documentos elaborados por los usuarios, etc., lo que facilita el acceso y uso de la información. Si bien el medio es muy importante, su esencia radica en lo que se haga con él, la fuerza que tenga y el uso que se le dé.

En este segmento se les enseña a los usuarios a diseñar un blog y la forma de usarlo como medio de publicación académica. Se les propone a los profesores trabajar el blog por equipos, de manera que se le dé paso al trabajo colaborativo, a la responsabilidad individual y colectiva, y al desarrollo de la escritura en los estudiantes así como a las posiciones reflexivas y críticas que implican los puntos de vista expuestos, que en muchos casos son divergentes.

Los compromisos y las labores académicas que estén realizando los usuarios con la información acopiada los presentarán 
en este sistema, lo que motivará a los estudiantes a trabajar en equipo y a incrementar su interés por el tema, el compromiso académico y la comprensión; también a desarrollar actividades de socialización y participación en otros blogs, puesto que esto los prepara para asumir la confrontación y discusión de temáticas con perspectivas variadas. Se sugiere a los profesores permitir al equipo de estudiantes generar su propio blog (enseñándoles previamente a diseñarlo y utilizarlo) para facilitar el trabajo colaborativo. Si bien en esta estrategia este segmento se presenta al final de la fase, como resultado de toda la actividad, se recomienda enseñar a usarlo desde el principio, de manera que sea el espacio en el cual los estudiantes consignen todo el proceso de enseñanza y de aprendizaje que conlleva la estrategia.

^ Uso de información y propiedad intelectual.

El uso de la información para el desarrollo de los compromisos educativos debe estar precedido de una valoración positiva hacia el trabajo intelectual de aquéllos que han publicado los resultados para ponerlos al alcance de la sociedad, sea en una revista, libro, video, una fotografía, película, canción, melodía, etc. En este sentido, el respeto por las ideas y creaciones de ellos se refleja en las referencias bibliográficas pertenecientes a citas directas e indirectas, al igual que en la bibliografía del trabajo que se entrega, y valorará así los derechos morales del autor, que en el caso colombiano están respaldados en la Ley 23 de 1983, la Ley 44 de 1994 y el Decreto 1360 de 1989 y los derechos de autor en Internet (Colombia, Ministerio del Interior, 2012, en línea).

Significa entonces que los usuarios de la información, sujetos que intervienen en el proceso didáctico, deben ser conscientes de las normas, las leyes y los códigos de conducta que rigen sus acciones mientras realizan sus compromisos y labores 
académicas, lo que supone que se precisa de una comprensión ética sobre los detalles de la legislación vigente (Opazo, 2011).

En la síntesis que realizó el usuario, utilizó la información que seleccionó y organizó, y con ayuda de la hermenéutica comprendió e interpretó. Cuando él realiza su escrito se apoya en las fuentes, en ocasiones haciendo uso de las palabras textuales de los autores que está leyendo y en otras con sus propias palabras, y con el trabajo de las categorías crea sus propios párrafos. En todo el proceso se ampara en los autores de los documentos disponibles en los diferentes SID y es allí donde él debe comprender la importancia de los derechos de autor y el papel que juegan la citación y la bibliografía. Para facilitarle esta labor se le deben presentar y enseñar a usar algunos gestores de referencia bibliográfica, como Endnote y Reference Manager, entre otros, o los gestores de bases de datos como Access, MySQL, que agilizan la labor y siguen una normalización en la presentación. Este segmento debe aprovecharse también para hablar del plagio, mostrando páginas en las que es visible este fenómeno y hacer referencia a las leyes y normas que existen en los diferentes países para penalizar este delito.

^ Socialización y evaluación.

A la complejidad de los procesos de enseñanza y de aprendizaje se le añade la evaluación de ambos, labor compleja, pues el solo hecho de considerarla como una acción que se desarrolla para buscar las mejoras de los procesos, exige reflexionar y revisar todos los pasos dados desde el inicio de éstos, durante su ejecución y al finalizarlos; esto sugiere que no sólo se evalúan contenidos o acciones que se desarrollan, sino también la comprensión y apropiación consciente de los saberes en el estudiante y la labor del docente, por consiguiente el comportamiento y actitudes de éstos, quienes le dan vida a la acción educativa. 
La evaluación se diseña en un contexto y se aplica, en primera instancia, a sujetos con una historia de vida que influye en su desempeño, características que se deben tener en cuenta para comprender e interpretar los resultados en forma crítica y argumentada, de manera que se realice una labor cualitativa y formativa, pues ya no se evalúa para constatar la capacidad memorística del estudiante o cuánta información transmite el profesor en un lapso de tiempo establecido; se evalúa para hacer visible la apropiación crítica del saber cultural de los estudiantes cuando transforman la información en conocimiento, y la capacidad del profesor para comunicar el conocimiento del objeto de estudio con un estilo comprensible, que permita la interacción de los sujetos en el aula y abra la confrontación y discusión a partir del diálogo. Esto como proceso que requiere de la reflexión, facilita la construcción de un horizonte dirigido a la comprensión por parte de los sujetos que intervienen en el proceso formativo, en un sentido dialógico y contextualizado de la acción educativa (Salinas, 2002).

La evaluación de los estudiantes se realiza para valorar el avance de éstos en su proceso formativo, acción que informa al profesor y a los mismos estudiantes sobre los aspectos que se deben adecuar y mejorar para alcanzar los fines propuestos en el proceso didáctico.

Para evaluar se cuenta con diversos instrumentos y medios, diseñados o adaptados dependiendo de la acción o función que se quiera revisar. Actualmente las evaluaciones se pueden realizar en forma presencial o virtual, sobre un papel o con los recursos tecnológicos, en un día o en el transcurso de un tiempo estipulado; las aplicaciones varían, lo importante es comprender el valor de este proceso en la formación de los sujetos que participan de ella.

Como se dijo, el blog es un sistema que hace posible socializar el trabajo de los usuarios (profesores y estudiantes) y co- 


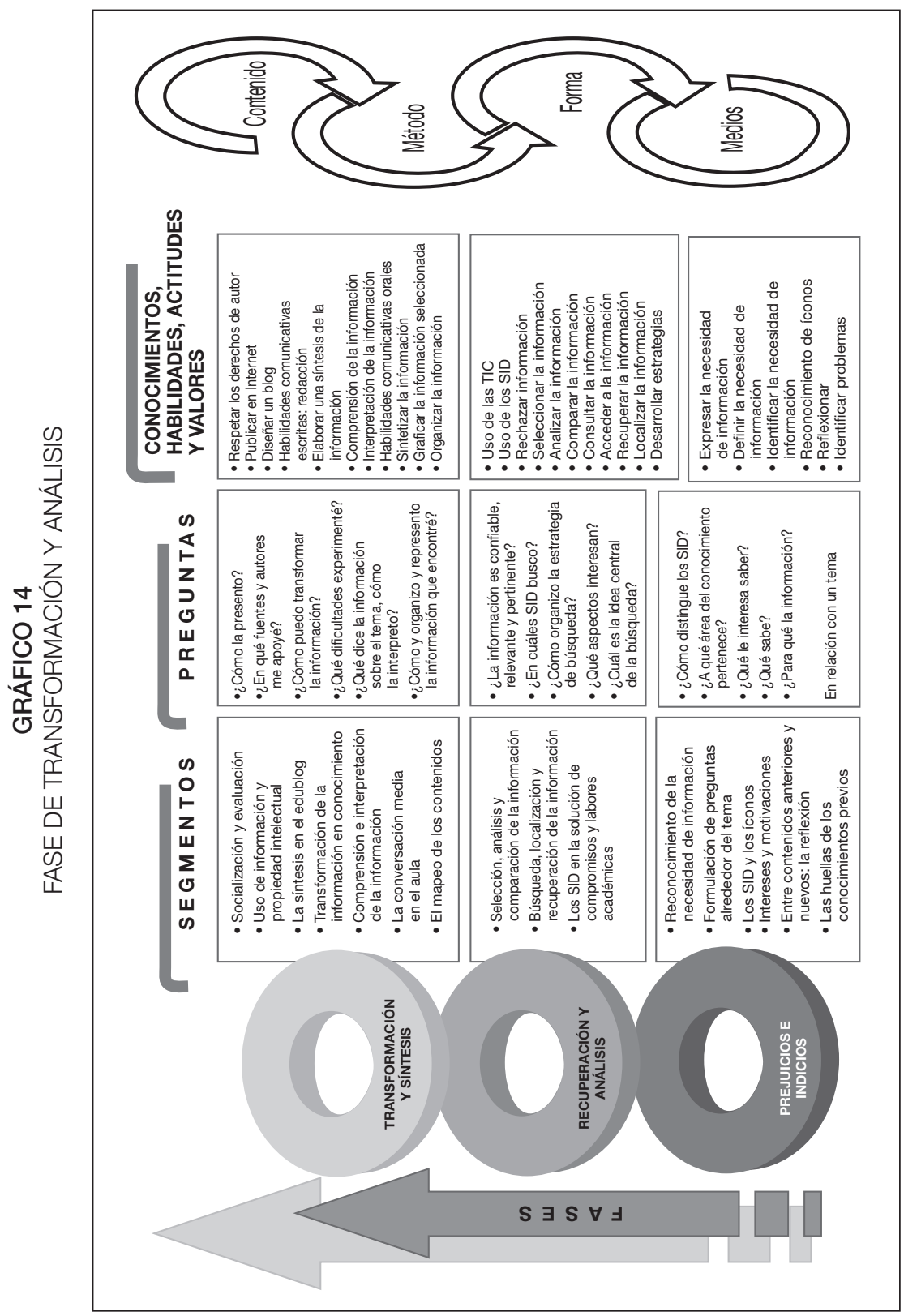


nocer, en parte, su aprendizaje; sin embargo, no se quiere limitar éste, y que en ocasiones es necesario darles la oportunidad a los usuarios (especialmente a los estudiantes) de enfrentarse a un público. Por consiguiente, se propone realizar un evento apoyado por la institución educativa, en el que ellos presenten sus bitácoras, resultado de su trabajo, a modo de ponencias, y la evaluación se organiza como momentos, al cual acuden personas de reconocida trayectoria en la temática, de manera que no sólo el profesor sea quien evalúe el trabajo. Estas personas valorarán el trabajo escrito (definitivo), el uso de las fuentes y sistemas de información así como la presentación en público; el profesor también participa de esta evaluación, para dar un seguimiento del compromiso y de la labor académica durante el desarrollo de la estrategia. También se presenta la coevaluación, aquélla que se hace entre compañeros, y la autoevaluación, en la que el estudiante evalúa su desempeño y resultados. Esta valoración final que, por requisitos curriculares tiene una nota calificativa, se caracterizará por ser una evaluación formativa. No obstante, se recomienda evaluar el desarrollo del proceso a medida que se avanza en cada una de las fases de la estrategia didáctica TRINCO.

De esta manera, y como puede observarse a modo de síntesis en la gráfica (véase Gráfica 15), TRINCO se diseñó teniendo en cuenta el concepto de estrategia didáctica que se desarrolló para esta investigación, de allí que se tenga el soporte teórico con base en la didáctica universitaria y los cuatro componentes del sistema didáctico: contenido, método, forma y medios; al igual que la organización en fases y segmentos que permiten la formulación de preguntas orientadoras hacia la preparación de contenidos. El proceso de esta estrategia didáctica TRINCO les permite a los usuarios de los SID (profesores y estudiantes) desarrollar habilidades, adquirir conocimientos y asumir actitudes y valores en relación con el uso y la transformación de la información en conocimiento. 
SISTEMAS DE INFORMACIÓN DOCUMENTAL (SID): MEDIOS DIDÁCTICOS PARA TRANSFORMAR

\section{LA INFORMACIÓN EN CONOCIMIENTO}

Con este trabajo se destaca una relación sistémica entre áreas del conocimiento para lograr la transformación de los datos y la información en conocimiento, donde el usuario de la información es un sujeto que hace parte de esta reflexión, ya que en la utilización de los SID son las personas quienes a partir de su empleo consciente, se benefician con un trabajo interdisciplinario con la ciencia de la información, la didáctica y la teoría de sistemas.

Inmersos en la sociedad, que es un sistema complejo, ${ }^{3}$ se encuentran otros sistemas, como el educativo que, aunque diferentes, se retroalimentan. Dentro del sistema educativo, se encuentran también la pedagogía y la didáctica, sistemas interesados en la formación intelectual de los miembros de la sociedad. En esa formación participan los SID con su variedad de fuentes de información y de esta forma se complejiza el sistema.

Los SID les facilitan a las personas (sus usuarios) morar en las sociedades complejas, convivir y compartir el mundo de los variados mundos en los que habitan, razón por la que apoyan la didáctica para transformar la información en conocimiento técnico, tecnológico, científico o artístico para la sociedad. Como expone R. Vélez "[...] las sociedades de la información y el conocimiento permiten a las comunidades penetrar en la complejidad y ganarse en ella un lugar de privilegio, por cuanto la inteligencia y sus variantes garantizan nuevas formas de civilidad y convivencia en el marco de ámbitos complejos" (2002: 15).

3 Complejo es "aquello que no puede resumirse en una palabra maestra, aquello que no puede retrotraerse a una ley, aquello que no puede reducirse a una idea simple" (Morin, 1994: 21). 
Aquí, la interacción es central y como los hombres son sujetos y no objetos, se construyen y propician espacios desde la estrategia didáctica TRINCO para conversar, discutir, reflexionar y comprender la proyección de la información y el conocimiento en relación con la vida y el hombre, superando así una mirada simplificadora sobre esta acción.

Esta situación compleja, que además debe coexistir con el entorno, requiere de una comunicación constante y significativa, como se da con esta estrategia, a fin de que el uso de los SID no sea un evento aislado, sino una constante que conserva su identidad y donde estos medios se vuelven significativos en la construcción del conocimiento, como parte de los procesos de enseñanza y aprendizaje del ambiente universitario. De esta manera, la comunicación debe llevar a la reflexión permanente, para percibir lo que se está construyendo y cómo se está haciendo.

Para comprender lo que es un SID se parte de la teoría de sistemas, que se afianza por la tendencia a analizar y crear entidades $^{4}$ en donde prima la interacción y el trabajo en equipo para superar el aislamiento de los fenómenos. Se percibe así la importancia que tienen las relaciones, las cuales, pueden ser de tipo estructural cuando se refieren a la organización, a su estado, a su configuración, y a los elementos y partes que conforman la entidad; también pueden ser funcionales estas relaciones, cuando se realizan acciones encaminadas al logro de objetivos o propósitos que responden a normas, procedimientos, criterios y evaluaciones generadas por el tipo de sistema (Rincón, 1998).

Se dice entonces que con la teoría general de sistemas se logra que el sistema se vea como una unidad compleja en la que el «todo» es más que la "suma» de las partes que lo constitu-

4 La entidad se caracteriza porque su existencia puede ser concreta (los sentidos la perciben) o abstracta si las características se relacionan con cualidades propias de un concepto (Rojas, 1998). 
yen; situación que fortalece el trabajo inter y transdisciplinario, puesto que es necesario diferenciar la unidad, la naturaleza material de su objeto; así como los tipos y complejidad de los fenómenos (Morin, 1994). O, en otras palabras, el sistema es un todo organizado por cada una de las partes que lo componen y que buscan solidariamente un objetivo. En esa medida cabe preguntarse: ¿qué es un sistema de información (SI)?

Un SI es el conjunto de elementos planificados y estructurados para tratar y administrar los datos y la información, que se preparan y organizan para poder ser utilizados con el fin de cubrir una necesidad. En este sistema se requieren personas, datos, actividades y recursos materiales (informáticos y de comunicación) entre otras cosas. El término se aplica en diferentes campos del conocimiento, tales como informática, teoría de sistemas o representación del conocimiento.

Se caracteriza porque conserva registros acerca de las características y evolución de otro sistema, el cual se conoce como sistema del mundo real o sistema objeto (Walker, 1991), que "[...] abstrae y selecciona ciertas características del sistema objeto, de acuerdo con los propósitos del sistema de información y con los intereses de sus usuarios" (Codina, 1994); no obstante, el sistema excluye algunas variables y parámetros del mundo real; es decir, no los registra, como es el caso de las bibliotecas y los centros de documentación en los que se encuentran documentos impresos, así como documentos electrónicos distribuidos en red, con la particularidad de que todos presentan un conocimiento registrado y no meros datos.

Volviendo a Codina, este señala que un SI es "[...] un sistema que mantiene registros sobre las características y la evolución de otro sistema, denominado sistema objeto. Un sistema de información posee los elementos necesarios para capturar, almacenar, representar y recuperar información. Todo sistema de información acepta una clase de datos como entrada, los 
somete a algunas transformaciones y proporciona información a unos usuarios" (Codina, 1994). Los SI se caracterizan entonces por ser un conjunto de personas, apoyadas en las TIC y otros recursos para desarrollar una serie de procedimientos que les permitan a otros (usuarios) recuperar la información de acuerdo con sus necesidades laborales, académicas, de distracción, etcétera.

Continuando con la reflexión alrededor del concepto SID, entonces ¿qué es un documento en tanto medio y en cuanto contenido?

Se ha dicho que la información genera conocimiento y es producto del conocimiento, por lo tanto, es abstracta pero no por ello de apropiación difícil. Para que se dé la apropiación de la información se requiere de un medio que represente físicamente su contenido (el conocimiento); esto es, volverla tangible en un soporte duradero que puede ser creado y manejado a partir de una tecnología, aunque también se puede almacenar y recuperar en algún sistema; esto es lo que se denomina documento. Se muestra así cómo el documento es medio y a la vez contenido.

Con el tiempo el término ha variado su concepción y características, de acuerdo con el enfoque disciplinar que se mire. Desde la ciencia de la información se asumen algunas representaciones físicas que dan origen a los sistemas de información: los archivos con los manuscritos y documentos administrativos, la biblioteca con libros y revistas, los sistemas automatizados con bits, los museos con diversos objetos y otros tridimensionales conocidos como realias. La información que contienen esos documentos es lo que se organiza en el sistema (Moscoso, 2002). De allí que se diga que "[...] un documento es un conjunto de señales coherentes, registradas en un soporte material, realizadas con intención de comunicar y que, en su forma final, pueden ser interpretadas por un ser humano" (Codina, 1994). 
El documento en sí vive un ciclo de producción, distribución, conservación y utilización (Varela, 2007) y su valor depende de varias características. Por su origen se dice que el documento enseña, pues conlleva un saber plasmado con la intensión de difundir el conocimiento para que se conozca y se utilice, como dice Moreiro (1995: 137-138): "[...] los documentos comunican información. Deben realizarse como información para alguien. Están destinados a que las personas acrecienten lo que saben" y para facilitar esto están los SID; es una manera de fijar el conocimiento, de allí que en la ciencia de la información se hable del documento cognitivo, el cual, de acuerdo con Van Slype "[...] recoge un trabajo científico, técnico o cultural y que [...] es susceptible de interesar a la humanidad en su conjunto" (1988: 65).

En otro sentido, el contenido de un documento puede ser valorado por criterios, tales como su presentación, profundidad temática y científica, la accesibilidad, su originalidad y novedad, periodo o época de la información y la fecha de publicación, entre otros. A pesar de que para otros estos criterios no incidan y carezcan de importancia, lo cierto es que su valoración depende de la necesidad de información que manifieste el usuario, y de que el contenido de ese documento satisfaga esa necesidad y permita considerarlo como un documento relevante o irrelevante. Además, continuando con Codina (1994, en línea) "[...] los documentos cognitivos constituyen la memoria social de la humanidad, el registro de todos sus logros científicos y culturales, así como la memoria que registra su pasado y su historia. Un fondo de documentos cognitivos es, de hecho, un depósito de conocimientos que, convenientemente explotado, puede ser puesto a disposición de toda la sociedad". En palabras de Varela (2007: 50):

El documento se caracteriza por ser todo lo que representa o expresa, con la ayuda de signos gráficos (palabras, imágenes, diagramas, mapas, figuras, símbolos), un objeto, una idea. Un documento es 
un material, un objeto que proporciona un dato o información. Es el apoyo del aprendizaje y la memoria de la humanidad. Hoy en día, el concepto de documento ha sido ampliado para soportar toda la información que permite el almacenamiento físico.

Con el pasar del tiempo la información se ha ido acumulando y con la presencia de las TIC la velocidad de transmisión y la superación de los límites espaciales ha sido vertiginosa, así como la disposición de múltiples medios que permiten disponer y registrar información representada en imagen y sonido, además del texto. Esto lleva a modificar los conceptos que se tienen de tiempo y espacio (tiempo sincrónico y asincrónico, espacio real y espacio virtual). ${ }^{5}$ Con la presencia de las TIC se debe hablar de documento analógico (impreso) y de documento digital (hipertexto), a pesar de que también se encuentran documentos digitales lineales. De tal suerte, con el uso de Internet y sus variadas aplicaciones se ha vuelto natural la lectura en la computadora, relegando de su centralidad al papel; sin embargo, el hecho de que el documento sea digital no lo aleja del mundo de la información registrada (Codina, 2002).

Luego de estas precisiones ¿cómo comprender qué y cuáles son los SID como medios didácticos?

Ya se vio que un SI se entiende como un conjunto de elementos ordenadamente relacionados entre sí (datos registrados e información) que cubren una necesidad y que se pueden aplicar a diversas disciplinas. Además el SI cumple con la función de conservar registros con las características y la evolución de otro sistema. En el caso de los SID, que es otro sistema de información centrado en los documentos y la información registrada, los datos e información procedentes de fuentes externas

5 Lo que confirma la visión de McLuhan (1972): la forma lineal de pensar generada por la imprenta de Gutenberg sufriría un cambio, y la percepción y comprensión sería algo global a partir de las imágenes y los hipertextos. 
e internas se identifican, seleccionan, almacenan, analizan, procesan y organizan para dar lugar a la difusión, recuperación y transformación de la información para la resolución de problemas planteados por el usuario que busca generar conocimiento. Procesos que se realizan para que cualquier usuario pueda acceder y disponer de esa información cuando la requiera, bien sea a partir de un proceso manual o uno computarizado.

Como señala Schulz (2001: 668): los SID “[...] generan, reúnen, combinan, almacenan, codifican y difunden datos, información y conocimiento, caracterizando una herramienta que sistematiza el funcionamiento de los procedimientos que se establecen a través de una estrategia predeterminada". Por consiguiente,

Los SID se entienden como el conjunto de personas,
máquinas y procedimientos que organizan la
información documental en una información que se
puede buscar, recuperar y usar para la toma de
decisiones. Entre ellos se encuentran las unidades
de información como bibliotecas, centros de documentación,
archivos y museos, así como bases de datos, redes
y herramientas como Internet, portales, buscadores,
metabuscadores, repositorios y sitios Web, que permiten la
intercomunicación en el ciberespacio y que facilitan
el acceso a la información y al conocimiento
por parte de los miembros de la sociedad.

Consecuentemente, dentro de los SID el carácter permanente de la información en un documento que se puede utilizar sin límites y por un variado número de sujetos, caracteriza su discurso; se dice entonces, que "[...] un sistema de información documental es un sistema que acepta como entrada documentos cognitivos y necesidades de información, y que produce como salida personas 
informadas" (Willits cit. por Moscoso, 2002: 524). El fin de los SID es facilitar el acceso a la información útil que responda a una necesidad específica de un usuario (estudiantes, profesores, ciudadanos en general), con el objetivo de que éste pueda transformar esa información en conocimiento.

El acceso se alcanza buscando la recuperación de la información en los SID, lo que se puede lograr por tantas posibilidades como atributos lo permitan a partir del análisis y la descripción del contenido o materia del documento. Se cuenta con atributos estructurales como título, autor, lugar y año de publicación, casa editora, etc.; y también se dispone de los atributos semánticos: tema, contenido, materia, palabras clave, enfoque, alcance, resumen, tesauro, etc. Las probabilidades de recuperación son enormes porque usando las aplicaciones tecnológicas utilizadas en las bases de datos, es posible combinar operaciones booleanas que permiten variadas combinaciones y no se limitan a una sola forma de recuperación; esto es importante porque la búsqueda, acceso y recuperación dependen de la necesidad de información que manifieste el usuario; una recuperación que no se sabe por anticipado si será relevante.

La teoría de sistemas permite hablar de los SID porque ayuda a comprender las relaciones y la comunicación que se requiere entre los equipos de trabajo, así como entre los usuarios y el personal, o entre los diferentes subsistemas (cada uno con funciones distintas aunque interrelacionadas entre sí), pues facilitan la labor de selección, adquisición, organización, difusión y acceso a la información. No obstante, si uno de estos subsistemas falla, el resultado esperado puede variar y no debe sorprender porque, como se dice con base en la teoría de la complejidad, la incertidumbre forma parte de la realidad.

Si un SID se caracteriza por sus objetivos, metas, fines y propósitos que se formulan teniendo en cuenta el contexto en que se desenvuelven, al igual que por las entradas y los procesos 
requeridos para lograr salidas que satisfagan a la entidad, y especialmente a los usuarios, entonces en un SID -como las unidades de información- los documentos y las necesidades de información de los usuarios se constituyen en entradas al sistema, mientras que las salidas se representan en las personas satisfechas con sus hallazgos informativos y regularmente informadas. Una información que en muchas ocasiones no pierde vigencia, como ocurre con las obras de filósofos como Habermas, Platón, Hume; de pedagogos como Comenio, Dewey, Freire o de literatos como Yourcenar, García Márquez, Shakespeare, Dumas, que se pueden encontrar en papel o en documento digital, constituyen de alguna manera una entrada "permanente" al sistema.

Los SID al contener en los documentos información que representa la producción del conocimiento de la humanidad juegan el papel de intermediarios entre productores y usuarios, y en el contexto universitario (puede ser otro contexto educativo) los convierte en medios que entran en el espacio áulico, pues aquello que contienen: la información, una vez leída y orientada por un método, permite la discusión en la clase, la confrontación del saber cultural del objeto de estudio y la apropiación del saber por parte del estudiante, esperando que tome lugar la transformación de la información en conocimiento.

En este apartado se ha hecho alusión a los diferentes SID que, como medios, pueden contribuir a la transformación de los datos y la información en conocimiento; el siguiente gráfico reúne aquéllos que se consideraron en esta investigación: 
GRÁFICO 16

CLASES DE SISTEMAS DE INFORMACIÓN DOCUMENTAL -SID

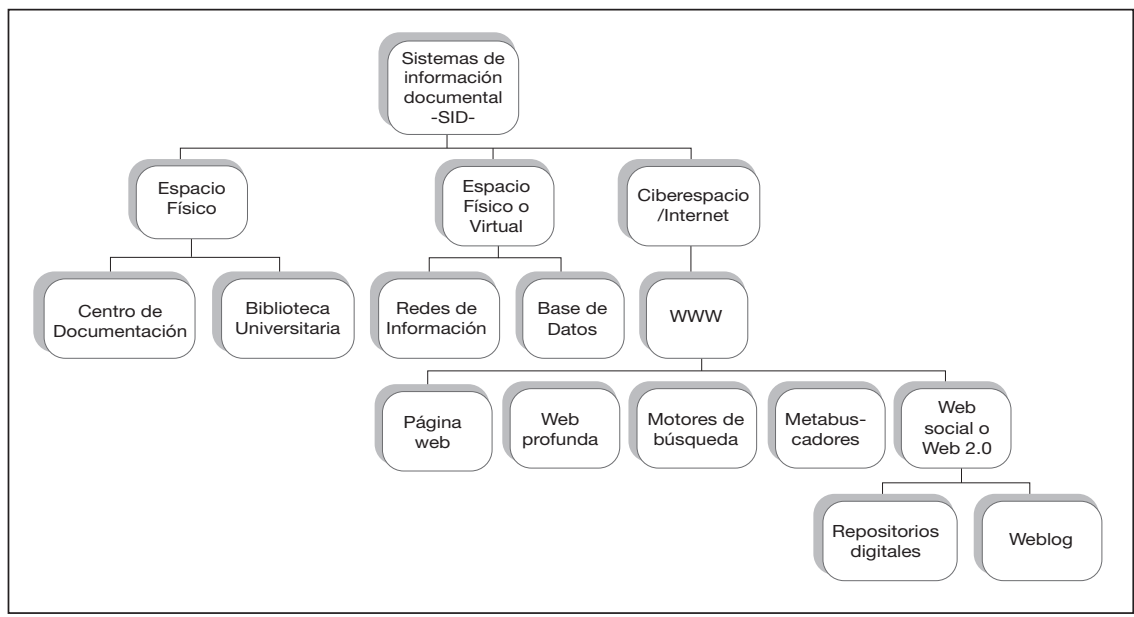

En general, los SID aseguran el flujo de la información, a través de la instauración de políticas y la comunicación permanente con los usuarios, y para ello, hoy en día, muchos de ellos desarrollan sus actividades a través de sus sitios Web. Estos SID se consideran elementos clave en el desarrollo de las universidades y demás instituciones de educación superior, puesto que "[...] cualquier institución universitaria debe asumir que la información documental es la principal fuente de conocimientos para estudiantes, profesores e investigadores y que las bibliotecas, los centros de documentación y otras unidades de servicios de información son los entes que soportan toda la actividad intelectual y, al mismo tiempo conforman el SID que permite el flujo de información y conocimiento en el entorno universitario" (Calderin, 2007, en línea).

En síntesis, puede decirse que un SID es el conjunto de procedimientos normalizados que permite la gestión de los documentos y la explotación metódica de la información mediante 
las tecnologías adecuadas. Procurar y discernir las fuentes de información necesarias; almacenar en un repositorio seguro la información recogida, cualquiera que sea su naturaleza y sobre cualquier soporte; analizar y sintetizar los contenidos, normalizando su representación para permitir la interoperabilidad entre sistemas; elaborar y canalizar la salida de productos documentales de valor añadido y disponer de la información en reserva, conservarla y actualizarla para poder suministrar los datos a demanda de los usuarios, son los objetivos de la gestión documental, facilitados por las TIC.

\section{LOS COMPONENTES DIDÁCTICOS Y SUS INTERRELACIONES CON LA ESTRATEGIA DIDÁCTICA TRINCO O LA SUBVERSIÓN DEL SISTEMA DIDÁCTICO CON LA PRESENCIA DE LOS SID}

La estrategia didáctica TRINCO se estructuró teniendo en cuenta los sistemas complejos en los cuales el orden y el desorden, el todo y las partes son algunas de sus características. En este apartado se retoma esta idea, puesto que se ha hecho referencia al sistema didáctico constituido por varios componentes como uno de los todos. Las partes de este todo en las que se hace énfasis en esta investigación son cuatro: medios, método, contenido y forma, que se han explicado aquí de manera separada, aunque con rápida alusión a las interrelaciones que forman con los otros. No obstante, y en busca de un mayor acercamiento al horizonte, se presenta una serie de posibles combinaciones que muestran las interrelaciones entre esas partes, y que generan nuevos todos y reconfiguran la tradición del sistema didáctico, pues se ha visto cómo los SID, en cuanto sistema con la información y las fuentes documentales, tienen una presencia y un lugar central en los cuatro componentes mencionados. 
Ahora bien, estos nuevos todos generan complejas interacciones que proporcionan otras posibilidades de realizar el proceso didáctico en la estrategia didáctica TRINCO para el contexto universitario. De esta forma, se presentan nuevos tejidos producto de las interrelaciones, lo que modifica el orden de la dinámica de los procesos de enseñanza y de aprendizaje. Esos tejidos, esos nuevos todos se organizan en triadas que permiten ver sus interacciones, sus encuentros internos, allí donde cada uno aporta en forma independiente sus características para complementarse con los otros en estos procesos interrelacionados e interactuar permanentemente con los SID.

\section{Los SID en tanto Medios y su relación con el Contenido y el Método}

En el proceso de enseñanza los procedimientos metódicos requieren, regularmente, de medios didácticos para facilitar su quehacer y propiciar la comprensión y el aprendizaje de los contenidos del objeto de estudio. En este proceso, el uso de los medios requiere de una planeación previa de parte del profesor, que entraña el cómo y el cuándo, ya que la acción didáctica de los medios es un acto que se realiza con un método. Como afirma Klingberg (1990: 420) "[...] la eficacia de los métodos de enseñanza empleados puede elevarse mediante el empleo de los medios de enseñanza", cita a la que se le puede agregar: para facilitar la apropiación de los contenidos por parte de los estudiantes.

En esta triada dialéctica es posible visualizar el trabajo por conseguir, no sólo la apropiación del contenido para transformarlo en conocimiento, sino también el desarrollo de las habilidades, las actitudes y los valores de los aprendices a partir de su objeto de estudio. En este sentido la apropiación del contenido depende, en parte, de los prejuicios, los preconceptos y la reflexión del estudiante, al igual que de sus intereses y motivaciones. 
Se reitera que los medios didácticos tienen un vínculo con el contenido, en la medida en que le posibilitan al estudiante su asimilación y apropiación por distintos medios y recursos. En esa premisa, los medios tienen una incidencia en los procesos de enseñanza y aprendizaje, ya que se convierten en el puente que conecta prejuicios, experiencias, conocimientos previos y reflexiones con el nuevo contenido.

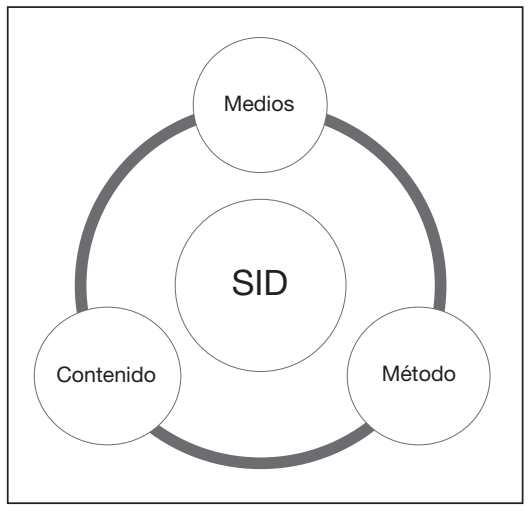

de anécdotas, de biografías, etc., que integradas con las lecturas de documentos favorecen la comprensión amparada en las explicaciones que se dan en el espacio áulico y que fortalecen la conversación y el diálogo, que motiva e incita a los estudiantes a reflexionar (Litwin, 2007).

Indudablemente el método que se utiliza en el proceso de enseñanza está revestido de decisiones previas en relación con el contenido, pues el interés de aquél es hacer posible que el estudiante se enfrente al contenido, razón por la que se exige que "[...] los métodos de la clase sean adecuados a los temas" (Klafki, 1990-1991: 103). Estas dos dimensiones del proceso didáctico son indisociables, no obstante que el acercamiento del estudiante hacia los contenidos temáticos se realiza a partir de los medios que se utilizan para facilitar la acción metódica. 
Estas acciones dan cuenta de la reflexión del profesor frente a su labor docente que busca traducir a los estudiantes un saber que incidirá en su desempeño social y profesional en un contexto determinado.

Abordar los contenidos también incluye la planeación de los compromisos y labores académicas que enfrentarán los estudiantes para lograr su comprensión, así se vincula la práctica con la teoría y en el caso del profesor con la investigación, con la acción reflexionada. El estudio de los contenidos y su organización temática requiere del uso de medios como los SID, pues éstos son portadores de la documentación que alberga la información de los conocimientos que otros han plasmado y que el profesor pretende llevar al aula de clase. Al respecto dice Litwin "[...] al elegir los contenidos para la enseñanza se deberán diseñar situaciones y herramientas que contemplen esta naturaleza situada y distribuida, de tal manera que provea oportunidades para cultivar residuos cognitivos deseables y no limitados" (1997: 58).

En un proceso didáctico la información se convierte en un insumo tanto para la enseñanza como para el aprendizaje, y la presencia de los SID con sus variadas aplicaciones tecnológicas, favorece el desempeño personal, académico y profesional de las personas que en él intervienen (profesores y estudiantes como usuarios de la información), pues posibilitan el acceso rápido y fácil a gran cantidad de información, sin que por ello se desconozca la importancia del método y su interacción con el estudiante y el contenido. 


\section{Los SID en tanto Medios y su relación con la Forma y el Método}

Dice Álvarez:

La forma, el método y el medio son los componentes operacionales del proceso docente-educativo; ellos interrelacionados entre sí conforman una tríada dialéctica en la que el método expresa lo más esencial de la dinámica del proceso; y la forma y el medio su expresión fenoménica. La primera desde el punto de vista estructural (espacio temporal) y la segunda desde el punto de vista de su portador material (Álvarez, 1999: 61).

En muchas ocasiones las acciones que se realizan dentro de los procesos de enseñanza y de aprendizaje con los medios didácticos como los SID, impulsan la creatividad de los estudiantes e incentivan la formación de las actitudes y los valores en ellos; para esto el profesor deberá organizar las diferentes acciones de acuerdo tanto con los objetivos que se buscan como con el método de enseñanza y las estrategias didácticas que emplee; y también deberá acompañarlos, asesorarlos y hacer seguimiento de su aprendizaje.

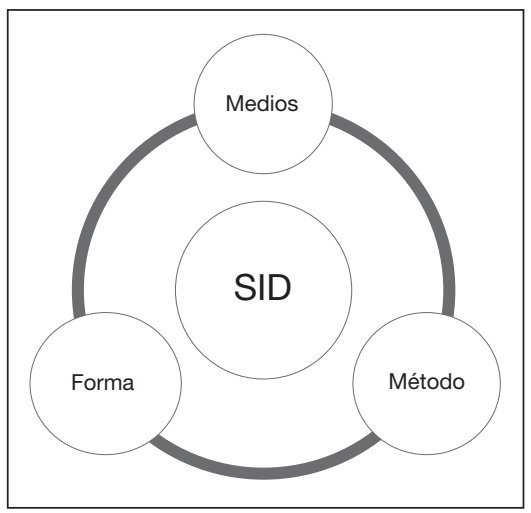

Desde luego es menester que se organice el grupo de estudiantes para realizar la labor propuesta, en la que se pueden generar procesos de aprendizaje de tipo individual o colectivo (parejas o grupos pequeños). Si son procesos individuales la responsabilidad es de un solo sujeto, lo que promueve la autonomía y el trabajo independiente y consciente del estudiante; si el proceso es 
grupal, se generan discusiones en las que se confronten las opiniones, se presentan diferentes puntos de vista, se valora la apropiación y solidez de los saberes y tiene cabida el diálogo reflexivo, lo que permite que se dé un intercambio y regulación de los aprendizajes. Arroyave lo sintetiza de la siguiente manera: "[...] es pues, un proceso de aprendizaje intencionado con una forma interactiva" (2001: 23), paro lo que sin duda es necesario acudir a los SID, en tanto medios didácticos, para realizar las actividades propuestas, ya sea para comunicarse, revisar conceptos, sustentar posiciones o para elaborar el producto final.

\section{Los SID en tanto Medios y su relación con la Forma y el Contenido}

Entre el contenido y su presentación existe una conexión intencionada que se propone lograr una comprensión significativa por parte del estudiante, por lo tanto "el contenido ha de ser "no arbitrario" y "sustancial»" (Zabalza, 2004: 144); es decir, debe relacionar el nuevo contenido o nueva información con los conocimientos previos del estudiante. Además, el profesor debe propender a una comunicación fluida en la que el lenguaje, sin perder su rigor disciplinario y académico, debe ser comprendido para evitar la dispersión y la ambigüedad. Sin embargo, como es inevitable que en el aula se hable con un lenguaje científico, se debe contar con los medios y fuentes de información que permitan aclarar los términos, palabras, expresiones, personajes, etc.; fuentes como diccionarios, enciclopedias, manuales, directorios, atlas, entre otros, que se localizan en bibliotecas y centros de documentación y que se pueden prestar para llevar al aula, o se utilizan estos SID como espacio áulico. También es factible disponer de medios electrónicos que faciliten el uso de determinados SID a los que se acuda para resolver las inquietudes y con los que se evite desvirtuar la información que se pretende comunicar. 


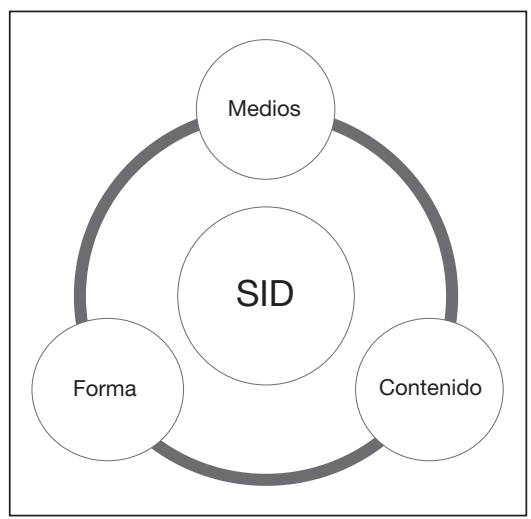

Cuando una situación de éstas se presenta, se recomienda organizar a los estudiantes en equipos para que se responsabilicen de resolver las inquietudes a partir de las fuentes o los medios didácticos como los SID, momentos en los que el bibliotecólogo, con la estrategia didáctica TRINCO, puede o debería participar para facilitar la labor. Esta situación es posible abordarla también en ciertos intervalos de tiempo, en consonancia con el contenido que se va a comunicar.

Durante los procesos de enseñanza y aprendizaje, los procedimientos, criterios, temas, problemas, fenómenos o sucesos relacionados con un contenido pueden organizarse por periodos de tiempo, tales como horas, días, semanas, quincenas, meses, bimestres o semestres, tiempo en el cual tanto estudiantes (individual o por grupos) como profesores, utilizarán los SID como apoyo. Para la apropiación de este contenido cabe diseñar ejercicios, talleres, tareas o proyectos que, sin duda, precisarán del uso de los SID como medios para cumplir con el compromiso académico. Esta posible labor académica da cuenta de lo necesario que es planear la secuenciación temática, el tiempo de su impartición, los recursos y medios que se utilizarán, la organización específica del grupo, e incluso la evaluación que se hará y la colaboración que hará el bibliotecólogo. 


\section{Método, Contenido y Forma, y su interrelación con los SID}

Se ha dicho que el método es indisociable del contenido y, se considera sobre el primero "[...] es el componente del proceso formativo que expresa la configuración interna del proceso, para que transformando el contenido se alcance el objetivo" (Arroyave, 2001: 35). De allí que se tome al método como el enlace entre estudiantes y contenido; este último, como se vio, tiene un soporte en las fuentes de información que se localizan en los SID, de manera que del método dependerá, en parte, el ambiente que se genere y en el que se moverán estudiantes y profesores en el aula de clase en busca de la comprensión y el aprendizaje.

El abordaje de los contenidos además de incluir el "qué» se ofrecerá, también cubrirá el «cómo» se hará comprensible ese "qué» ante un grupo de estudiantes, que puede estar disperso en sus individualidades o coordinado para trabajar en forma coopera$\mathrm{da}$, con el fin de apropiarse del contenido; entonces se conside-

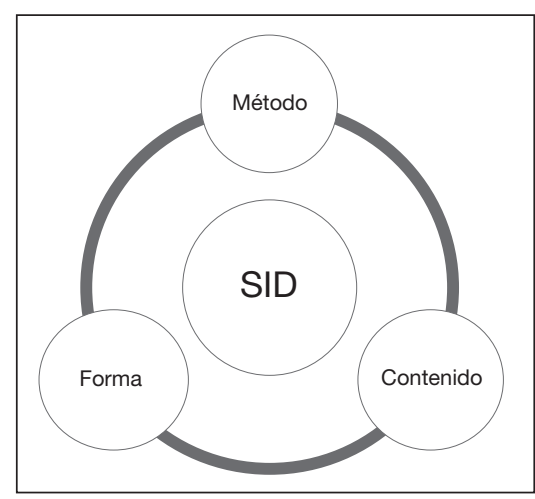
rará la manera de presentar, organizar, y planear todo para que resulte funcional y productivo.

Esta apreciación la presenta Carlos Álvarez de la siguiente manera:

Pero no es sólo él, como sujeto aislado, el estudiante está inmerso en su grupo. Así, la asimilación del contenido a través de la actividad aprendizaje [método] está mediatizada por la personalidad del grupo estudiantil en sus relaciones sociales. Esas relaciones contenido-grupo tienen que tener un carácter interno y nunca pueden 
ser algo impuesto, obligatorio; es el resultado de la posición activa del colectivo escolar en esa interacción. El grupo encuentra su papel en el aprendizaje cuando se identifica con la problemática social, cuando entiende su papel en las relaciones sociales y en el que está presente la guía del profesor (Álvarez, 1999: 48).

Se observa entonces la existencia de un enlace dialéctico entre método, forma y contenido, pues mientras el método organiza internamente el proceso y la forma lo hace con lo externo del proceso didáctico (espacios, tiempos, distribución de grupos y sujetos -profesores, estudiantes, bibliotecólogos-, bibliotecas, sitios web, el ciberespacio), el contenido los cohesiona al organizar el saber cultural de la sociedad para un objeto de estudio, con apoyo de los SID. Así, el método se diseña de acuerdo con el objeto de estudio del que emanan los contenidos y sobre los cuales recaerá la acción de un profesor reflexivo y consciente de su papel, que facilitará la apropiación y comprensión de los estudiantes en el lapso de tiempo planeado.

En la dinámica del proceso didáctico profesores y estudiantes, profesores entre sí, al igual que los estudiantes entre sí, y por momentos con los bibliotecólogos, caminan en pos de la transformación de la información (contenidos) en conocimiento, pero como son sujetos sensibles al ambiente, al espacio, a las dilaciones del tiempo y a la complejidad propia de las interacciones humanas, se organizan de diferentes formas, respondiendo al tipo de contenido y al método que se emplee en su momento; el interés principal radicará en asegurar la comprensión y el aprendizaje de cada estudiante, por lo tanto, del grupo en general. En esta triada dialéctica se encierra, como lo expone Arroyave (2001: 41):

la posibilidad de ofrecer múltiples formas de organización en el proceso de aprendizaje (individual, grupal, por parejas), puede tener efectos positivos en la impartición, adquisición y apropiación de los conocimientos, del desarrollo de habilidades, de facultades, de capa- 
cidades, de nuevos hábitos [actitudes] y valores en las relaciones de los sujetos actores del proceso: estudiantes-estudiantes, estudiantesprofesores y profesores-profesores [estudiantes-bibliotecólogos, profesores-bibliotecólogos].

GRÁFICO 17

LA SUBVERSIÓN DEL SISTEMA DIDÁCTICO CON LOS SID

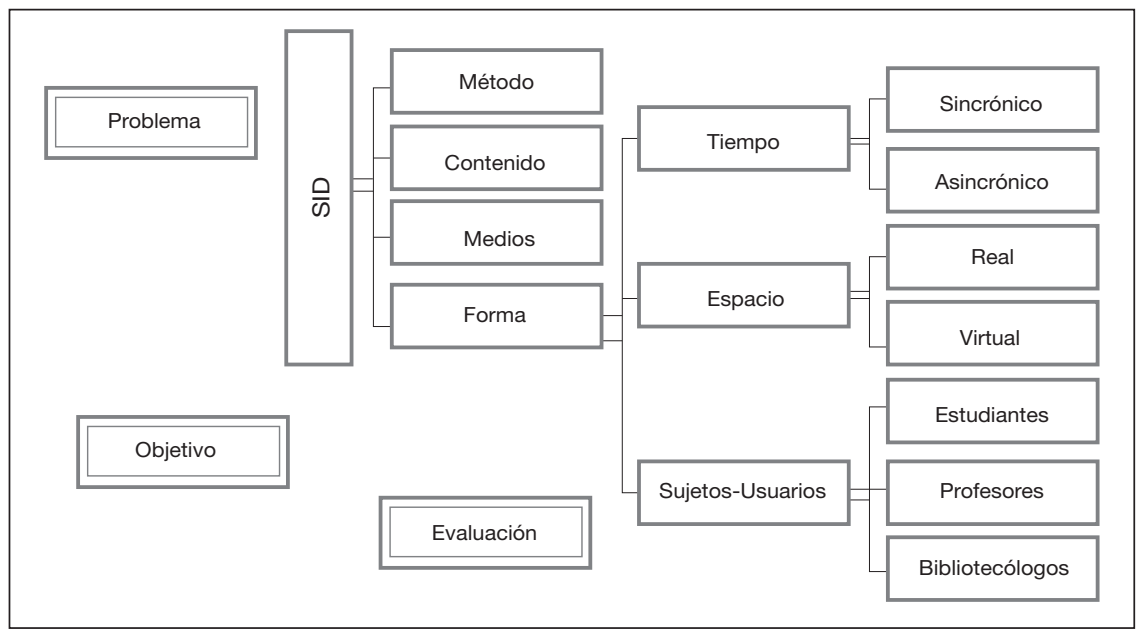

En el gráfico anterior se sintetizan las posibles interrelaciones que se forman entre los componentes del sistema didáctico; en éstas siempre están presentes los sujetos, profesores, estudiantes y bibliotecólogos como agentes y usuarios dinamizadores de los SID, todos en su respectivo papel como sujetos activos de los procesos de enseñanza y de aprendizaje que pretenden alcanzar la transformación de la información en conocimiento para una sociedad que demanda de ellos un aporte académico, intelectual y cultural.

En el proceso didáctico tienen presencia -como sujetos centrales- los profesores y los estudiantes, quienes conservan una relación directa con la información, bien porque ésta es la representación gráfica del contenido que se comunica en el espacio 
áulico, o bien porque requieren de ella para preparar su participación en la discusión, o porque la necesitan para realizar acciones evaluativas propias del proceso. Al necesitar de este recurso, muchos acuden a los SID como medios que les permiten solucionar su necesidad formativa al usar los recursos para recuperar la información; en otras ocasiones los SID se convierten en medios didácticos para comprender un contenido, un tema o un fenómeno, esta situación convierte a estos sujetos en lo que en la ciencia de la información se denomina como usuarios de la información.

Los sujetos del proceso formativo, que a su vez están en las categorías de los usuarios de la información en el ámbito universitario, ejecutan acciones en consonancia con las acciones de otras personas y entidades de su contexto, visibles en la interacción entre profesor-estudiante, estudiante-estudiante, profesor-profesor, y ahora con el bibliotecólogo como gestor de los SID, lo que arroja interrelaciones como profesor-bibliotecólogo, estudiante-bibliotecólogo, o estudiante-profesor-bibliotecólogo, como agentes y sujetos pedagógicos dinamizadores de actividades en las que los tres tienen incidencia, y por lo tanto "[...] se influyen y complementan mutuamente" (Arroyave, 2001).

Las acciones de cada uno llevan una insignia que los representa en su individualidad, así como en sus intereses y necesidades formativas e informativas, y enriquecen el entorno social en que se mueven, que se ha visto permeado por los avances tecnológicos y que ha modificado -en parte- su forma de comunicarse, por eso el profesor y los bibliotecólogos deben tener presente que los estudiantes son gente muy joven que influidos por la época que viven son muy icónicos, una generación llena de color y de imagen. ${ }^{6}$ Situación que lleva a sugerir que el

6 Unidad de sentido que surge luego de la conversación con profesores usuarios y bibliotecólogos. 
profesor debe estar abierto a la presencia y uso de las TIC y sus aplicaciones, a los cambios de la universidad y de la sociedad a raíz de estos recursos, pues el desarrollo tecnológico incide en los procesos de enseñanza y de aprendizaje. El profesor deberá saber para qué y por qué sirven las tecnologías y sus aplicaciones en el proceso educativo.

En esta interacción de profesores y estudiantes con los bibliotecólogos y los SID (portadores de la información real y virtual), la mediación centrada en la comunicación posibilita la transformación de la información en conocimiento.

\section{VIVENCIA CON LA ESTRATEGIA DIDÁCTICA TRINCO: TRANSFORMACIÓN DE LA INFORMACIÓN EN CONOCIMIENTO}

La vivencia es un término que incluye diversos matices desde una relación productiva o significativa; se puede decir con Gadamer que "[...] algo se convierte en una vivencia en cuanto que no sólo es vivido sino que el hecho de que lo haya sido ha tenido algún efecto particular que le ha conferido un significado duradero" (2005: 104); esto significa que cuando se presenta una situación determinada, se vive al tiempo que ésta genera un desenlace determinado y puede dar lugar a algo que permanecerá; es decir, que se encuentra su sentido al superarse lo extraño y lo incomprensible (Gadamer, 2005). Fue el propósito de vivenciar la estrategia didáctica TRINCO, ponerla en escena, llevándola a la realidad con una prueba piloto, con la cual se evidenció su efectividad y pasó de ser una propuesta posible a una estrategia real, que permitió verificar que su uso efectivamente permitía la transformación de la información en conocimiento. A continuación hacemos una descripción de la prueba piloto. 
Tipo de usuarios: la prueba pilotó se diseñó para aplicarla a un número aleatorio e indeterminado de estudiantes de diferentes instituciones universitarias, áreas del conocimiento y semestres académicos: Universidad de Antioquia: Microbiología y Bioanálisis ( $9^{\circ}$ semestre), Educación Física $\left(10^{\circ}\right.$ semestre); Politécnico Colombiano Jaime Isaza Cadavid: Comunicación Audiovisual ( $6^{\circ}$ semestre); Instituto Tecnológico Metropolitano: Artes Visuales (4 $4^{\circ}$ semestre).

Tema de discusión: Los derechos de autor

Medios y recursos didácticos: computadoras con acceso a Internet, SID: bibliotecas universitarias, bases de datos y WwW; guía para la aplicación de la estrategia didáctica TRINCO.

Fechas: 27 y 28 de abril de 2012

Duración: dos sesiones conjuntas entre bibliotecóloga-profesora y estudiantes, con duración de cuatro horas cada una. Los estudiantes dedicaron ocho horas extraclases.

Procedimiento: en primer lugar se les explicó a los estudiantes el objetivo de la investigación, la función de la estrategia didáctica TRINCO, lo que se esperaba de ellos y la forma cómo se desarrollaría la acción didáctica. Todo se hizo de manera informal a través de la conversación y la lectura de la guía, permitiendo que los estudiantes expusieran sus inquietudes sobre el proceso y la estrategia misma; y brindando además la posibilidad de comunicarse con la investigadora vía e-mail o telefónica.

El nombre de la estrategia llamó mucho la atención por su sonoridad y porque se confundía con BRINCO, término que se volvió un juego; se aclaró la sigla y en adelante solo se mencionó el término TRINCO, no estrategia. 
A partir de las preguntas formuladas en la guía, se avanzó en el desarrollo de la misma con ejercicios prácticos, indicándoles a los estudiantes que la fase tres sería resuelta por ellos solos en su tiempo y espacio.

La primera fase permitió que los estudiantes dieran a conocer sus experiencias con los SID en diferentes momentos, se discutió el tema propuesto y de qué manera podría serles útil en el momento en que se encontraban; esto arrojó que un estudiante de los últimos semestres lo utilizaría para empezar a organizar su trabajo de grado; otro se encontraba organizando una exposición sobre los derechos de autor en la fotografía, mientras que otro más estaba interesado en los derechos de autor en las obras musicales.

A medida que se avanzó en la discusión de las preguntas, se aclararon las necesidades de información de cada uno de ellos de acuerdo con sus intereses.

Cada estudiante disponía de una computadora con conexión a Internet, de manera que la segunda fase se adelantó haciendo uso de esta herramienta, pues fue necesario consultar diccionarios y enciclopedias especializadas para determinar las palabras clave por las cuales se buscaría la información. Se enseñó la búsqueda en OPAC disponibles en línea, en bases de datos y en sitios web con el apoyo de los operadores booleanos, aspecto que mostró la dificultad de los estudiantes para comprenderlos, pero con los ejemplos que se presentaron alrededor del tema de los derechos de autor se superó el problema.

Los estudiantes organizaron su propio proceso de búsqueda definiendo el contexto y período de interés; las inquietudes se formularon para todos con la intención de que los demás participaran en la discusión y posible solución a partir de la vivencia del momento. El análisis y selección de los documentos se hizo con base en aquéllos que se encontraron en las bases de datos y sitios web, tratando de que cuando consultaran los 
impresos disponibles en los sistemas de bibliotecas, los agregaran al resultado final.

Por último, se les pidió entregar el gráfico del primer segmento de la fase tres, compartir la dirección del edublog donde se observara la transformación de la información en conocimiento, y responder a la evaluación final que se incluía en la guía.

La conversación estuvo presente en todas las fases, pues las preguntas abrieron la posibilidad de dialogar y discutir, así como para enfrentar las inquietudes expresadas por los estudiantes a medida que avanzaban con TRINCO.

Resultados: se confrontan al finalizar la vivencia con la estrategia didáctica TRINCO.

Guía de la estrategia: 


\section{ESTRATEGIA DIDÁCTICA TRINCO: TRANSFORMACIÓN DE LA INFORMACIÓN EN CONOCIMIENTO -- Guía de aprendizaje -- \\ Aplicación de la prueba piloto}

Institución universitaria:

Programa académico: Semestre:

Nota introductoria: a propósito de la importancia de respetar los derechos de autor y conocer la reciente Ley 1520, conocida como la Ley Lleras 2.0, se plantea este tema de investigación. Para abordarlo, el estudiante y futuro profesional utilizará los diferentes Sistemas de Información Documental -SID-, pues se pretende que desarrolle las habilidades, conocimientos y actitudes necesarias que le permitan buscar, localizar, recuperar y usar efectivamente la información en su desempeño y que, finalmente, transforme esa información en conocimiento, de acuerdo con lo que haya analizado, comprendido e interpretado en los documentos seleccionados. Para lograrlo deberá tener en cuenta la siguiente guía de trabajo:

\section{Fase de prejuicios e indicios}

Antes de iniciar la búsqueda de información, deberá comprender los conocimientos previos y aquello de lo que necesita informarse, planteándose preguntas como:

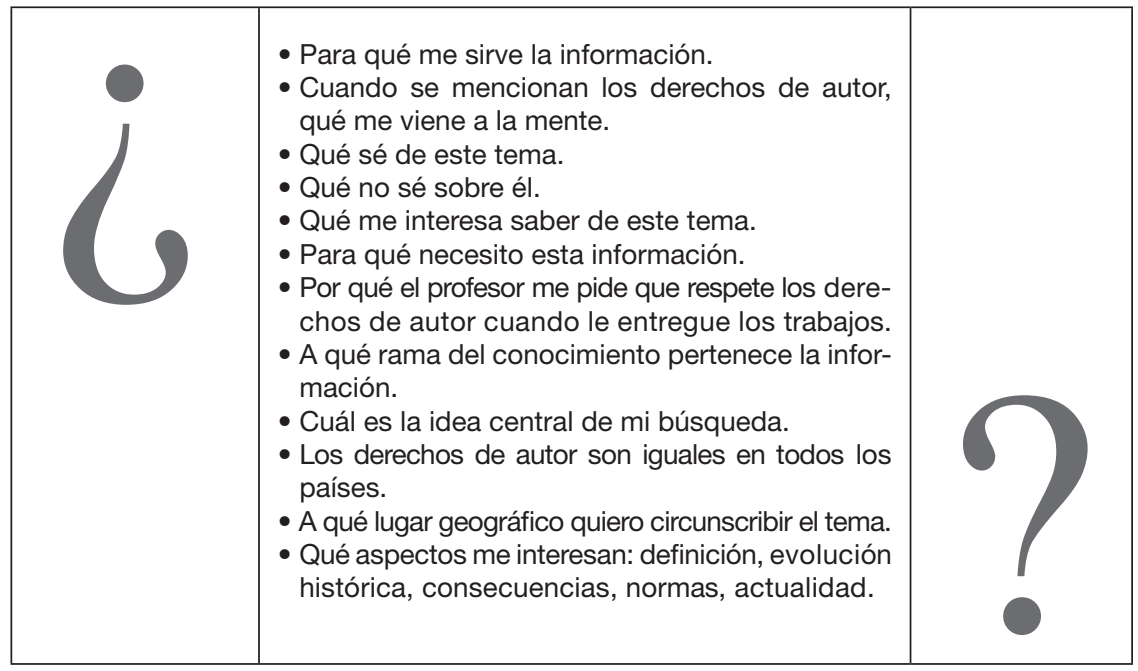

Buscar en libros de referencia como enciclopedias o diccionarios especializados para defi- 


\section{Didáctica de los Sistemas de Información...}

nir los términos le ayudará a definir el tema. ¿Ha buscado alguna vez información sobre este tema?, ¿dónde?. Existen Sistemas de Información Documental (SID) que le ayudan a identificar y definir un tema de búsqueda; ¿sabe qué es un SID?, ¿cuáles SID conoce y ha utilizado?, ¿cómo los reconoce?, ¿tienen algún ícono diferenciador?. Responder estas preguntas le ayudará en forma general a comprender el tema sobre el cual va a investigar y los lugares a donde puede acudir para buscar y encontrar posibles respuestas.

Se le sugiere elaborar un mapa con las ideas que van surgiendo, así podrá visualizar su objeto de investigación. Para el diseño debe tener presente:

- La idea central.

- Piense en los subtemas (sólo uno de ellos será el que desarrolle en la actividad).

- Piense en aspectos relacionados con cada uno de los subtemas, esos aspectos los puede investigar.

- Indique los SID en los que cree que encontrará la información.

\section{Fase de recuperación y análisis}

Una vez definidos los elementos de su necesidad de información, debe saber dónde empezar a buscar. Elabore una lista de esos sitios o SID, verifique y procure la accesibilidad a ellos. Le serán de gran ayuda para continuar con la actividad.

Como ya reconoció algunos SID es el momento de profundizar en ellos, conocer sus características y concentrarse en aquéllos que permitirán optimizar la búsqueda y recuperación de la información, de acuerdo con las necesidades e ideas que tenga del trabajo a desarrollar. En otras palabras, reconocerá las fuentes de información (que existen en los SID), en las que hará la búsqueda y aprenderá a utilizarlas.

Para ello deberá responder: 


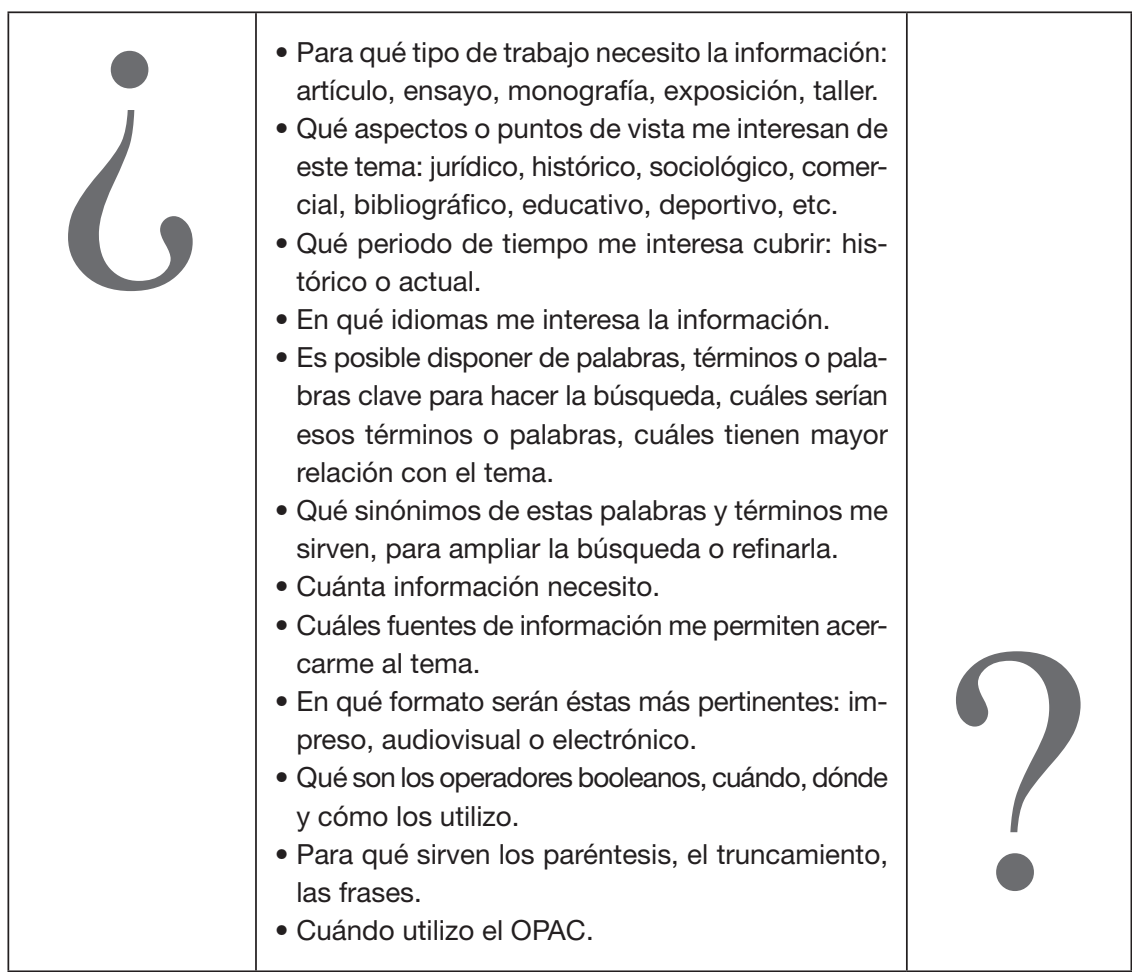

La estrategia de búsqueda está organizada, es momento de aplicarla para proceder a recuperar la información.

\begin{tabular}{|l|l|}
\hline & $\begin{array}{l}\text { Dónde encontraría la fuente impresa, cómo la } \\
\text { buscaría. } \\
\text { - Cómo buscaría el tema en una base de datos y } \\
\text { en cuál base de datos. } \\
\text { - De qué manera me servirán los metabuscadores, } \\
\text { o es suficiente con los buscadores tradicionales } \\
\text { - Localicé la información en una base de datos, } \\
\text { pero no encuentro el artículo completo; cómo } \\
\text { hago para obtenerlo. }\end{array}$ \\
\hline
\end{tabular}

Ya recuperó los documentos que localizó en los diferentes SID, en este momento debe analizar la importancia y validez de la información que éstos contienen, para eso determine: 


\begin{tabular}{|l|l|}
\multicolumn{1}{|c|}{$\begin{array}{l}\text { De las fuentes que encontré ¿cuáles } \\
\text { son las mejores y las más indica- } \\
\text { das? Para determinarlo, responda las } \\
\text { siguientes preguntas: }\end{array}$} \\
\hline \multicolumn{1}{|c|}{ PREGUNTA } \\
\hline
\end{tabular}


- ¿Cuáles son las ideas principales de los documentos?

- ¿Cuál es la fecha de creación del sitio web?

- ¿Cuáles son las clases de fuentes de información en las que encontró el tema? ¿Con ellas sí puede profundizar al nivel que pretende?

- ¿A quién va dirigida la publicación: investigadores, expertos, profesionales, público en general?

- ¿La publicación es muy técnica o muy elemental?

- ¿La obra presenta un solo punto de vista o varios?

- ¿Cuál es la formación académica de quién escribe? ¿Ha escrito otros documentos? ¿A qué institución pertenece?

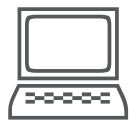

\section{Fase de transformación o síntesis}

Una vez seleccionados los documentos se entra a la fase en la cual se inicia el proceso de comprensión e interpretación de la información. Con sus palabras, o algunas veces con ayuda de los autores, va a escribir sus propias ideas. Para ello se le sugiere:

Organice las fuentes de información por su nivel de

importancia, de acuerdo con su necesidad

de información.

Determine el lenguaje que utilizan los documentos, sea

general o especializado.

Separe los temas básicos de los complementarios y asígneles una palabra o frase que los identifique.

Anote los propósitos del documento.

Lleve este resultado a un gráfico.

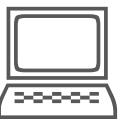

Es el momento de conversar: cómo se siente realizando esta actividad, qué ha sido lo más difícil de comprender y qué lo más fácil. ¿Qué sugerencias tiene para los compañeros, para el profesor y para la actividad? 
- Lea cuidadosamente los documentos seleccionados

- Determine si el contenido de los documentos responde a las preguntas que se formuló o a la necesidad de información que se planteó

- ¿El contenido es coherente, presenta cohesión en su redacción, es pertinente con el interés que tiene y es imparcial?

- ¿Cree que se omitió alguna información?

- ¿Los conceptos más importantes de los documentos tienen relación entre sí?

- ¿La información de los diferentes documentos presenta puntos de acuerdo o de desacuerdo entre ellos?

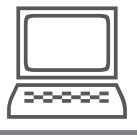

- Organice un esquema categorial, el cual puede surgir de las palabras o frases con las que identificó los temas básicos en la fase anterior; en esas categorías también puede tener subcategorías.

- Seleccione los párrafos y las ideas de los documentos que se ubican en las categorías.

- Una vez organizados, revise y determine cuáles ideas o párrafos son concurrentes o similares y cuáles son diferentes o no se repiten en las ideas seleccionadas.

- ¿Cómo se ven esas ideas en la vida cotidiana, en su mundo real? ¿Se cumple todo lo que dice allí?

- ¿Con cuáles ideas está de acuerdo y con cuáles en desacuerdo? ¿Por qué?

- ¿Le surgen preguntas alrededor de este tema? ¿Cuáles?

- ¿Qué concluye de estas ideas y propuestas?

- ¿Tiene alguna propuesta sobre este tema?

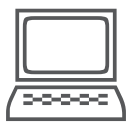

Revise el esquema y organícelo nuevamente con las ocurrencias y las diferencias que encuentre, escriba las respuestas que le da a las últimas cinco preguntas anteriores. Organice sus respuestas y sus ideas en un texto que sea coherente y comprensible. 
No olvide anotar las referencias bibliográficas que utilizó y tenga en cuenta la norma en la que se apoyó para las citas textuales y las indirectas.

Es el momento de "publicar" o pasar su escrito a un espacio abierto: el edublog. Allí compartirá su reflexión y experiencia con los compañeros y el profesor. Pero antes, responda estas preguntas:

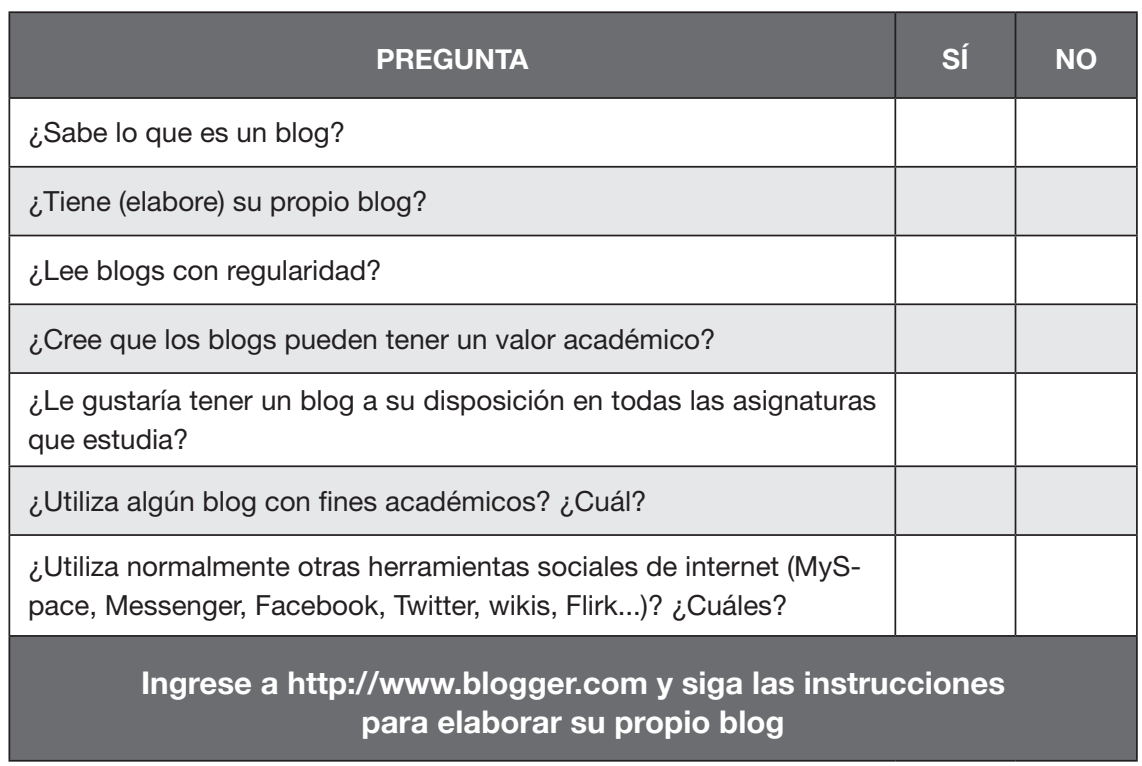




\section{ESTRATEGIA DIDÁCTICA TRINCO: TRANSFORMACIÓN DE LA INFORMACIÓN EN CONOCIMIENTO -- Evaluación de la estrategia -- Aplicación de la prueba piloto}

A continuación se pide que evalúe su experiencia con esta estrategia; lo que permitirá corroborar la pertinencia y calidad y, en caso de ser necesario, mejorar el diseño y aplicación.

Muchas gracias por su colaboración.

¿Cuál fue su tema de investigación?

¿Cree que las ideas iniciales que tenía acerca de los derechos de autor se modificaron? ¿De qué manera?

¿Qué opinión tiene de esta estrategia?

¿Le recomendaría esta estrategia a algún compañero o profesor?

¿Por qué?

¿Qué sugerencias tiene para esta estrategia? ¿Se puede dejar así o en qué se debe mejorar?

Señale las habilidades, conocimientos, valores y actitudes que obtuvo con esta estrategia:

\begin{tabular}{|l|l|l|l|}
\hline & Identificar problemas & Rechazar información & \\
\hline & Reflexionar & Uso de los SID & \\
\hline & Reconocimiento de íconos & Uso de las TIC & \\
\hline & Identificar la necesidad de información & Organizar la información & \\
\hline & Definir la necesidad de información & Graficar la información seleccionada & \\
\hline & Expresar la necesidad de información & Sintetizar la información & \\
\hline & Desarrollar estrategias de búsqueda & Habilidades comunicativas orales & \\
\hline & Localizar la información & Interpretación de la información & \\
\hline & Recuperar la información & Comprensión de la información & \\
\hline & Acceder a la información & Elaborar una síntesis de la información & \\
\hline & Consultar la información & Habilidades comunicativas escritas: redacción & \\
\hline & Comparar la información & Diseñar un blog & \\
\hline & Analizar la información & Publicar en Internet & \\
\hline & Seleccionar la información & Respetar los derechos de autor & \\
\hline
\end{tabular}




\section{EVALUACIÓN DE LA ESTRATEGIA}

\section{DIDÁCTICA TRINCO}

La evaluación es un proceso esencial que debe llevarse a cabo en cualquier acción que involucre el aprendizaje de los sujetos, pues permite comprobar el nivel de cumplimiento de los objetivos trazados y el aprendizaje de los participantes; además de identificar las inconsistencias y dificultades que podrán ser resueltas en los diferentes segmentos de las fases y, por ende, hacer futuras mejoras y desarrollos en la estrategia didáctica TRINCO.

Se recomienda dedicar el tiempo suficiente a la evaluación tanto de los segmentos por parte de los participantes, como a la evaluación de los profesores y bibliotecólogos, y hacerlo de una manera constructiva, incluso desde el momento en que ya esté planeando la implementación de la estrategia y hasta que finalice. También se evalúa el aprendizaje y la comprensión de los usuarios, las actividades, los medios y recursos didácticos, el manejo del tiempo, y el de los contenidos. Si el programa está diseñado para el beneficio de los participantes es razonable tener en cuenta que éstos pueden aportar ideas y sugerencias para futuros cursos; de ahí la importancia de sistematizar y difundir los resultados de la evaluación para obtener una retroalimentación de quienes participan en el proceso. Por lo tanto, con la evaluación:

- Se busca conocer el grado de comprensión por parte del usuario sobre los temas discutidos, los compromisos y las labores académicas realizadas.

- Se reconoce el proceso de enseñanza llevado a cabo por el profesor y el bibliotecólogo, su facilidad de comunicación y la capacidad para hacerse comprender, así como sus manejos del tiempo. 
- Se hace posible verificar la calidad y eficacia del diseño y la planificación de la estrategia didáctica.

- Se tienen en cuenta los procesos realizados dentro de la formación y los segmentos de las fases que constituyen el proceso, aplicando una evaluación formativa y cualitativa.

- Las preguntas del usuario son orientadas para que él mismo encuentre las respuestas a partir del proceso de reconocimiento de sus conocimientos previos y su necesidad de información.

- Se utiliza la evaluación grupal, apoyándose en la autoevaluación y la coevaluación partiendo de parámetros planteados con antelación.

La evaluación de la estrategia se realizó desde el primer momento del encuentro con los estudiantes, acción que realizó la investigadora como parte de su labor con la prueba piloto. Se observó la participación de los estudiantes durante el curso, la interacción entre ellos, los temas que discutían y las respuestas que daban a las preguntas; y de igual manera, se tuvo en cuenta el interés que mostraron hacia la temática planteada: los derechos de autor.

Como resultado de esta prueba piloto y con el fin de disponer de un soporte que permitiera determinar la comprensión del tema, consecuentemente el aprendizaje en el uso de los SID por parte de los estudiantes, se solicitó la entrega de un gráfico, de acuerdo con las siguientes orientaciones:

Una vez seleccionados los documentos [segunda fase], se entra a la fase en la cual se inicia el proceso de comprensión e interpretación de la información [fase tres]. Con sus palabras, o algunas veces con ayuda de los autores, va a escribir sus propias ideas. Para ello se le sugiere que: 
- Organice las fuentes de información por su nivel de importancia, de acuerdo con su necesidad de información.

- Determine el lenguaje que utilizan los documentos, sea éste general o especializado.

- Separe los temas básicos de los complementarios y asígneles una palabra o frase que los identifique.

- Anote los propósitos del documento.

- Lleve este resultado a un gráfico.

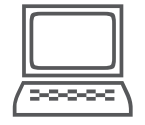

Cada uno de los estudiantes elaboró el gráfico, en los cuales demostró la comprensión de las orientaciones y del trabajo en general, pues de no haber realizado las acciones en las fases anteriores, posiblemente no hubiera podido graficar la información en este segmento.

Otro soporte de la viabilidad de la estrategia son los siguientes edublogs elaborados por los mismos estudiantes:

- Derechos de autor en medios audiovisuales: http://manejomusicaaudiovisual.blogspot.com/

- Los derechos de autor en la fotografía: http://paito-alvarez.blogspot.com/

- Ley 1520 de 2012 (Ley Lleras) ¿privatización o protección?: http://sandra-sanchezna.blogspot.com/

- Ley 1520 de 2012: Medidas Tecnológicas de Protección a los Derechos de Autor: http://maryloaiza1.blogspot.com/

Los cuatro edublogs muestran el proceso de transformación de la información en conocimiento, teniendo en cuenta los documentos referenciados en la bibliografía y comparados con el escrito; además de que la bibliografía fue presentada siguiendo dos tipos de normas: dos estudiantes se apoyaron en las normas ICONTEC y los otros dos en las normas APA. 
Por último, se pidió que contestaran la evaluación de la estrategia TRINCO (ver formato de evaluación), organizada con una serie de preguntas, de cuyas respuestas se puede determinar:

- Para tres estudiantes las ideas que tenían del tema no se modificaron, sino que ampliaron su conocimiento, pues abordaron nuevos documentos que permitieron esa opción; la otra estudiante asegura que no sabía -prácticamente- nada del tema, pero le quedan nuevas perspectivas y conocimientos sobre un tema de interés general.

- Los estudiantes tienen opiniones positivas de la estrategia pues, según ellos, lograron realizar un trabajo de investigación amplio y complejo a pesar de lo dispendioso; esto les permitió conocer nuevas fuentes de información y manejar la información para redactar sus trabajos con coherencia. También resaltaron que es una forma muy organizada de buscar la información, lo que permite una adquisición puntual de ella, además de confrontar los saberes y la comprensión de lo leído.

- Los cuatro coincidieron en que les recomendarían la estrategia a profesores y compañeros, pues facilita y agiliza la búsqueda de la información, y ayuda a seleccionar aquella que realmente se necesita, además de mostrarles un camino para transformar la información. Asimismo, una vez organizada y jerarquizada la información, la estrategia les permitió reducir el tiempo de escritura del trabajo final. Indicaron que lograron aprender mucho: llegar a conclusiones y sentirse cómodos con el compromiso académico.

- En cuanto a las sugerencias para mejorar la estrategia, dos manifestaron que la dejarían así; la otra estudiante sugiere que se reduzca el número de preguntas, ya que se hace largo el tiempo, no obstante aclara que "en general es muy buena" la estrategia. 
- En cuanto a las habilidades, conocimientos, valores y actitudes que dicen haber obtenido, casi todos lo lograron, con excepción de las habilidades comunicativas orales (dos), la identificación de problemas (uno), consultar la información (uno) y el uso de las TIC (uno).

En consecuencia, y como resultado de la prueba piloto para verificar la posibilidad de utilizar la estrategia didáctica TRINCO para transformar los datos y la información en conocimiento, se comprueba que ésta cumple con las expectativas y se puede aplicar con esa intención. 


\section{Consideraciones finales o el cierre temporal de la experiencia hermenéutica}

as consideraciones finales, también conocidas como conclusiones, se asumen como otro proceso del círculo de la comprensión de la experiencia hermenéutica que, temporalmente, se cierra para abrirse en otro momento, cuando surjan nuevas preguntas, nuevas posibilidades o se pretenda contestar algunos de los interrogantes que aquí se formulan.

Se resalta que las estrategias didácticas son procesos para desarrollar habilidades para el aprendizaje, éstas emanan de la reflexión teórica y exigen una planificación sistemática de cada uno de los pasos que las componen; razón de más para decir que antes de utilizarlas es necesario analizar, comprender y reconocer a los sujetos y el contexto donde se utilizarán, y adaptarlas a esas circunstancias.

La ciencia de la información le hace un gran aporte a la educación, al poner a su disposición los Sistemas de Información Documental (SID) como medios que albergan la información del saber que se ha elaborado en el transcurso de la humanidad; a su vez, la educación le aporta a la ciencia de la información la com- 
prensión de la didáctica para poder llevar los SID al aula como medios didácticos que facilitan, junto con otros componentes del sistema didáctico, la transformación de la información en conocimiento.

Con esta investigación se realizan varios aportes, unos nuevos y otros a manera de síntesis de la transformación de la información. Algunos de ellos son:

- La transformación de los conceptos dato, información y conocimiento a partir de la ciencia de la información para comprenderlos como insumo de los documentos que se localizan en los SID.

- La estrategia didáctica TRINCO, aporta una forma de mostrar el camino para acercarse a la información y al conocimiento que se requiere en los procesos de enseñanza y de aprendizaje en el acto educativo, con lo que también se introducen procesos hermenéuticos de comprensión e interpretación sobre lo que se lee, lo cual, se transforma y comunica en una síntesis a través de diferentes herramientas, como el edublog, una forma de optimizar las Tecnologías de la Información y la Comunicación (TIC), y se incorporan las nuevas formas de interacción de las personas a través de las redes sociales.

- A la Ciencia de la Información le hace un gran aporte la claridad de las fases de la estrategia didáctica TRINCO; en tanto la educación, destaca el papel de la segunda fase de la estrategia para aclarar por qué los SID, además de medios, son espacios que albergan información; mientras la tercera fase esclarece el proceder hermenéutico.

- El proceso de comunicación se desvela al mostrar la conversación como otro elemento transversal del acto educativo, donde cada uno de los sujetos que intervienen en él ya sea discutiendo, preguntando o aportando, juegan un papel 
protagónico para el interés de transformar los datos y la información en conocimiento, como una forma de apropiarse de este último y, tal vez, generar nuevo conocimiento.

- La relación entre los componentes del sistema didáctico con los SID, donde éstos son transversales a cada uno y organizan la información para hacerla disponible a los sujetos del proceso educativo, que requieren de ella en todo momento, subvierten así el sistema didáctico de la didáctica.

- La experiencia hermenéutica, como enfoque de carácter cualitativo para la investigación, convierte las vivencias de los sujetos o su modo de ver la realidad en elementos que permiten encontrar el horizonte para crear la estrategia didáctica.

- La experiencia hermenéutica es un proceso metodológico que posibilita, no sólo comprender e interpretar los textos fijos, sino también los textos vivos (los sujetos); y en esa medida se convierte en un medio transformador del sujeto que, como hermeneuta, asume un estilo de vida que permea su desempeño académico, profesional y personal.

La estrategia didáctica TRINCO les permitirá a los profesores potenciar y dinamizar las acciones educativas en ese espacio privilegiado con los estudiantes, con el uso consciente de los SID, portadores de los datos y la información para su formación profesional, y ellos aprenderán así a transformar el conocimiento que requieren para su desempeño en una sociedad que está en constante cambio. 



\section{Bibliografía}

Abadal, E. y Codina, L. (2005), "Recuperación de información", en Codina, L. (Eds.). Bases de datos documentales: características, funciones y método, Madrid: Síntesis.

Aguirre, J. (2001), "Ciberespacio y comunicación: nuevas formas de vertebración social en el siglo XXI" en Revista de Estudios Literarios. Disponible en: http://www.ucm.es/info/ especulo/numero27/cibercom.html [Fecha de consulta: 4 de febrero de 2009].

Alás, A. et al., (2002), Las tecnologías de la información y la comunicación en la escuela, Caracas: Laboratorio Educativo: Barcelona: Graó.

Alonso, A. (2004), Los medios en la comunicación educativa: una perspectiva sociológica, México: Limusa: Universidad Pedagógica Nacional.

Álvarez, C. y González, E. (2002), Lecciones de didáctica general, Bogotá: Cooperativa Editorial Magisterio. 
Álvarez, C. (1999), La escuela en la vida: didáctica, La Habana: Pueblo y Educación.

Angeloni, M. (2003), "Elementos intervenientes na tomada de decisão", en Ciência da Informação, 32 (1), 17-22.

Arnold, M. y Osorio, F. (1998), Introducción a los conceptos básicos de la teoría general de sistemas. Cinta de Moebio, 3. Disponible en: http://rehue.csociales.uchile.cl/publicaciones/moebio/03/frames45.htm [Fecha de consulta: 25 de enero de 2010].

Arroyave, D. (2001), La didáctica como un sistema complejo, Tesis de doctorado en Pedagogía, no publicada. Universidad de Pinar del Río, Pinar del Río, Cuba.

Association of College and Research Libraries (2003), "Standards and Guidelines", en College E Research Libraries News, 64 (5), 329-336.

Barnett, R. (2001), Los limites de la competencia: el conocimiento, la educación superior y la sociedad, Barcelona: Gedisa.

Beazley, H., Boenisch, J. y Harden, D. (2004), La continuidad del conocimiento en las empresas, Bogotá: Norma.

Beltrán, J. (1996), "Estrategias de aprendizaje”, en Beltrán, J. y Genovard, C. (coords.). Psicología de la instrucción, Madrid: Síntesis.

Bernhard, P. (2005), La formación en el uso de la información: una ventaja en la enseñanza superior. Situación actual, Anales de Documentación, 409-434. Disponible en: http:// redalyc.uaemex.mx/, http://www.um.es/fccd/anales/ [Fecha de consulta: 10 de abril de 2008].

Bertalanffy, L. (2001), Teoría general de los sistemas: fundamentos, desarrollos y aplicaciones, México: Fondo de Cultura Económica. 
Bogdan, R. (1994), Grounds for cognition. How goal-guided behavior shapes the mind, New Jersey: Lawrence Earlbaum.

Bolívar, A. (2005), "Conocimiento didáctico del contenido y didácticas específicas. Profesorado", en Revista de Currículum y Formación del Profesorado, 9(2), 1-39. Disponible en: http://www.ugr.es/ recfpro/rev92ART6.pdf [Fecha de consulta: 15 de abril de 2009].

Brookes, B. (1975), "The fundamental problem of information science", en Horsnell, V. (ed.) Informatics 2, Londres: ASLIB.

Burch, J. y Strater, F. (1981), Information systems: theory and practice, California: Willey.

Calderín, M. (2007), Sistema de información documental en la academia: situación actual y perspectivas futuras, caso UCAB, Hologramática, 7(14). Disponible en: http://www.cienciared. com.ar/ra/usr/3/333/n6_v1pp51_76.pdf [Fecha de consulta: 2 de febrero de 2009].

Camilloni, A., Cols, E. y Feeney, S. (2008), El saber didáctico, Buenos Aires: Paidós.

Capurro, R. y Hjorland, B. (2007), "O conceito de informação”, en Perspectiva em Ciência da Informação, 12 (1). Disponible en: http://www.scielo.br/pdf/pci/v12n1/11.pdf [Fecha de consulta: 2 de febrero de 2009].

Capurro, R. (1978), Information: A contribution to the foundation of the concept of information based on its etymology and in the bistory of ideas. Munich, Germany: Disponible en: http://www.capurro.de/info.html [Fecha de consulta: 19 de enero de 2010]. 
- - - (2008), Pasado, presente y futuro de la noción de información, en Encuentro Internacional de Expertos en Teorías de la Información: un enfoque interdisciplinar. Universidad de León (Castilla y León, España), 6-7 de noviembre. Disponible en: http://www.capurro.de/leon.pdf [Fecha de consulta: 8 de noviembre de 2009].

Carvajal, E. (2002), La trascendencia del método, la metodología, la didáctica, la estrategia, la metódica y la mediación en el proceso docente investigativo universitario, Monografía de especialización en Educación, no publicada. Universidad de Antioquia, Medellín, Colombia.

Casares, J. (1997), Diccionario ideológico de la lengua española: desde la idea a la palabra, desde la palabra a la idea, Barcelona: Gustavo Gili.

Castells, M. (1989), La ciudad informacional: tecnologías de la información, reestructuración económica y el proceso urbano-regional, Madrid: Alianza.

- - - (1998), La era de la información: economía, sociedad y cultura, vol. 1, Madrid: Alianza Editorial.

Catoggio, L. (2008), "El principio de indisponibilidad del lenguaje y la fusión de horizontes en la hermenéutica filosófica de Hans-Georg Gadamer", en Ideas y Valores, 137, 113-129. Disponible en: http://www.revistas.unal.edu.co/ index.php/idval/article/viewFile/1490/2115 [Fecha de consulta: 11 de noviembre de 2009].

Codina, L. (1994), "Modelo conceptual de un sistema de información documental”, en Revista Española de Documentación Científica, 17(4). Disponible en: http://www.bibliologia.info/archivos/codina2.pdf [Fecha de consulta: 2 de febrero de 2009]. 
- - - (2002), "Información documental e información digital", en López, J. Manual de ciencias de la documentación, Madrid: Pirámide.

Cohen, M. (1964), "El arte de la escritura", en El Correo de la Unesco, 17, 4-8.

Colombia. Ministerio del Interior (2012), Proyecto de Ley: Por el cual se regula la responsabilidad por las infracciones al derecho de autor y los derechos conexos en Internet. Bogotá: Autor. Disponible en: http://www.mij.gov.co/Ministerio/ Library/Resource/Documents/ProyectosAgendaLegistaliva/ Derechos\%20de\%20Autor\%20en\%20Internet1680.pdf [Fecha de consulta: 10 de marzo de 2012].

- - - (2012), Dirección Nacional de Derecho de Autor, Jurisprudencia colombiana sobre derecho de autor $y$ derechos conexos, Bogotá: Autor. Disponible en: http://www. derechodeautor.gov.co/htm/legal/jurisprudencia/listado.asp [Fecha de consulta: 10 de marzo de 2012].

Comenio, J. (1992), Pampedia: educación universal, Valladolid: Universidad Nacional de Educación a Distancia.

- - - (2007), Didáctica magna (17ª ed.), México: Porrúa.

Corominas, J. y Pascual, J. (1980), Diccionario crítico etimológico castellano e hispánico, Madrid: Gredos.

Davenport, T.; Prusak, L. (1998), Working Knowledge: How Organizations Manage What They Know, Massachusetts: Harvard Business School Press.

Debons, A., Horne, E. y Cronenweth, S. (1988), Information science: an integrated view, Boston: Hall.

Descartes, R. (1989), Discurso del método ( $1^{\text {a }}$ ed.), Madrid: Alfaguara.

Díaz, Á. (1997), Didáctica y currículum: convergencia en los programas de estudio, México: Paidós. 
Díaz, D. (2001), "La didáctica universitaria: una alternativa para transformar la enseñanza", en Acción Pedagógica, 10 (1-2), 64-72.

Dodd, L. (2007), The impact of Problem-Based Learning on the information behavior and literacy of Veterinary Medicine students at University College Dublin. The Journal of Academic Librarianship, 2 (33). Disponible en: http://vnweb. hwwilsonweb.com/hww/jumpstart.jhtml? recid=0bc05f7a 67b1790ee228b7083660069fa16d3f8e2796c1993356e761 51439b779ac6fd2b33673e58 \&fmt=P [Fecha de consulta: 30 de mayo de 2008].

Dretske, F. (1999), Knowledge and the flow of information, Chicago: The University of Chicago Press.

Eco, U. (1991), Tratado de semiótica general ( $5^{\text {a }}$ ed.), Barcelona: Lumen.

EFE (11 Ene. 2009), "Muere lentamente: un falso Neruda que no para de crecer en Internet", en $A B C . e s$. Disponible en: http://www.abc.es/20090111/cultura-literatura/muerelentamente-falso-neruda-200901111836.html [Fecha de consulta: 18 de febrero de 2009].

EFE (15 Sep. 2008), "Es urgente la separación entre rumores y ciencia en Internet", en El Espectador, Disponible en: http:// www.elespectador.com/tecnologia/articulo-urgenteseparacion-entre-rumores-y-ciencia-internet [Fecha de consulta: 15 de septiembre de 2008].

Fernández, J. (2009), Hispanoteca cultura y lengua: portal de lengua y cultura hispanas para países de habla alemana, Austria: Universität Innsbruck Zentraler Informatikdienst. Disponible en: http://culturitalia.uibk.ac.at/hispanoteca/Foro-preguntas/ARCHIVO-Foro/Conocimiento.htm [Fecha de consulta: 10 de septiembre de 2009]. 
Ferrater, J. (1994), Diccionario de filosofía. Barcelona: Ariel.

Flores, M. (2009), "Epistemología y Hermenéutica: Entre lo conmensurable y lo inconmensurable", Cinta de Moebio, 36, 198-211. Disponible en: http://www.facso.uchile.cl/ publicaciones/moebio/36/flores.pdf [Fecha de consulta: 4 de marzo de 2010].

Flores, T. y Torres, G. (2005), La gestión de la información; como alfabetización en la formación de usuarios de la UAM Unidad Xochimilco, Tesis de maestría en Ciencia de la Información, no publicada, Universidad Autónoma de México, México. Disponible en: http://www.um.es/cugio/tesis/ TomasFlores_tesis_2UAM.pdf [Fecha de consulta: 25 de mayo de 2008].

Freire, P. (1972), Educación como práctica de la libertad, Bogotá: Convergencia.

- - (1997), Pedagogía de la autonomía: saberes necesarios para la práctica educativa, México: Siglo XXI Editores.

Gadamer, H-G. (2005), Verdad y método, t. I. Salamanca: Sígueme.

- - - (2006a), Estética y hermenéutica (3 ${ }^{\mathrm{a}} \mathrm{ed}$ ), Madrid: Tecnos.

- - - (2006b), Verdad y método, t. II. Salamanca: Sígueme, 2 tomos.

García, J. y García, Á. (1996), Teoría de la educación. I. Educación y acción pedagógica, Salamanca: Universidad de Salamanca.

Génova F., G. (1996), Charles Pierce: la lógica del descubrimiento, Navarra: Universidad de Navarra.

Goetz, J. y LeCompte, M. (1988), Etnografía y diseño cualitativo en investigación educativa, Madrid: Morata. 
González, E. y Castrillón, G. (2001), "Acerca de las concepciones didácticas o del conversar sobre el conocimiento", en Cuadernos Pedagógicos, 15, 45-50.

González, E. y Díaz, D. (2008), "Desde el currículo hasta la didáctica o sobre la circulación de los saberes y sus controles en la universidad: un ejemplo en la enseñanza de la Medicina”, en Iatreia, 21 (1), 83-93. Disponible en: http://www. scielo.org.co/pdf/iat/v21n1/v21n1a10.pdf [Fecha de consulta: 24 de septiembre de 2008].

González, E. (1998), La educación: metáfora de la vida: modelo pedagógico basado en la comunicación para generar acciones creativas en el mundo de la vida, Tesis de Doctorado en Ciencias Pedagógicas, no publicada, Universidad de La Habana, La Habana, Cuba.

- - (2005), "El desarrollo de competencias científicas en la educación superior", en Lectiva, 10, 39-46.

- - - (2006), Sobre la hermenéutica o acerca de las múltiples lecturas de los real, Medellín: Universidad de Medellín.

- - - (2011a), "La didáctica en la educación superior", en La Gaceta Didáctica, 8, 1.

- - - (2011b), "Sobre la experiencia hermenéutica o acerca de otra posibilidad para la construcción del conocimiento", en Discusiones Filosóficas, 12 (18), 1-19.

González, F. (1995), Comunicación, personalidad y desarrollo, La Habana: Pueblo y Educación.

González, M. N. (2003), "La sociedad del conocimiento: conceptos y premisas", en Contribución al desarrollo de la sociedad del conocimiento, México: UNAM, Centro Universitario de Investigaciones Bibliotecológicas. 
González, M. (2003), "Rememoración y tradición: la hermenéutica entre Heidegger y Gadamer", en Signos Filosóficos, 10, 87-102. Disponible en: http://148.206.53.230/revistasuam/signosfilosoficos/include/getdoc.php?id= $292 \&$ article $=282 \&$ mode $=$ pdf [Fecha de consulta: 8 de octubre de 2007].

Gotbeter, G. (2006), "Una didáctica basada en la implementación de proyectos", en 12 (ntes): papel y tinta para el día a día en la escuela, 6. Disponible en: http://www.12ntes. com/revista/numero06.pdf [Fecha de consulta: 15 de agosto de 2008].

Grisales, L. (2011), Desde la pregunta, en tanto mediación, hacia la traducción como un principio didáctico en la educación superior, Tesis de doctorado en Educación, no publicada, Universidad de Antioquia, Medellín, Colombia.

Gutiérrez, C. (2008), "La filosofía y su historia", en Ideas y valores: revista colombiana de filosofía, 137, 63-73. Disponible en: http://dialnet.unirioja.es/servlet/listaarticulos? tipo_busqueda=EJEMPLAR\&revista_busqueda=9639 \&clave_busqueda=198050 [Fecha de consulta: 11 de noviembre de 2009].

Habermas, J. (1989), Teoría de la acción comunicativa, Buenos Aires: Taurus.

Hegel, G. (1973), Enciclopedia de las ciencias filosóficas ( $\left.2^{\mathrm{a}} \mathrm{ed}.\right)$, México: Porrúa.

Heidegger, M. (1971), El ser y el tiempo (2a ed.), México: Fondo de Cultura Económica.

- - - (1990), De camino al habla, Barcelona: Ediciones del Serbal.

- - (2005), La idea de la filosofía y el problema de la concepción del mundo, Barcelona: Herder. 
Henao, J. y Castañeda, L. (2002), Ciencia y pedagogía: el papel del lenguaje en la apropiación del conocimiento, Bogotá: ICFES.

Huaylupo, J. (2008), "La relatividad y significación de los datos", en Cinta Moebio 32, 127-152. Disponible en: www.moebio. uchile.cl/32/huaylupo.html [Fecha de consulta: 15 de enero de 2009].

Huertas, J. (2009), "Aprender a fijarse metas: nuevos estilos motivacionales", en Pozo, J. y Pérez, M., Psicología del aprendizaje universitario: la formación en competencias, Madrid: Morata.

Kant, I. (1787), Crítica de la razón pura. Disponible en: www.planetalibro.com.ar [Fecha de consulta: 10 de marzo de 2010].

Kaplún, M. (1998), Una pedagogía de la comunicación, Madrid: Ediciones de La Torre.

Karpatschof, B. (2007), "Human activity. Contributions to the anthropological sciences from a perspective of activity theory", en Information Research, 12 (3). Disponible en: http://informationr.net/ir/12-3/Karpatschof/Karp00.html [Fecha de consulta: 25 de abril de 2010].

Klafki, W. (1990-1991), "Sobre la relación entre didáctica y metódica”, en Revista Educación y Pedagogía, 2 (5), 85-108.

Klingberg, L. (1990), Introducción a la didáctica general, La Habana: Editorial Pueblo y Educación.

Kornwachs, K. (1996), "Pragmatic information and system surface”, en Kornwachs, K. \& Jacoby, K. (eds.), Information. New questions to a multidisciplinary concept, New York: Wiley \& Sons.

Lalande, A. (ed.) (1953), Vocabulario técnico y crítico de la filosofía, Buenos Aires: Ateneo, 2 t. 
Laudon, K. y Laudon, J. (1996), Administración de los sistemas de información: organización y tecnología ( $3^{\mathrm{a}}$ ed.), México: Prentice Hall.

Litwin, E. (1997), Las configuraciones didácticas: una nueva agenda para la enseñanza superior, Buenos Aires: Paidós.

- - - (2001), Las nuevas tecnologías y las prácticas de la enseñanza en la Universidad. Disponible en: http:// www. litwin.com.ar/site/Articulos2.asp [Fecha de consulta: 10 de junio de 2007].

- - - (2007), La integración: una estrategia de enseñanza para favorecer mejores reflexiones en la enseñanza superior. Disponible en: http://www.litwin.com.ar/site/Articulos1.asp [Fecha de consulta: 10 de junio de 2007].

- - - (2008), El oficio de enseñar: condiciones y contextos. Buenos Aires: Paidós.

- - - (2009), "Controversias y desafíos para la universidad del siglo XXI", en Primer Congreso Internacional de Pedagogía Universitaria, 7, 8 y 9 de septiembre 2009, Buenos Aires, Argentina. Disponible en: http://www.uba.ar/imagenes_noticias/image/conferencia2.pdf [Fecha de consulta: 8 de septiembre de 2009].

Locke, J. (2002), Ensayo sobre el entendimiento humano ( $2^{\mathrm{a}} \mathrm{ed}$.), México: Fondo de Cultura Económica.

Lopera, H. (2010), Cibercultura crítica universitaria: el poder de transformar la sociedad informatizada. Una propuesta desde el enfoque de las pedagogías decoloniales para orientar la formación crítica universitaria en la era digital, Tesis de maestría en Educación, no publicada, Universidad de Antioquia, Medellín, Colombia. Disponible en: http://www.slideshare.net/hlopera/cibercultura-crticauniversitaria-el-poder-de-transformar-la-sociedadinformatizada [Fecha de consulta: 12 de marzo de 2012]. 
López, J. (2004), Diccionario enciclopédico de ciencias de la documentación, Madrid: Taurus. 2 vol.

Machlup, F. y Mansfield, U. (eds.) (1983), The study of information. Interdisciplinary messages, New York: Wiley-Interscience.

Mahler, G. (1995), Quantum information, en Kornwachs, K. y Jacoby, K. (eds.). Information: new questions to a multidisciplinary concept, proceedings heraeus. Berlin: Akademie Verlag.

Marzal, M. y Calzada, F. (2003), "Un análisis de necesidades y hábitos informativos de estudiantes universitarios en Internet", en Binaria: revista de comunicación, cultura y tecnología, 3. Disponible en: http://www.uem.es/binaria/ in.html [Fecha de consulta: 17 de julio de 2008].

McLuhan, M. (1972), Galaxia Gutenberg, Madrid: Aguilar.

Medawar, P. (1982), Consejos a un joven científico, México: Fondo de Cultura Económica.

Mikhailov, A., Chernyi, A. y Giliarevskii, R. (1984), Scientific communications and informatics, Estados Unidos: Information Resources.

Mockus, A. (2001), Foro Plan de Desarrollo: para vivir todos de un mismo lado, Fecha de consulta en: 27 de febrero de 2004, de Internet (s. w.)

- - - Hernández, C., Charum, C., Castro, M. y Granés, J. (1995), Las fronteras de la escuela: articulaciones entre conocimiento escolar y conocimiento extraescolar, Bogotá: Cooperativa Editorial Magisterio.

Moliner, M. (1997), Diccionario del uso del español, Madrid: Gredos.

Monereo, C. (coord.) (1998), Estrategias de enseñanza y aprendizaje. Formación del profesorado y aplicación en la escuela, Barcelona: Graó. 
- - (2009), "Aprender a encontrar y seleccionar información: de Google a la toma de apuntes”, en Pozo, J. y Pérez, M. Psicología del aprendizaje universitario: la formación en competencias. Madrid: Morata.

Monlau, P. (1856), Diccionario etimológico de la lengua castellana: precedido de unos rudimentos de etimología, Madrid: Imprenta y Estereotipia de U. Riyadkneyra. Disponible en: http://books.google.com.co/books?printsec=frontcover \&pg=PP7\&id=RIDHLtPhwC0C\# $\mathbf{v}=$ onepage\& $\mathrm{q}=\& \mathrm{f}=$ false [Fecha de consulta: 15 de octubre de 2009].

Montero, E. (2001), "Educación e ingreso como predictores de la esperanza de vida: evidencias de un análisis de regresión aplicado a indicadores de desarrollo humano", en Revista de Ciencias Sociales, 4 (94), 51-60.

Monzón, L. (2011), "El blog y el desarrollo de habilidades de argumentación y trabajo colaborativo”, en Perfiles Educativos, 33 (131), 80-93. Disponible en: http://redalyc.uaemex. $\mathrm{mx} /$ redalyc/pdf/132/13218531006.pdf [Fecha de consulta: 21 de junio de 2011].

Morales, E. (1998), "La información en su ir y venir", en La información en el inicio de la era electrónica, México: UNAM, Centro Universitario de Investigaciones Bibliotecológicas.

Moreiro, J. (1995), “Los sistemas de información documental: consideraciones sobres sus características, concepto y funciones”, en Boletín Millares Carlo, 14, 137-150.

- - - (2006), Conceptos introductorios al estudio de la información documental, Lima: Fondo Editorial Universidad Católica del Perú; Bahía: Universidade Federal da Bahia.

Moreno, M. (2008), La hipótesis abductiva o explicativa como experimentación en la perspectiva de Pierce, Inédita.

Morin, E. (1986), El método, t. 3., El conocimiento del conocimiento, Madrid: Cátedra. 
- - - (1994), Introducción al pensamiento complejo, Barcelona: Gedisa.

- - - (2001), Los siete saberes necesarios para la educación del futuro, Barcelona: Paidós.

Moscoso, P. (2002), "Sistemas de información documental: concepto, modelo, estructura y organización”, en López. J. (coord.), Manual de ciencias de la documentación, Madrid: Pirámide.

Muñoz, D. (2001), "El círculo de la comprensión: sobre la hermenéutica de Hans-George Gadamer", en Palimpsesto, 1, 48-57.

Muñoz, J. (2000), "Conocimiento/saber”, en Muñoz, J. y Velarde, J. (eds.), Compendio de epistemología, Madrid: Trotta.

Naranjo, E. y Álvarez, D. (2003), Desarrollo de habilidades informativas: una forma de animar a leer, Medellín: Universidad de Antioquia, Escuela Interamericana de Bibliotecología.

Naranjo, E., Rendón, N. y Giraldo, C. (2006), Evolución y tendencias de la formación de usuarios, Medellín: Universidad de Antioquia, Escuela Interamericana de Bibliotecología.

Navaridas, F. (2004), Estrategias didácticas en el aula de clase, España: Universidad de la Rioja.

Not, L. (1992), La enseñanza dialogante, Hacia una educación en segunda persona, Barcelona: Herder.

- - - (1994), Las pedagogías del conocimiento. México: Fondo de Cultura Económica.

Novak, J. y Gowin, D. (1988), Aprendiendo a aprender, Barcelona: F. E. Peacock. 
Núñez, I. (2007), "Gestión humana o de personas en la construcción de las sociedades del conocimiento", en Acimed, 16 (3). Disponible en: http://bvs.sld.cu/revistas/aci/vol16_ 3_07/aci10907.htm [Fecha de consulta: 28 de mayo de 2008].

Opazo, H. (2011), "Ética en investigación: desde los códigos de conducta hacia la formación del sentido ético", en REICE, 9 (2), pp. 61-78. Disponible en: http://www.rinace.net/reice/ numeros/arts/vol9num2/art04.pdf [Fecha de consulta: 13 de enero de 2012].

Pasquali, A. (1979), Comprender la comunicación, Caracas: Monte Ávila.

Peirce, Ch. (1970), Deducción, inducción e hipótesis, Buenos Aires: Aguilar.

- - (1988), El hombre, un signo: el pragmatismo de Peirce, Barcelona: Crítica.

- - - (2005), El ícono, el índice y el símbolo, trad. Sara Barrena. Disponible en: http://www.unav.es/gep/Icono IndiceSimbolo.html [Fecha de consulta: 4 de septiembre de 2011].

Piaget, J. (1969), Biología y conocimiento: ensayo sobre las relaciones entre las regulaciones orgánicas y los procesos cognoscitivos, México: Siglo XXI Editores.

Platón (1975). Diálogos (15ª ed.). México: Porrúa

- - - (1990), La república. Libro VII, Valencia: Universitat de València.

- - - (1992), Teeteto o sobre la ciencia, Manuel Balasch (trad.), Barcelona: Anthropos.

Pozo, J. (1999), Aprendices y maestros: la nueva cultura del aprendizaje, Madrid: Alianza. 
Prasaad, H. (1992), Information needs and user, Varanasi: Indian Bibliographic Center.

Rajadell, N. (1995), "Estrategias para el cambio de procedimientos (saber hacer)", en González, A., Medina, A. y Torre, S. (coords), Didáctica general: modelos y estrategias para la intervención social, Madrid: Universitas.

Real Academia Española (1729, 1734), Diccionario de la lengua castellana, en que se explica el verdadero sentido de las voces, su naturaleza y calidad, con las phrases o modos de hablar, los proverbios o refranes, y otras cosas convenientes al uso de la lengua [...], Tomo segundo. Que contiene la letra C. Madrid: Imprenta de Francisco del Hierro. Disponible en: http://buscon.rae.es/ntlle/SrvltGUIMenuNtlle?c md=Lema\&sec=1.0.0.0.0 [Fecha de consulta: 3 de mayo de 2010].

- - (2002), Diccionario de la Real Academia Española-DRAE. (22 a ed.) Disponible en: http://buscon.rae.es/draeI/. [Fecha de consulta: 15 de septiembre de 2009].

Rendón, M. (1997), Bases teóricas y filosóficas de la bibliotecología, México: UNAM, Centro Universitario de Investigaciones Bibliotecológicas.

- - - (2005), "Relación entre los conceptos: información, conocimiento y valor. Semejanzas y diferencias", en Ciência da Informação, 34 (2), 52-61.

Ricoeur, P. (2006), Teoría de la interpretación: discurso y excedente de sentido ( $6^{\mathrm{a}}$ ed.), México: Siglo Veintiuno Editores, Universidad Iberoamericana.

Rifkin, J. (2000), La era del acceso: la revolución de la nueva economía, Barcelona: Paidós. 
Rincón, J. (1998), Cooperación del personal académico: mecanismo para la integración del sistema universitario nacional. San Fernando de Apure (Ven.), Universidad Simón Rodríguez. Disponible en: http://members.tripod.com/ gepsea/sistema.htm [Fecha de consulta: 2 de febrero de 2009].

Ríos, F. (1997), Obras completas III. Escritos breves, Barcelona: Anthropos. Disponible en: http://books.google.com.co/books? $\mathrm{id}=\mathrm{mDKzZjNJYPsC} \& \mathrm{pg}=\mathrm{PA} 60 \& \mathrm{dq}=\mathrm{REIN}+$ DIDACTICA $\& \mathrm{hl}$ =es\&ei=TX1ETPefGYP58Aa77ekO\&sa=X\&oi=book_result $\& \mathrm{ct}=$ result\&resnum $=2 \& \mathrm{ved}=0 \mathrm{CC} 8 \mathrm{Q} 6 \mathrm{AEwAQ}{ }^{\#} \mathrm{v}=$ onepage $\& q \& f=$ false [Fecha de consulta: 21 de septiembre de 2010].

Ros, J. (2002), "Los centros de documentación: planificación técnica general”, en López, J. (coord.), Manual de ciencias de la documentación, Madrid: Pirámide.

Rosemberg, D. (2000), "A leitura e os canais intermediários de informação na formação continuada de professores universitários", en Encontros Bibli, 10, 1-10. Disponible en: http:// www.periodicos.ufsc.br/index.php/eb/article/view/61/ 117 [Fecha de consulta: 17 de julio de 2008].

Ruíz, R. (2000), La razón y el conocimiento silencioso. Detroit (Mich.): [S. n.]. Disponible en: http://books.google.com. co/books?id= 1B5KN8Z7wt0C\&pg=PA24\&dq $=\mathrm{La}+\mathrm{raz} \% \mathrm{C} 3$ $\% \mathrm{~B} 3 \mathrm{n}+\mathrm{y}+\mathrm{el}+\mathrm{conocimiento}+$ silencioso $\& \mathrm{hl}=\mathrm{es} \& \mathrm{ei}=\mathrm{uOe} 6 \mathrm{TZ}$ eNOsnL0QHdlsHMBQ\&sa=X\&oi=book_result\&ct=result\& resnum $=1 \&$ ved=0CCwQ6AEwAA $\# \mathbf{v}=$ onepage $\& q=\mathrm{La} \% 20$ raz $\%$ C 3\%B3n $\% 20 y \% 20$ el $\% 20$ conocimiento $\% 20$ silencioso\&f=false [Fecha de consulta: 2 de marzo de 2009].

Russell, B. (1963), Fundamentos de la filosofía, Barcelona: Ediciones G.P.

Rujano, J. (2006), Taller de estrategias didácticas para la docencia universitaria. Disponible en: http://www.slideshare. net/wilmerGuillen/estrategias [Fecha de consulta: 18 de octubre de 2009]. 
Salako, O. y Tiamiyu, M. (2007), "Use of search engines for research by postgraduate students of the University of Ibadan, Nigeria", en African Journal of Library, Archives EInformation Science, 17(2), 103-115. Disponible en: http://www. sciencedirect.com/science?_ob=ArticleURL\&_udi=B6VB44RPKYS5-2\&_user $=506061 \&$ \&doc $=1 \&$ \& fmt $=$ \&_orig $=$ search\&_sort $=\mathrm{d} \& \mathrm{view}=\mathrm{c} \&$ _acct $=\mathrm{C} 000025027 \&$ \&version $=1 \&$ _ urlVersion $=0 \&$ _userid $=506061 \& \mathrm{md} 5=\mathrm{b} 22926 \mathrm{fad} 84 \mathrm{bcab} 61$ 27d7571c4f4105b [Fecha de consulta: 7 de marzo de 2008].

Salinas, M. (2002), La evaluación de los aprendizajes en la universidad, Medellín: Universidad de Antioquia.

Salvador, J. (2002), "Formación en recuperación de información: análisis de los cursos y asignaturas en las escuelas de biblioteconomía y documentación de Norteamérica y España", en Documentación de las Ciencias de la Información, 25, 189-215. Disponible en: http://eprints.rclis.org/bitstream/10760/8724/1/DCI-RIPlanesdeEstudio.pdf [Fecha de consulta: 7 de marzo de 2008].

Santaella, L. (1998), "La evolución de los tres tipos de argumento: abducción, inducción y deducción", en Analogía filosófica: revista de filosofía, investigación y difusión 12 (1), 9-20. Disponible en: http://www.unav.es/gep/AN/Santaella. html [Fecha de consulta: 31 de marzo de 2008].

Sastre, N. (2007), Productos y servicios para la formación de usuarios de bibliotecas universitarias: el uso de bases de datos en entornos Web. Disponible en: http://www.um. es/fccd/jagh/sastre.pdf [Fecha de consulta: 17 de julio de 2008].

Schulz, M. (2001), "The uncertain relevance of newness: organizational learning and knowledge flows", en Academy of Management Journal, 44 (4), 661-681.

Shannon, C. y Weaver, W. (1972), The mathematical theory of communication, Urbana: University of Illinois Press. 
Shera, J. (1990), Los fundamentos de la educación bibliotecológica, México: UNAM, Centro Universitario de Investigaciones Bibliotecológicas.

Silva, A., Souza, E., Bezerra, L. \& Ramalho, F. (2007), "Déficit informacional: obstáculos no uso de canais (in)formacionais por docentes do Programa de Pós-Graduação em Economia - PPGE/UFPB", en Informação \& Sociedades: Estudos, João Pessoa 17 (3), 107-117. Disponible en: http://www. okara.ufpb.br/ojs2/index.php/ies/article/viewFile/ 977/1610 [Fecha de consulta: 17 de julio de 2008].

Silva, P. (2007), "Sistemas de informação em bibliotecas: o comportamento dos usuários e bibliotecários frente às novas tecnologias de informação", en Revista Digital de Biblioteconomia e Ciência da Informação, 5 (2), 1-24. Disponible en: http://server01.bc.unicamp.br/seer/ojs/ [Fecha de consulta: 15 de mayo de 2008].

Simpson, J. y Weiner, E. (eds.) (1989), Oxford English Dictionary ( $2^{\mathrm{a}}$. ed.), Oxford, UK: Clarendon Press.

Skinner, B. F. (1968), La revolución científica de la enseñanza, Bruselas: Dessart.

Slype, G. van. (1988), Documentologie, Bruxelles: Press Universitaires de Bruxelles.

Somoza, M. y Abadal, E. (2007), "La formación de usuarios en las bibliotecas universitarias españolas", en El profesional de la información, 16 (4), 287-293. Disponible en: http:// eprints.rclis.org/archive/00011294/01/epi2007164.pdf [Fecha de consulta: 17 de julio de 2008].

Spang-Hanssen, H. (1970), "How to teach about information as related to documentation", en Human IT, 5 (1), 125-143. Disponible en: http://etjanst.hb.se/bhs/ith//1-01/hsh.htm [Fecha de consulta: 20 de septiembre de 2009]. 
Stake, R. E. (1998), Investigación con estudio de casos. Madrid: Ediciones Morata.

Stepp, E. (1993), "The virtualisation of institutes of research", en Electronic Journal of Virtual Culture, 6(1). Disponible en: http://hegel.lib.ncsu.edu/stacks/serials/aejvc/aejvc-v1n06stepp-virtualization [Fecha de consulta: 21 de septiembre de 2008].

Suaiden, E. (2007), A dimensão social do conhecimento. Scire: representación y organización del conocimiento, 13 (1), 21-31. Disponible en: http://ibersid.eu/ojs/index.php/scire/ article/ view/ 1706/1678 [Fecha de consulta: 13 de diciembre de 2007].

Talizina, N. (1988), Psicología de la enseñanza, Moscú: Progreso.

Torre, S. y Barrios, O. (coord.), (2002), Estrategias didácticas innovadoras: recursos para la formación y el cambio $\left(2^{\mathrm{a}}\right.$ ed.), Barcelona: Octaedro.

Truncellito, D. (2009), "Epistemology", en Fieser, J. y Dowden, B. (eds.), Internet Encyclopedia of Philosophy. Disponible en: http://www.iep.utm.edu/epistemo/ [Fecha de consulta: 23 de junio de 2009].

UNESCO. (2007), Education Thesaurus (6 $6^{\mathrm{a}}$ ed.). Disponible en: http://www.ibe.unesco.org/es/servicios/documentos-enlinea/tesauro-de-la-educacion-unesco-oie/sexta-edicion2007.html [Fecha de consulta: 19 de enero de 2008].

- - (2008), Thesauro de la Unesco, París: UNESCO. Disponible en: http://databases.unesco.org/thessp/ [Fecha de consulta: 25 de julio de 2008].

Uribe, A., Ramírez, G., Arroyave, M., Pineda, M., Valderrama, Á. y Preciado, J. (2007), Acceso, conocimiento y uso de Internet en la Universidad de Antioquia, Medellín: Universidad de Antioquia. 
Varela, A. (2007), Informação e autonomia: a mediação segundo Feuerstein. São Paulo: Senac.

Vargas, G. (2006a), Filosofía, pedagogía, tecnología: investigaciones de epistemología de la pedagogía y filosofía de la educación ( $3^{\mathrm{a}}$ ed.), Bogotá: Universidad Pedagógica Nacional.

- - - (2006b), Tratado de epistemología: fenomenología de la ciencia, la tecnología y la investigación social ( $\left.2^{\mathrm{a}} \mathrm{ed}.\right)$, Bogotá: San Pablo; Universidad Pedagógica Nacional.

Vargas, P. y Villegas, D. (2004), Biblioteca viva, vive la biblioteca acerca de la biblioteca un proyecto didáctico, Monografía de Especialización en Educación, no publicada. Disponible en: http://cybertesis.udea.edu.co:8595/sdx/udea/notice. xsp?id=udea.2004.vargas_p-principal\&qid=pcd-q\&base $=$ documents\&dn=1\&id_doc=udea.2004.vargas_p\&num $=\&$ query=Facultad\%20de $\% 20$ Educaci\%C3\%B3n\&isid=udea. 2004.vargas_p [Fecha de consulta: 25 de marzo de 2007].

Vásquez, C. (2010), No ponerse de acuerdo. Disponible en: http://www.udea.edu.co/portal/page/portal/BibliotecaPortal/DetalleNoticia?p_id=53084101\&p_siteid=37 [Fecha de consulta: 30 de octubre de 2010].

- - - (2011), Conversemos. Disponible en: http://www. udea. edu.co/portal/page/portal/BibliotecaPortal/DetalleNoticia? p_id=68012191\&p_siteid=37 [Fecha de consulta: 1 de marzo de 2011].

Vélez, J. (2002), "El retorno de los brujos", en El Malpensante, 42, 62-63.

Vélez, R. (2002), "Vivimos en ámbitos complejos", en Círculo de Humanidades, 10, 9-16.

Walker, D. (1991), Sistemas de información basados en ordenador, Barcelona: Marcombo. 
Webster, F. (2002), Theories of the information society ( $2^{\mathrm{a}} \mathrm{ed}$.). London: Routledge. Disponible en: http://books.google. com.co/ books?id=h2f0TVyWaj4C\&printsec $=$ frontcover\&d $\mathrm{q}=\% 22$ Theories + of + the+information + society $\% 22+\% 2 \mathrm{~B}+\mathrm{W}$ ebster\&source $=$ bl\&ots $=$ drb8nBZPps\&sig=EvkAMtOXBdH 9TyJJ6_5h1PuTmfM\&hl=es\&ei=8OvZS_n8MYfG8 wTznMxR\&sa=X\&oi=book_result\&ct=result\&resnum $=2 \&$ ved=0CBEQ6AEwAQ ${ }^{\#} \mathrm{v}=$ onepage $\& \mathrm{q} \& \mathrm{f}=$ false $[\mathrm{Fech}$ a de consulta: 28 de enero de 2010].

Weizsäcker, C. (1980), The unity of nature, New York: Farrar, Straus, Giroux.

Wiener, N. (1948), Cybernetics or communication and control in the animal and the machine ( $2^{\mathrm{a}} \mathrm{ed}$.), Cambridge, MA: MIT Press.

Williams, R. (1998), “The documentation and special libraries movements in the United States, 1910-1960", en Hahn, T. y Buckland, M. (eds.), Historical studies in information science, Medford, NJ: ASIS/InformationToday. Disponible en: http: //books.google.com.co/books?id=4crkFsx $73 \mathrm{msC} \&$ printsec $=$ frontcover $\& \mathrm{dq}=\% 22 \mathrm{Historical}+$ studies + in + infor mation+science $\% 22 \&$ source $=$ bl\&ots $=J Y o s q 1 O b A B \& s i g=U$ K9zDLYkQuLqziR 2 mvNghLEWdao\&hl=es \&ei=7 jZS5TLDZHM9gTCrdBL\&sa=X\&oi=book_result\&ct=result \&resnum $=2 \& v e d=0 C A 8 Q 6 A E w A Q{ }^{\#} \mathbf{v}=$ onepage $\& q \& f=$ false [Fecha de consulta: 28 de enero de 2010].

Williams, D. y Coles, L. (2007), Teachers' approaches to finding and using research evidence: an information literacy perspective, en Educational Research, 49 (2), 185-206. Disponible en: http://apps.isiknowledge.com/full_record.do?product= UA $\% 26$ search_mode $=$ GeneralSearch $\% 26 q i d=1 \% 26$ SID $=3$ AKdcjmKNPk@oDjJ@GI\%26page=1\%26doc=1\%26colnam e=OS [Fecha de consulta: 20 de marzo de 2007].

Zabalza, M. (2004), Diseño y desarrollo curricular (9 ${ }^{\mathrm{a}}$ ed.), Madrid: Narcea. 
Zema, J. (¿2006?), O significado filosófico da noção de informação. Disponible en: http://www.uff.br/ppgci/textos/significadofilosoficozeman.doc [Fecha de consulta: 4 de junio de 2008].

Zuluaga, O. (1999), Pedagogía e bistoria: la bistoricidad de la pedagogía, la enseñanza, un objeto de saber, Santafé de Bogotá: Siglo del Hombre: Anthropos; Medellín: Universidad de Antioquia. 
ANEXos 


\section{Anexo 1. Ficha bibliográfica referencial}

\section{FICHA BIBLIOGRÁFICA REFERENCIAL}

Doctorado en Educación - Línea Didáctica de la Educación Superior

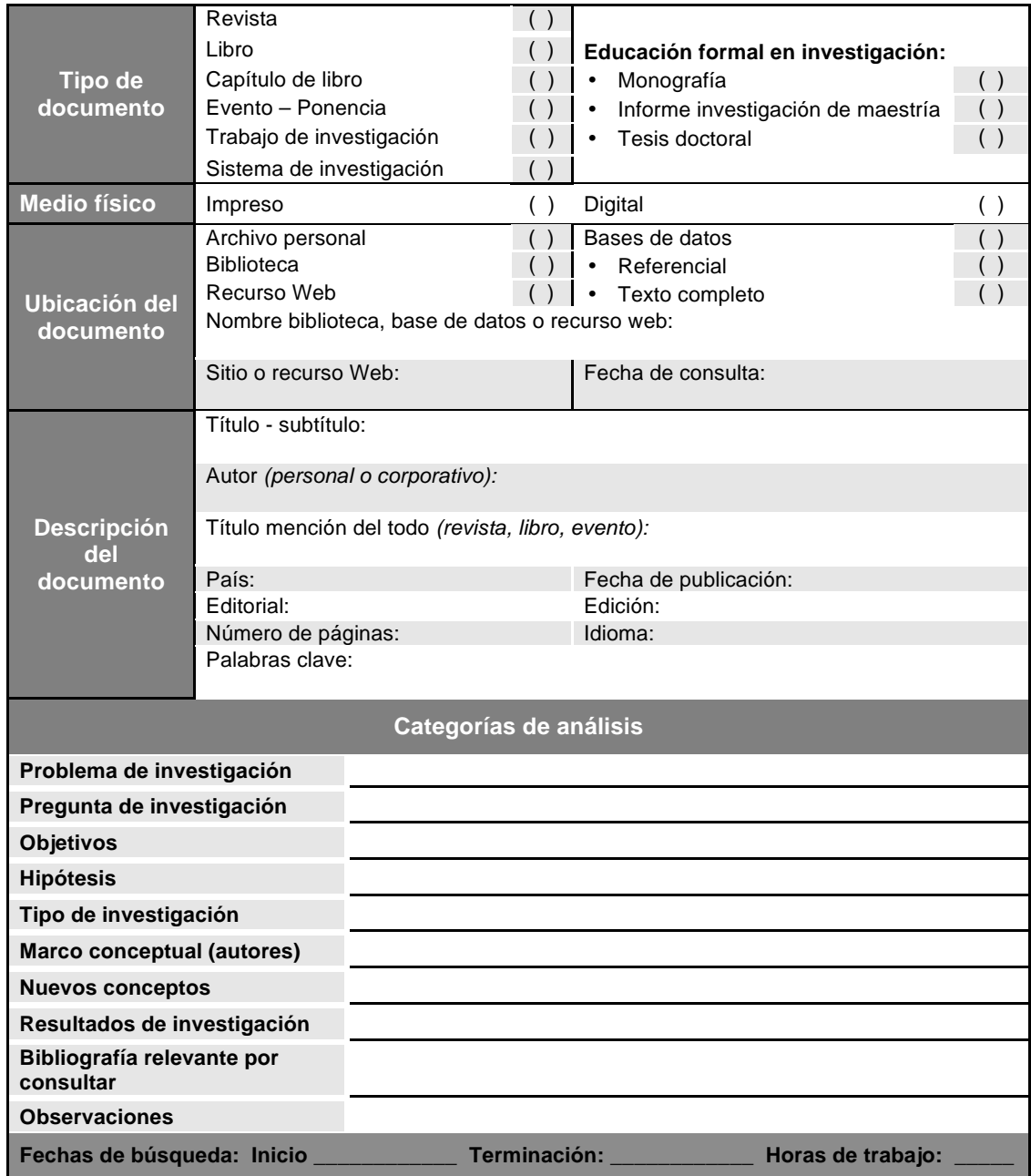

Adaptación al diseño realizado en la Línea Didáctica de la Educación Superior, Facultad de Educación, Universidad de Antioquia, 2007. 
Anexo 2. Cuestionario profesores

\begin{tabular}{c}
\hline DIDÁCTICA DE LOS SISTEMAS DE INFORMACIÓN DOCUMENTAL: \\
$\substack{\text { UNIIERSIDAD } \\
\text { DEIOQUIA } \\
1803}$ \\
\hline \hline
\end{tabular}

Investigación desarrollada por:

Cuestionario profesores $N^{\circ}$

Edilma Naranjo, estudiante de Doctorado en Educación. Facultad de Educación, Universidad de Antioquia.

Objetivo del cuestionario:

Con este cuestionario se pretende indagar a los profesores universitarios acerca de los prejuicios, las percepciones y los sentimientos que poseen sobre el uso de los Sistemas de Información Documental (SID) y la forma como los emplean en los cursos que ofrecen.

Por favor, marque con una $X$ la respuesta seleccionada. Si lo requiere puede marcar varias respuestas.

\section{INFORMACIÓN GENERAL}

1. Nombre de la Universidad:

2. Facultad, Escuela o Instituto:

\section{PREJUICIOS, PERCEPCIONES Y SENTIMIENTOS}

3. ¿Qué considera usted que son los Sistemas de Información Documental (SID)?

4. ¿Cree importante involucrar el uso de los SID para el desarrollo de las clases?
4.1. Sí
4.2. No

5. De los SID que se presentan a continuación, señale aquellos que usted usa:

5.1 .

5.2 .

Bibliotecas

5.6 .

5.7 .

Repositorios

5.3 . Centros de documentación Metabuscadores

5.4 . Archivos

5.5 . Bases de datos

5.9 . Ninguno de las anteriores Sitios Web Otro(s):

6. Usted utiliza los SID para: (puede elegir más de una opción)

6.1.

6.2 .

6.3 . Preparar las clases Elaborar trabajos Preparar exámenes
6.4. Estar informado

6.5. Divertirse

6.6. Otra(s): 
7. De los siguientes SID, señale los que usted considere que deben saber utilizar los estudiantes:

$\begin{array}{ll}\text { 7.1. } & \text { Bibliotecas } \\ \text { 7.2. } & \text { Centro de documentación } \\ \text { 7.3. } & \text { Archivo } \\ \text { 7.4. } & \text { Bases de datos } \\ \text { 7.5. } & \text { Sitios Web }\end{array}$

7.6. Repositorios

7.7. Metabuscadores

7.8. Ninguno de las anteriores

7.9. Otro(s):

8. En el desarrollo de los cursos que usted facilita, ¿ considera que los estudiantes usan los SID en su proceso de formación?
8.1. Sí
8.2. No
¿Por qué?

9. ¿Usted sabe orientar a los estudiantes en el uso de los SID?
9.1. Sí
9.2. No

10. ¿Usted ha recibido algún curso de capacitación en el uso de los SID?

10.1. Sí

10.2. No

11. ¿ Le gustaría participar en un curso para aprender a utilizar los SID?
11.1. Sí
11.2. No ¿Por qué?

12.Considera que usted enseña:(puede elegir más de una opción)
12.1.
12.2 .
Datos
12.3 Información Conocimiento

Explique cómo lo hace

13.De las siguientes habilidades de pensamiento, señale aquellas que usted ayuda a desarrollar en los estudiantes:

\begin{tabular}{|c|c|c|c|}
\hline 13.1 & Inferir & 13.15 & Contextualizar \\
\hline 13.2 & Relacionar & 13.16 & Diseñar \\
\hline 13.3 & Argumentar & 13.17 & Resolver enigmas \\
\hline 13.4 & Refutar & 13.18 & Pronosticar \\
\hline 13.5 & Observar & 13.19 & Comprender \\
\hline 13.6 & Comparar & 13.20 & Interpretar \\
\hline 13.7 & Clasificar & 13.21 & Sintetizar \\
\hline 13.8 & Estipular leyes & 13.22 & Leer \\
\hline 13.9 & Abstraer & 13.23 & Escribir \\
\hline 13.10 & Validar & 13.24 & Escuchar \\
\hline 13.11 & Elaborar hipótesis & 13.25 & Hablar \\
\hline 13.12 & Modelar & 13.26 & Evaluar \\
\hline 13.13 & Analizar & 13.27 & Ninguna de las anteriores \\
\hline 13.14 & Simular & 13.28 & Otra(s): \\
\hline
\end{tabular}


14.En el aula de clase usted desarrolla estrategias como:(puede elegir más de una opción)

\begin{tabular}{|c|c|c|c|}
\hline 14.1 & Debates & 14.16 & Historias de vida \\
\hline 14.2 & Mesas redondas & 14.17 & Asesorías \\
\hline 14.3 & Seminarios & 14.18 & Tutorías \\
\hline 14.4 & Aprendizaje Basado en Problemas & 14.19 & Conferencias \\
\hline 14.5 & Formulación de preguntas & 14.20 & Simposios \\
\hline 14.6 & Foros & 14.21 & Panel \\
\hline 14.7 & Aprendizaje significativo & 14.22 & Mapas conceptuales \\
\hline 14.8 & Talleres & 14.23 & Mentefactos \\
\hline 14.9 & Club de revistas & 14.24 & Mapas mentales \\
\hline 14.10 & Mayéutica & 14.25 & Diseño de experimentos \\
\hline 14.11 & Dialéctica & 14.26 & Elaboración de ensayos \\
\hline 14.12 & Lectura enigmática & 14.27 & Artículos \\
\hline 14.13 & Trabajo de campo & 14.28 & Cuentos \\
\hline 14.14 & Trabajo de laboratorio & 14.29 & Ninguna de las anteriores \\
\hline 14.15 & Estudio de casos & 14.30 & Otra(s): \\
\hline
\end{tabular}

15.Cree que cuando propicia algunas de las estrategias anteriores, los estudiantes:(puede elegir más de una opción)

15.1. Comprenden más

15.2. Están en condiciones de interpretar lo que se dice

15.3. Pueden elaborar nuevos escritos

15.4. Ninguna de las anteriores

15.5. Otra(s):

III. OBSERVACIONES Y COMENTARIOS

¡Muchas gracias por su colaboración! 


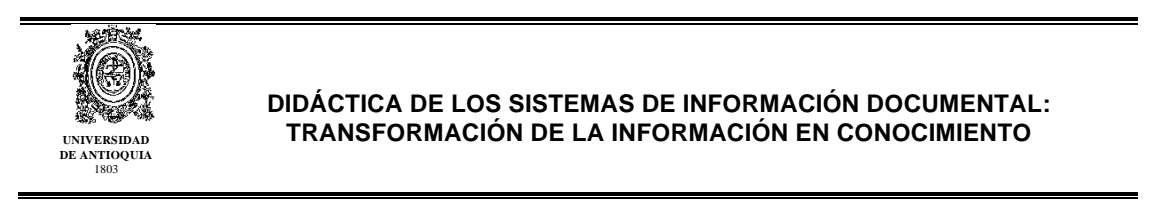

Investigación desarrollada por:

Cuestionario estudiantes $N^{\circ}$

Edilma Naranjo, estudiante de Doctorado en Educación. Facultad de Educación, Universidad de Antioquia.

Objetivo del cuestionario:

Con este cuestionario se pretende indagar a los estudiantes universitarios acerca de los prejuicios, las percepciones y los sentimientos que poseen sobre el uso de los Sistemas de Información Documental (SID) y la forma como los emplean en los cursos que reciben.

Por favor, marque con una $X$ la respuesta seleccionada. Si lo requiere puede marcar varias respuestas.

\section{INFORMACIÓN GENERAL}

1. Nombre de la Universidad:

2. Facultad, Escuela o Instituto: Semestre o nivel que cursa

\section{PREJUICIOS, PERCEPCIONES Y SENTIMIENTOS}

3. ¿Qué considera usted que son los Sistemas de Información Documental (SID)?

4. ¿Cree usted que los profesores usan los SID en el desarrollo de las clases?

4.1. Sí ¿Cuáles utilizan?

4.2. No. - ¿ ¿ Por qué cree que no los utilizá?

5. De los SID que se presentan a continuación, señale aquellos que usted usa:
5.1 .
5.2 .
5.3 .
Bibliotecas
5.4 . Centros de documentación
5.5 . Archivos Bases de datos Sitios Web

5.6.

5.7.

Repositorios

5.8. Ninguno de las anteriores

5.9 . Otro(s):

6. ¿Los profesores lo motivan para que usted utilice los SID?
6.1. Sí
6.2. No. 
7. Usted utiliza los SID para: (puede elegir más de una opción)

7.1.

7.2 .

7.3.
Estudiar

Elaborar trabajos

Preparar exámenes
7.4 .

7.5 .

7.6.
Estar informado

Divertirse

Otra(s):

8. ¿Cree que los profesores deben saber utilizar los SID?

8.1. Sí

8.2. No ¿Por qué?

9. Usted cree que los profesores le enseñan:

9.1 .

9.2 .

9.3.

Datos Información
Conocimiento

Explique cómo lo hacen

10.De las siguientes habilidades de pensamiento, señale las que considere que los profesores le ayudan a desarrollar en los cursos:

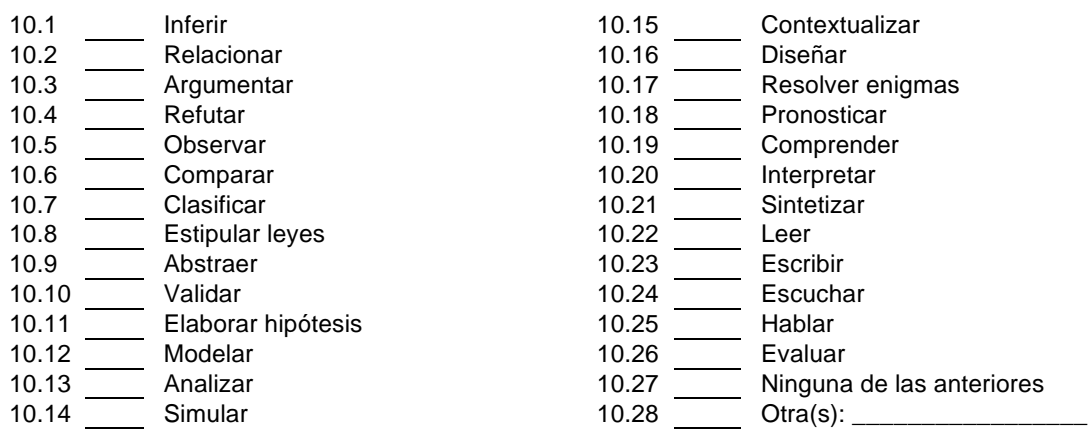

11.Usted considera que los profesores desarrollan en el aula estrategias como: (puede elegir más de una opción)

11.1

11.2

11.3

11.4

11.5

11.6

11.7

11.8
Debates

Mesas redondas

Seminarios

Aprendizaje Basado en Problemas

Formulación de preguntas

Foros

Aprendizaje significativo

Talleres
11.16

11.17

11.18

11.19

11.20

11.21

11.22

11.23
Historias de vida

Asesorías

Tutorías

Conferencias

Simposios

Panel

Mapas conceptuales

Mentefactos 
11.9

11.10

11.11

11.12

11.13

11.14

11.15
Club de revistas

Mayéutica

Dialéctica

Lectura enigmática

Trabajo de campo

Trabajo de laboratorio

Estudio de casos
11.24

11.25

11.26

11.27

11.28

11.29

11.30
Mapas mentales

Diseño de experimentos

Elaboración de ensayos

Artículos

Cuentos

Ninguna de las anteriores

Otra(s):

12.Cree que cuando los profesores propician algunas de las estrategias anteriores, usted: (puede elegir más de una opción)

12.1.

12.2 .

Comprende más

12.3. Puede elaborar nuevos escritos

12.4. Ninguna de las anteriores

12.5. Otra(s):

\section{OBSERVACIONES Y COMENTARIOS}

¡Muchas gracias por su colaboración! 
Anexo 4. Guía de conversación con bibliotecólogos

\begin{tabular}{c}
\hline \hline DIDÁCTICA DE LOS SISTEMAS DE INFORMACIÓN DOCUMENTAL: \\
TRANSFORMACIÓN DE LA INFORMACIÓN EN CONOCIMIENTO \\
UNIIERSIDAD \\
I803 \\
\hline
\end{tabular}

GUÍA DE CONVERSACIÓN CON BIBLIOTECÓLOGOS

Investigación desarrollada por:

Edilma Naranjo Vélez, estudiante de Doctorado en Educación. Facultad de Educación, Universidad de Antioquia.

Con la conversación se pretende llegar a un acuerdo, lo cual, exige la concentración entre quienes lo hacen, lo que conlleva a valorar los puntos de vista de cada uno y ponerse en su lugar para tratar de entender lo que dice. Se busca comprender el fenómeno a partir del punto de vista del otro o de los otros, desde un escrito o desde la oralidad para interpretarlo. No se busca el consenso sobre un tema, sino que los contenidos objetivos de la conversación no son más que un medio para conocer el horizonte del otro (Gadamer, 2005, 373).

\section{Temas a conversar:}

of Los sistemas de información documental (SID): concepto, valoración, frecuencia de uso, difusión, valoración como medios didácticos.

ar Los datos y la información: diferencias, visión de los usuarios.

ar El conocimiento: su transformación desde la información, pretensiones desde la disciplina.

as La formación de usuarios: los SID, los profesores, los estudiantes, las tendencias.

ar Estrategias didácticas: las que conoce, recomendaciones para un programa de formación de usuarios con profesores. 
Anexo 5. Guía de conversación con usuarios reconocidos (profesores)

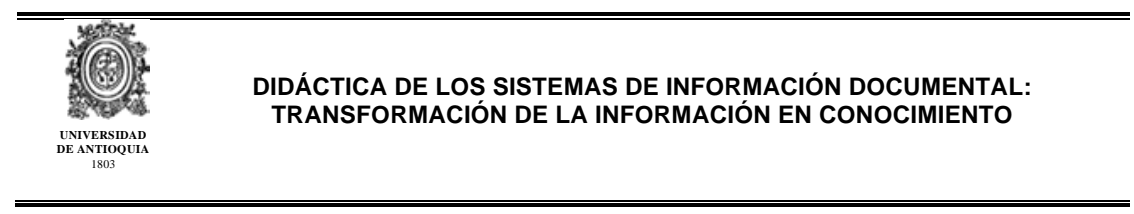

\section{GUÍA DE CONVERSACIÓN USUARIOS RECONOCIDOS (PROFESORES)}

$\underline{\text { Investigación desarrollada por: }}$

\section{Edilma Naranjo Vélez, estudiante de Doctorado en Educación. Facultad de} Educación, Universidad de Antioquia.

Con la conversación se pretende llegar a un acuerdo, lo cual, exige la concentración entre quienes lo hacen, lo que conlleva a valorar los puntos de vista de cada uno y ponerse en su lugar para tratar de entender lo que dice. Se busca comprender el fenómeno a partir del punto de vista del otro o de los otros, desde un escrito o desde la oralidad para interpretarlo. No se busca el consenso sobre un tema, sino que los contenidos objetivos de la conversación no son más que un medio para conocer el horizonte del otro (Gadamer, 2005, 373)

\section{Temas a conversar:}

ar Los sistemas de información documental (SID): concepto, valoración, frecuencia de uso, difusión.

ar Los datos y la información: el uso para la enseñanza, el aprendizaje por parte de los alumnos, su transformación.

Go El conocimiento: qué significa, cómo se comunica, cómo lo alcanzan los estudiantes.

Go Estrategias didácticas: las que más favorecen los procesos de enseñanza, su combinación con los SID, la implementación, su evaluación, su consideración como medios didácticos, sugerencias. 
Didáctica de los Sistemas de Información Documental: transformación de la información en conocimiento. Coordinación editorial, Carlos Ceballos Sosa; revisión y evaluación editorial, Aurea Gabriela Mondragón Pérez; formación editorial y revisión de pruebas, Editorial Albatros, S.A. de C.V. Instituto de Investigaciones Bibliotecológicas y de la información / UNAM. Se terminó de producir en Ciudad Universitaria, México. D. F. en el mes de septiembre de 2014. 